\author{
Universidade de São Paulo \\ Escola de Engenharia de São Carlos \\ Departamento de Engenharia Elétrica
}

GEYVERSON TEIXEIRA DE PAULA

\title{
Cálculo da Força Contra Eletromotriz em Máquinas Síncronas com Ímãs na Superfície do Rotor
}





\section{GEYVERSON TEIXEIRA DE PAULA}

\section{Cálculo da Força Contra Eletromotriz em Máquinas Síncronas com Ímãs na Superfície do Rotor}

Tese de Doutorado apresentada a Escola de Engenharia de São Carlos da Universidade de São Paulo, como parte dos requisitos para obtenção do Título de Doutor em Ciências, Programa de Engenharia Elétrica.

Área de Concentração: Sistemas Dinâmicos.

Orientador: Prof. Dr. José Roberto Boffino de Almeida Monteiro

São Carlos

2016 
AUTORIZO A REPRODUÇÃO TOTAL OU PARCIAL DESTE TRABALHO, POR QUALQUER MEIO CONVENCIONAL OU ELETRÔNICO, PARA FINS DE ESTUDO E PESQUISA, DESDE QUE CITADA A FONTE.

Paula, Geyverson Teixeira de

Cálculo da Força Contra Eletromotriz em Máquinas Síncronas com Ímãs na Superfície do Rotor / Geyverson Teixeira de Paula; orientador José Roberto Boffino de Almeida Monteiro. São Carlos, 2016.

Tese (Doutorado) - Programa de Pós-Graduação em Engenharia Elétrica e Área de Concentração em Sistemas Dinâmicos -- Escola de Engenharia de São Carlos da Universidade de São Paulo, 2016.

1. Máquina Sincrona. 2. Força Contra Eletromotriz. 3. Tensor de Maxwell. 4. Elementos Finitos. I. Título. 


\section{FOLHA DE IULGAMENTO}

Candidato: Engenheiro GEYVERSON TEIXEIRA DE PAULA.

Título da tese: "Cálculo da força contra eletromotriz em móquinas síncronas com ímãs no rotor".

Data da defesa: $28 / 04 / 2016$

Comissäo Julgadora:

Resultado:

Prof. Dr. José Roberto Boffino de Almeida Monteiro

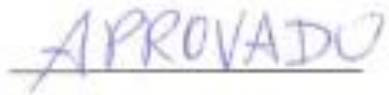
(Orientador)

(Escola de Engenharia de Sāo Carlos/EESC)

Prof. Dr. Manoel Luis de Aguiar

(Escola de Engenharia de Sāo Carlos/EESC)

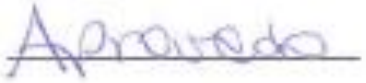

Prof. Dr. Marcelo Suetake

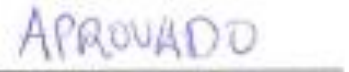

(Universidade Federal de Săo Carlos/UFSCar)

Aproucdo

Prof. Dr. Julio Carlos Teixeira

(Universidade Federal do $A B C / U F A B C$ )

Prof. Dr. Claudionor Francisco do Nascimento [Universidade Federal de São Carlos/UFSCar]

Coordenador do Programa de Pós-Graduação em Engenharia Elétrica:

Prof. Associado Luis Fernando Costa Alberto

Presidente da Comissāo de Pós-Graduaçāo:

Prof. Associado Paulo César Lima Segantine 

Aos meus pais, verdadeiros heróis, que entre os dias quentes e as noites congelantes, de norte a sul e de leste a oeste deste país, na boléia de um caminhão se valeram do sacrifício dos próprios sonhos para verem os sonhos de seus filhos serem realizados. Ao meu pai, Valdeir, e a minha mãe, Eudislene, minha eterna gratidão. 



\section{Agradecimentos}

Ao Prof. Dr. José Roberto Boffino de Almeida Monteiro pela amizade e excelente orientação ao longo dos trabalhos de iniciação científica, monografia de conclusão de curso, dissertação de mestrado e tese de doutorado, além é claro, do esclarecimento de inúmeras dúvidas sobre máquinas elétricas, acionamento de máquinas elétricas e eletrônica de potência. Agradeço também, a confiança em mim depositada para a realização de todos os trabaIhos desenvolvidos em conjunto ao longo desta jornada, que teve início em meados de 2009 quando eu ainda era um aluno de graduação.

Ao Prof. Dr. Diógenes Pereira Gonzaga que me apresentou o incrível universo das máquinas elétricas, primeiramente, com um apresentação e demonstração fantástica de todo o potencial das máquinas elétricas e como elas mudaram o mundo e, em segundo lugar, com a reprodução de um experimento baseado no antigo programa de televisão chamado " $O$ mundo de Beakman".

Ao Prof. Dr. Manoel Luís de Aguiar pelo apoio e incentivo em estudar a aplicação de máquinas elétricas em veículos elétricos desde 2009, quando, como aluno de graduação eu apareci em sua sala com inúmeras dúvidas e uma grande vontade de fazer algo diferente em um projeto extracurricular que envolvia o tema.

Ao Prof. Dr. Evandro Luís Linhari Rodrigues pela amizade e inúmeros conselhos pessoais e profissionais durante a graduação e pós-graduação.

Aos meus amigos, Thales, Marcelo, Tati, William, Carlos, Edson, Luan, Rafael, Paulo pela companhia nos momentos de estudos e nas inúmeras empreitadas durante o doutorado. 

“Here's to the crazy ones. The misfits. The rebels. The troublemakers. The round pegs in the square holes. The ones who see things differently. They're not fond of rules. And they have no respect for the status quo. You can praise them, disagree with them, quote them, disbelieve them, glorify or vilify them. About the only thing you can't do is ignore them. Because they change things. They invent. They imagine. They heal. They explore. They create. They inspire. They push the human race forward. Maybe they have to be crazy. How else can you stare at an empty canvas and see a work of art? Or sit in silence and hear a song that's never been written? Or gaze at a red planet and see a laboratory on wheels? While some may see them as the crazy ones, we see genius. Because the people who are crazy enough to think they can change the world, are the ones who do..." 



\section{Resumo}

Paula, G. T. (2016). Cálculo da Força Contra Eletromotriz em Máquinas Síncronas com Ímãs na Superfície do Rotor. Tese (Doutorado) - Escola de Engenharia de São Carlos, Universidade de São Paulo, São Carlos, 2016.

O presente trabalho trata do cálculo da força contra eletromotriz em carga de uma máquina síncrona com ímãs na superfície do rotor (cuja forma de onda de força contra eletromotriz é não senoidal) sendo esta alimentada por correntes de fase cujas forma de onda são quadradas. Para conduzir esta investigação e calcular a força contra eletromotriz da máquina em estudo, faz-se uma revisão sobre o Método da Permeabilidade Fixa, método este que permite a linearização do ponto de operação da máquina. Dessa forma, as simulações são conduzidas por meio do método dos elementos finitos e do Método da Permeabilidade Fixa, levando-se em conta a forma de onda da corrente de alimentação. Atenção especial é dada ao modo que se analisa o fluxo concatenado e a forma de obtenção da força contra eletromotriz uma vez que as formas de onda do fluxo concatenado sofrem variações abruptas a cada $60^{\circ}$ elétricos. Além destes parâmetros, analisa-se também cada uma das parcelas do torque eletromagnético, i.e., torque mútuo, torque de relutância e torque de borda, sendo realizado ao final do trabalho, uma comparação entre a soma da estimativa de cada parâmetro com o valor do torque eletromagnético obtido por meio de uma simulação não linear.

Palavras-chave: Máquina Síncrona, Força Contra Eletromotriz, Tensores de Maxwell, Elementos Finitos. 



\section{Abstract}

Paula, G. T. (2016). Assessment of Surface Mounted Magnet Synchronous Machine's OnLoad Back-EMF. (Ph.D. Degree) - Escola de Engenharia de São Carlos, Universidade de São Paulo, São Carlos, 2016.

This work deals with the assessment of a surface mounted magnet synchronous machine's parameters (whose back-EMF is approximately trapezoidal) and that is fed by an ideal square current waveform. In order to investigate and describe each machine's parameter, a review on Frozen Permeability Method is presented. Some simulation by means of finite element method with the aid of Frozen Permeability Method are carried out taking into account that the machine is fed by an ideal square current waveform. The results for flux-linkage waveform and back-EMF waveform are shown and analyzed. A special attention is given to backEMF calculation since the linkage flux of each phase has an abrupt change every sixty electrical degrees due to the phase commutation. In addition, an attention is given to each torque component on load condition, i.e., mutual torque, reluctance torque, cogging torque and a comparison between the electromagnetic torque and the summation of these components.

Key Word: Synchronous Machine, Back-EMF, Maxwell Stress Tensor, Finite Element Method. 



\section{Lista de Figuras}

Figura 1.1 - Topologia de Máquinas Síncronas de Ímã Permanente no Rotor 3

Figura 2.1 - Método da Permeabilidade Fixa 10

Figura 2.2 - Emprego do Método da Permeabilidade Fixa .............................................. 12

Figura 2.3 - Modelo Físico do Estator Reconstruído. ...................................................... 13

Figura 2.4 - Densidade de Fluxo Radial na Posição Inicial ............................................... 14

Figura 2.5 - Densidade de Fluxo Tangencial na Posição Inicial ....................................... 15

Figura 2.6 - Distribuição de Fluxo Eletromagnético ..................................................... 16

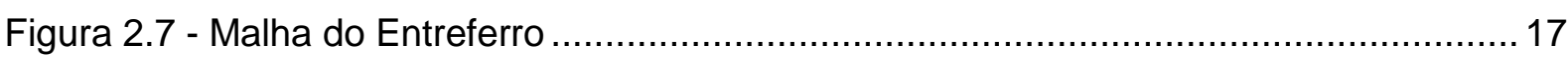

Figura 3.1 - Força Contra Eletromotriz - Método Convencional ........................................ 28

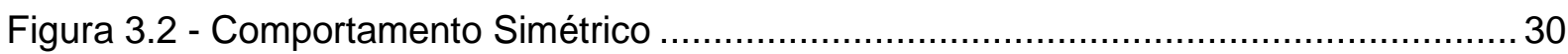

Figura 3.3 - Segregação das Regiões do Fluxo Concatenado com a Fase A ...................... 30

Figura 3.4 - Componentes da Força Contra Eletromotriz ................................................ 32

Figura 3.5 - Força Contra Eletromotriz Composta.............................................................. 32

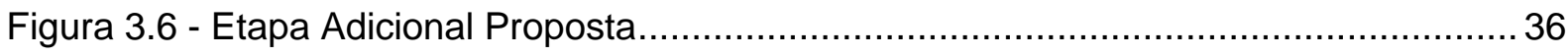

Figura 4.1 - Estator das Máquinas em Estudo........................................................... 40

Figura 4.2 - Rotores dos Casos em Estudo........................................................... 40

Figura 4.3 - Forma de Onda da Corrente de Alimentação................................................ 43

Figura 4.4 - Fluxo Magnético (Operação em vazio) .......................................................... 44

Figura 4.5 - Força Contra Eletromotriz (Operação em Vazio) .............................................. 45

Figura 4.6 - Torque de Borda (Operação em vazio) ....................................................... 45

Figura 4.7 - Fluxo Magnético Concatenado (Carregamentos de 5, 10 e 20A) ......................46

Figura 4.8 - Força Contra Eletromotriz (Carregamentos de 5, 10 e 20A) ............................. 47

Figura 4.9 - Componentes do Fluxo Magnético (Carregamento de 5A) ............................. 48

Figura 4.10 - Componentes do Fluxo Magnético (Carregamento de 10A) ........................... 48

Figura 4.11 - Componentes do Fluxo Magnético (Carregamento de 20A) ........................... 48

Figura 4.12 - Região 1: Componentes da Força Contra Eletromotriz .................................. 49

Figura 4.13 - Região 2: Componentes da Força Contra Eletromotriz ................................. 49

Figura 4.14 - Região 3: Componentes da Força Contra Eletromotriz ................................. 49

Figura 4.15 - Força Contra Eletromotriz - Método da Composição..................................... 50

Figura 4.16 - Força Contra Eletromotriz - Método dos Tensores ..........................................50

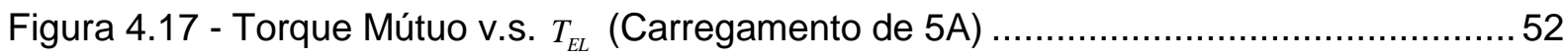

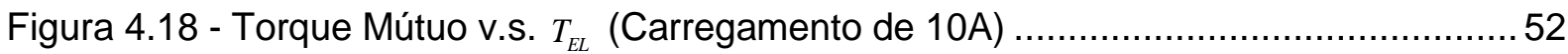




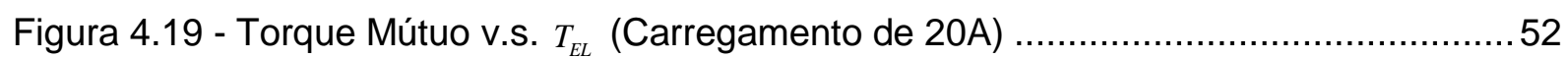

Figura 4.20 - Torque de Borda (Carregamento de 5A) .................................................. 53

Figura 4.21 - Torque de Borda (Carregamento de 10A) ..................................................53

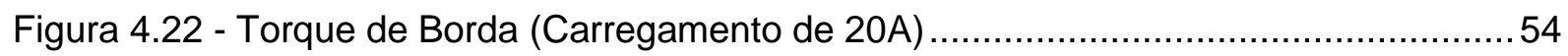

Figura 4.23 - Amplitude e Frequência do Torque de Borda ...................................................55

Figura 4.24 - Indutância de Linha Vista pelo Inversor ................................................... 55

Figura 4.25 - Torque de Relutância (Carregamento de 10A) ............................................56

Figura 4.26 - Torque de Relutância (Carregamento de 20A) ...........................................56

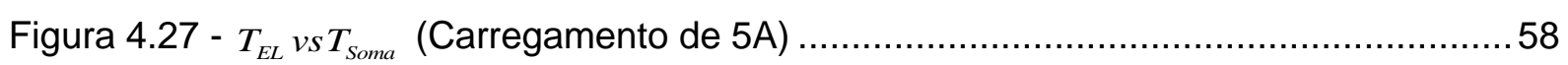

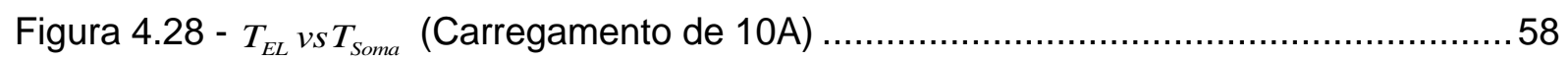

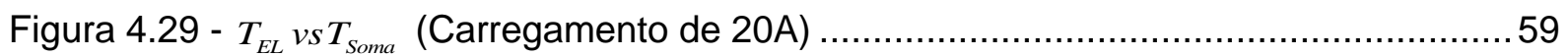

Figura 4.30 - Fluxo Magnético Concatenado (Operação em vazio) ...................................61

Figura 4.31 - Força Contra Eletromotriz (Operação em Vazio) ......................................... 61

Figura 4.32 - Torque de Borda (Operação em vazio) ..................................................... 61

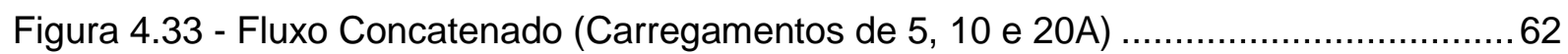

Figura 4.34 - Força Contra Eletromotriz - Método Convencional ....................................... 62

Figura 4.35 - Componentes do Fluxo Magnético (Carregamento de 5A) ............................. 63

Figura 4.36 - Componentes do Fluxo Magnético (Carregamento de 10A) ...........................63

Figura 4.37 - Componentes do Fluxo Magnético (Carregamento de 20A) ............................... 64

Figura 4.38 - Região 1: Componentes da Força Contra Eletromotriz ....................................64

Figura 4.39 - Região 2: Componentes da Força Contra Eletromotriz ................................... 64

Figura 4.40 - Região 3: Componentes da Força Contra Eletromotriz .................................65

Figura 4.41 - Força Contra Eletromotriz - Método da Composição ........................................ 65

Figura 4.42 - Força Contra Eletromotriz - Método dos Tensores ........................................66

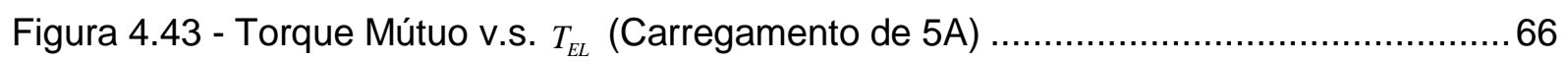

Figura 4.44 - Torque Mútuo v.s. $T_{E L}$ (Carregamento de 10A) ..........................................66

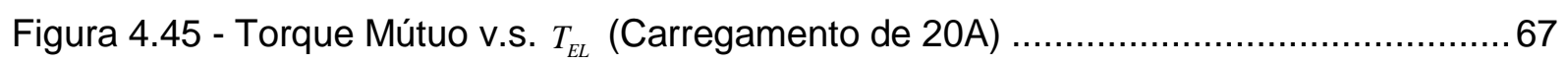

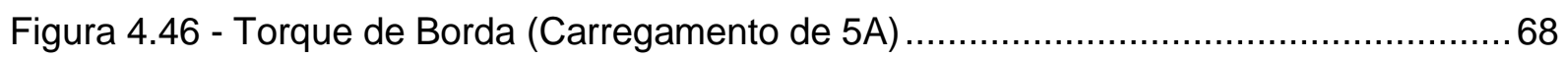

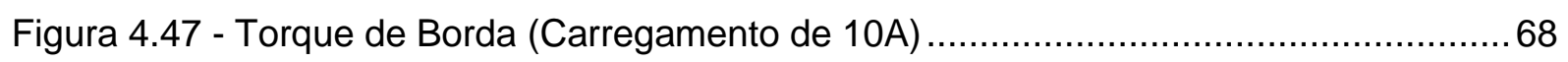

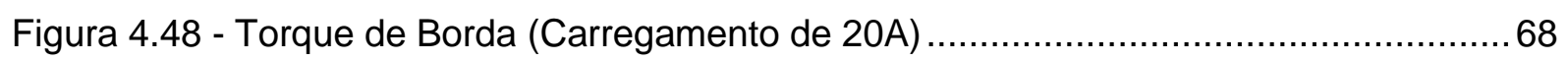

Figura 4.49 - Amplitude e Frequência do Torque de Borda ............................................. 69

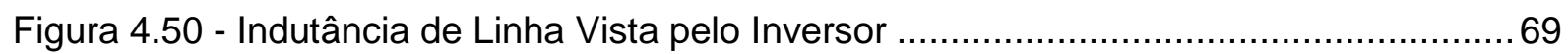

Figura 4.51 - Torque de Relutância (Carregamento de 5A) ...............................................70

Figura 4.52 - Torque de Relutância (Carregamento de 10A) ............................................. 70

Figura 4.53 - Torque de Relutância (Carregamento de 20A) .......................................... 70

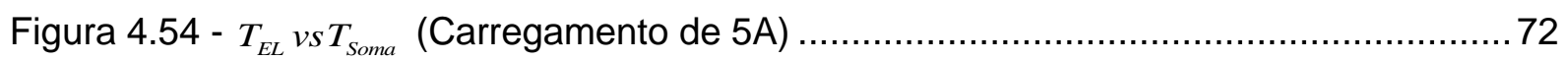




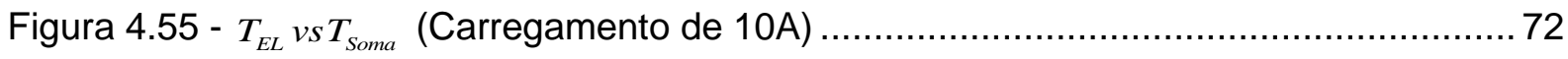

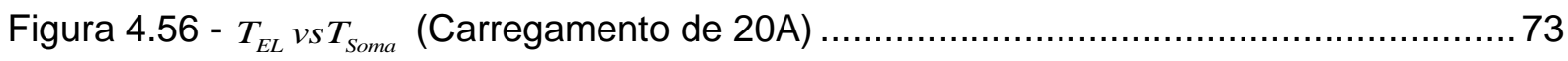

Figura 4.57 - Fluxo Magnético Concatenado (Operação em vazio) ................................... 74

Figura 4.58 - Força Contra Eletromotriz (Operação em Vazio) ......................................... 74

Figura 4.59 - Torque de Borda (Operação em vazio) ................................................... 74

Figura 4.60 - Fluxo Magnético Concatenado (Carregamentos de 5, 10 e 20A) ................... 75

Figura 4.61 - Força Contra Eletromotriz - Método Convencional ...................................... 75

Figura 4.62 - Componentes do Fluxo Magnético (Carregamento de 5A) ............................ 76

Figura 4.63 - Componentes do Fluxo Magnético (Carregamento de 10A) .......................... 76

Figura 4.64 - Componentes do Fluxo Magnético (Carregamento de 20A) ........................... 76

Figura 4.65 - Região 1: Componentes da Força Contra Eletromotriz ................................. 77

Figura 4.66 - Região 2: Componentes da Força Contra Eletromotriz ................................. 77

Figura 4.67 - Região 3: Componentes da Força Contra Eletromotriz .................................. 78

Figura 4.68 - Força Contra Eletromotriz - Método da Composição.................................... 78

Figura 4.69 - Força Contra Eletromotriz - Método dos Tensores ....................................... 78

Figura 4.70 - Torque Mútuo v.s. $T_{E L}($ Carregamento de 5A) ............................................ 79

Figura 4.71 - Torque Mútuo v.s. $T_{E L}$ (Carregamento de 10A) ….................................... 79

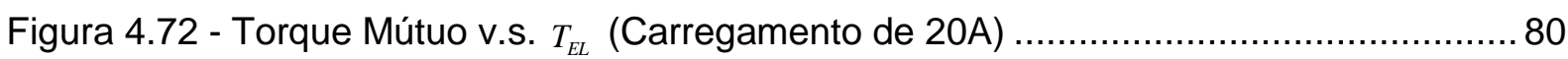

Figura 4.73 - Torque de Borda (Carregamento de 5A) ................................................. 80

Figura 4.74 - Torque de Borda (Carregamento de 10A) ................................................ 81

Figura 4.75 - Torque de Borda (Carregamento de 20A) ................................................. 81

Figura 4.76 - Amplitude e Frequência do Torque de Borda ............................................ 81

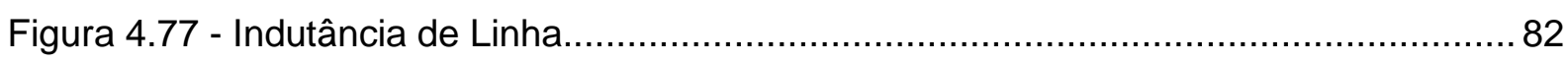

Figura 4.78 - Torque de Relutância (Carregamento de 5A) ............................................ 82

Figura 4.79 - Torque de Relutância (Carregamento de 10A)........................................... 83

Figura 4.80 - Torque de Relutância (Carregamento de 20A).......................................... 83

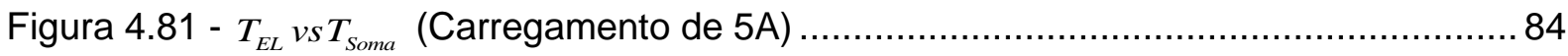

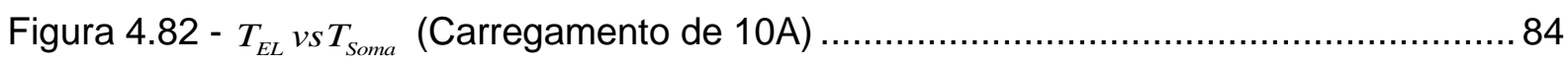

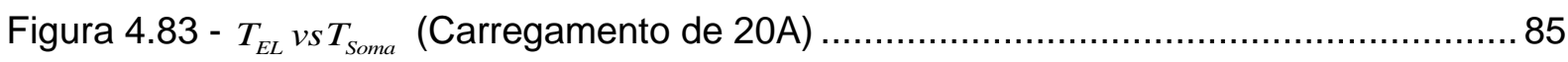

Figura A.1 - Arranjo para medição da força contra eletromotriz .......................................94

Figura A.2 - Esquema elétrico para medição da força contra eletromotriz.......................... 94

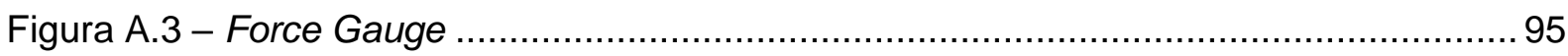





\section{Lista de Tabelas}

Tabela 2.1 - Tamanho Máximo do Elemento v.s. Precisão ............................................... 16

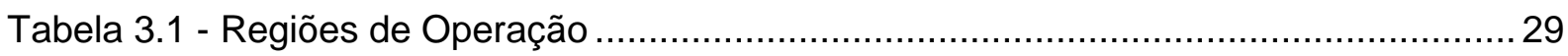

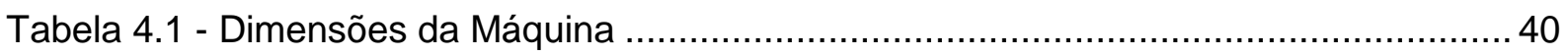

Tabela 4.2 - Características dos Rotores ................................................................ 42

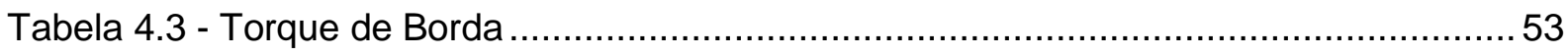

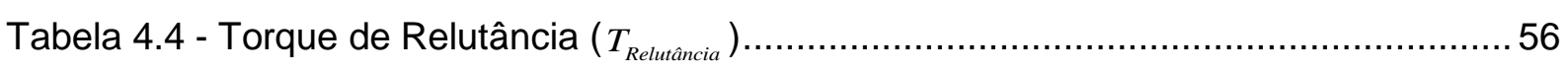

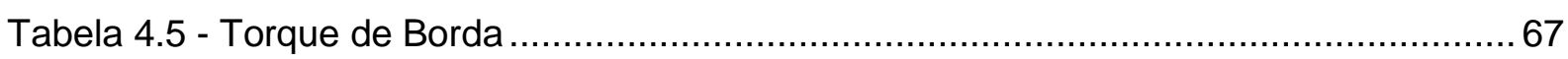

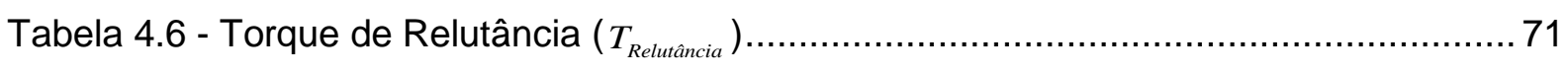

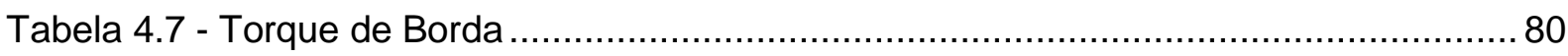

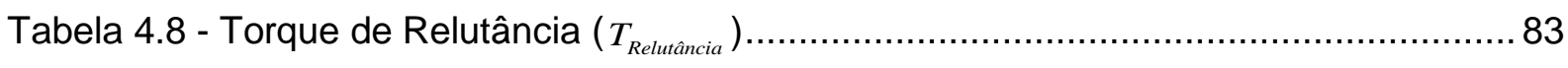





\section{Sumário}

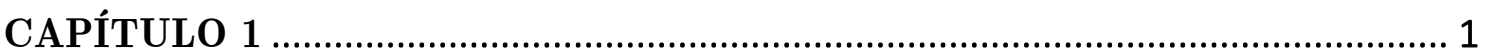

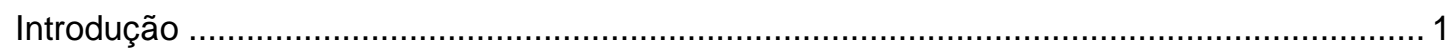

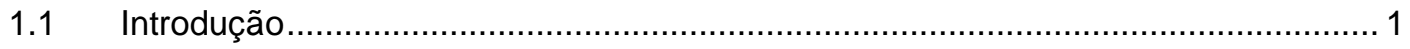

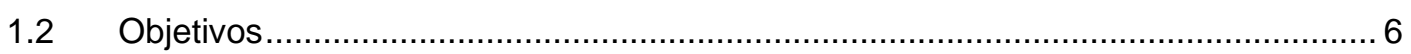

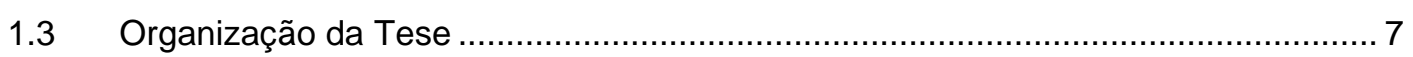

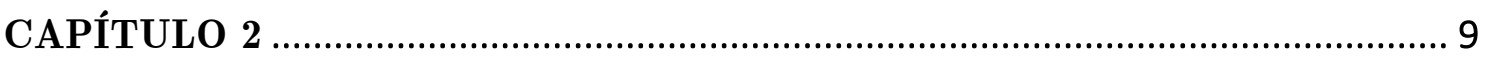

Método da Permeabilidade Fixa, Simulação em Elementos Finitos e Critérios de Simulação 9

2.1 Introdução

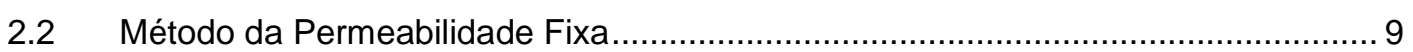

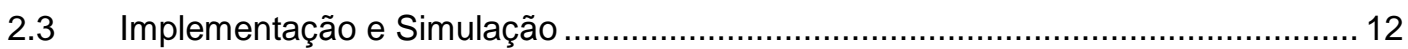

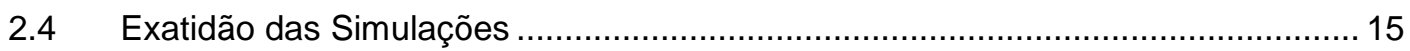

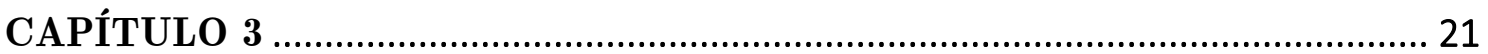

Torque Eletromagnético e o Cálculo da Força Contra Eletromotriz .......................................21

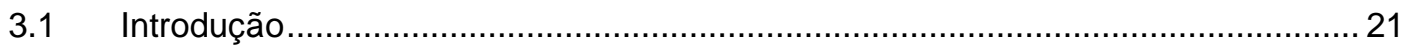

3.2 Definição e Formulação do Torque Eletromagnético ............................................21

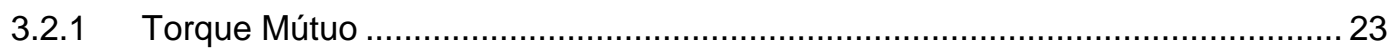

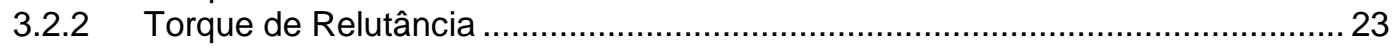

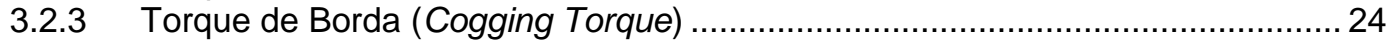

3.3 Definição e Formulação da Força Contra Eletromotriz …...................................... 25

3.4 Força Contra Eletromotriz: Método da Composição das Regiões ........................... 28

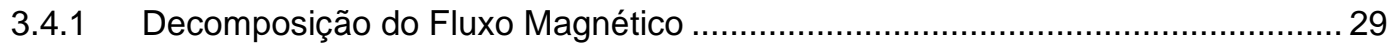

3.4.2 Composição da Força Contra Eletromotriz …................................................. 31

3.5 Força Contra Eletromotriz : Método dos Tensores ……........................................ 33

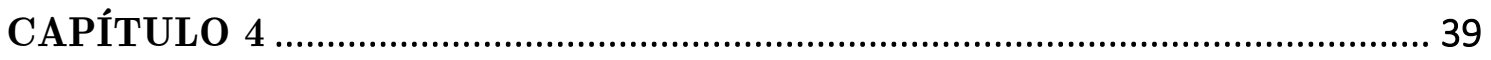

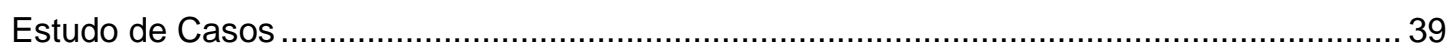

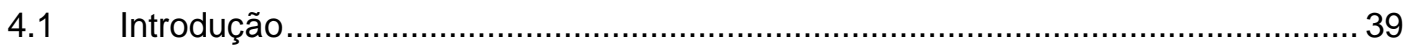




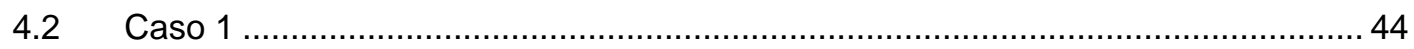

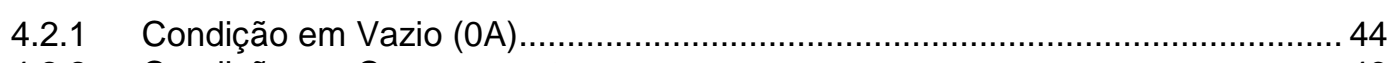

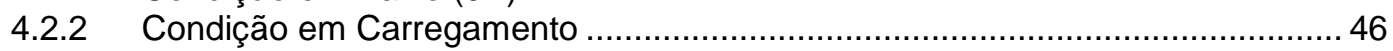

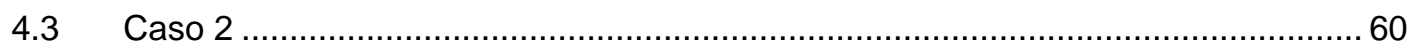

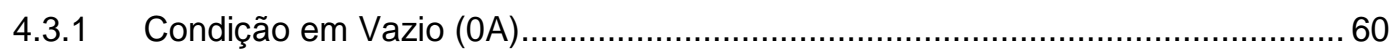

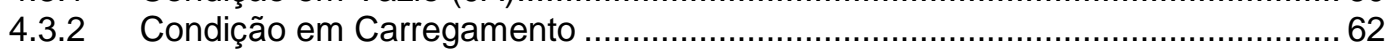

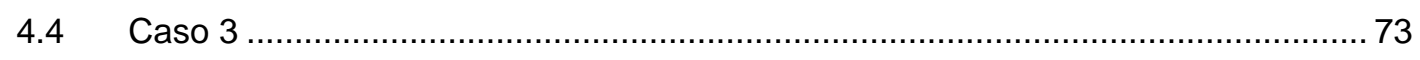

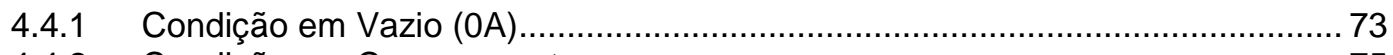

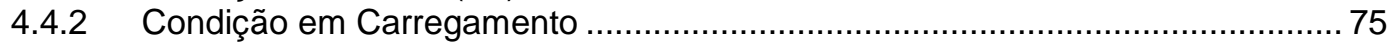

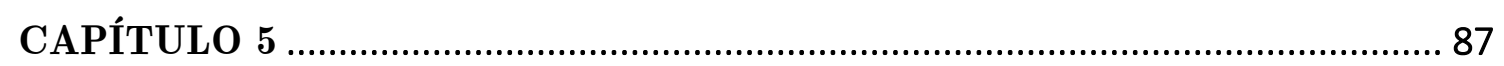

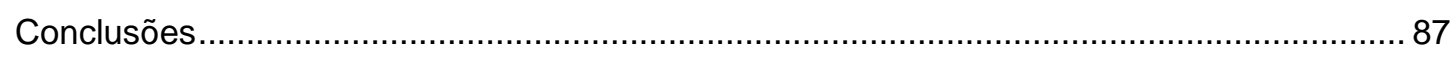

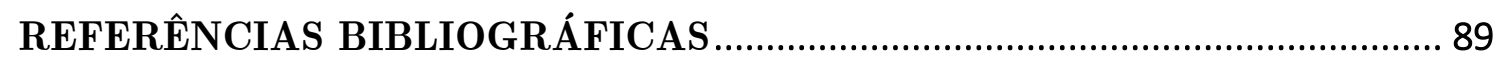

APÊNDICE A: BANCADA EXPERIMENTAL ............................................ 93

A.1 Força Contra Eletromotriz (Operação em Vazio) ............................................ 93

A.2 Torque Eletromagnético (Operação em Carga) .......................................... 95 


\section{Capítulo 1}

\section{Introdução}

\subsection{Introdução}

Aliados à evolução dos materiais ferromagnéticos e ímãs, os motores elétricos têm aumentado cada vez mais sua presença nas aplicações cotidianas, sejam elas residenciais, comerciais ou industriais [1], [2].

Esse crescimento tem sido feito de forma a se alcançar melhores índices de eficiência energética, uma vez que os motores correspondem à $65 \%$ do consumo de energia em países industrializados [1] e dentre esses $65 \%$, boa parte é consumida nas indústrias, onde se encontram motores de porte maior.

Os índices de eficiência energética para os motores partem principalmente de legislações que visam reduzir o desperdício de energia e aliviar a matriz energética do país. Além, é claro, das recentes crises econômicas que afetam desde o consumo de energia residencial como também as indústrias.

Há várias formas de se classificar os motores existentes no mercado, mas de um modo geral, eles podem ser divididos em duas grandes classes: os motores com escova (brushed) e os motores sem escova (brushless) [3]. Dentre os motores sem escova (brushless) encontram-se os motores síncronos com ímãs e sem escova que têm apenas os ímãs como fonte de excitação. Este tipo de motor tem apresentado um emprego crescente em aplicações in- 
dustriais, comerciais e residenciais [1], [2], [4]; que se justifica por duas de suas grandes vantagens: alta eficiência e alta densidade de energia (por meio do uso de ímãs de terras raras ou por topologias de rotor que permitem maior densidade de fluxo no entreferro utilizando ímãs de ferrite, por exemplo) [3]. A alta eficiência desta máquina está diretamente relacionada com a ausência de perdas ôhmicas no circuito do rotor e com a ausência de escovas [5], estas sendo substituídas por acionamento elétrico por meio de um inversor. Vale lembrar que a alta densidade de energia contribui para que esta máquina tenha valores altos de torque/corrente e torque/volume [1], [2], [4], [6].

Apesar destas duas grandes vantagens é necessária uma atenção especial no projeto dessa máquina uma vez que, a mesma apresenta algumas características intrínsecas que influenciam diretamente na robustez, confiabilidade, eficiência e eficácia de sua operação. Essas características estão diretamente relacionadas à forma de onda do fluxo concatenado por fase e consequentemente à forma de onda da força contra eletromotriz; à forma de onda da indutância e consequentemente ao torque de relutância devido à variação da indutância; e à forma de onda e amplitude do torque de borda (cogging torque).

A atenção dada a um ou mais destes parâmetros durante o projeto da máquina vai depender exclusivamente de qual topologia está sendo projetada, mas sempre atentando para a forma de onda da força contra eletromotriz que é a principal responsável pela produção de torque nestas máquinas dada sua interação com as correntes de fase. Dentre as topologias possíveis para estas máquinas estão as de ímãs montados na superfície do rotor, as de ímãs semi-enterrados no rotor, as de ímãs enterrados transversalmente e as de ímãs enterrados longitudinalmente, como mostra a Figura 1.1 [3].

Estas máquinas podem ser dividas ainda, com relação a forma de onda da força contra eletromotriz, podendo ser senoidal ou não senoidal. De um modo geral, a forma de onda não senoidal da força contra eletromotriz se assemelha a um trapézio. Dentre essas duas formas de onda de força contra eletromotriz, um estudo realizado em [7] demonstra que as máquinas com forma de onda trapezoidal de força contra eletromotriz são mais eficientes do que as máquinas com forma de onda senoidal. Das topologias apresentadas, as máquinas com ímãs na superfície do rotor têm a flexibilidade de poderem ser projetadas para terem qualquer uma destas formas de onda de força contra eletromotriz e apresentam ainda um valor muito baixo na variação da indutância e consequentemente do torque de relutância, sendo muitas vezes desprezados pela maioria dos autores [1], [2], [4], [8]. 
Figura 1.1 - Topologia de Máquinas Síncronas de Ímã Permanente no Rotor

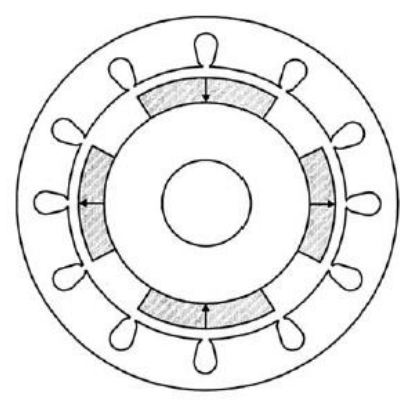

(a)

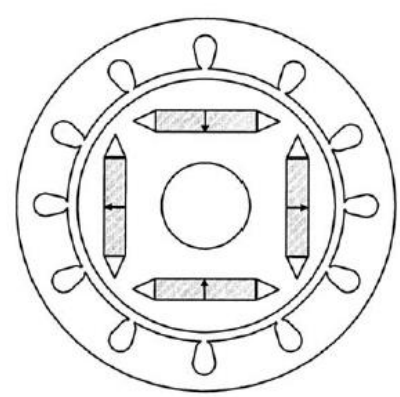

(c)

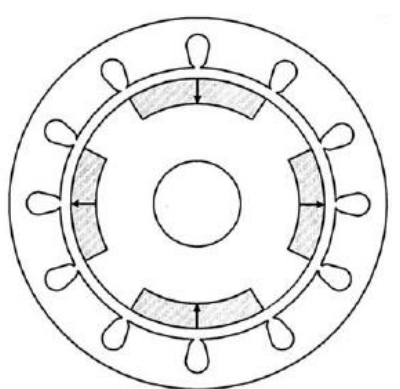

(b)

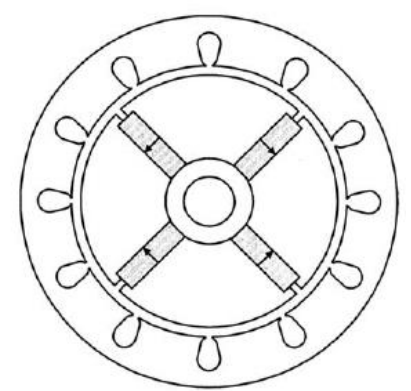

(d)

a) ímãs montados na superfície do rotor; b) ímãs semi-enterrados no rotor; c) ímãs enterrados transversalmente; d) ímãs enterrados longitudinalmente.

Fonte: Chau, K.T., Chan, C.C. (2008)[3].

O resultado final de toda e qualquer máquina é baseado no torque que a mesma é capaz de produzir, e o quão suave e sem ondulações é este torque. Os fatores que contribuem para as ondulações no torque das máquinas de ímã na superfície do rotor são a qualidade da forma de onda da força contra eletromotriz, o torque de borda (cogging torque) e o torque de relutância devido à variação da indutância.

Tendo em vista que o núcleo da máquina é composto de material ferromagnético, e este apresenta um comportamento não linear a ponto de sofrer um fenômeno físico conhecido como saturação magnética - em que o acréscimo da intensidade de campo magnético resulta em um acréscimo pequeno na densidade de fluxo magnético na máquina (graças à baixa permeabilidade relativa nesse ponto de operação) -, várias pesquisas têm sido desenvolvidas nos últimos anos, especialmente nas últimas duas décadas, a fim de se investigar os efeitos da saturação magnética nos parâmetros da máquina síncrona de ímãs no rotor e consequentemente no torque.

Os principais parâmetros sob investigação na literatura correlata são:

- A forma de onda do fluxo concatenado e a forma de onda da força contra eletromotriz: como demonstrado em [9]-[13] as formas de onda desses dois parâmetros são afetados tanto pela saturação em alguns pontos da máquina como 
pela forma de onda da corrente de alimentação, que nesses trabalhos eram puramente senoidais. Segundo [6], [14]-[16] há ocorrência de distorções nesses dois parâmetros em máquinas síncronas com ímãs na superfície do rotor sendo alimentadas com correntes quadradas. O mesmo ocorre quando um máquina síncrona com ímãs na superfície tem suas correntes moduladas por largura de pulso, como mostrado em [12].

- A indutância, que segundo [9]-[11], [13], [17], [18], sofre influência da alimentação senoidal estando a máquina ou não em plena carga. Essas variações foram observadas e mostraram a produção de torque de relutância mesmo em máquinas com ímãs na superfície do rotor.

- A forma de onda do torque de borda e as variações na frequência dessa parcela do torque é demonstrada em [10], [13], [19], [20] que também avaliam métodos diferentes para se obter essa parcela. Nesses trabalhos são mostrados, principalmente, a influência da distribuição do fluxo magnético no cálculo do torque de borda com a máquina alimentada, evidenciando as diferenças entre o torque de borda em carga e o torque de borda em vazio.

- A presença ou não do torque de relutância devido à variação da indutância como demonstrado em [9]-[11], [13], [17], [18].

- A oscilação no torque eletromagnético ocorre em virtude das variações em todos os parâmetros acima. De um modo geral, todos os trabalhos mencionados empregam o Método da Permeabilidade Fixa ora por meio de simulações usando o método dos elementos finitos ora por meio de simulações de circuito magnético (magnetic circuit model, MCM [21]). Excetuando [6], [14]-[16], [22], [23], os demais trabalhos avaliam a máquina síncrona com ímã no rotor com acionamento senoidal e cujas topologias envolvem ímãs semi-enterrados ou ímãs enterrados.

A investigação dos efeitos da saturação e do acionamento, principalmente na forma de onda da força contra eletromotriz, é de grande valia já que a mesma é a principal fonte de torque nas máquinas síncronas com ímã no rotor. Portanto, as alterações na forma de onda da força contra eletromotriz, devido à saturação eletromagnética e a corrente de acionamento, influenciam diretamente a forma de onda do torque eletromagnético. Adicionalmente, como a forma de onda da força contra eletromotriz é função de parâmetros físicos do estator e rotor (i.e., espessura do dente, largura da sapata do dente, altura do dente, permeabilidade do material utilizado na construção do estator e rotor, número de bobinas e de espiras, densidade 
radial (normal) e tangencial do fluxo no entreferro), torna-se fundamental ao projetista da máquina ter conhecimento de como a força contra eletromotriz se altera à medida que o carregamento eletromagnético da máquina aumenta. Podendo, portanto, atuar nos parâmetros físicos citados a fim de se obter uma forma de onda de força contra eletromotriz menos sensível à saturação eletromagnética na faixa de operação desejada para a máquina.

A análise e levantamento da força contra eletromotriz com máquina em condição de carga nunca foi tarefa fácil apesar de contar com a contribuição de vários pesquisadores na busca por um método eficaz para a separação de fluxo durante décadas. O método mais eficaz e mais difundido surgiu em 1998 [24], sendo conhecido como Método da Permeabilidade Fixa (Frozen Permeability Method). Algumas melhorias e avanços ora para o método, ora para a análise dos parâmetros, têm sido propostas por alguns autores em [19], [25] a fim de se refinar os resultados obtidos.

Em linhas gerais, o Método da Permeabilidade Fixa propõe a linearização do circuito eletromagnético da máquina entorno do ponto de operação da mesma, i.e., a partir da curva de magnetização CC de cada material da máquina (estator e rotor, principalmente) encontrase o ponto de operação e então, a permeabilidade desse ponto é calculada e fixada. Dessa forma, com base nos valores de permeabilidade obtidos, cria-se um novo circuito eletromagnético para a máquina, agora linearizada. Com esse novo circuito eletromagnético, são realizadas simulações em busca, ora da contribuição do fluxo dos ímãs, ora da contribuição do fluxo da corrente de armadura para obtenção dos parâmetros desejados. O Método da Permeabilidade Fixa foi inicialmente desenvolvido para ser usado juntamente com o método dos elementos finitos, no entanto, também é possível de ser implementado em simulações de circuito magnético (magnetic circuit model, MCM) [25].

De um modo geral, os trabalhos desenvolvidos e apresentados até o momento têm focado esforços na obtenção da força contra eletromotriz para máquinas acionadas com correntes puramente senoidais [9]-[11], [13], [17]-[21], [24], [25]. Por outro lado, alguns trabalhos mais recentes [6], [12], [14]-[16] utilizando ora acionamento por largura de pulso (PWM Pulse Width Modulation) ora forma de onda quadrada no modo seis pulsos (six-step) têm mostrado que a obtenção da força contra eletromotriz por meio da derivada do fluxo concatenado com cada fase resulta em formas de onda de força contra eletromotriz inapropriadas/imprecisas para o cálculo do torque eletromagnético. O principal problema ocorre em torno dos pontos de comutações e em regiões com variações abruptas de permeabilidade[12] e/ou fluxo eletromagnético, resultando em oscilações consideráveis na forma de onda da força contra eletromotriz. 
Os problemas na obtenção da força contra eletromotriz ocorrem devido à redução de ordem de precisão pela aplicação da derivada no fluxo. Por sua vez, o fluxo é calculado com base na densidade de fluxo magnético. Como foi levantado pelos autores de [22], [23], os programas de elementos finitos empregam elementos triangulares de primeira ordem buscando, principalmente, uma resolução rápida para o problema, o que resulta em uma distribuição da densidade de fluxo magnético $(B)$ um pouco deteriorada já que a densidade de fluxo magnético vem da diferenciação do vetor potencial magnético $(A)$, assim, a função de $B$ tem uma ordem de precisão menor que $A$ em um grau. Portanto, ao longo do processo de cálculo da densidade de fluxo magnético, do cálculo do fluxo e por fim do cálculo da força contra eletromotriz por meio da derivada do fluxo, ocorrem perdas significativas de precisão, levando a erros consideráveis. Essas observações, juntamente com as observações anteriores, salientam a necessidade de um método matemático que calcule de maneira apropriada/precisa a força contra eletromotriz.

No presente trabalho são propostos dois novos métodos de se obter a forma de onda da força contra eletromotriz: método da composição da regiões e método dos tensores. As investigações são conduzidas tomando por base uma máquina síncrona com ímãs na superfície do rotor e sua alimentação é realizada por meio de um conversor elétrico ideal, mais precisamente uma ponte inversora trifásica operando no modo seis pulsos, com duas chaves em condução simultânea (120) (six-step mode) produzindo correntes com forma de onda quadrada e largura de $120^{\circ}$ elétricos.

\subsection{Objetivos}

O presente trabalho apresenta o desenvolvimento de dois novos métodos para o cálculo e obtenção da forma de onda da força contra eletromotriz em máquinas síncronas com ímãs no rotor (método da composição da regiões e método dos tensores). Os dois métodos apresentados visam superar as falhas na obtenção da forma de onda da força contra eletromotriz como vem sendo feita ao longo dos anos. Apesar dos dois métodos serem demonstrados para máquinas com forma de onda de força contra eletromotriz não senoidal e com alimentação com onda quadrada de corrente, não implica que sejam de aplicação exclusiva a essa topologia de máquina ou forma de acionamento, já que este tipo de acionamento foi considerado por apresentar o caso mais crítico de obtenção da forma de onda da força contra eletromotriz.

Como objetivos secundários, tem-se: 
- Obter o torque mútuo a partir da força contra eletromotriz obtida pelos dois métodos propostos;

- Obter o torque de borda (cogging torque);

- Obter o torque de relutância devido à variação da indutância;

- Obter o torque resultante da soma dos torques de relutância, borda e mútuo pelos dois métodos proposto para o cálculo da força contra eletromotriz;

- Comparar o torque resultante com o torque eletromagnético (obtido por meio de simulação não linear) e com o valor experimental do torque.

\subsection{Organização da Tese}

O Capítulo 2 apresenta uma revisão sobre o método da permeabilidade fixa, a sua forma de implementação e a forma como as simulações, empregando o método, são conduzidas e os critérios para garantir a precisão nos resultados.

No Capítulo 3 é apresentada a formulação do torque eletromagnético produzido, dando especial atenção as suas parcelas. Cada uma delas é descrita de maneira sucinta a fim de se esclarecer a sua origem e como afeta o torque eletromagnético da máquina. Apresenta ainda, a importância do estudo da força contra eletromotriz por fase, os resultados referentes a sua forma de onda da força contra eletromotriz pelo método convencional (obtida por meio da derivada do fluxo concatenado com cada fase) e pelos métodos propostos: método da composição das regiões e o método dos tensores.

O Capítulo 4 avalia os métodos de cálculo da força contra eletromotriz para três estudos de caso, todos com o mesmo estator, porém com rotores diferentes. São apresentadas também as formas de onda do torque de borda, da indutância e do torque de relutância. Por fim, é apresentada a comparação entre a forma de onda do torque resultante da soma das parcelas do torque eletromagnético, obtido pelos três métodos de cálculo da força contra eletromotriz, e a forma de onda do torque eletromagnético resultante da simulação não linear. Para o primeiro caso em estudo, também são apresentados resultados experimentais para a força contra eletromotriz e para o torque eletromagnético. São comparadas as formas de onda do torque eletromagnético e do torque resultante da soma das componentes do torque eletromagnético para as condições de carregamento de 50\%, 100\% e 200\%. 
No Capítulo 5 são apresentadas as conclusões relativas aos objetivos cumpridos e os métodos propostos para cumpri-los. Ressalta-se ainda, os trabalhos futuros para a expansão do trabalho realizado nesta tese de doutorado. 


\section{Capítulo 2}

\section{Método da Permeabilidade Fixa, Simulação em Elementos Finitos e Critérios de Simulação}

\subsection{Introdução}

O presente capítulo apresenta uma revisão sobre o método da permeabilidade fixa e a forma como as simulações em elementos finitos empregando o método da permeabilidade fixa são conduzidas. Também são apresentados os critérios adotados para melhorar a precisão dos resultados das simulações assim como a precisão do cálculo das parcelas do torque.

\subsection{Método da Permeabilidade Fixa}

A elaboração do Método da Permeabilidade Fixa (MPF) surgiu da tentativa de se aplicar o teorema da sobreposição de fontes aos problemas de eletromagnetismo cujos materiais envolvidos apresentam comportamento não linear, permitindo, portanto, a avaliação das contribuições de cada uma das fontes de fluxo eletromagnético no fluxo resultante ou a contribuição de cada uma das parcelas do torque eletromagnético no torque resultante. No entanto, este tipo de problema assim como a análise de fluxos magnéticos em máquinas elétricas, são não lineares e a aplicação direta do teorema da sobreposição é inviável e resulta em valores não condizentes com a realidade. Portanto a utilização do Método da Permeabilidade Fixa 
proposto em [24] contorna esse problema ao propor a linearização do ponto de operação $(O P)$ na curva de magnetização do material ferromagnético, fixando-se a permeabilidade do material $\left(\mu_{O P}\right)$ e então, aplica-se o teorema de sobreposição de fontes para analisar a contribuição de cada uma das fontes de fluxo magnético em uma máquina ou problema semelhante.

Quando aplicado juntamente com o método dos elementos finitos, o Método da Permeabilidade Fixa encontra o ponto de operação $(O P)$ e fixa a malha de elementos finitos com base nos valores de permeabilidade calculados para cada elemento da malha segundo a curva de magnetização do material do problema. Com os valores fixados em cada elemento dessa malha, o material passa a ser linear. Permitindo, portanto, o emprego do teorema da sobreposição de fontes. A Figura 2.1 ilustra o Método da Permeabilidade Fixa aplicado a uma curva de magnetização e um ponto de operação também fictício.

Figura 2.1 - Método da Permeabilidade Fixa

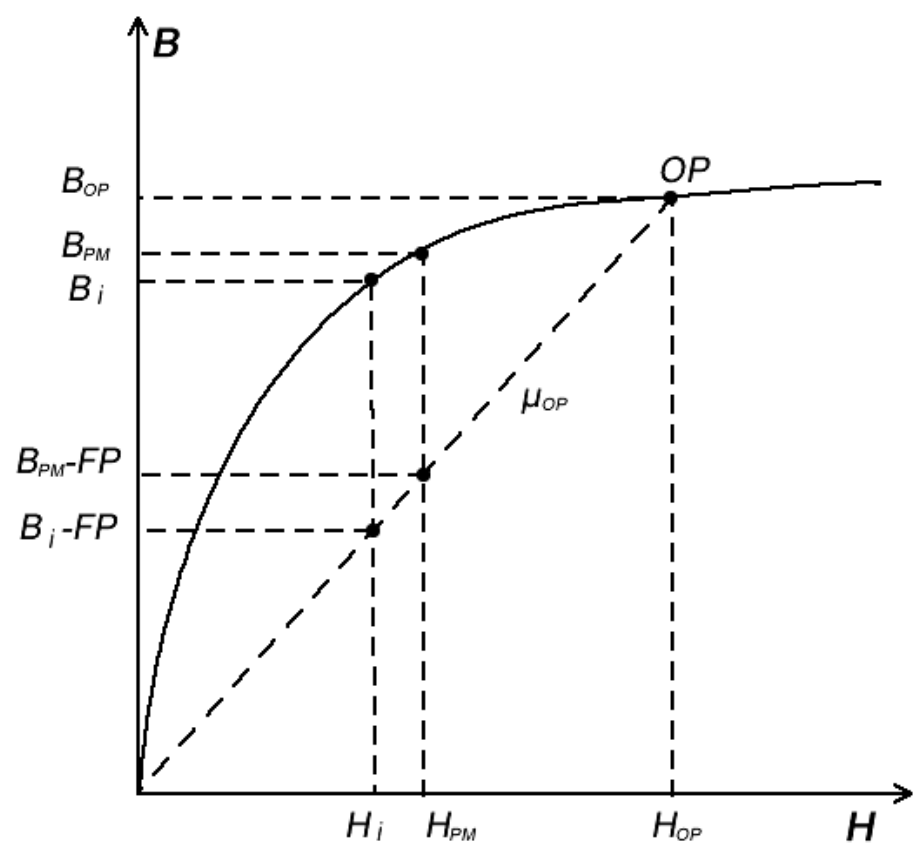

Sem a linearização proposta pelo Método da Permeabilidade Fixa, a soma das densidades de fluxo magnético de cada fonte de fluxo magnético - no presente trabalho os ímãs ( $\left.B_{P M}\right)$ e as correntes de armadura $\left(B_{i}\right)$ - não resulta na densidade de fluxo magnético do ponto de operação da máquina $\left(B_{O P}\right)$. Apenas a soma das intensidades de fluxo magnético de cada fonte de fluxo magnético - ímãs $\left(H_{P M}\right)$ e correntes de armadura $\left(H_{i}\right)$ - resulta na intensidade de fluxo magnético do ponto de operação da máquina $\left(H_{O P}\right)$.

Com a linearização proposta pelo Método da Permeabilidade Fixa, a soma das densidades de fluxo magnético de cada fonte de fluxo magnético - ímãs $\left(B_{P M}-F P\right)$ e correntes de 
armadura $\left(B_{i}-F P\right)$ - resulta na densidade de fluxo magnético do ponto de operação da máquina $\left(B_{O P}\right)$. Ao passo que, a soma das intensidades de fluxo magnético de cada fonte de fluxo magnético não sofre alteração - ímãs $\left(H_{P M}\right)$ e correntes de armadura $\left(H_{i}\right)$ - e continua resultando na intensidade de fluxo magnético do ponto de operação da máquina $\left(H_{O P}\right)$ [9], [10], [13], [19], [24], [25].

O fluxograma da Figura 2.2, extraído de [6], demonstra os passos de simulação e emprego do Método da Permeabilidade Fixa.

- No primeiro passo, tem-se a simulação da máquina sem corrente (apenas os ímãs são fonte de fluxo magnético), a fim de se obter os valores e formas de onda para a força contra eletromotriz (em vazio) e para o torque de borda (cogging torque). Estes parâmetros (força contra eletromotriz e torque de borda) em vazio servem como base comparativa para as condições de carregamento, tornando possível verificar as distorções e variações nestes parâmetros à medida que o carregamento eletromagnético aumenta.

- No segundo passo é realizada a simulação com a máquina carregada eletromagneticamente segundo a condição desejada. Neste ponto, tanto os ímãs como as bobinas alimentadas com correntes são fonte de fluxo magnético. Com esta simulação são obtidos os valores de amplitude e forma de onda do torque eletromagnético e a frequência e amplitudes de suas oscilações.

- O terceiro passo emprega o Método da Permeabilidade Fixa, sendo salva e fixada a malha de permeabilidade da simulação em carga feita por meio do método dos elementos finitos relativa ao passo anterior. Dessa forma, é gerado o modelo linearizado em elementos finitos, a partir do qual, torna-se possível avaliar as contribuições de cada uma das fontes de fluxo magnético e de torque para a máquina em estudo.

- No quarto e último passo, tem-se a simulação, já com o modelo linearizado da máquina, em que são avaliadas ora a contribuição dos ímãs como fonte de fluxo magnético, ora a contribuição das correntes de armadura como fonte de fluxo magnético. Para a simulação apenas com os ímãs como fonte de fluxo magnético, são obtidos os valores de amplitude, frequência e forma de onda do fluxo concatenado com as bobinas, a força contra eletromotriz e o torque de borda (cogging torque). Para a simulação apenas com as correntes como fonte de fluxo magnético, são obtidos os valores de amplitude, frequência e forma de onda do fluxo 
gerado pelas bobinas, a indutância e o torque de relutância (devido à variação da indutância).

Figura 2.2 - Emprego do Método da Permeabilidade Fixa

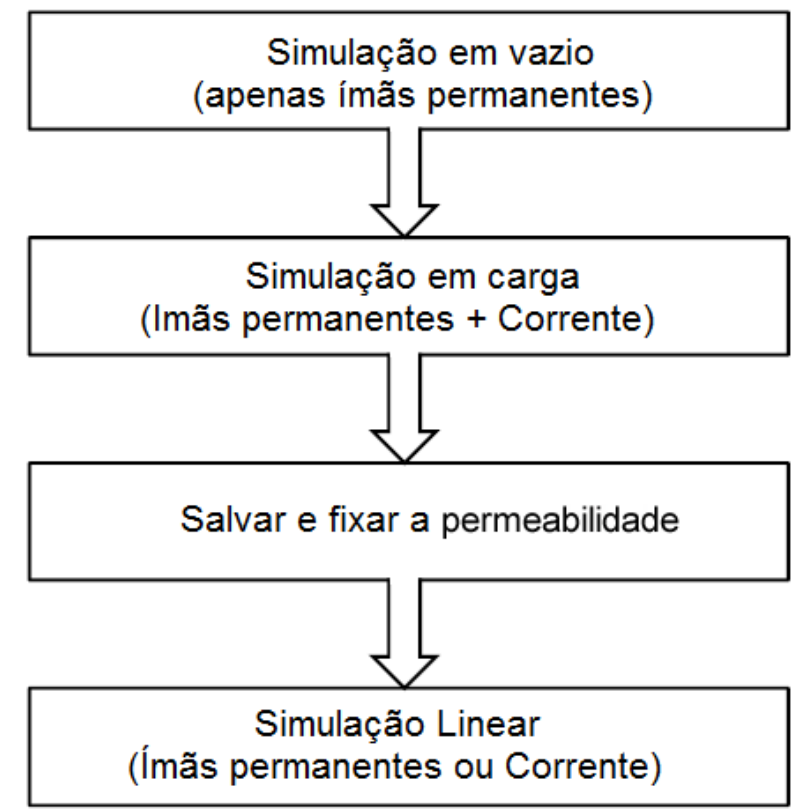

Fonte: Paula, G. T. (2013)[6].

\subsection{Implementação e Simulação}

As simulações conduzidas neste trabalho são realizadas com o auxílio de dois softwares: o FEMM (Finite Element Method Magnetics) [26], responsável pelas simulações em elementos finitos; e o software desenvolvido pelo autor [6], responsável pelo emprego do Método da Permeabilidade Fixa nos arquivos de entrada e saída do FEMM por meio de conexão ActiveX.

Como mencionado, o software utilizado nas simulações da máquina em elementos finitos é o FEMM [26], de uso livre para fins acadêmicos e que permite ao usuário a automatização de alguns processos e rotinas de simulação por meio de scripts baseados na linguagem LUA, além de permitir a inclusão e edição dos materiais utilizados na simulação, refinamento de malha de elementos finito de forma independente em cada material. O software permite também a interação com outros softwares por meio de uma conexão ActiveX.

Já o software desenvolvido pelo autor [6], responsável pelo emprego do Método da Permeabilidade Fixa por meio de conexão ActiveX, utiliza os arquivos de resposta (".ans") gerados na segunda etapa de simulação (simulação com carregamento) para gerar um novo 
arquivo de entrada (".fem") que contém o mesmo modelo físico da máquina, porém, com o agrupamento de elementos de malha que contenham valores de permeabilidade relativa próximos, seguindo a margem de tolerância ("a") determinada pelo usuário (Figura 2.3). As características elétricas dos materiais são mantidas, fixando-se apenas a permeabilidade magnética relativa dos mesmos. Recriado o modelo físico da máquina, este linearizado, geram-se dois novos arquivos de entrada: "modelo_PM.fem" e "modelo_CURRENT.fem", um preparado para quarta etapa de simulação (vide Figura 2.2) com os ímãs como fonte de fluxo magnético e o outro preparado para a quarta etapa de simulação (vide Figura 2.2) com as correntes como fonte de fluxo magnético.

Figura 2.3 - Modelo Físico do Estator Reconstruído.

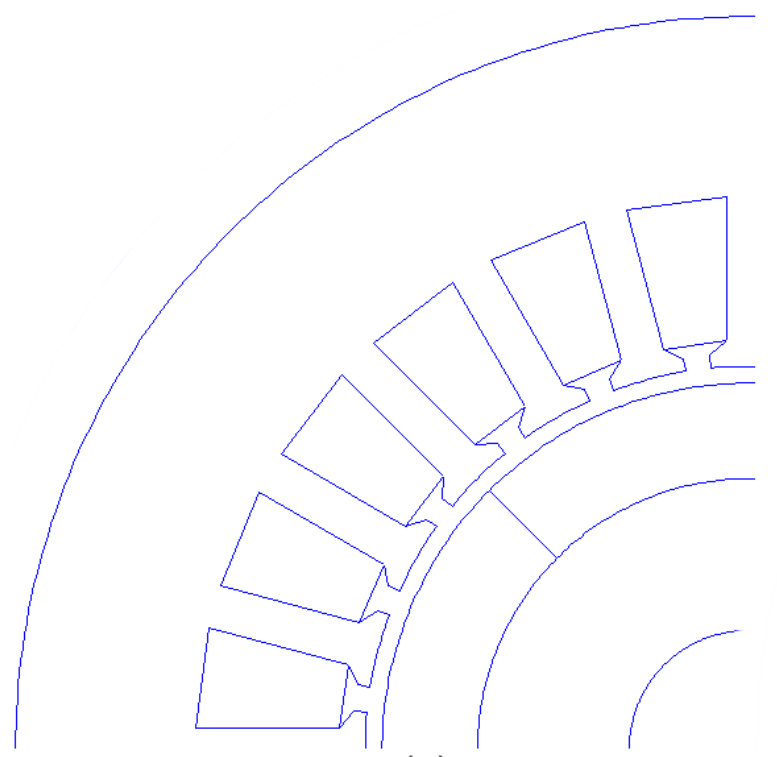

(a)

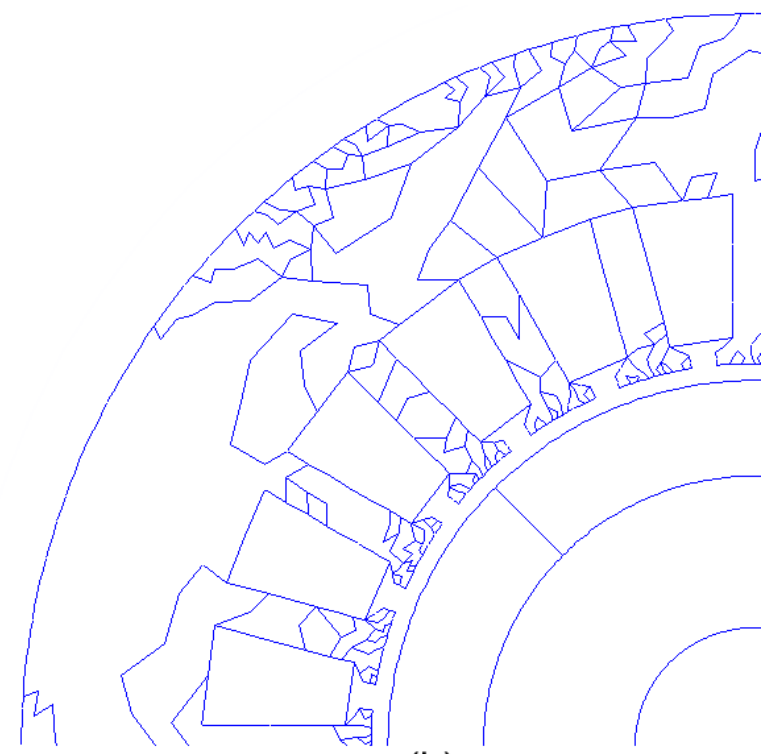

(b)

a) material homogêneo; b) material não homogêneo.

Fonte: Paula, G. T. (2013)[6].

Segundo [6], a margem "a" de tolerância deve ser mantida menor que $10 \%$ a fim de se manter a fidelidade entre o modelo linearizado e o modelo não linear. A influência desta margem de tolerância na energia de cada elemento é expressa por (2.1), que mostra os valores extremos para a variação da densidade de energia o que não quer dizer que todos os elementos estejam exatamente nos pontos extremos.

$$
\frac{B^{2}}{2 \mu_{R} \mu_{0}(1+a)} \leq \frac{W}{m^{3}} \leq \frac{B^{2}}{2 \mu_{R} \mu_{0}(1-a)}
$$

A fim de se ilustrar a eficácia do software desenvolvido pelo autor [6] para o emprego do Método da Permeabilidade Fixa, a Figura 2.4 ilustra um exemplo de resultado da densidade de fluxo radial no centro do entreferro da máquina estudada em [6] sob condição de 
carregamento eletromagnético de $100 \%$, ilustrando a contribuição da corrente de armadura e dos ímãs permanentes na densidade de fluxo resultante. Este apresentado na legenda como: "Não-Linear", para o resultante da simulação não linear (segundo passo da Figura 2.2); e "Corrente + Ímã", para o resultante da simulação linear com as duas fontes de fluxo magnético. As contribuições dos fluxos provenientes da corrente e dos ímãs, obtidas com as simulações empregando o modelo linearizado da máquina (quarto passo da Figura 2.2) são nomeadas por "Corrente apenas" e "Ímã apenas", respectivamente.

Figura 2.4 - Densidade de Fluxo Radial na Posição Inicial

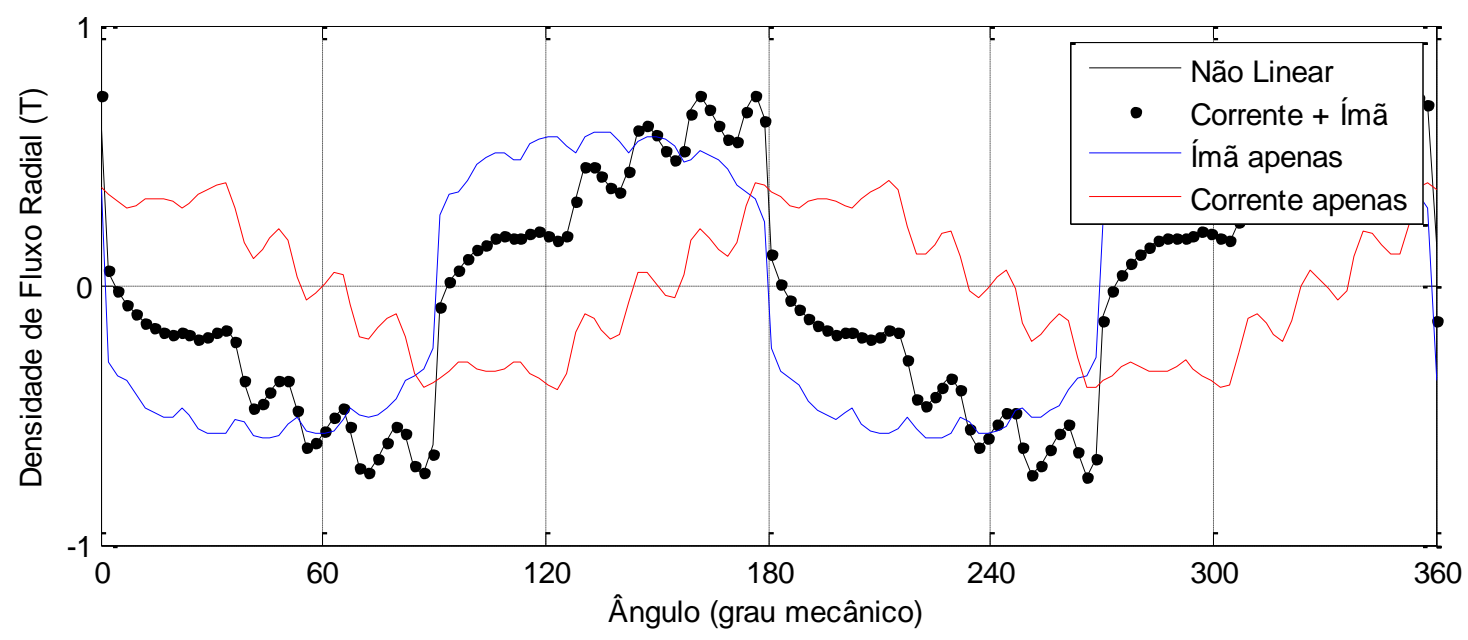

Já a Figura 2.5 ilustra um exemplo de resultado da densidade de fluxo tangencial no entreferro da máquina estudada em [6] sob condição de carregamento eletromagnético de $100 \%$, ilustrando a contribuição da corrente de armadura e dos ímãs permanentes na densidade de fluxo resultante. Esse apresentado como: "Não-Linear", para o resultante da simulação não linear (segundo passo da Figura 2.2); e "Corrente + Ímã", para o resultante da simulação linear com as duas fontes de fluxo magnético. As contribuições dos fluxos provenientes da corrente e dos ímãs, obtidas com as simulações empregando o modelo linearizado da máquina (quarto passo da Figura 2.2) são nomeadas por "Corrente apenas" e "Ímã apenas", respectivamente.

Como visto nas Figuras 2.4 e 2.5, os modelos lineares resultantes do emprego do Método da Permeabilidade Fixa permitem a decomposição das contribuições de cada fonte de fluxo magnético presente na máquina.

A Figura 2.6 mostra a contribuição de cada fonte de fluxo eletromagnético para a distribuição das linhas de fluxo magnético na máquina sob carregamento eletromagnético de 100\%. Na Figura 2.6(a) tem-se o resultado para as linhas de fluxo a partir do modelo não linear da máquina (segundo passo da Figura 2.2). Já a Figura 2.6(b) ilustra o resultado para as linhas de fluxo a partir do modelo linear da máquina com as duas fontes de fluxo magnético 
(corrente de armadura e ímãs permanentes). As Figuras 2.6(c) e (d) ilustram as contribuições dos ímãs permanentes e da corrente de armadura (modelo linear) no fluxo magnético, respectivamente.

Figura 2.5 - Densidade de Fluxo Tangencial na Posição Inicial

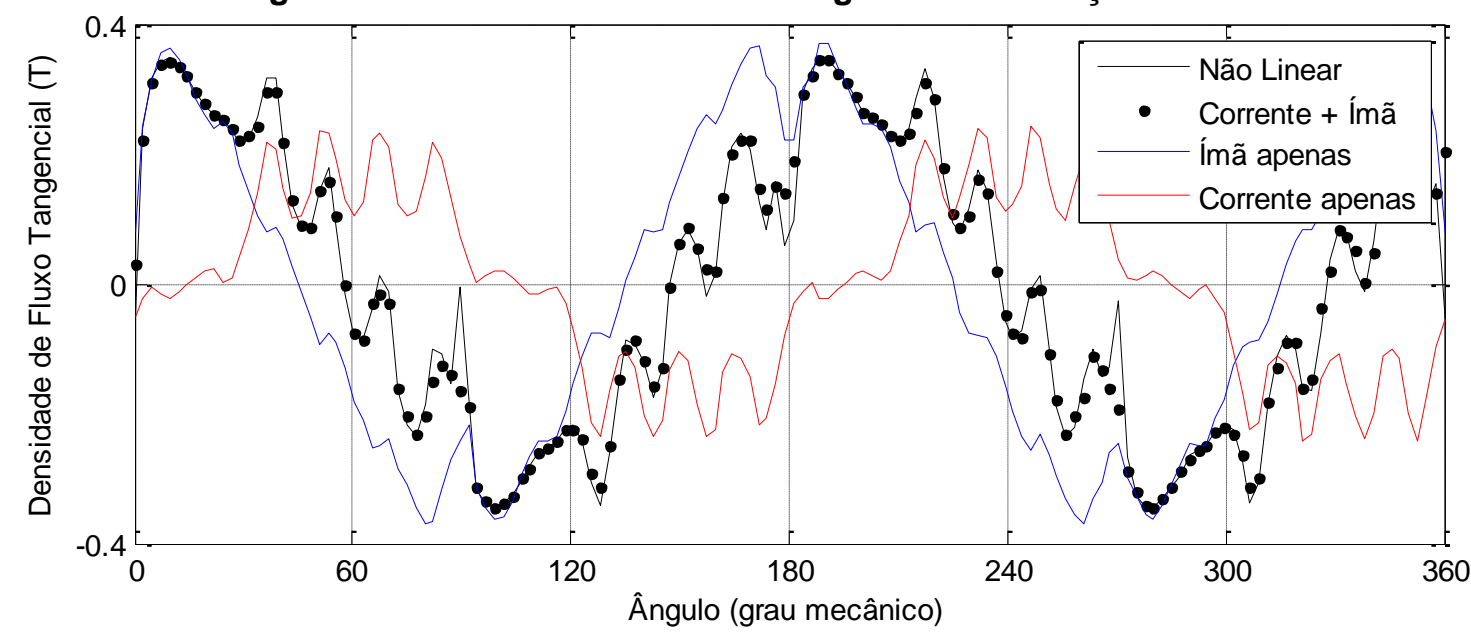

\subsection{Exatidão das Simulações}

Apesar de evidenciado o emprego correto do Método da Permeabilidade Fixa pelo software desenvolvido pelo autor [6], ainda restam algumas questões de ajustes de tamanho de elemento de malha e de grau de precisão na obtenção da distribuição da densidade de fluxo eletromagnético que envolvem detalhes técnicos que são apresentados nesta subseção.

No que diz respeito ao tamanho máximo de um elemento de malha e à quantidade de elementos presentes nesta malha gerada pelo software de elementos finitos para a simulação da máquina em estudo, observam-se cerca de 16 mil elementos e mais de 33 mil nós no modelo, sendo que o refino da malha no entreferro foi realizado de forma interativa buscandose o melhor custo computacional sem que a precisão nos resultados do torque fosse comprometida. A Tabela 2.1 apresenta os valores de torque para a condição de $100 \%$ de carga e para diferentes valores de tamanho máximo de cada elemento da malha no entreferro tomando como base o valor de $0,3 \mathrm{~mm}$ como tamanho máximo de perímetro para cada elemento de malha. 
Figura 2.6 - Distribuição de Fluxo Eletromagnético

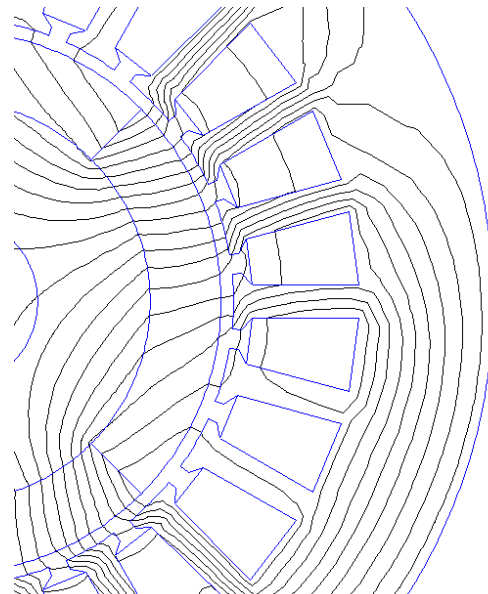

(a)

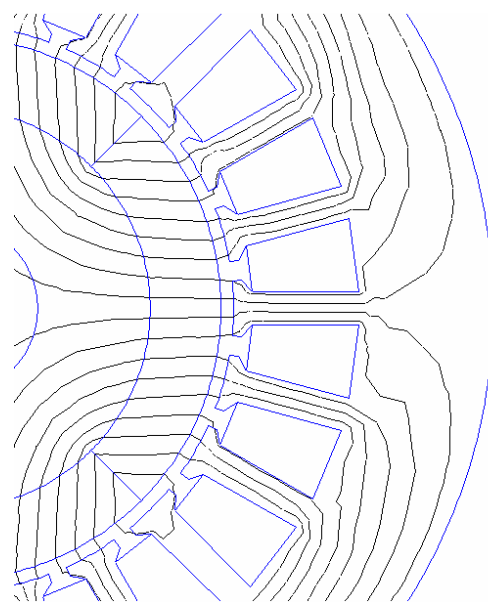

(c)

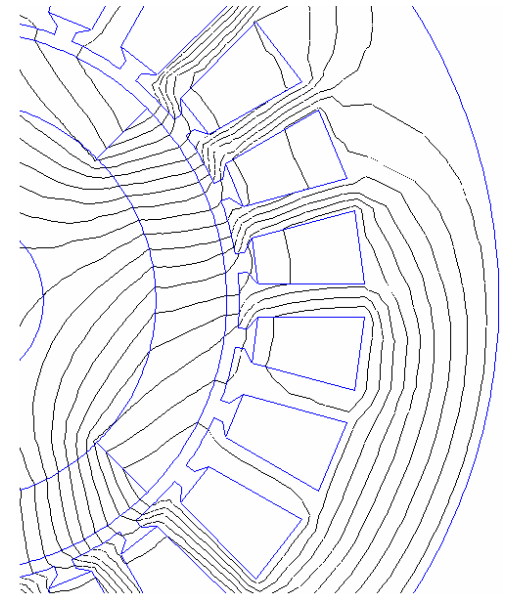

(b)

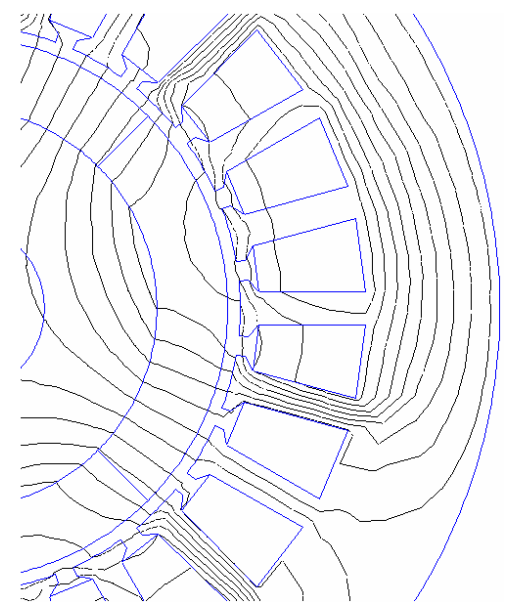

(d)

a) simulação não linear; b) simulação linear com as duas fontes de fluxo (corrente de armadura e ímãs permanentes); c) simulação linear apenas com os ímãs permanentes; d) simulação linear apenas com a corrente de armadura.

Tabela 2.1 - Tamanho Máximo do Elemento v.s. Precisão

\begin{tabular}{|c|c|c|c|c|c|c|c|c|c|}
\hline \multicolumn{5}{|c|}{ Início do Período } & \multicolumn{5}{|c|}{ Final do Período } \\
\hline Torque & $\begin{array}{l}\text { Tamanho } \\
\text { Máx. (mm) }\end{array}$ & $\begin{array}{c}\text { Cama- } \\
\text { das }\end{array}$ & Nós & $\begin{array}{c}\text { Dife- } \\
\text { rença } \\
\%\end{array}$ & Torque & $\begin{array}{l}\text { Tamanho } \\
\text { Máx. (mm) }\end{array}$ & $\begin{array}{c}\text { Cama- } \\
\text { das }\end{array}$ & Nós & $\begin{array}{c}\text { Dife- } \\
\text { rença } \\
\%\end{array}$ \\
\hline 3,954 & Auto & 2 & 9791 & $-1,09$ & 3,819 & Auto & 2 & 9983 & $-1,05$ \\
\hline 3,998 & 0,3 & 5 & 18385 & 0,00 & 4,268 & 0,3 & 5 & 18826 & 0,00 \\
\hline 3,993 & 0,4 & 4 & 15877 & $-0,13$ & 4,263 & 0,4 & 4 & 16111 & $-0,13$ \\
\hline 4,014 & 0,5 & 3 & 15003 & 0,04 & 4,262 & 0,5 & 3 & 15233 & $-0,15$ \\
\hline 3,952 & 0,6 & 2 & 10473 & $-1,16$ & 4,221 & 0,6 & 2 & 10583 & $-1,11$ \\
\hline 3,952 & 0,7 & 2 & 9892 & $-1,16$ & 4,221 & 0,7 & 2 & 10054 & $-1,11$ \\
\hline
\end{tabular}

O tamanho máximo denominado por "Auto" diz respeito ao valor atribuído de forma automática pelo FEMM. Tamanhos máximos menores que $0,3 \mathrm{~mm}$ resultam em tempo com- 
putacional elevado e nota-se que a diferença entre os valores de torque para o tamanho máximo de $0,3 \mathrm{~mm}$ e $0,4 \mathrm{~mm}$ não é expressiva e permanece constante $(0,13 \%)$ do início ao fim do período de $60^{\circ}$ elétricos, referente ao intervalo de comutação entre duas fases no modo de operação à seis pulsos. Esta diferença relativa constante do início ao fim de um intervalo correspondente à comutação entre duas fases favorecerá na etapa final deste trabalho, na qual será realizada a comparação entre o valor do torque eletromagnético avaliado por meio de uma simulação não linear e o valor do torque eletromagnético avaliado por meio da soma das parcelas do torque obtidas pela força contra eletromotriz e torque de borda (cogging torque). Desta forma, o erro relativo desta comparação não sofrerá interferência da malha entre um passo e outro da simulação.

Em termos de custo computacional, o tamanho máximo de $0,4 \mathrm{~mm}$ é ligeiramente mais lento que o $0,5 \mathrm{~mm}$, mas mais rápido do que o $0,3 \mathrm{~mm}$ devido à quantidade de nós na malha total. Portanto, para as simulações conduzidas neste trabalho, foi utilizado o valor de $0,4 \mathrm{~mm}$ para o tamanho máximo de cada elemento dentro da malha do entreferro, o que resulta em uma malha formada por 4 camadas no entreferro, garantido um grau de precisão compatível com a aplicação. A Figura 2.7 ilustra a malha escolhida para o entreferro contendo 4 camadas de elementos representadas em níveis de preto/cinza.

Figura 2.7 - Malha do Entreferro

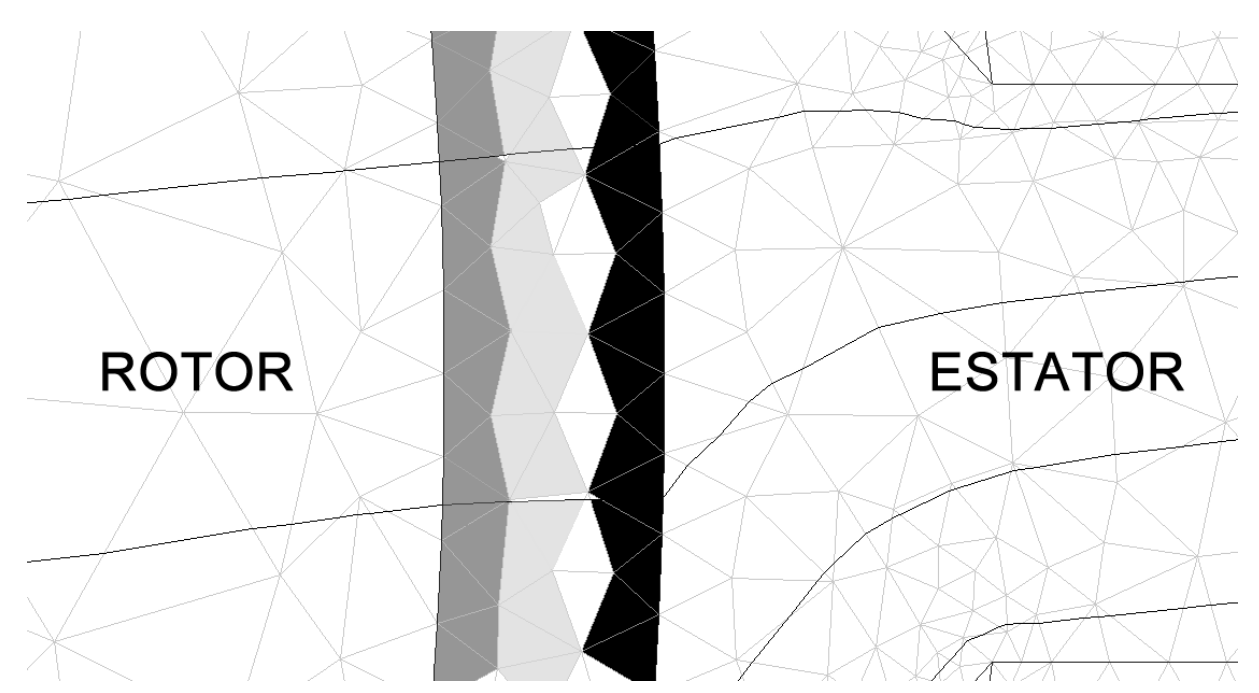

Já, com relação ao grau de precisão na obtenção da distribuição da densidade de fluxo eletromagnético $(B)$ e aplicação da mesma no cálculo do torque por meio dos tensores de Maxwell, foi empregado a técnica conhecida como Método dos Tensores de Maxwell com Filtro Harmônico (Maxwell Stress Harmonic Filter Method) proposta em [22], [23].

Como ressaltado pelos autores de [22], [23] a maioria dos programas geradores de malha em elementos finitos empregam elementos triangulares de primeira ordem buscando, 
principalmente, uma resolução rápida para o problema. No entanto, os resultados para a distribuição da densidade de fluxo magnético $(B)$ ficam um pouco deteriorados já que a densidade de fluxo magnético vem da diferenciação do vetor potencial magnético $A$, assim, a função de $B$ tem uma ordem de precisão menor que $A$ em um grau. Apesar disso, os resultados para o vetor potencial são muito satisfatórios ao se empregar funções de primeira ordem para descrevê-lo, mas os resultados para a função $B$, que é constante por partes ao longo de cada elemento, pode acarretar erros grosseiros especialmente nas regiões de fronteira entre elementos de diferentes valores de permeabilidade magnética relativa (no entreferro, principalmente). A expressão (2.2) demonstra o emprego do Tensor de Maxwell para o cálculo do torque e a expressão (2.3) demonstra a redução na ordem de precisão em $B$ por meio da derivada parcial de $A$.

$$
\begin{gathered}
T_{E L}=\frac{l_{f e}}{\mu_{0}} \int_{0}^{2 \pi} r^{2} B_{R} B_{T} d \theta \\
B_{R}=\frac{\partial A}{r \partial \theta} \\
B_{T}=-\frac{\partial A}{\partial r}
\end{gathered}
$$

Onde:

- $B_{R} \quad$ - Componente Radial da densidade de fluxo magnético;

- $B_{T} \quad$ - Componente Tangencial da densidade de fluxo magnético;

- $\quad r \quad$ - Raio do centro do entreferro;

- $\theta \quad$ - Ângulo em radianos;

- $l_{f e} \quad$ - Comprimento ativo do pacote de lâminas do estator;

- $\mu_{0} \quad$ - Permeabilidade absoluta do vácuo;

- A - Vetor potencial magnético.

Uma alternativa para manter o grau de precisão do torque semelhante ao grau de precisão do potencial magnético $A$ é descrita pelos autores de [22], [23] ao se propor a descrição do potencial $A$ de forma analítica e posteriormente aplicar a derivada e em seguida o tensor de Maxwell. Dessa forma, a expressão para o torque seria uma função explícita do potencial 
A.

Consideram-se dois círculos concêntricos dentro do entreferro do rotor de raios $R_{1} \mathrm{e}$ $R_{2}$, com $R_{1}<r<R_{2}$, referentes às fronteiras interna e externas do entreferro de modo que o vetor potencial $A$ pode ser escrito como proposto em [27] .

$$
A(r, \theta)=\sum_{n=1}^{\infty}\left[\left(c_{n} r^{n}+d_{n} r^{-n}\right)\left(g_{n} \cos (n \theta)+h_{n} \sin (n \theta)\right)\right]
$$

Sendo que o vetor potencial magnético nas duas fronteiras do entreferro pode ser descrito pela série de Fourier:

$$
\begin{aligned}
& A\left(R_{1}, \theta\right)=a_{01}+\sum_{n=1}^{\infty}\left[a_{n 1} \cos (n \theta)+b_{n 1} \sin (n \theta)\right] \\
& A\left(R_{2}, \theta\right)=a_{02}+\sum_{n=1}^{\infty}\left[a_{n 2} \cos (n \theta)+b_{n 2} \sin (n \theta)\right]
\end{aligned}
$$

Escrevendo (2.4) em termos de $R_{1}$ e $R_{2}$, os coeficientes do produto cruzado resultante da distribuição dos termos dentro de (2.4) podem ser escritos como:

$$
\begin{aligned}
& c_{n} g_{n}=\frac{1}{\delta_{n}}\left[a_{n 1}\left(\frac{R_{1}}{R_{2}}\right)^{n}-a_{n 2}\right] \\
& c_{n} h_{n}=\frac{1}{\delta_{n}}\left[b_{n 1}\left(\frac{R_{1}}{R_{2}}\right)^{n}-b_{n 2}\right] \\
& d_{n} g_{n}=\frac{1}{\delta_{n}}\left[a_{n 2}-a_{n 1}\left(\frac{R_{1}}{R_{2}}\right)^{n}\right] \\
& d_{n} h_{n}=\frac{1}{\delta_{n}}\left[b_{n 2}-b_{n 1}\left(\frac{R_{1}}{R_{2}}\right)^{n}\right]
\end{aligned}
$$

Onde:

$$
\delta_{n}=\left(\frac{R_{1}}{R_{2}}\right)^{n}-\left(\frac{R_{2}}{R_{1}}\right)^{n}
$$


Para chegar a definição destes termos, deve ser considerado que a máquina está balanceada de forma que os termos $a_{01}=a_{02}=0$. Substituindo-se (2.7) a (2.11) em (2.4) e, aplicando o resultado em (2.2) e (2.3), considerando, ainda, as simetrias presente em um motor com $p$ pares de polos, chega-se em uma nova expressão no domínio discreto para o torque utilizando o tensor de Maxwell (2.12).

$$
T e l=p \frac{2 \pi l_{f e}}{\mu_{0}} \sum_{n=1}^{\infty} \frac{n^{2}\left(a_{n 2} b_{n 1}-a_{n 1} b_{n 2}\right)}{\left(\frac{R_{1}}{R_{2}}\right)^{n}-\left(\frac{R_{2}}{R_{1}}\right)^{n}}
$$

Pela expressão (2.12), torna-se notória a produção de torque pela interação entre componentes harmônicos de mesma ordem no entreferro do motor. A grande vantagem deste método é a redução da sensibilidade do cálculo do torque aos elementos da malha justamente por utilizar uma descrição analítica do vetor potencial $A$. Outros autores [28]-[30] desenvolveram formulações semelhantes à (2.4) para descrever o vetor potencial $A$ e chegaram em fórmulas equivalentes, numericamente, à (2.12) mas que não favorecem a análise do torque em termos de harmônicos no entreferro. 


\section{Capítulo 3}

\section{Torque Eletromagnético e o Cálculo da Força Contra Eletromotriz}

\subsection{Introdução}

O presente capítulo apresenta a formulação do torque eletromagnético produzido pela máquina em estudo, dando especial atenção as parcelas do mesmo. Cada uma dessas parcelas do torque eletromagnético é descrita de maneira sucinta a fim de se esclarecer a origem de cada uma e como elas influenciam o torque eletromagnético da máquina. Ressalta-se aqui, a importância da força contra eletromotriz, que dada sua interação com a corrente da fase correspondente, contribui para a produção do torque mútuo que é a maior parcela do torque eletromagnético. São mostrados também, os problemas relacionados com o cálculo da força contra eletromotriz pela derivada do fluxo magnético concatenado e são propostos dois novos métodos para a obtenção da força contra eletromotriz.

\subsection{Definição e Formulação do Torque Eletromagnético}

No processo de conversão de energia elétrica em energia mecânica, uma máquina elétrica rotativa, qualquer que seja a sua classificação, tem como variáveis mecânicas de saída o torque e a velocidade angular do eixo, sendo a variável de maior importância o torque 
uma vez que a partir do mesmo se torna possível determinar a aplicabilidade da máquina e a capacidade de carga mecânica suportada pela mesma [2].

Em toda e qualquer máquina elétrica rotativa a descrição matemática do torque pode ser feita ou em termos de fluxo eletromagnético ou em termos de corrente. Em ambos os casos são obtidos os mesmos resultados; no entanto, a determinação do torque eletromagnético por meio do fluxo eletromagnético é inconveniente já que a estimação e determinação dessa variável é custosa. Portanto, opta-se pela determinação do torque eletromagnético por meio da corrente e consequentemente, pela variação da coenergia do sistema (3.1) [4].

$$
T_{E L}=\frac{\partial W_{C}}{\partial \theta}
$$

Onde:

- $W_{C} \quad$ - Coenergia do sistema (Joule).

Para a máquina de ímãs em estudo, com os enrolamentos de estator conectados em $\mathrm{Y}$, a coenergia do sistema é definida por (3.2) [4]:

$$
W_{C}=i_{\text {Linha }} \phi+\frac{1}{2} L_{\text {Linha }} i_{\text {Linha }}^{2}-\frac{1}{2} \Re \phi^{2}
$$

Onde:

- $\quad$ - Relutância vista pelo circuito magnético que tem como fonte de fluxo os ímãs permanentes.

Substituindo-se (3.2) em (3.1), obtém-se a formulação do torque eletromagnético (3.3) [4].

$$
T_{E L}=i_{\text {Linha }} \frac{\partial \phi}{\partial \theta}+\frac{1}{2} i_{\text {Linha }}^{2} \frac{\partial L_{\text {Linha }}}{\partial \theta}-\frac{1}{2} \frac{\partial \Re \phi^{2}}{\partial \theta}
$$

Notoriamente, apesar da conveniência do emprego da coenergia por tratar do equacionamento em termos de corrente de alimentação da máquina, resta ainda a determinação do fluxo magnético proveniente dos ímãs para a solução de (3.3). Ainda mais trabalhosa do que a determinação desse fluxo, é a determinação de maneira analítica da relutância vista pelo circuito magnético que tem como fonte de fluxo os ímãs. Recorre-se, portanto, a meios computacionais, principalmente o método dos elementos finitos para a solução do problema. 
Ao se formular o torque eletromagnético $\left(T_{E L}\right)$ por meio da coenergia do sistema é possível observar três parcelas distintas em (3.3). Cada uma dessas parcelas trata da contribuição, ora de diferentes fontes de fluxo magnético dentro da máquina, ora da interação entre essas fontes a fim de se produzir torque na máquina. Dessa forma, a cada uma dessas parcelas é atribuído um nome diferente, tratando-se, portanto, de uma parcela diferente que vem a compor o torque eletromagnético (3.4).

$$
T_{E L}=T_{\text {Mútuo }}+T_{\text {Relutância }}+T_{\text {Borda }}
$$

No presente capítulo, são apresentadas as noções gerais e a nomenclatura de cada componente do torque eletromagnético e alguns detalhes relevantes de cada um, explorando principalmente, o estudo da força contra eletromotriz que está diretamente associada ao torque mútuo.

\subsubsection{Torque Mútuo}

A primeira parcela de (3.3), conhecida como torque mútuo ( $\left.T_{\text {Mútuo }}\right)$ em (3.4), diz respeito à interação entre as duas fontes de fluxo magnético dentro da máquina de ímãs no rotor (3.5). As fontes são a corrente de armadura e os ímãs. Essa parcela é responsável por contribuir com quase a totalidade do valor do torque eletromagnético [1], [2], [4].

$$
T_{\text {Mútuo }}=i_{\text {Linha }} \frac{\partial \phi}{\partial \theta}=\frac{i_{A}(\theta) e_{A}(\theta)+i_{B}(\theta) e_{B}(\theta)+i_{C}(\theta) e_{C}(\theta)}{\omega_{\text {Mec }}}
$$

Onde:

- $i_{A}, i_{B}, i_{C}-$ Correntes das fases A, B e C respectivamente;

- $e_{A}, e_{B}, e_{C}-$ Forças Contra Eletromotrizes das fases A, B e C respectivamente;

Dada a dependência do torque mútuo com a forma de onda da força contra eletromotriz, toda e qualquer variação e oscilação nos valores e forma de onda da força contra eletromotriz refletirá diretamente na qualidade do torque mútuo produzido pela máquina. A definição, formulação e os problemas relacionados com o cálculo e obtenção da força contra eletromotriz quando a máquina se encontra em carga são detalhados na Seção 3.3

\subsubsection{Torque de Relutância}

A segunda parcela de (3.3), conhecida como torque de relutância ( $\left.T_{\text {Relutancia }}\right)$ em (3.4), 
diz respeito ao torque produzido pela variação da indutância de linha da máquina em estudo (3.6), uma vez que essa tem seus enrolamentos de estator conectados em $\mathrm{Y}$ e a corrente de linha é constante a cada intervalo de $60^{\circ}$ elétricos.

$$
T_{\text {Relutânica }}=\frac{1}{2} i_{\text {Linha }}^{2} \frac{\partial L_{\text {Linha }}}{\partial \theta}
$$

Segundo [6], [9]-[11], [13], [14], [16]-[21], [24], [25], apesar de não apresentar variação de relutância no rotor (rotor sem saliência) o valor da indutância de linha vista pelo inversor não é sempre constante, gerando, portanto, torque de relutância devido à saturação nos dentes do estator. O comportamento dessa parcela de torque está ligado diretamente com a forma de onda da indutância de linha vista pelo inversor e com o ponto de saturação do material do estator.

\subsubsection{Torque de Borda (Cogging Torque)}

A terceira parcela de (3.3), conhecida como torque de borda $\left(T_{B o r d a}\right)$ em (3.4), diz respeito ao torque produzido pela variação da relutância vista pelo circuito magnético que tem como fonte de fluxo magnético os ímãs do rotor (3.7). Em outras palavras, trata-se do torque produzido pela interação entre as aberturas de ranhuras do estator e as bordas dos ímãs do rotor, que é intrínseco a este tipo de máquina.

$$
T_{\text {Borda }}=-\frac{1}{2} \frac{\partial \Re \phi^{2}}{\partial \theta}
$$

Com o auxílio do método dos elementos finitos é possível avaliar essa parcela do torque eletromagnético empregando-se tanto o método do trabalho virtual quanto o método dos tensores de Maxwell. O método do trabalho virtual, como descrito em (3.7), requer dois passos de simulação por analisar a variação da coenergia do sistema com relação à variação da posição do rotor. Já com o método dos tensores de Maxwell, como descrito em (3.8) e baseado em [8], [13], [31], é necessário apenas um passo de simulação para o cálculo do torque na posição desejada do rotor [31]. As formas de onda obtidas pelos dois métodos podem diferir uma da outra caso a malha de elementos finitos no entreferro não esteja bem refinada [13], [19], [22], caso contrário, os resultados são idênticos entre si.

$$
T_{\text {Borda }}=\frac{l_{f e} r^{2}}{\mu_{0}} \int_{0}^{2 \pi} B_{R}(\theta) B_{T}(\theta) d \theta
$$

Segundo [1], [2], [4], essa componente do torque eletromagnético tem comportamento 
oscilatório muito bem determinado quando a máquina está em condição de operação em vazio, justamente por se tratar de uma característica intrínseca desse tipo de máquina. Ainda, em conceito essa componente apresenta valor médio igual à zero. Segundo [32], a frequência de oscilação do torque de borda $\left(f_{\text {Borda }}\right)$ pode ser descrita com relação ao harmônico fundamental de uma revolução elétrica da máquina como apresentado em (3.9).

$$
f_{\text {Borda }}(i)=\frac{M M C\left[2 p, N_{R}\right]}{2 \pi} i
$$

Onde:

- $\quad M M C \quad$ - Mínimo Múltiplo Comum;

- $\quad N_{R} \quad$ - Número de ranhuras do estator;

- $2 p \quad$ - Número de polos;

- $i \quad$ - Ordem do harmônico.

Ainda segundo [1], [2], [4], quanto maior a razão entre o número de ranhuras do estator e o número de polos, maior a amplitude do torque de borda.

Apesar dos resultados para a forma de onda do torque de borda para a condição de operação em vazio obtidos pelos método dos tensores de Maxwell apresentar valor médio igual à zero, trabalhos recentes têm destacado um valor médio diferente de zero quando se analisa a máquina sob carregamento eletromagnético [9]-[11], [13], [19], [25], [33], [34]. Ainda, segundo [10], foi observada a redução pela metade do valor da frequência de oscilação do torque de borda à medida que o carregamento da máquina aumenta. Deve-se levar em conta que os trabalhos citados acima, diferentemente de [6], [15] e do presente trabalho, investigam máquinas síncronas com ímãs no rotor com forma de onda de corrente senoidal.

\subsection{Definição e Formulação da Força Contra Eletromotriz}

Não somente o valor do patamar da força contra eletromotriz por fase, mas também a forma de onda da mesma são fatores de grande valia no projeto de uma máquina síncrona de ímãs no rotor visto que, aliados à forma de onda da corrente de alimentação da máquina, são determinantes na qualidade da forma de onda de torque mútuo produzido neste tipo de máquina. A forma de onda da força contra eletromotriz é o parâmetro mais importante a compor 
o torque eletromagnético, sendo responsável pela produção da maior parcela do torque graças a sua interação com a corrente de alimentação.

A formulação da força contra eletromotriz está diretamente ligada à forma de onda do fluxo concatenado e é descrita por (3.10), sendo a mesma simbolizada por " $e$ ":

$$
e=\frac{\partial \phi}{\partial t}=\frac{\partial \theta}{\partial t} \frac{\partial \phi}{\partial \theta}=\omega_{M e c} \frac{\partial \phi}{\partial \theta}
$$

Onde:

- $\omega_{\text {Mec }}$ - Velocidade mecânica angular do rotor (rad/s)

- $\quad t \quad$ - Tempo (s).

Expandindo-se a expressão do fluxo em (3.10) segundo [2], [4], tem-se (3.11):

$$
e=\omega_{M e c} N_{B o b} N_{C} r_{1} l_{f e} \frac{\partial}{\partial \theta} \int_{\theta_{2}}^{\theta_{1}} B(\theta) d \theta
$$

Onde:

- $\quad N_{B o b}$ - Número de bobinas por fase;

- $\quad N_{C} \quad$ - Número de condutores por bobinas;

- $\quad r_{1} \quad$ - Raio interno do estator (m);

- $\quad l_{f e} \quad$ - Altura do pacote de lâminas do estator (m);

- $\quad B(\theta)$ - Densidade de fluxo magnético dentro das bobinas $(\mathrm{T})$;

- $\quad \theta_{1}, \theta_{2}$ - Posição inicial e final do rotor (rad);

- $\theta$ - Posição angular do rotor (rad).

A maior dificuldade em lidar com (3.11) está relacionada à descrição analítica da densidade de fluxo magnético dentro das bobinas $(B(\theta)$, em (3.11)). Vale-se então do método dos elementos finitos como uma ferramenta na determinação e descrição do fluxo magnético em cada fase, e a partir dele, obtém-se a força contra eletromotriz. Ressalta-se, ainda, que a descrição da densidade de fluxo magnético segue os critérios e formulações apresentadas na 
Seção 2.4 .

Como mencionado no Capítulo 1 e observado em (3.11), a forma de onda da força contra eletromotriz é diretamente dependente de parâmetros físicos da máquina (e.g., número de bobinas, número de espiras) e diretamente afetada pela geometria dos dentes do estator e pela variação da permeabilidade nos mesmos (já que estes estão indiretamente representados pela densidade de fluxo magnético dentro das bobinas em (3.11)).

Portanto, uma forma de onda de força contra eletromotriz menos sensível à saturação e ao acionamento da máquina, favorece a produção de um torque mais suave e com menos oscilações. Porém, para se reduzir as oscilações no torque eletromagnético provenientes das variações na força contra eletromotriz é preciso um método que, primeiramente consiga segregar o fluxo eletromagnético do entreferro em fluxo proveniente da corrente de armadura e fluxo proveniente dos ímãs. E que em uma segunda etapa, seja possível calcular a força contra eletromotriz quando a máquina está carregada. Ao se obter a força contra eletromotriz com a máquina sob carregamento eletromagnético desejado, torna-se possível compará-la com a força contra eletromotriz em vazio e observar as variações nos valores de amplitude e na forma de onda da mesma e, por meio de outras ferramentas/técnicas de otimização de projeto, são feitos ajustes nas dimensões de dente de estator, abertura de ranhura, largura e espessura da sapata do dente buscando melhorar a força contra eletromotriz e torná-la mais constante possível dentro da faixa de operação desejada para a máquina.

O método utilizado para a separação da contribuição dos fluxos no entreferro utilizado no presente trabalho é o método da permeabilidade fixa (MPF), como mencionado no Capítulo 2. O método existente para o cálculo e obtenção da força contra eletromotriz em carga é feito a partir de (3.10) e (3.11), em que o fluxo proveniente apenas dos ímãs é derivado a fim de se obter a força contra eletromotriz. No entanto, como salientado no Capítulo 1 , trabalhos recentes têm obtido a forma de onda da força contra eletromotriz valendo-se de (3.10) e (3.11) , no entanto, são máquinas síncronas de ímãs no rotor com forma de onda de corrente senoidal [9]-[11], [13], [17]-[21], [24], [25]. Por outro lado, alguns trabalhos mostraram que o emprego dessas expressões para a obtenção da forma de onda da força contra eletromotriz para acionamento em six-step ou com modulação por largura de pulso resulta em uma forma de onda com oscilações provenientes da operação derivada, já que o fluxo concatenado com cada fase apresenta algumas variações abruptas durante a comutação das fases [6], [12], [14]-[16] e, mesmo com a aplicação de filtros para mitigar essas oscilações nos resultados da forma de onda, algumas variações continuam notáveis e refletem diretamente na estimação da parcela do torque mútuo e no torque eletromagnético resultando. Oscilações estas que não estão presentes no modelo não linear simulado, levando-se a conclusão de que o método 
expressado por (3.10) e (3.11), aqui chamado de Método Convencional para obtenção da força contra eletromotriz, não é suficiente para o cálculo correto da força contra eletromotriz quando a máquina está sob carregamento eletromagnético. Portanto, surge a necessidade de um método que calcule corretamente a força contra eletromotriz em qualquer condição. $A$ Figura 3.1 ilustra as oscilações geradas pelo método convencional de cálculo da força contra eletromotriz para correntes com forma de onda quadradas em modo six-step, ao passo que segundo [12], mesmo em uma condição em que a força contra eletromotriz foi obtida com o método convencional e posteriormente filtrada para uma máquina com ímãs na superfície do rotor com um acionamento com modulação por largura de pulso ( $P W M)$, também há oscilações na forma de onda.

Figura 3.1 - Força Contra Eletromotriz - Método Convencional

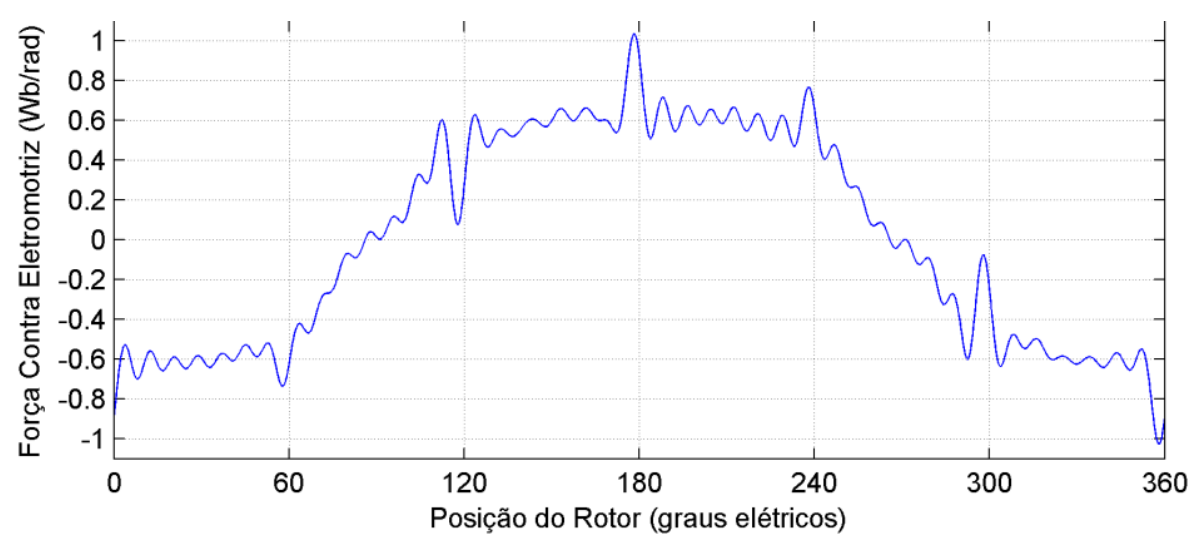

Nas seções seguintes são propostos dois métodos para o cálculo da força contra eletromotriz quando a máquina está sob carregamento. Ambos os métodos são aplicados depois do método da permeabilidade fixa ter sido aplicado nas simulações.

\subsection{Força Contra Eletromotriz: Método da Composição das Regi- ões}

Portanto, para contornar o problema apresentado, é mostrado aqui que o fluxo concatenado deve analisado por regiões correspondentes às regiões de acionamento e empregando-se a operação de derivada sobre essas regiões do fluxo concatenado, obtém-se as formas de onda de força contra eletromotriz para cada região [16]. Por fim, a partir do método de composição, onde são utilizados os trechos correspondentes de forma de onda de cada uma das formas de onda obtidas por região a fim de se compor a força contra eletromotriz final. O método da decomposição do fluxo concatenado com as bobinas de cada fase e da composição da força contra eletromotriz são apresentados em mais detalhes nas subseções 
a seguir. O presente método, é aqui nomeado como Método da Composição das Regiões, para futuras referências.

\subsubsection{Decomposição do Fluxo Magnético}

O método aqui proposto leva em consideração a forma de onda da corrente de alimentação da máquina no modo six-step, onde apenas duas fases estão alimentadas a cada instante. Ao se observar a o modo six-step para alimentação das fases da máquina, é possível notar seis regiões em que a máquina apresenta comportamento eletromagnético diferente, i.e., são impostas diferentes condições de orientação de fluxo magnético dentro da máquina segundo a orientação das correntes nas bobinas de cada fase, por meio de uma ponte inversora trifásica [35]. Essas regiões são descritas na Tabela 3.1.

Tabela 3.1 - Regiões de Operação

\begin{tabular}{|c|c|c|c|c|}
\hline \multirow{2}{*}{$\begin{array}{l}\text { Posição do Rotor } \\
\text { (Graus Elétricos) }\end{array}$} & \multicolumn{2}{|c|}{ Fases } & \multirow{2}{*}{ Região' } & \multirow{2}{*}{ Regiãc } \\
\hline & Ligadas & Desligadas & & \\
\hline 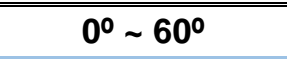 & $+C,-A$ & B & $1^{\prime}$ & 1 \\
\hline $60^{\circ} \sim 120^{\circ}$ & $+\mathrm{C},-\mathrm{B}$ & A & $2^{\prime}$ & 2 \\
\hline $120^{\circ} \sim 180^{\circ}$ & $+A,-B$ & C & 3 & 3 \\
\hline $180^{\circ} \sim 240^{\circ}$ & $+A,-C$ & B & $4^{\prime}$ & 1 \\
\hline $240 \circ \sim 300^{\circ}$ & $+B,-C$ & A & 5 & 2 \\
\hline $300^{\circ} \sim 360^{\circ}$ & $+B,-A$ & C & 6 & 3 \\
\hline
\end{tabular}

Contudo, ao se observar as regiões propostas na Tabela 3.1, nota-se claramente que há apenas três regiões cujo comportamento do fluxo magnético seja diferente, sendo as outras regiões simétricas ao apresentarem correntes em fase oposta às três primeiras regiões e também, o polo magnético do rotor está oposto ao polo magnético para as três primeiras regiões. A Figura 3.2 ilustra o conceito da simetria proposta em uma máquina de dois polos e três ranhuras para as regiões 1' e 4' em que, ambas podem ser consideradas como sendo a mesma região (região 1) por apresentarem a mesma orientação e comportamento de fluxo magnético.

Partindo-se da simetria proposta, têm-se as regiões: Região 1, quando as fases $A$ e $C$ estão ativas; Região 2, quando as fases B e C estão ativas; e Região 3, quando as fases A e B estão ativas. A Figura 3.3 exemplifica o processo de segregação do fluxo magnético por fase segundo as regiões propostas aplicado a uma condição de carregamento eletromagnético de 20A para a máquina utilizada em [6]. 
Figura 3.2 - Comportamento Simétrico

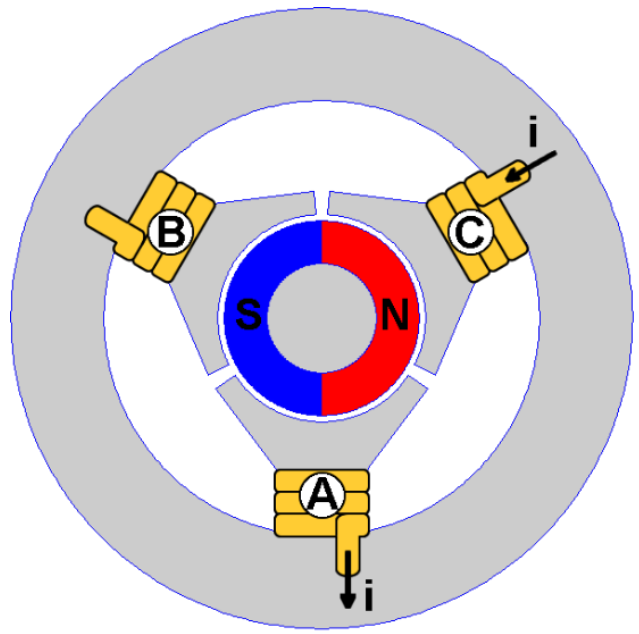

(a)

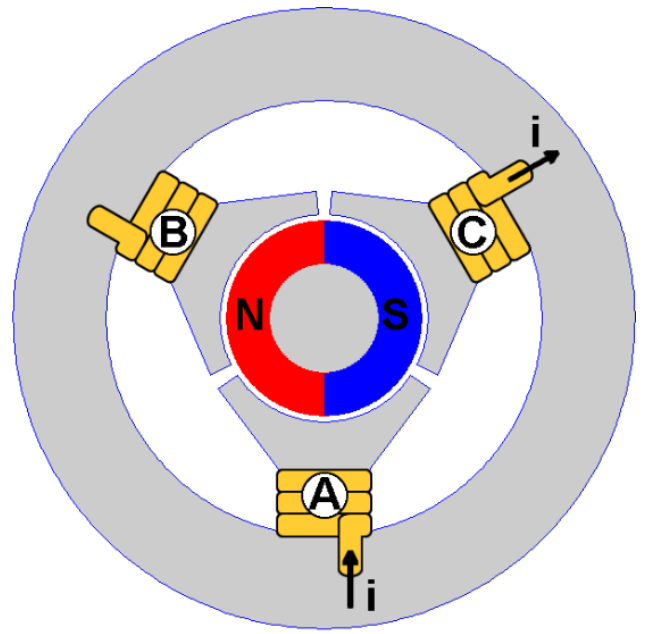

(b)

a) Região 1': Fases +C e -A ligadas; b) Região 4': Fases -C e +A ligadas.

A segregação do fluxo magnético por fase por meio das regiões propostas tem como base a lei da conservação da energia. Em linhas gerais, para que o comportamento dentro da máquina seja conservativo é necessário que as condições de campo impostas pelas correntes de fase sejam mantidas durante uma revolução elétrica completa do rotor. Desta forma, criase um campo conservativo, o que está de acordo com a formulação do princípio de conservação de energia que, segundo [36], [37] o trabalho realizado nessa revolução completa, i.e., sair de um ponto $A$, ir a um ponto $B$ e retornar ao ponto $A$, resultaria em trabalho resultante nulo por estar sob um campo de força conservativo. No acionamento da máquina, cujo objetivo é produzir torque, busca-se continuamente a produção de trabalho ao se comutar as fases do inversor de frequência e manter o campo não conservativo.

Figura 3.3 - Segregação das Regiões do Fluxo Concatenado com a Fase A

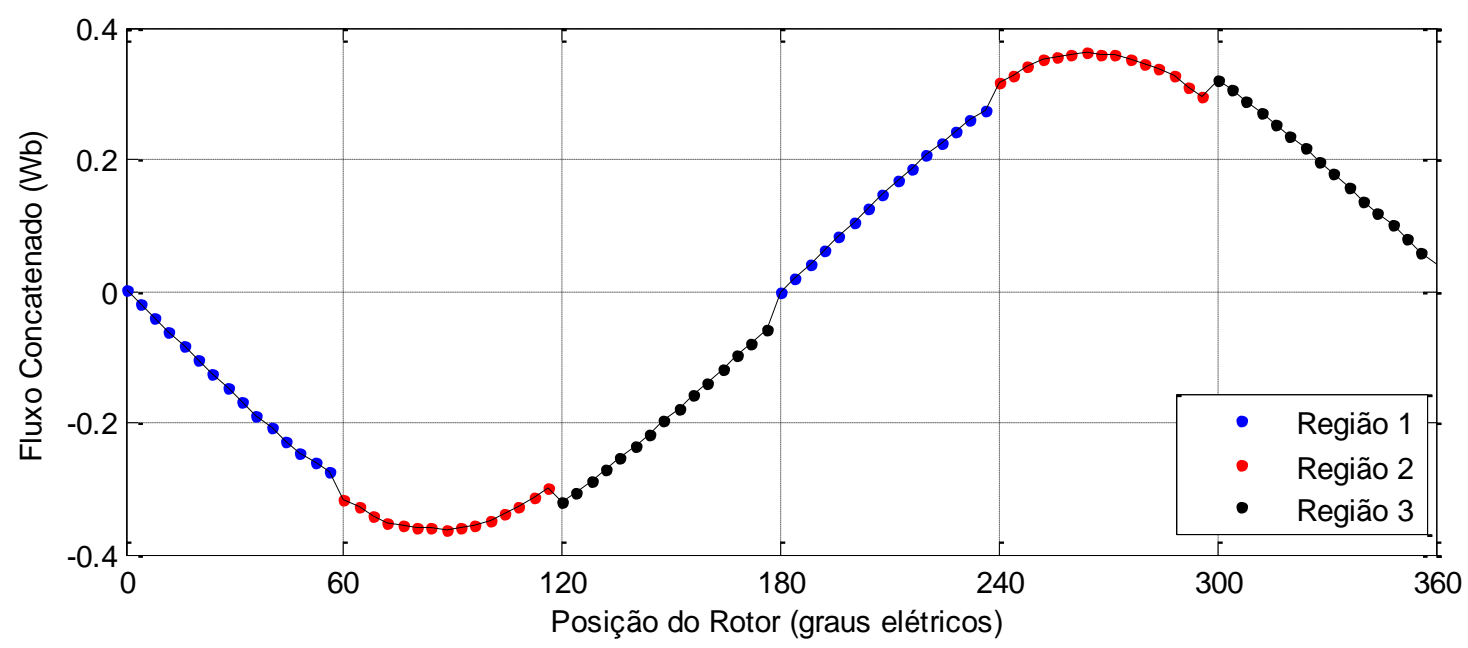


Portanto, os trechos da forma de onda do fluxo concatenado apresentados em cada região ilustrada na Figura 3.3 são trechos constituintes de uma forma de onda de fluxo concatenado com uma fase para uma revolução elétrica completa mantendo-se as condições de alimentação da máquina de acordo com o proposto nessa região. Dessa maneira, são necessárias seis simulações para a obtenção do fluxo magnético para cada uma das regiões, no entanto, graças à simetria observada, são necessárias apenas três simulações contendo as condições de alimentação em que as fases $-A$ e $+C$ estão ligadas (região 1 ), as fases $-B e+A$ estão ligadas (região 2) e as fases +A e -B estão ligadas (região 3).

Mesmo sendo apenas três simulações, o esforço computacional exigido é considerável uma vez que é necessária a realização de uma revolução elétrica completa em cada simulação, o que resulta em um esforço computacional três vezes maior do que a simulação contendo todas as condições de corrente.

Uma forma alternativa que contorna o problema de esforço computacional exigido pela simulação das três regiões, tem como base o uso dos resultados da forma de onda do fluxo concatenado por fase contendo todas as condições de corrente. E, a partir dessas formas de onda, aplica-se a segregação das regiões de fluxo e extrai-se os pontos de cada região segundo a posição em que esses pontos se encontram (posição do rotor). Assim, separados os pontos de cada região, aplica-se o processo de ajuste de curvas (curve fitting) por meio de algum software especialista (e.g., MatLab®, Origin $\left.{ }^{\circledR}\right)$, sendo obtidas as três curvas que representam, cada uma, a forma de onda de fluxo concatenado por fase para determinada região. De um modo geral, cada região resulta em uma forma de onda de fluxo concatenado, formando, portanto, três componentes de forma de onda de fluxo concatenado para uma única fase.

\subsubsection{Composição da Força Contra Eletromotriz}

A partir dos resultados obtidos na Subseção 3.4.1 emprega-se a operação derivada nas regiões de fluxo magnético e são obtidas as formas de onda das forças contra eletromotrizes de cada região como ilustrado na Figura 3.4. Em seguida, compõe-se as formas de onda de força contra eletromotriz. Para a composição da força contra eletromotriz é preciso levar em conta, novamente, as regiões propostas na Tabela 3.1, i.e., para cada posição $\theta$ do rotor é utilizada a forma de onda de força contra eletromotriz apropriada. Assim, para o intervalo de $0^{\circ}$ a $60^{\circ}$ elétricos do rotor, utiliza-se a força contra eletromotriz proveniente da Região 1 ; de $60^{\circ}$ a $120^{\circ}$, utiliza-se a força contra eletromotriz proveniente da Região 2 ; de $120^{\circ}$ a $180^{\circ}$, utiliza-se a força contra eletromotriz proveniente da Região 3 e assim por diante até que se complete uma revolução elétrica e a forma de onda da força contra eletromotriz resultante 
seja completamente determinada.

Embora as formas de onda da força contra eletromotriz compostas ilustradas na Figura 3.5 não sejam suaves e contínuas em torno dos pontos de comutação $\left(0^{\circ}, 60^{\circ}, 120^{\circ}, 180^{\circ}\right.$, $240^{\circ}, 300^{\circ}$ e $360^{\circ}$ elétricos), estas formas de onda são parcialmente suaves se observadas dentro dos intervalos de $60^{\circ}$ elétricos, contornando parcialmente o problema apresentado em [6], [12] e melhorando consideravelmente o cálculo do torque mútuo.

Figura 3.4 - Componentes da Força Contra Eletromotriz

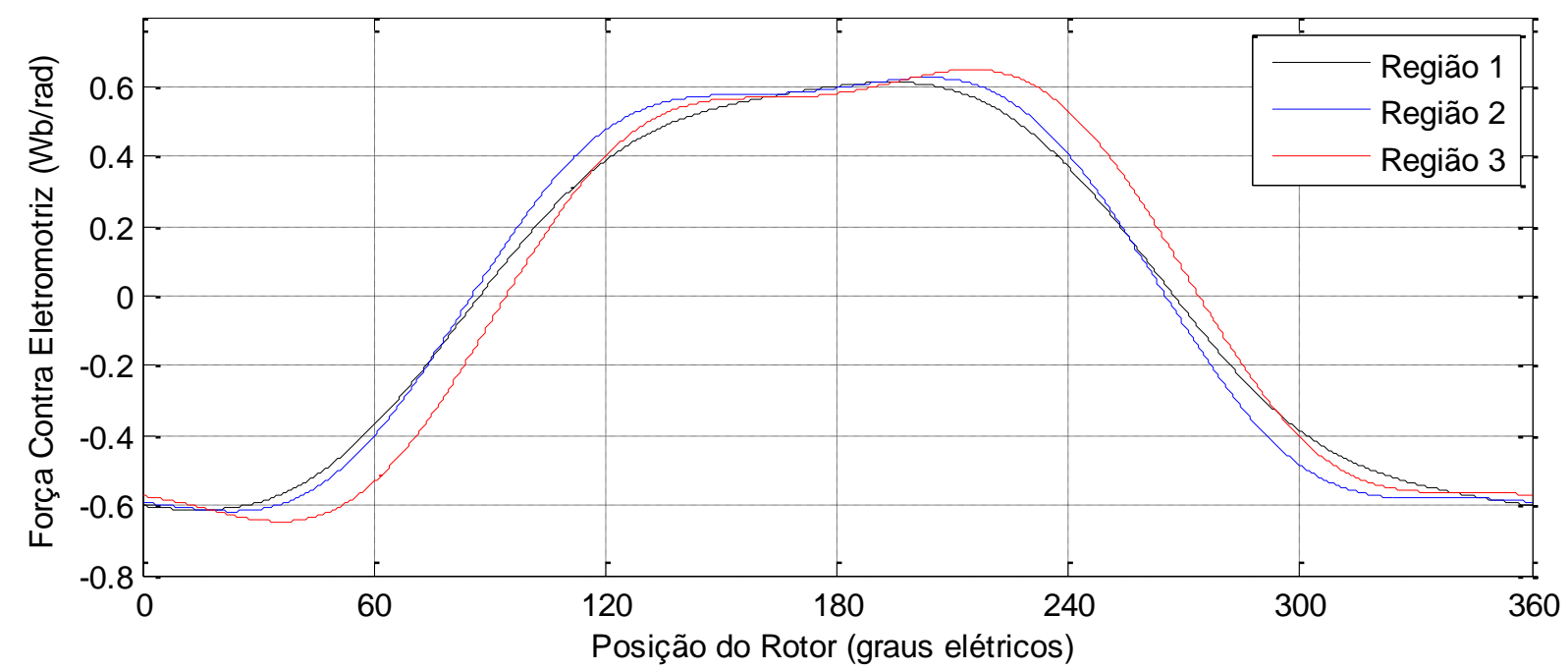

Figura 3.5 - Força Contra Eletromotriz Composta

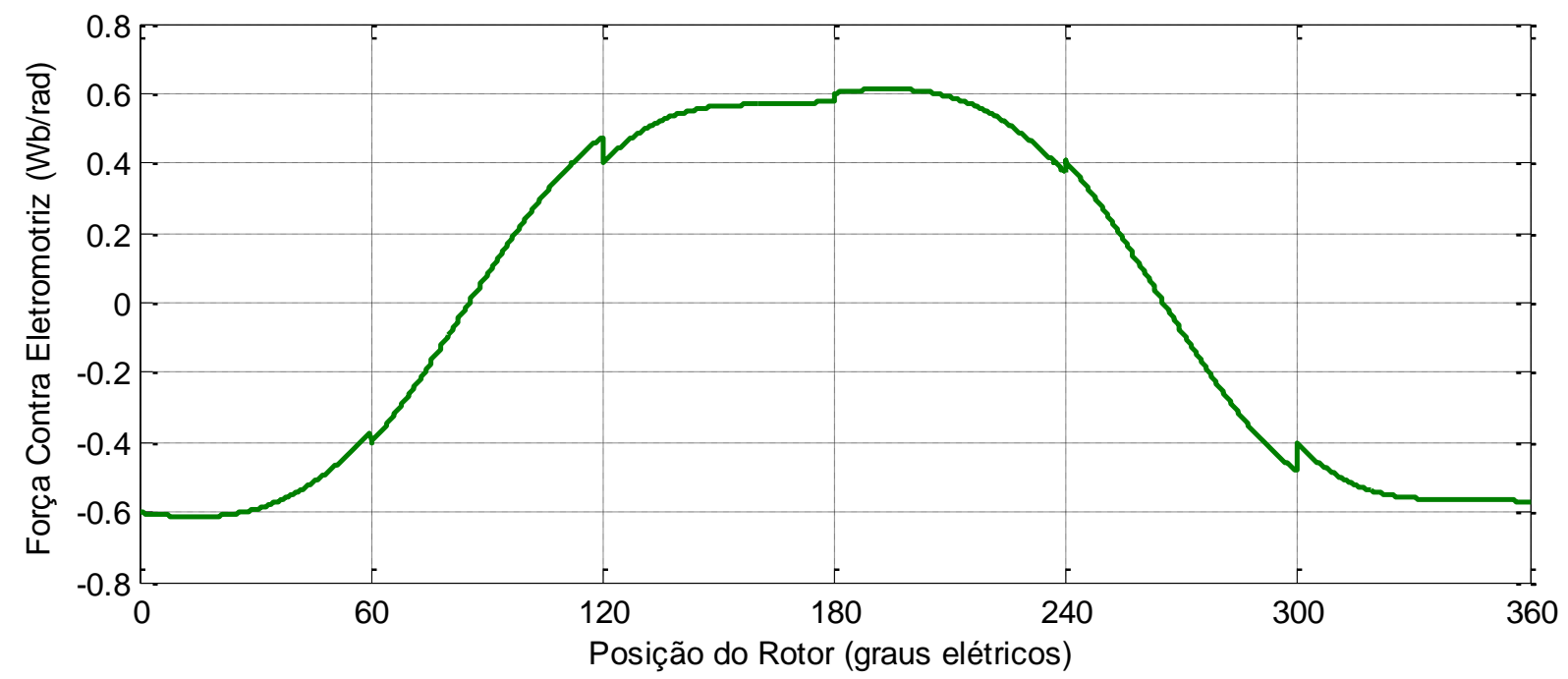




\subsection{Força Contra Eletromotriz : Método dos Tensores}

O presente método, é aqui nomeado como Método dos Tensores, para futuras referências.

Apesar das melhorias provenientes do emprego da força contra eletromotriz calculada pelo Método da Composição das Regiões para a avalição do torque mútuo da máquina em estudo, o método carrega intrinsecamente alguns erros numéricos e de aproximação que refletem diretamente na precisão na determinação do torque eletromagnético final, apresentando erros bem menores que os erros provenientes do método convencional, mas ainda sim em níveis consideráveis caso a expressão que descreva alguma das curvas de fluxo concatenado não esteja exata. Ainda, um erro intrínseco do método da composição está na dificuldade em manter a exatidão e precisão na forma de onda do torque à medida que a saturação aumenta. Além desses erros, destaca-se ainda, o custo computacional para a determinação das curvas e a dificuldade de implementação de uma forma automatizada para a realização do método.

A fim de se contornar todos esses problemas, propõe-se um novo método baseado na combinação entre o Método da Permeabilidade Fixa e os Tensores de Maxwell a partir da expansão da expressão do torque segundo a formulação do Método da Permeabilidade Fixa. Este método é descrito em detalhes a seguir.

Segundo o Método da Permeabilidade Fixa é válido afirmar:

$$
\begin{aligned}
& B_{O P}=B_{P M-F P}+B_{i-F P} \\
& H_{O P}=H_{P M-F P}+H_{i-F P}
\end{aligned}
$$

Onde:

- $B_{O P} \quad$ - Densidade de fluxo magnético do ponto de operação da máquina;

- $\quad B_{P M-F P}$ - Densidade de fluxo magnético (Contribuição dos Ímãs);

- $B_{i-F P} \quad$ - Densidade de fluxo magnético (Contribuição da Armadura);

- $H_{O P} \quad$ - Intensidade de fluxo magnético do ponto de operação da máquina;

- $H_{P M-F P}$ - Intensidade de fluxo magnético (Contribuição dos Ímãs);

- $H_{i-F P} \quad$ - Intensidade de fluxo magnético (Contribuição da Armadura). 
E segundo o emprego dos Tensores de Maxwell para o cálculo do torque eletromagnético, é válido afirmar:

$$
T e l=\frac{l_{f e}}{\mu_{0}} \int_{0}^{2 \pi} r^{2}\left(B_{O P}\right)_{R}\left(B_{O P}\right)_{T} d \theta
$$

Onde:

- $\left(B_{O P}\right)_{R}$ - Componente Radial da densidade de fluxo magnético do ponto de operação;

- $\left(B_{O P}\right)_{T} \quad$ - Componente Tangencial da densidade de fluxo magnético do ponto de operação;

Substituindo-se (3.12) em (3.13), obtém-se:

$$
T e l=\frac{l_{f e}}{\mu_{0}} \int_{0}^{2 \pi} r^{2}\left(B_{P M-F P}+B_{i-F P}\right)_{R}\left(B_{P M-F P}+B_{i-F P}\right)_{T} d \theta
$$

Os subscritos $R$ e $T$, externos aos parênteses, indicam as componentes Radiais e Tangenciais das funções contidas pelos parênteses. Expandindo-se a expressão dada em (3.14), chega-se a:

$$
\begin{aligned}
T e l= & \frac{l_{f e}}{\mu_{0}} \int_{0}^{2 \pi} r^{2}\left(B_{P M-F P}\right)_{R}\left(B_{P M-F P}\right)_{T} d \theta+\frac{l_{f e}}{\mu_{0}} \int_{0}^{2 \pi} r^{2}\left(B_{i-F P}\right)_{R}\left(B_{i-F P}\right)_{T} d \theta \\
& +\left[\frac{l_{f e}}{\mu_{0}} \int_{0}^{2 \pi} r^{2}\left(B_{P M-F P}\right)_{R}\left(B_{i-F P}\right)_{T} d \theta+\frac{l_{f e}}{\mu_{0}} \int_{0}^{2 \pi} r^{2}\left(B_{i-F P}\right)_{R}\left(B_{P M-F P}\right)_{T} d \theta\right]
\end{aligned}
$$

Observando-se a expressão dada em (3.15), é possível notar quatro parcelas distintas. Dessas quatro parcelas, apenas duas são extensamente trabalhadas na literatura, a primeira das parcelas é a utilizada para o cálculo do torque de borda $\left(T_{\text {Borda }}\right)$, cujo resultado pode ser obtido diretamente da simulação linear do método da permeabilidade fixa em que se tem apenas os ímãs como fonte de fluxo magnético em operação (quarta etapa de simulação da Figura 2.2); a segunda das parcelas é a utilizada para o cálculo do torque de relutância (devido à variação da indutância da máquina, $T_{\text {Relutancia }}$ ), cujo resultado pode ser também obtido diretamente da simulação linear do método da permeabilidade fixa em que se tem apenas as correntes de armadura como fonte de fluxo magnético em operação (quarta etapa de simula- 
ção da Figura 2.2). Já as duas parcelas restantes, que estão entre colchetes, podem ser definidas como as parcelas responsáveis pelo torque mútuo $\left(T_{\text {Mútuo }}\right)$, uma vez que estas parcelas lidam com a interação entre as distribuições das densidades de fluxo magnético provenientes dos ímãs e das correntes de armadura, assim como expresso em (3.3). Definem-se então:

$$
\begin{gathered}
T_{\text {Borda }}=\frac{l_{f e}}{\mu_{0}} \int_{0}^{2 \pi} r^{2}\left(B_{P M-F P}\right)_{R}\left(B_{P M-F P}\right)_{T} d \theta \\
T_{\text {Relutância }}=\frac{l_{f e}}{\mu_{0}} \int_{0}^{2 \pi} r^{2}\left(B_{i-F P}\right)_{R}\left(B_{i-F P}\right)_{T} d \theta \\
T_{\text {Mǘuo }}=\frac{l_{f e}}{\mu_{0}} \int_{0}^{2 \pi} r^{2}\left(B_{P M-F P}\right)_{R}\left(B_{i-F P}\right)_{T} d \theta+\frac{l_{f e}}{\mu_{0}} \int_{0}^{2 \pi} r^{2}\left(B_{i-F P}\right)_{R}\left(B_{P M-F P}\right)_{T} d \theta
\end{gathered}
$$

Assumindo-se a expressão dada em (3.18), como verdadeira para o Torque Mútuo da máquina em estudo, e que o Torque Mútuo também pode ser escrito em termos de corrente e força contra eletromotriz por:

$$
\omega_{M E C} T_{\text {Mütuo }}=i_{A}(\theta) e_{A}(\theta)+i_{B}(\theta) e_{B}(\theta)+i_{C}(\theta) e_{C}(\theta)
$$

Analisando-se (3.19) é possível notar que cada fase tem a sua contribuição no torque mútuo dada a interação entre a corrente desta fase e a força contra eletromotriz da mesma (3.20). Desta forma, se apenas uma das fases estiver acionada (ex.: fase A), o torque mútuo será igual a contribuição desta mesma fase para o torque mútuo. A partir desta afirmação e do modelo já linearizado (3.21) obtido a partir da terceira etapa de simulação proposta na Figura 2.2, propõe-se uma nova etapa, paralela à última etapa de simulação em que a corrente de uma das fases, a exemplo a fase $\mathrm{A}$, assumirá o valor unitário $(1 \mathrm{~A})$ ao passo que as correntes das outras fases assumiram valores iguais zero $(0 \mathrm{~A})$ e a contribuição do ímã será desativada (i.e. força coercitiva do ímã é igual a zero). Nota-se que esta etapa é semelhante a última etapa do método da permeabilidade fixa a não ser pelo estado das correntes, que no método da permeabilidade fixa tem-se todas com seus valores atribuídos segundo a alimentação de cada passo da simulação. A Figura 3.6 ilustra esta etapa paralela que foi proposta.

Como resultado desta proposição, avalia-se a força contra eletromotriz da fase acionada nesta etapa ao substituir (3.21) em (3.18) e isolando a parcela referente à contribuição da fase A, resultando em (3.22), que demonstra claramente a relação da força contra eletromotriz com os Tensores de Maxwell. 


$$
\begin{gathered}
T_{\text {Mútuo }}=T_{\text {Mútuo } A}+T_{\text {Mútuo } B}+T_{\text {Mútuo_C }} \\
T_{\text {Mútuo } A}=\frac{i_{A}(\theta) e_{A}(\theta)}{\omega_{M E C}} \\
T_{\text {Mútuo } B}=\frac{i_{B}(\theta) e_{B}(\theta)}{\omega_{M E C}} \\
T_{\text {Mütuo } C}=\frac{i_{C}(\theta) e_{C}(\theta)}{\omega_{M E C}} \\
B_{i-F P}=B_{i-F P_{-} A}+B_{i-F P_{-} B}+B_{i-F P_{-} C}
\end{gathered}
$$

Figura 3.6 - Etapa Adicional Proposta

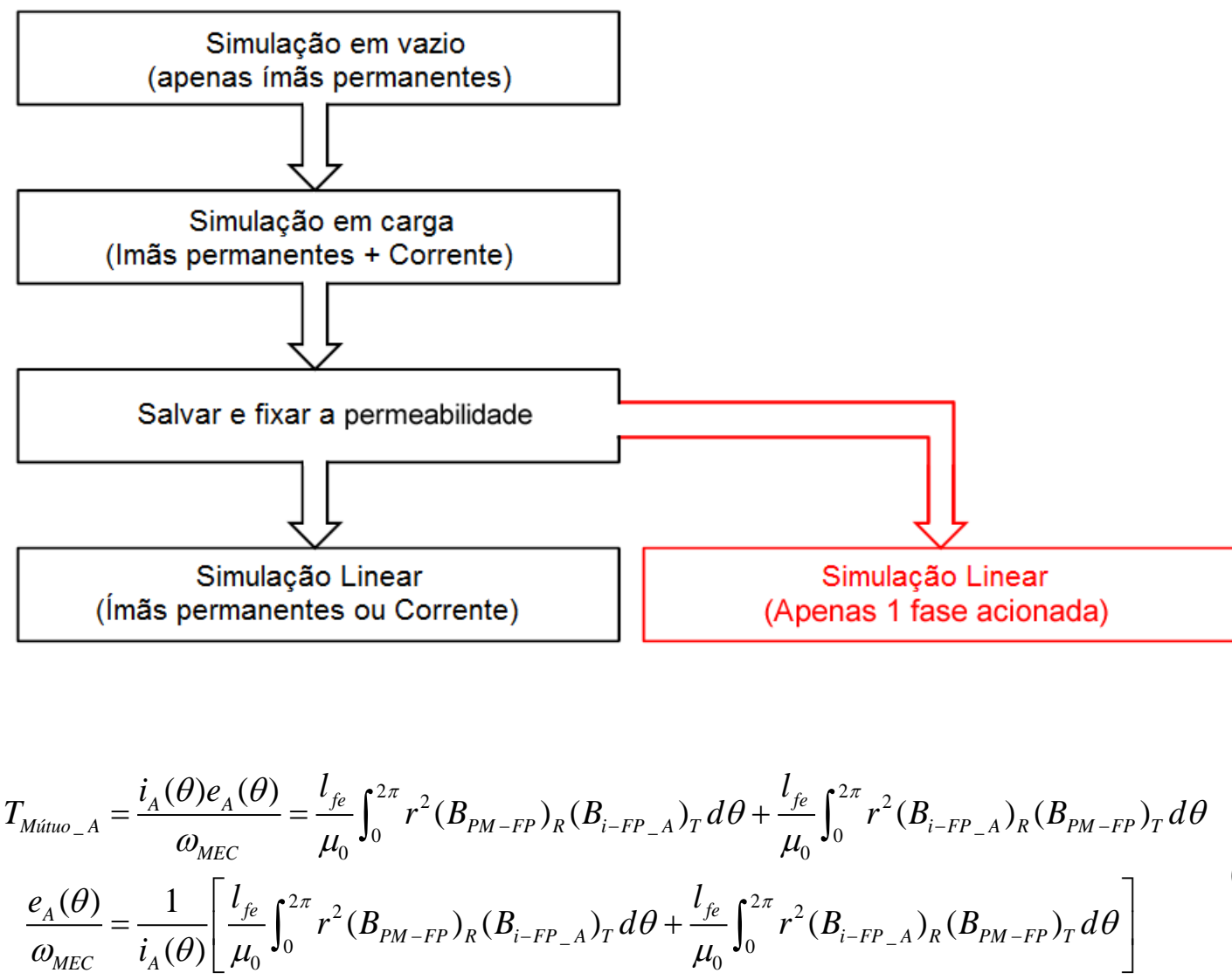

Vale ressaltar, que além do critério de precisão na obtenção dos valores de densidade de fluxo magnético no cálculo dos Tensores de Maxwell por meio do Filtro Harmônico, proposto em [22], [23] e mostrado na Seção 2.4 o uso da operação integral eleva em um grau o grau de precisão da expressão da força contra eletromotriz e evita problemas de erros locais de derivação, diferentemente do método convencional e do método da força contra eletromotriz composta. Além disso, tem-se que o método aqui proposto é de fácil implementação em qualquer software de elementos finitos voltados para simulação magnetostática. Vale ainda ressaltar, que da mesma forma que foi feito para uma máquina síncrona com acionamento em onda quadrada de corrente, o mesmo pode ser feito para uma máquina com acionamento 
em onda senoidal, já que a distribuição do mapa de permeabilidade, i.e., a permeabilidade de cada elemento dentro da malha, já foi fixada segundo a forma de onda de alimentação do acionamento desejado na terceira etapa de simulação da Figura 2.2. Portanto, é possível avaliar e analisar a força contra eletromotriz que as bobinas de cada fase "enxergam" e a partir disso, avaliar como a saturação afeta a forma de onda e servir de suporte para que o projetista faça ajustes no desenho da máquina a fim de se obter um desenho que proporcione uma força contra eletromotriz constante ao longo de toda faixa de acionamento da máquina. Como as simulações realizadas aqui são simulações magnetostáticas, os valores da força contra eletromotriz estão normalizados pela velocidade, resultando em weber/radiano. 



\section{Capítulo 4}

\section{Estudo de Casos}

\subsection{Introdução}

Neste capítulo são avaliados três estudos de casos para validação dos dois métodos propostos para o cálculo da força contra eletromotriz. Cada um desses casos apresenta configuração diferente de rotor (topologia e ímã) capaz de produzir de maneira significativa torque de relutância e/ou torque de borda que também contribuem para as ondulações do torque eletromagnético. Dessa forma, em meio a um cenário 'ruidoso' em que as outras parcelas de torque também contribuem com as ondulações no torque eletromagnético, torna-se possível verificar a versatilidade e precisão dos métodos propostos para obtenção da força contra eletromotriz, cujas distorções provocadas pelo carregamento eletromagnético influenciam diretamente nas ondulações do torque eletromagnético. Assim, o método mais preciso conseguirá refletir com exatidão as não linearidades e distorções na força contra eletromotriz.

Os três casos em estudo têm o mesmo estator, a mesma distribuição de bobinas e o mesmo número de condutores por bobina, como mostra a Figura 4.1. As características dimensionais deste estator são apresentadas na Tabela 4.1.

A escolha por este estator se baseia em uma máquina síncrona de ímãs na superfície do rotor que apresenta as mesmas características de estator e está presente no Laboratório de Controle e Eletrônica de Potência (LACEP) do Departamento de Engenharia Elétrica da Universidade de São Paulo, sendo ela um dos casos em estudo (Caso 1). 
Os três casos se diferenciam pelo ímã empregado e pela topologia do rotor, como ilustra a Figura 4.2.

Figura 4.1 - Estator das Máquinas em Estudo

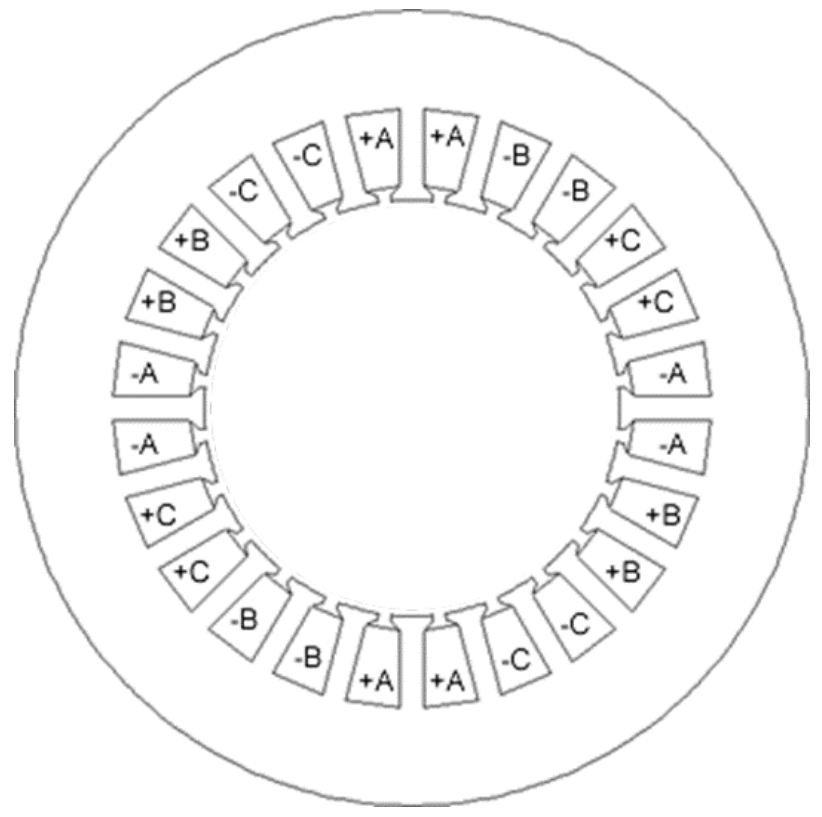

Tabela 4.1 - Dimensões da Máquina

\begin{tabular}{lc}
\hline \multicolumn{1}{c}{ Parâmetro } & Dimensão \\
\hline \hline Número de Ranhuras & 24 \\
\hline Diâmetro Externo do Estator & $116,6 \mathrm{~mm}$ \\
\hline Diâmetro Interno do Estator & $61 \mathrm{~mm}$ \\
\hline Espessura da Carcaça do Estator & $14,35 \mathrm{~mm}$ \\
\hline Largura do Dente & $3,52 \mathrm{~mm}$ \\
\hline Abertura de Ranhura & $2,15 \mathrm{~mm}$ \\
Espessura da Ponta da Sapata do Dente & $1 \mathrm{~mm}$ \\
\hline Diâmetro dos Condutores Utilizados & $21 \mathrm{AWG}$ \\
\hline \hline
\end{tabular}

Figura 4.2 - Rotores dos Casos em Estudo

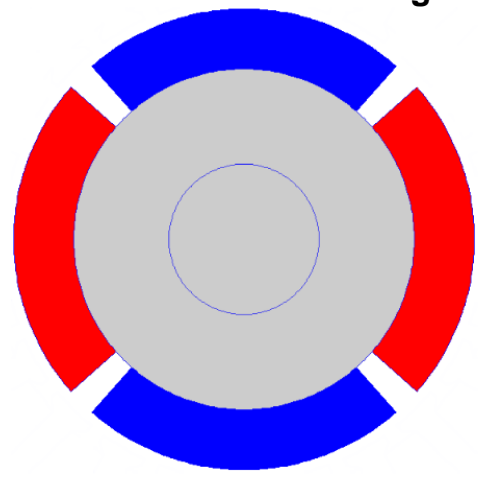

a)

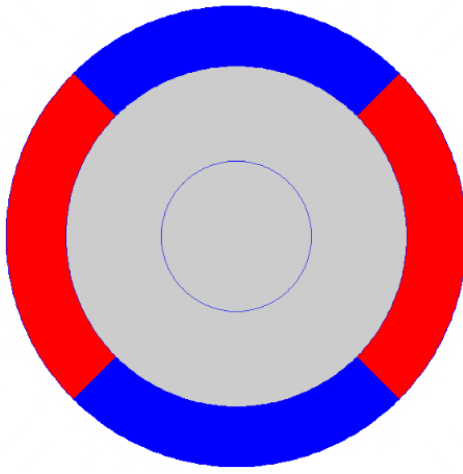

b)

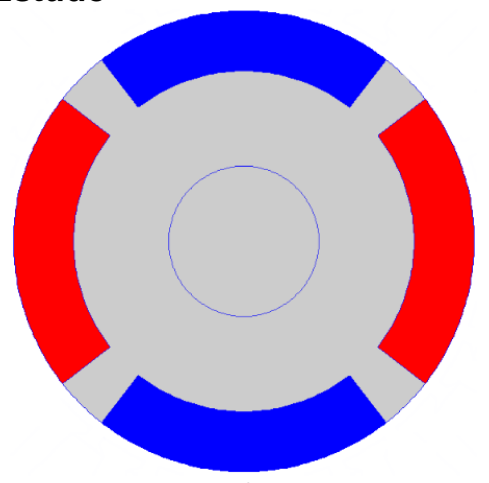

c)

a) Caso 1: Ímãs de Ferrite; b) Caso 2: Ímãs de Neodímio; c) Caso 3: Ímãs Semi-enterrados 
Caso 1: Como mencionado, apresenta rotor idêntico à máquina presente no laboratório que foi projetada e avaliada em [35] com o objetivo de substituir um motor de indução monofásico empregado em um compressor hermético para refrigeração. Sua primeira simulação em elementos finitos foi realizada por [38] avaliando-se as perdas no núcleo desta máquina caso os ímãs de ferrite fossem substituídos por ímãs de neodímio. Contém ímãs de Ferrite com 7,6mm de espessura e entreferro de $1,35 \mathrm{~mm}$. A corrente nominal desta máquina é 10A [35]. Os dados dimensionais deste rotor e seus ímãs são apresentados na Tabela 4.2. Para este caso, são avaliados dados de simulação e dados experimentais para as condições de $50 \%$ e $100 \%$ de carregamento. Condições experimentais acima de $100 \%$ de carregamento demonstraram-se como situações de risco para esta máquina, uma vez que a temperatura no enrolamento da mesma atinge valores elevados em um curto intervalo de tempo, abrindo a possibilidade de degradação da isolação dos condutores e consequente curto-circuito interno. Outro fator, oriundo do aquecimento, é a elevação do valor de resistência de fase/linha, implicando na necessidade de tensões CC mais elevadas. Assim, a condição de $200 \%$ de carregamento é apenas simulada.

Caso 2: O segundo caso é uma modificação do primeiro caso, em que os ímãs são substituídos por ímãs de Neodímio-Ferro-Boro de maior densidade de energia, mantendo a espessura de 7,6mm e o entreferro de 1,35mm. Essa mudança eleva o valor de amplitude da força contra eletromotriz e também do torque de borda (cogging torque). Para este caso, são avaliados apenas dados simulados para as condições de 50\%, 100\% e $200 \%$ de carregamento. Os dados dimensionais deste rotor e seus ímãs são apresentados na Tabela 4.2.

Caso 3: Este caso é uma modificação que mostra uma condição diferente para se avaliar o método de obtenção da força contra eletromotriz, já que nesta configuração de rotor têm-se torque de relutância considerável, além do torque de borda como característica intrínseca. Criando assim, um cenário mais 'ruidoso', como mencionado. Para este caso, são avaliados apenas dados simulados para as condições de 50\%, 100\% e $200 \%$ de carregamento. Os dados dimensionais deste rotor e seus ímãs são apresentados na Tabela 4.2 . 
Tabela 4.2 - Características dos Rotores

\begin{tabular}{lccc}
\hline \hline \multicolumn{1}{c}{ Parâmetro } & Caso1 & Caso 2 & Caso 3 \\
\hline \hline Número de Polos & 4 & 4 & 4 \\
Entreferro & $1,35 \mathrm{~mm}$ & $1,35 \mathrm{~mm}$ & $1,35 \mathrm{~mm}$ \\
Diâmetro Externo do Rotor & $58,3 \mathrm{~mm}$ & $58,3 \mathrm{~mm}$ & $58,3 \mathrm{~mm}$ \\
Diâmetro do Eixo & $19 \mathrm{~mm}$ & $19 \mathrm{~mm}$ & $19 \mathrm{~mm}$ \\
Espessura do Ímã & $7,6 \mathrm{~mm}$ & $7,6 \mathrm{~mm}$ & $7,6 \mathrm{~mm}$ \\
Ímã & Ferrite & NdFeB & NdFeB \\
Ângulo do arco do ímã & $82,5^{\circ}$ & $10 \mathrm{MGOe}$ & $10 \mathrm{MGOe}$ \\
\hline \hline
\end{tabular}

Deve-se levar em consideração que os casos analisados não apresentam inclinação no pacote de lâminas do estator (skewing slot), contribuindo, portanto, para a presença de torque de borda (cogging torque).

Em todos os casos investigados, as máquinas são alimentadas com correntes de estator conforme a Figura 4.3. Tomando-se por base que as simulações realizadas são simulações magnetostáticas utilizando o método dos elementos finitos, a forma perfeitamente quadrada das correntes apresentadas na Figura 4.3 é plausível de ser obtida na simulação. Outro fator que pesa a favor desta forma de onda de corrente perfeitamente quadrada, é que esta se trata da corrente ideal para o acionamento de máquinas síncronas com ímã no rotor cuja forma de onda da força contra eletromotriz é trapezoidal ou próxima a um trapézio, de maneira a aproveitar melhor a região de produção de torque. Parte-se destas condições ideais de onda quadrada a fim de se obter um cenário mais crítico na comutação das fases que proporcione variações mais abruptas no fluxo magnético da máquina. Contornados os problemas para este tipo de variação, a mesma solução se torna compatível para variações mais suaves no fluxo magnético.

O trabalho aqui apresentado adota os valores de correntes de 5, 10 e 20A, que representam 50, 100 e 200\% de carregamento eletromagnético na máquina real, respectivamente. Essas condições de corrente são mantidas para as variações propostas no rotor (Caso 2 e 3). A condição de $50 \%$ de carregamento ilustra uma condição intermediária entre a operação em vazio e a operação em carga plena, sendo utilizada para demonstrar que os métodos propostos para o cálculo da força contra eletromotriz avaliam corretamente a força contra eletromotriz mesmo quando esta não é muito afetada pela saturação eletromagnética ou pelo acionamento da máquina. A condição de $100 \%$ de carregamento visa demonstrar que os métodos propostos apresentam resultados coerentes para a forma de onda da força contra eletromotriz 
quando esta é distorcida pelo acionamento e/ou saturação da máquina em plena carga. Apesar de simuladas, as condições de carregamento superiores à 100\% são condições geralmente presentes em transitórios e não em regime permanente, pois a operação constante acima de $100 \%$ apresenta maiores perdas de energia, maiores desgastes mecânicos e causam danos nos enrolamentos (sobreaquecimento e redução da vida útil da isolação).

Figura 4.3 - Forma de Onda da Corrente de Alimentação
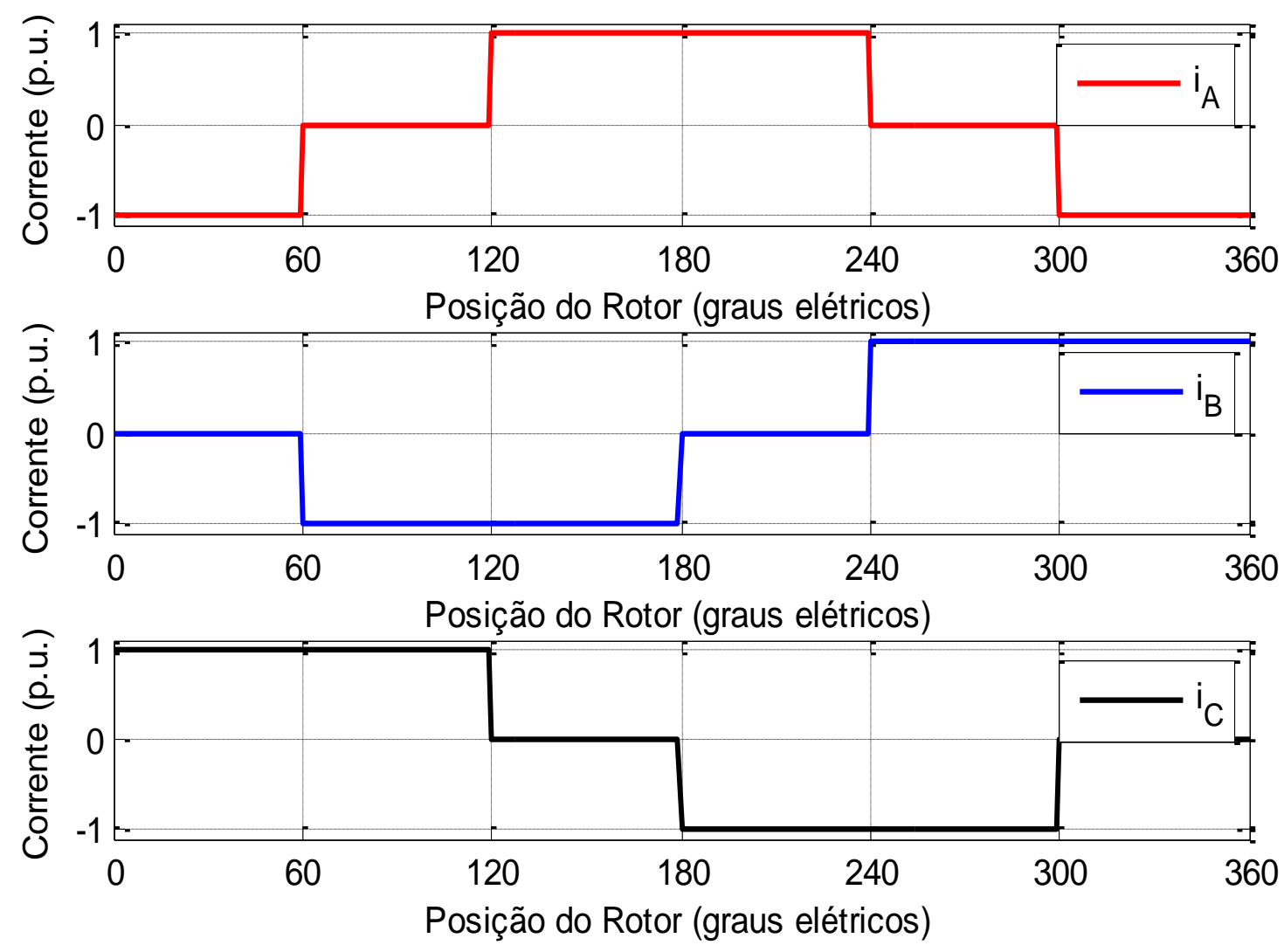

Para todos os casos em estudos são apresentados os seguintes dados nas subseções a seguir:

- Condição em Vazio $(0 A)$ :

- Fluxo Magnético Concatenado da Fase A;

- Força Contra Eletromotriz;

- Torque de Borda;

- Condição em Carregamento

- Fluxo Concatenado da Fase A e sua decomposição; 

- Força Contra Eletromotriz;
- Torque Mútuo;
- Torque de Borda;
- Torque de Relutância;
- Torque Eletromagnético.

\subsection{Caso 1}

Aqui são apresentados os resultados referentes ao emprego dos métodos para obtenção da força contra eletromotriz para o estudo de caso 1.

\subsubsection{Condição em Vazio (OA)}

As formas de onda de fluxo magnético concatenado com a fase A, força contra eletromotriz da fase $\mathrm{A}$ e torque de borda para a operação em vazio são mostradas da Figura $4.4 \mathrm{a}$ Figura 4.6. As demais fases têm os seus resultados omitidos neste trabalho uma vez que elas apresentam as mesmas características da fase A, excetuando-se o fato de serem $120^{\circ}$ e $240^{\circ}$ elétricos defasadas. Por meio de (3.9) é esperado como frequência fundamental do torque de borda o valor de 12 vezes a frequência fundamental de uma revolução elétrica.

Figura 4.4 - Fluxo Magnético (Operação em vazio)

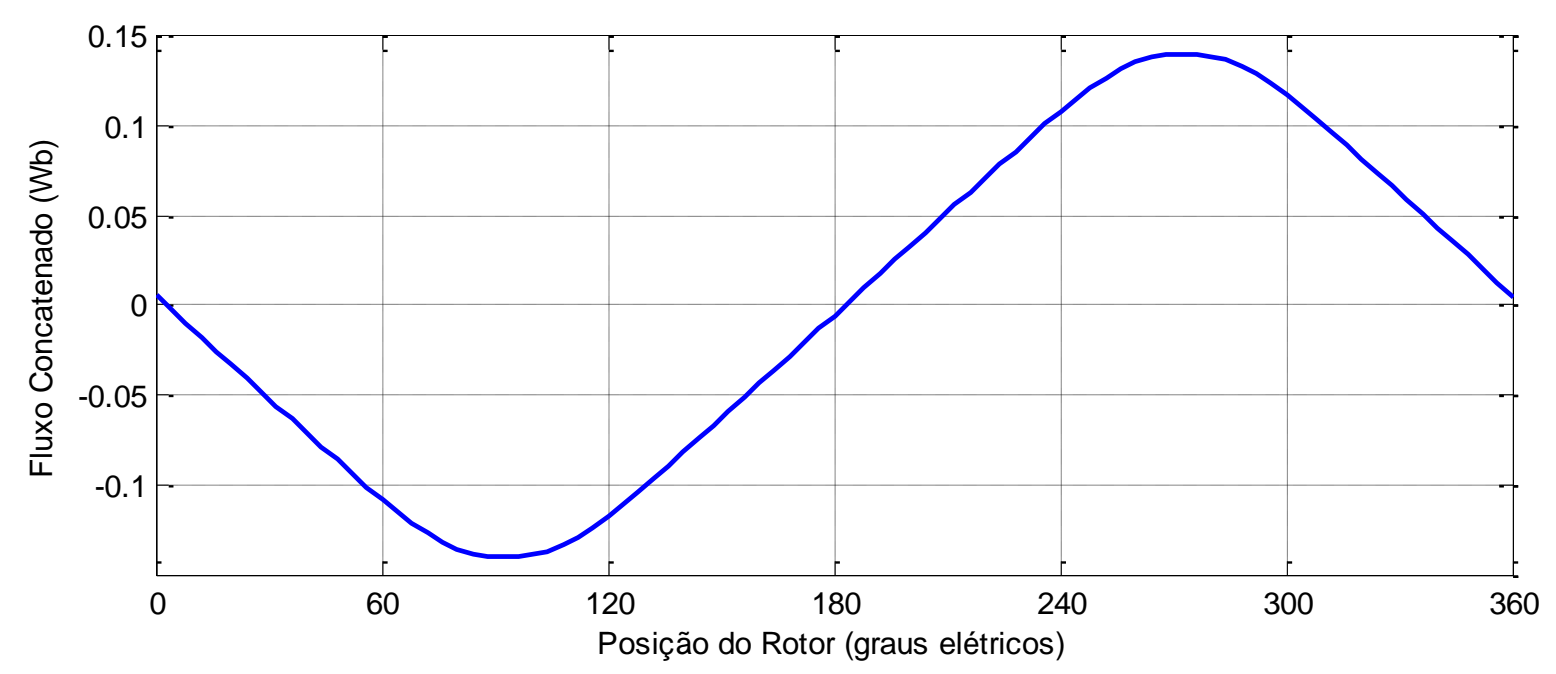


Figura 4.5 - Força Contra Eletromotriz (Operação em Vazio)

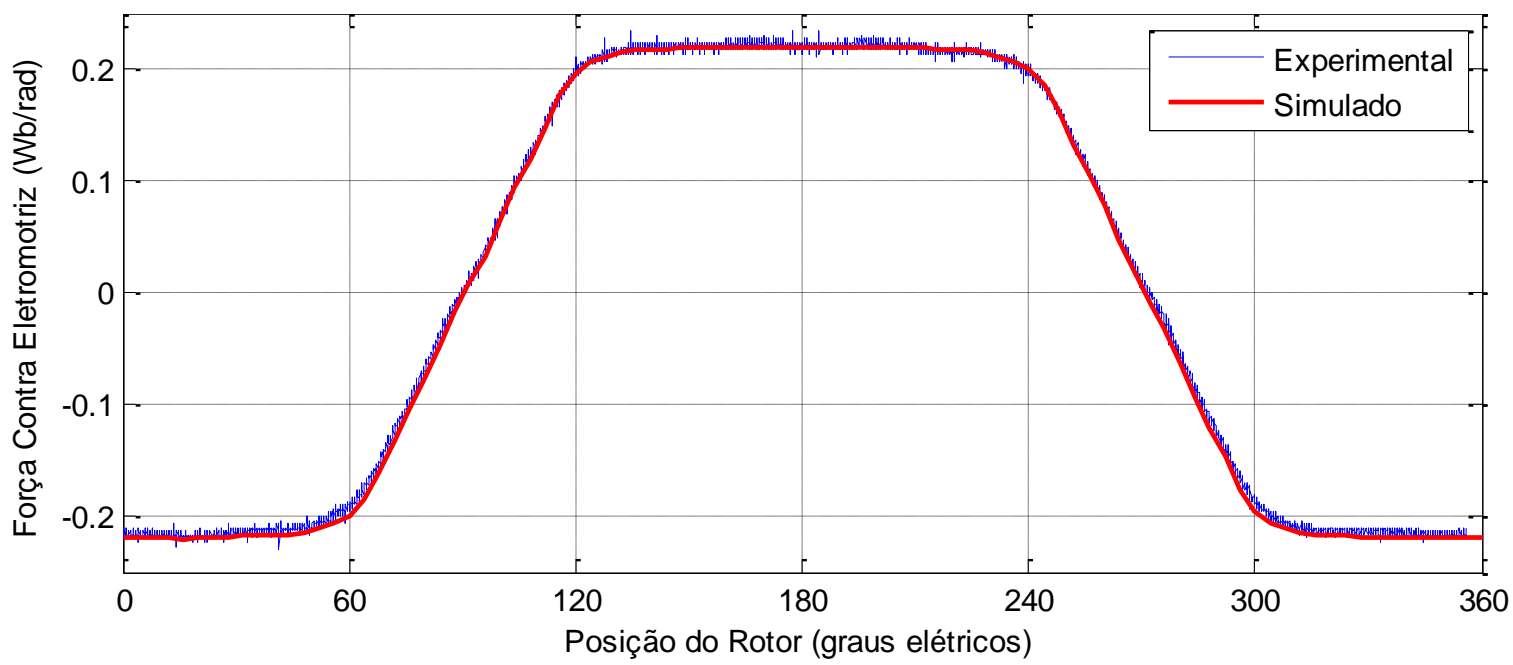

Na Figura 4.6 a forma de onda do torque de borda para a condição de operação em vazio foi obtida tanto com o método do trabalho virtual (derivada da coenergia) quanto com o método dos Tensores de Maxwell, sendo apresentada apenas uma forma de onda já que os dois métodos resultaram em uma forma de onda idêntica evidenciando que a malha do entreferro das simulações está bem ajustada. Portanto, para o cálculo do torque de borda para as condições de carregamento de 5, 10 e 20A será utilizado apenas o método dos Tensores de Maxwell, dado que, se tem ainda o emprego de Filtro Harmônico para o refino do cálculo por Tensor de Maxwell. O valor baixo para o torque de borda é justificável pela baixa densidade de energia dos ímãs de ferrite e pelo comprimento do entreferro ser considerável $(1,35 \mathrm{~mm})$ se comparado com a dimensão da máquina.

Figura 4.6 - Torque de Borda (Operação em vazio)

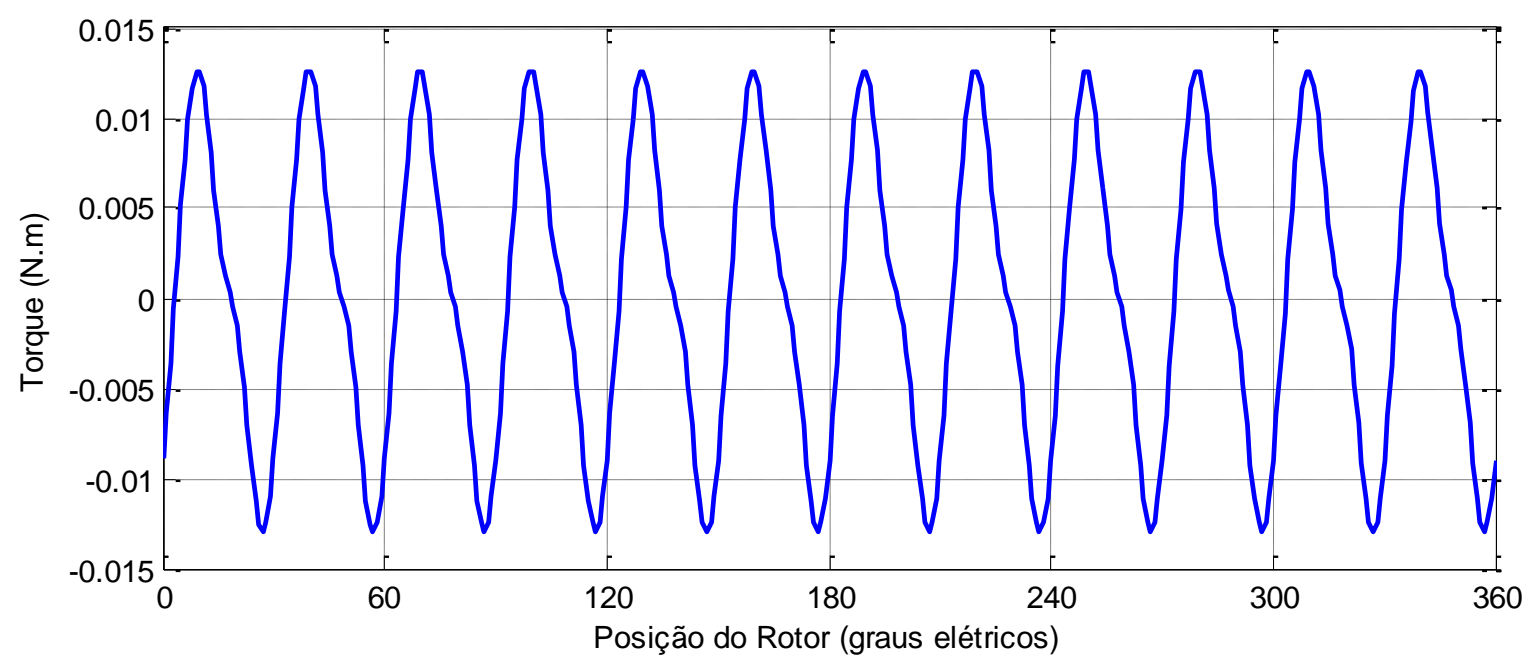




\subsubsection{Condição em Carregamento}

As formas de onda do fluxo magnético concatenado para a fase $A$ nas condições de carregamento de 5, 10 e 20A são ilustradas na Figura 4.7

Figura 4.7 - Fluxo Magnético Concatenado (Carregamentos de 5, 10 e 20A)

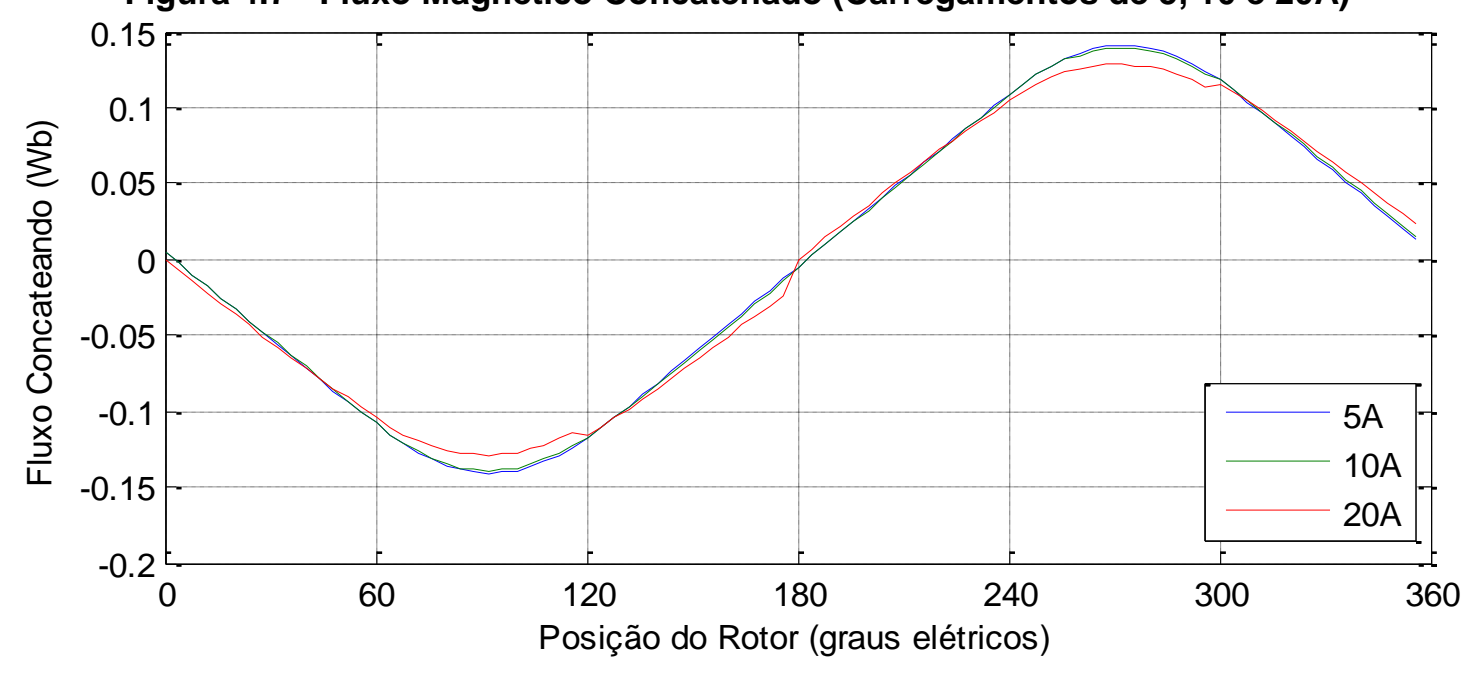

Valendo-se da aplicação da derivada sobre as formas de onda do fluxo magnético concatenado por fase (Método Convencional) apresentadas na Figura 4.7, são obtidas e apresentadas na Figura 4.8 as formas de onda das forças contra eletromotrizes para cada uma das condições de carregamento. Nota-se, que a força contra eletromotriz é ocorrida de oscilações que se repetem a cada $60^{\circ}$ elétricos e são mais evidentes nas condições de 10 e $20 \mathrm{~A}$ de carregamento. Em alguns trabalhos como [6], [12], [14]-[16] essas oscilações são mais evidentes em condições de carregamento menores que $100 \%$ devido ao tipo de ímã utilizado (ímã de terras raras). O período de repetição destas oscilações está diretamente relacionado com o chaveamento do inversor de frequência ideal operando no modo six-step para se produzir as correntes desejadas. O aparecimento destas oscilações está ligado à aplicação da operação derivada sobre as formas de onda de fluxo magnético concatenado nos pontos de comutação do inversor ( $0^{\circ}, 60^{\circ}, 120^{\circ}, 180^{\circ}, 240^{\circ}, 300^{\circ}$ e $360^{\circ}$ elétricos) já que, essas formas de onda de fluxo magnético concatenado apresentam variações descontínuas nesses pontos (vide Figura 4.7). Além das oscilações presentes ao se aplicar a operação de derivada (Método Convencional), esta operação realiza de maneira indireta a "conexão" entre dois estados diferentes da máquina quando a mesma está carregada. Como os dois estados que estão sendo "conectados/relacionados" por meio da derivada são estados diferentes um do outro ao apresentarem condições discrepantes de fluxo magnético circulante na máquina, surgem essas oscilações. 
Figura 4.8 - Força Contra Eletromotriz (Carregamentos de 5, 10 e 20A)

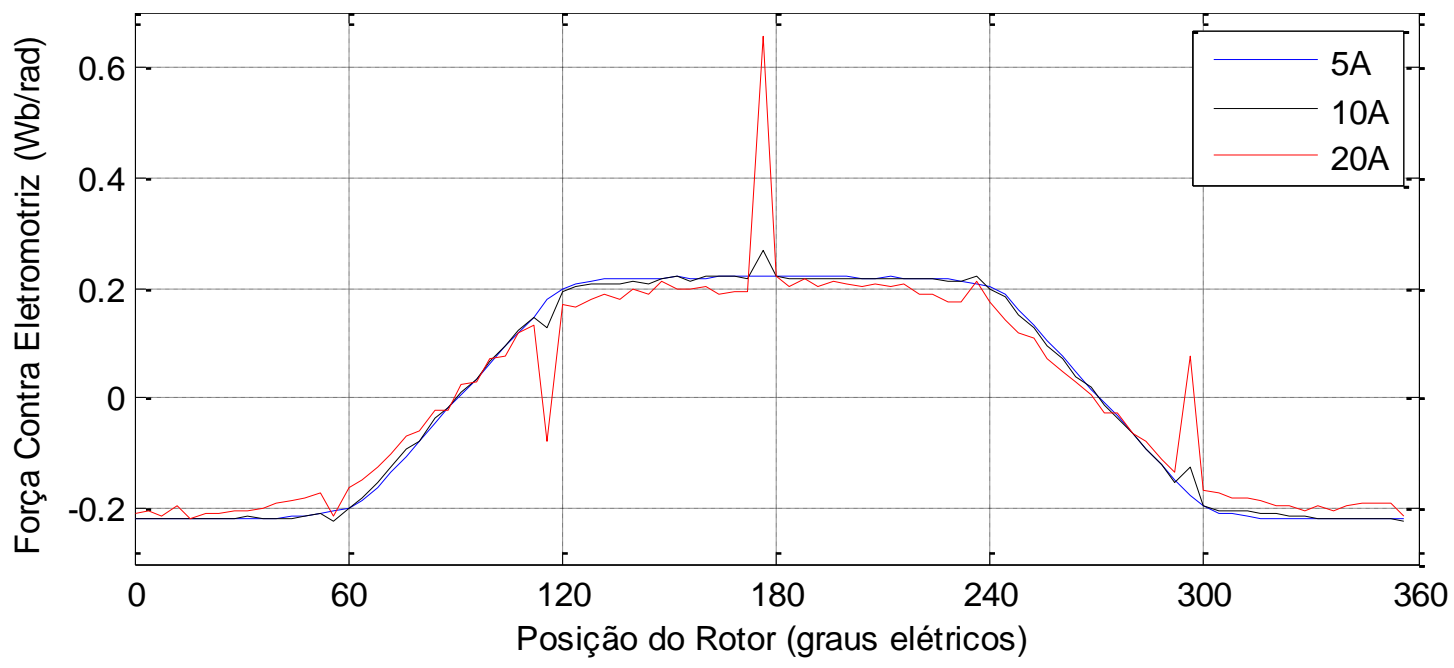

A fim de se contornar este problema presente no método convencional, os fluxos magnéticos concatenados apresentados na Figura 4.7 são decompostos em três componentes definidas pelo Método da Composição das Regiões, resultando nas regiões ilustradas da Figura 4.9 a Figura 4.11, para as condições de carregamento eletromagnético de 5, 10 e 20A. Vale lembrar que este método considera que para a condição de corrente igual a zero nas três fases (operação em vazio), as três componentes de fluxo magnético são coincidentes e são representadas por uma única forma de onda de fluxo magnético (Figura 4.4).

Para o carregamento de 5A é possível notar que as três regiões resultantes são praticamente idênticas. Isso ocorre devido ao baixo carregamento eletromagnético da máquina, baixa energia do ímã de ferrite e entreferro grande, resultando em pouco ou nenhuma alteração no fluxo magnético concatenado com cada fase e nenhuma distorção na forma de onda da força contra eletromotriz. O mesmo já não ocorre para as condições de carregamento de 10 e $20 \mathrm{~A}$.

A partir dos resultados obtidos com a decomposição do fluxo magnético concatenado para a fase $A$, emprega-se a operação derivada nas regiões de fluxo magnético e são obtidas as formas de onda das forças contra eletromotrizes de cada região como ilustrado da Figura 4.12 a Figura 4.14. Em seguida, compõe-se as formas de onda de força contra eletromotriz para as condições de carregamento eletromagnético de 5, 10 e 20A segundo o método da composição das regiões. Para a composição da força contra eletromotriz é preciso levar em conta, novamente, as regiões propostas na Tabela 3.1, i.e., para cada posição $\theta$ do rotor é utilizada a forma de onda de força contra eletromotriz apropriada. Assim, para o intervalo de $0^{\circ}$ a $60^{\circ}$ elétricos do rotor, utiliza-se a força contra eletromotriz proveniente da Região 1; de $60^{\circ}$ a $120^{\circ}$, utiliza-se a força contra eletromotriz proveniente da Região 2; de $120^{\circ}$ a $180^{\circ}$, utiliza-se a força contra eletromotriz proveniente da Região 3 e assim por diante até que se 
complete uma revolução elétrica e a forma de onda da força contra eletromotriz resultante seja completamente determinada.

Figura 4.9 - Componentes do Fluxo Magnético (Carregamento de 5A)

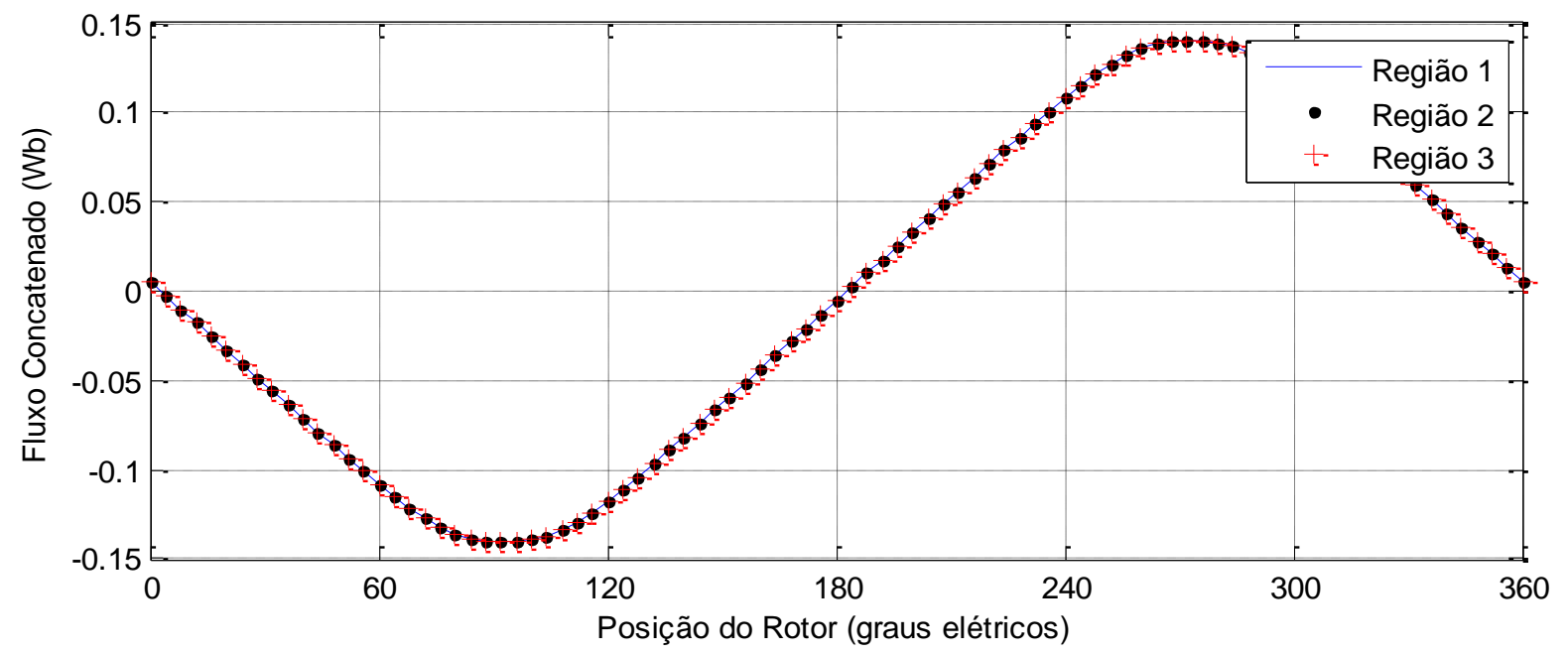

Figura 4.10 - Componentes do Fluxo Magnético (Carregamento de 10A)

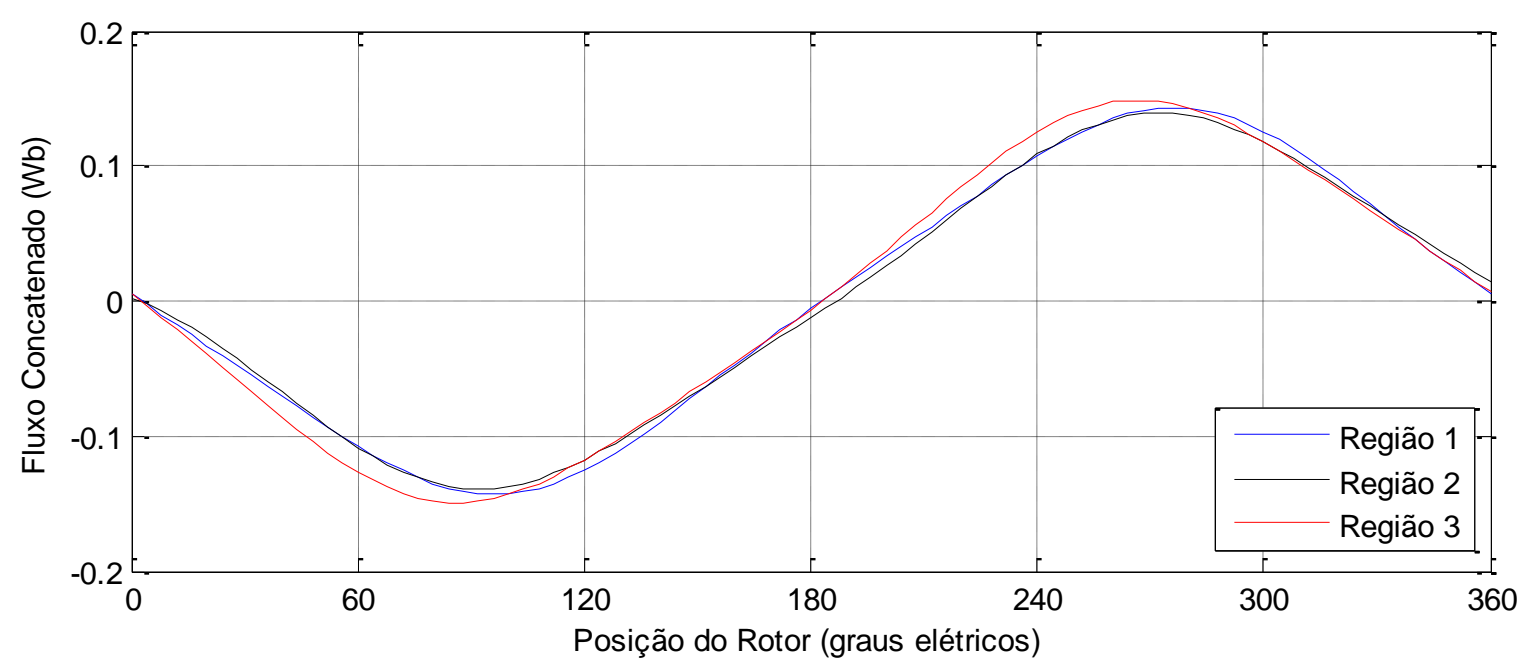

Figura 4.11 - Componentes do Fluxo Magnético (Carregamento de 20A)

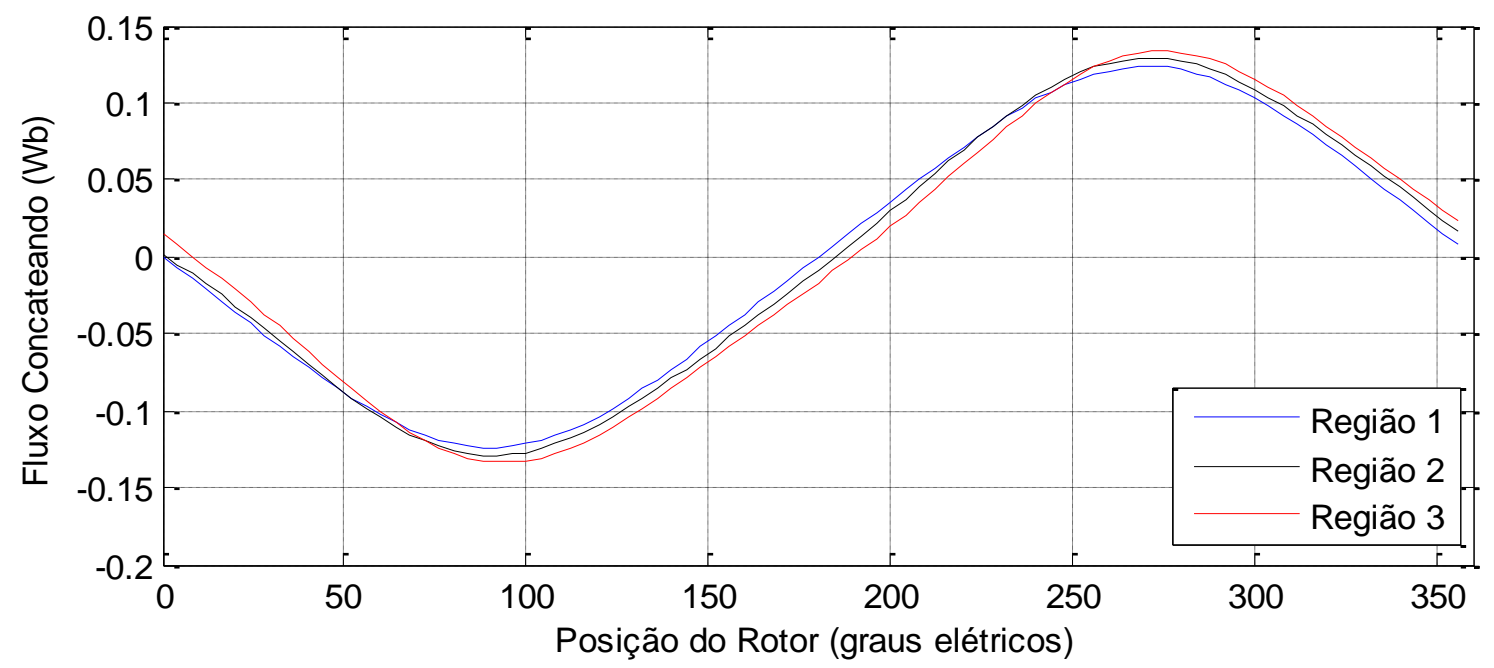


Figura 4.12 - Região 1: Componentes da Força Contra Eletromotriz

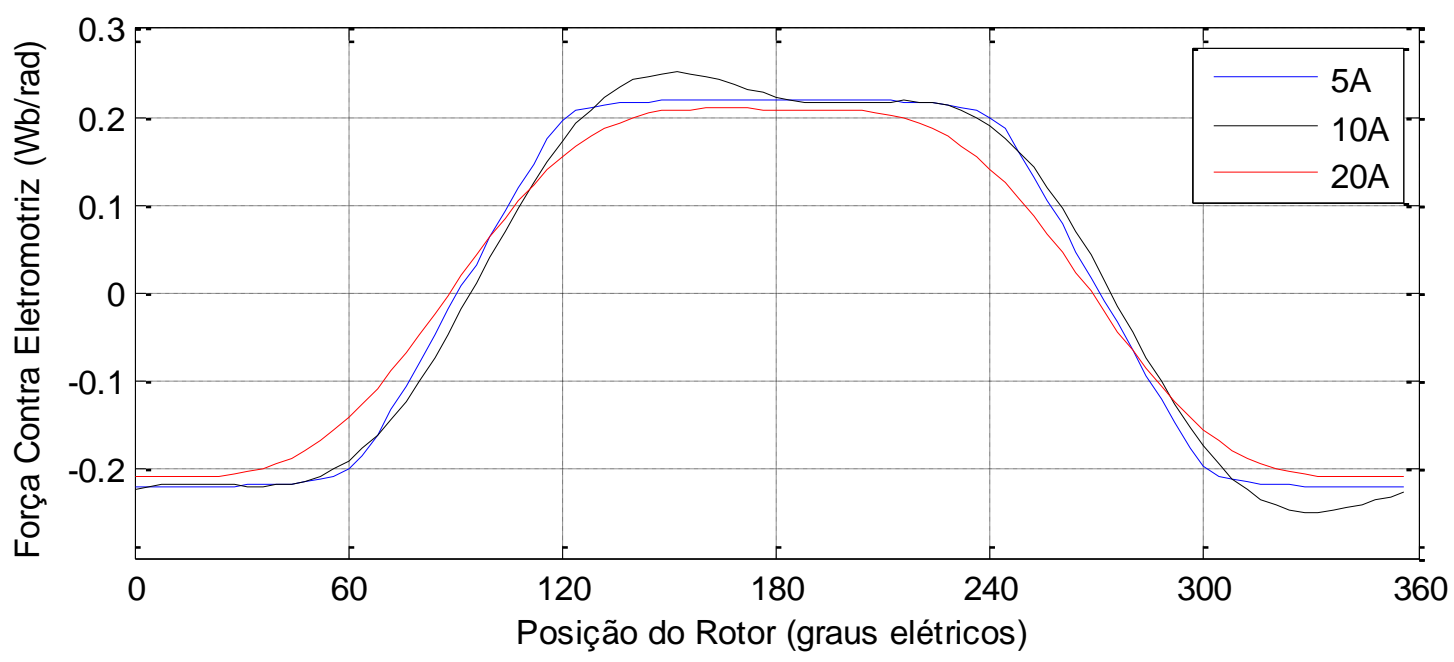

Figura 4.13 - Região 2: Componentes da Força Contra Eletromotriz

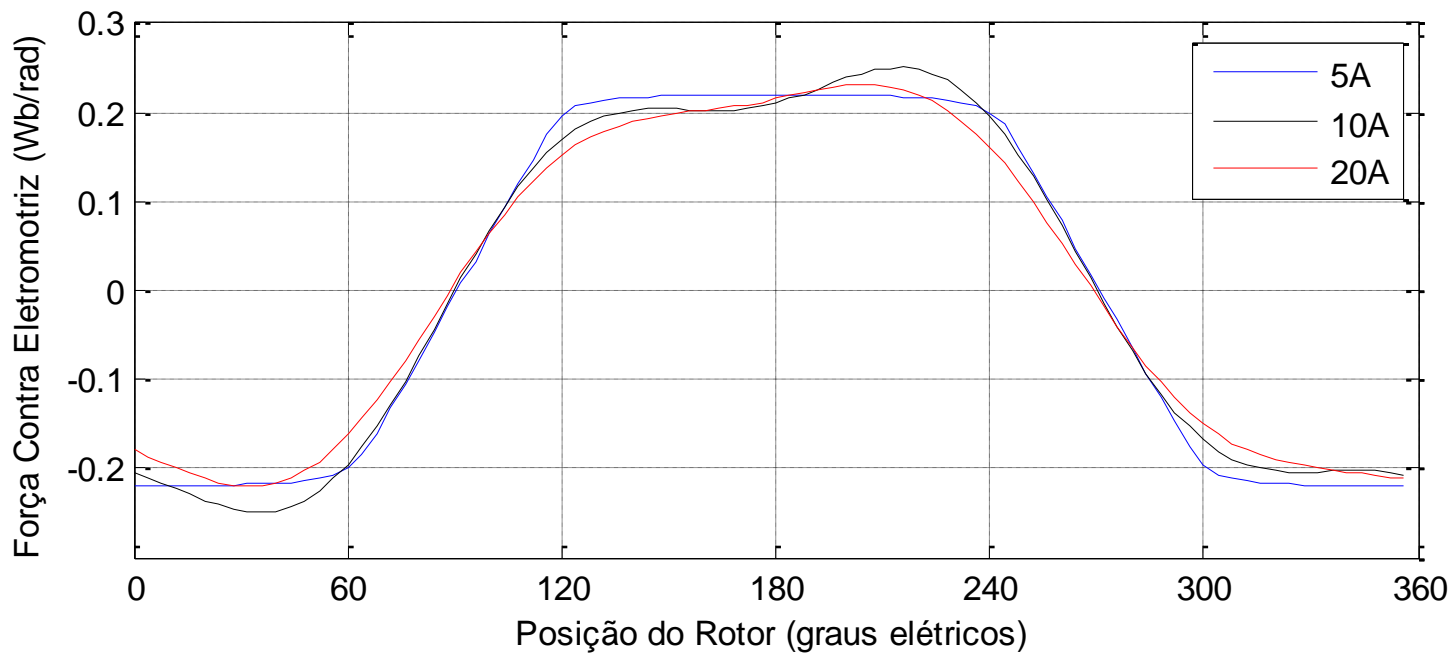

Figura 4.14 - Região 3: Componentes da Força Contra Eletromotriz

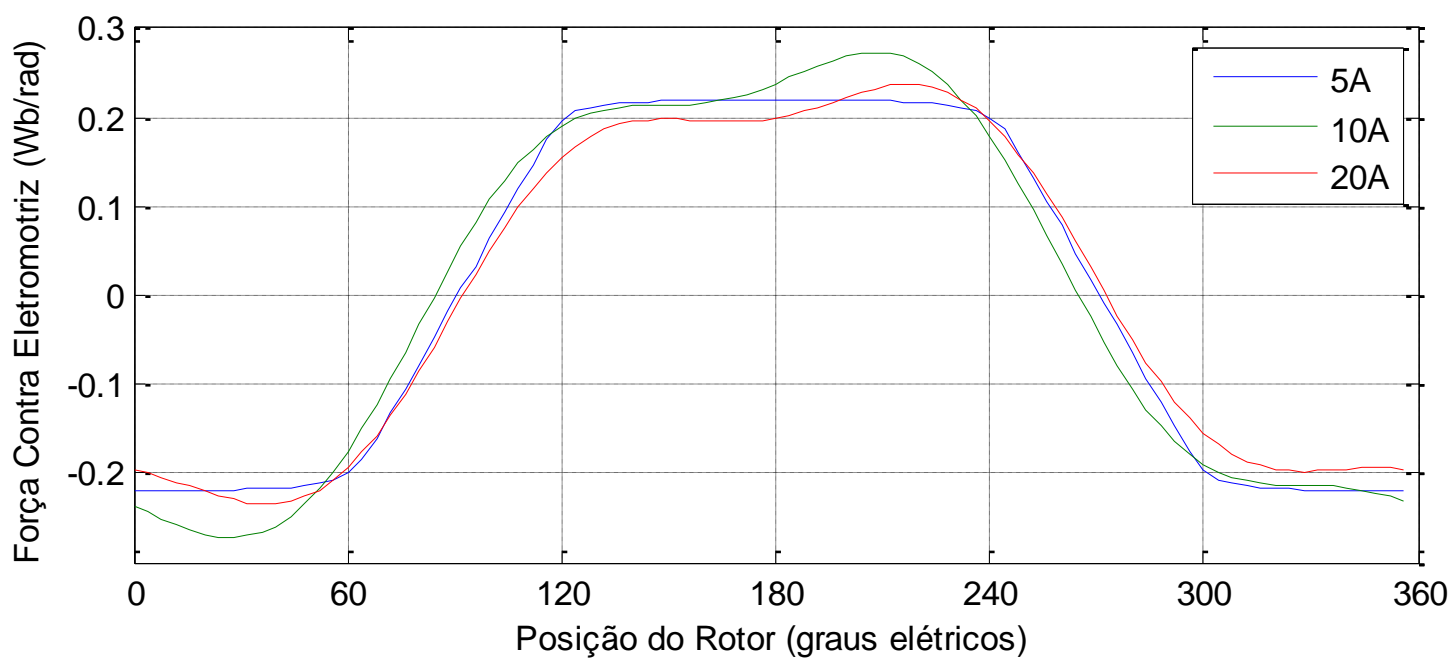

As formas de onda da força contra eletromotriz resultantes do emprego do método da composição por regiões para as condições de carregamento eletromagnético de 5, 10 e 20A 
são apresentadas na Figura 4.15.

Embora as formas de onda da força contra eletromotriz compostas ilustradas na Figura 4.15 não sejam suaves e contínuas nos pontos de comutação $\left(0^{\circ}, 60^{\circ}, 120^{\circ}, 180^{\circ}, 240^{\circ}, 300^{\circ}\right.$ e $360^{\circ}$ elétricos) principalmente para os carregamentos de 10 e $20 \mathrm{~A}$, estas formas de onda são suaves se observadas dentro dos intervalos de $60^{\circ}$ elétricos e contornam o problema da oscilação no ponto de comutação apresentado em [6], [12] e no emprego do método convencional, melhorando consequentemente o cálculo do torque mútuo.

Figura 4.15 - Força Contra Eletromotriz - Método da Composição

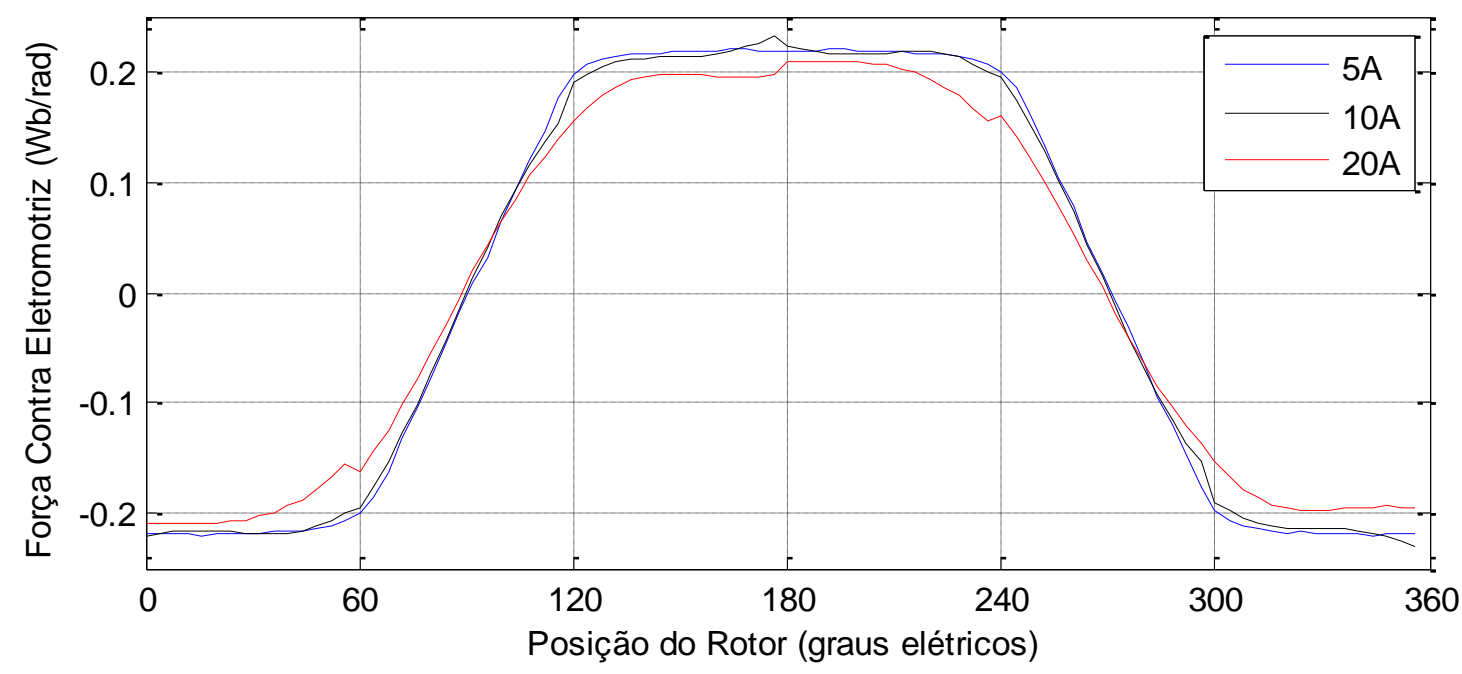

Aplicando-se o Método dos Tensores para a obtenção da força contra eletromotriz, obtém-se as formas de onda para as condições de carregamento de 5, 10 e 20A conforme ilustra a Figura 4.16.

Figura 4.16 - Força Contra Eletromotriz - Método dos Tensores

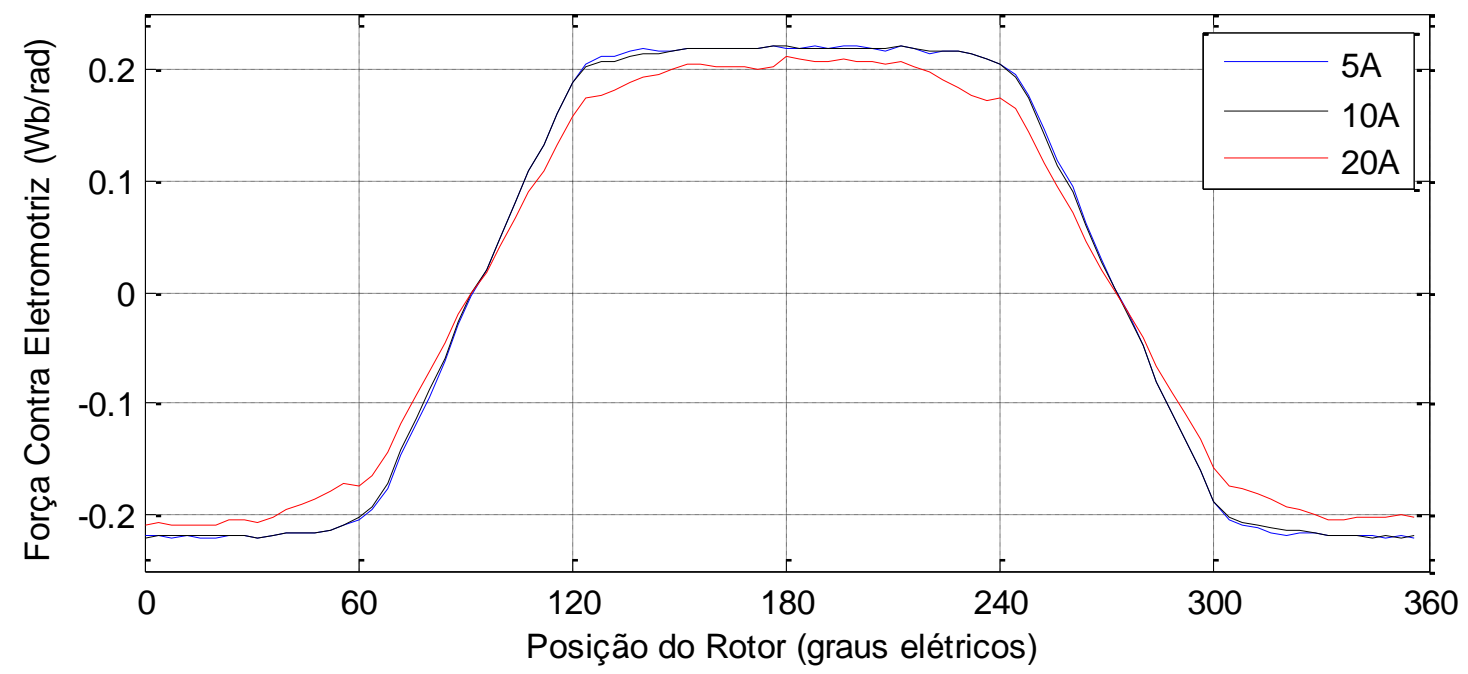

Nota-se, claramente, que essas formas de onda são suaves em quase todo o seu domínio. Diferentemente da força contra eletromotriz obtida pelo Método da Composição das 
Regiões, as formas de onda aqui obtidas carregam características não lineares acrescentadas por harmônicos de ordem mais elevada, caracterizando melhor os efeitos da saturação e do modo de alimentação das fases sob a força contra eletromotriz e não apresenta oscilações como as oscilações presentes na força contra eletromotriz obtida pelo Método Convencional nos pontos de comutação.

Tomando-se por base as formas de onda da corrente de armadura apresentadas na Figura 4.3 e as formas de onda das forças contra eletromotrizes para as condições de carregamento simuladas, obtém-se as formas de onda do torque mútuo, sendo as mesmas comparadas com as formas de onda do torque eletromagnético $\left(T_{E L}\right.$ - resultante das simulações não lineares) para cada uma das condições, como ilustradas nas Figuras 4.17 a 4.19.

As diferenças presentes nas formas de onda do torque mútuo estão diretamente relacionadas com as diferenças entre as formas de onda das forças contra eletromotrizes e, consequentemente, à saturação da máquina. Assim como no torque eletromagnético $\left(T_{E L}\right)$, notase que devido à saturação da máquina, a razão torque mútuo médio por corrente de armadura reduz à medida que a corrente de armadura aumenta.

No que diz respeito ao Torque de Borda, deve-se levar em conta que os trabalhos [9][11], [13], [19], [25], [33], [34], diferentemente de [6], [15] e do presente trabalho, investigam máquinas síncronas com ímãs no rotor com forma de onda de corrente puramente senoidal. De modo similar, investiga-se se há variação na frequência dessa parcela do torque eletromagnético para a máquina em estudo.

As formas de onda do torque de borda para as condições de carregamento de 5, 10 e $20 \mathrm{~A}$ são apresentadas nas Figuras 4.20 a 4.22. Os valores máximo, mínimo, médio e a razão entre o valor absoluto do torque de borda e a corrente de armadura são apresentados na Tabela 4.3, assim como o valor de amplitude deste torque. Como pode ser notado, os valores médios desta parcela do torque e suas amplitudes para as duas condições de carregamento aumentam à medida que o carregamento aumenta. A significância desta parcela do torque para este caso é baixa devido ao entreferro grande e a baixa densidade de energia dos ímãs de ferrite.

Semelhante à [10], onde o período de oscilação do primeiro harmônico do torque de borda mudou de 30 mecânicos (operação em vazio) para 60 mecânicos independente da condição de carregamento da máquina, aqui na máquina sob investigação, a frequência fundamental de oscilação do torque de borda continuou em 12 vezes a frequência fundamental 
de uma revolução elétrica até o carregamento de 5A. Quando a máquina passa dessa condição de carregamento e atinge o carregamento de 10 e 20A, as frequências de oscilação do Torque de Borda mudam, tendo como frequência base 6 vezes a frequência fundamental de uma revolução elétrica, como ilustra a Figura 4.23.

Figura 4.17 - Torque Mútuo v.s. $T_{E L}$ (Carregamento de 5A)

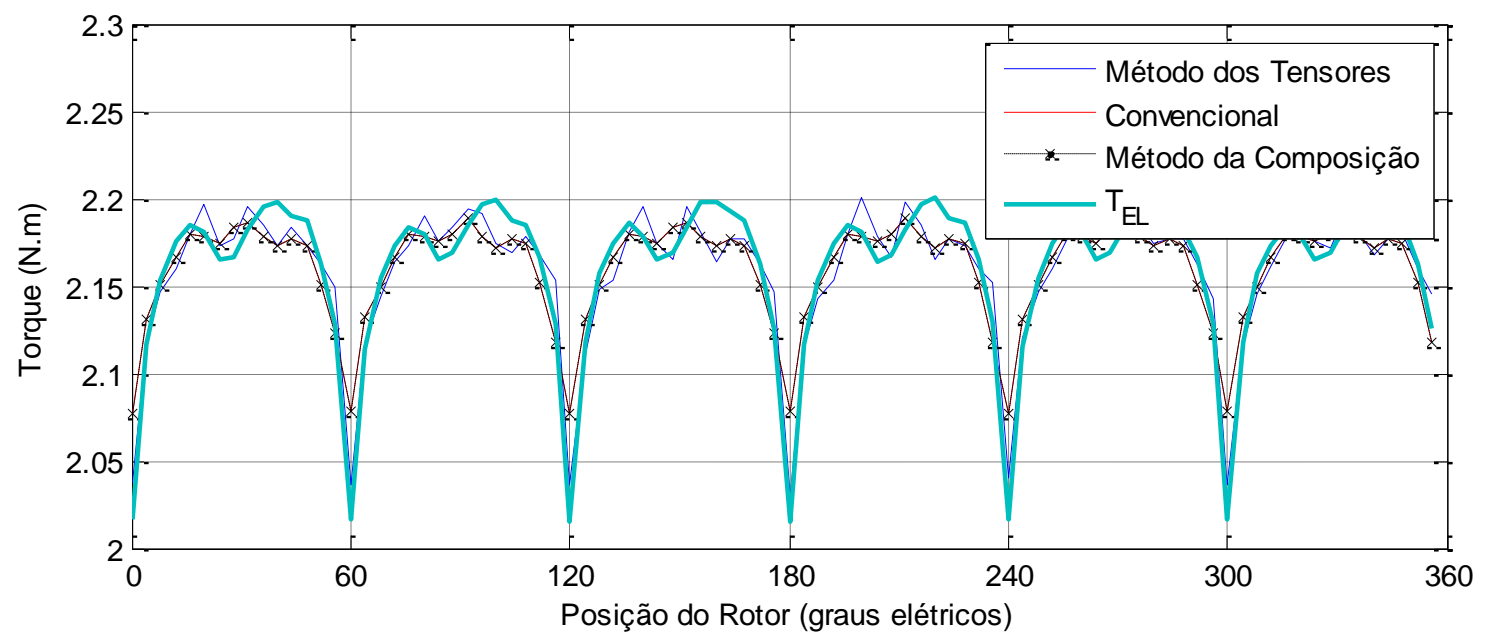

Figura 4.18 - Torque Mútuo v.s. $T_{E L}$ (Carregamento de 10A)

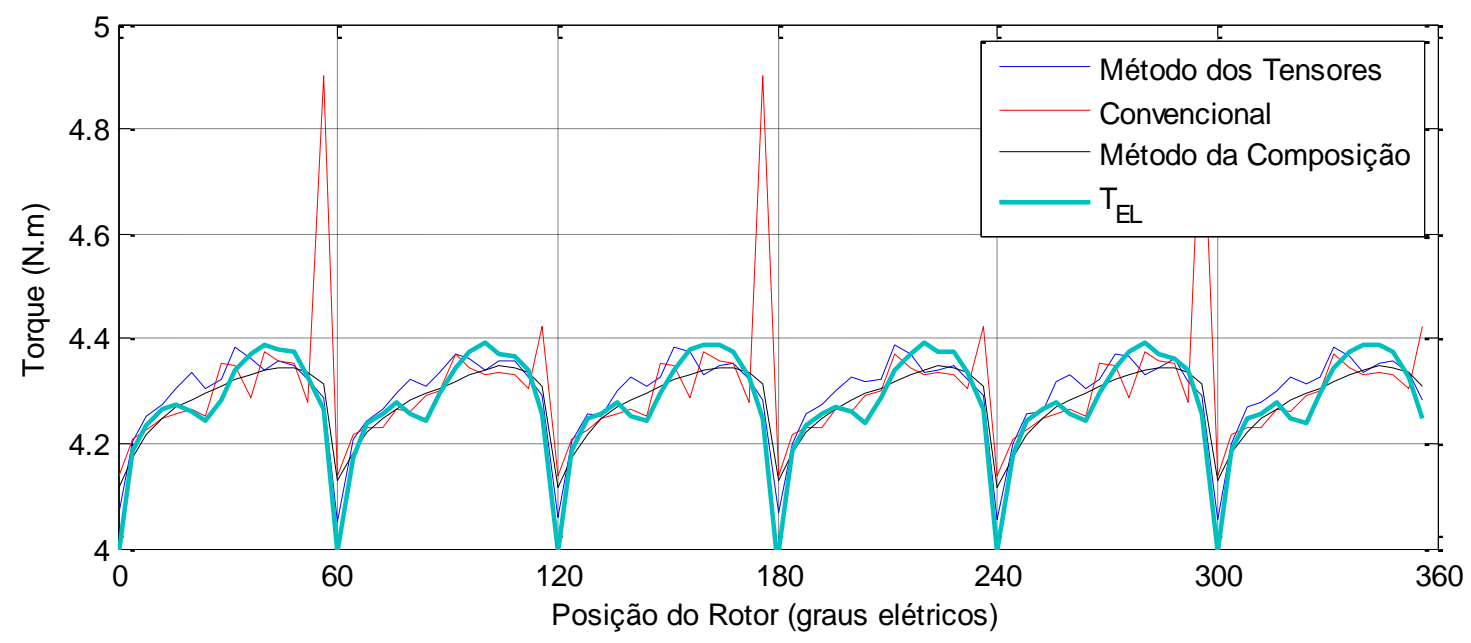

Figura 4.19 - Torque Mútuo v.s. $T_{E L}$ (Carregamento de 20A)

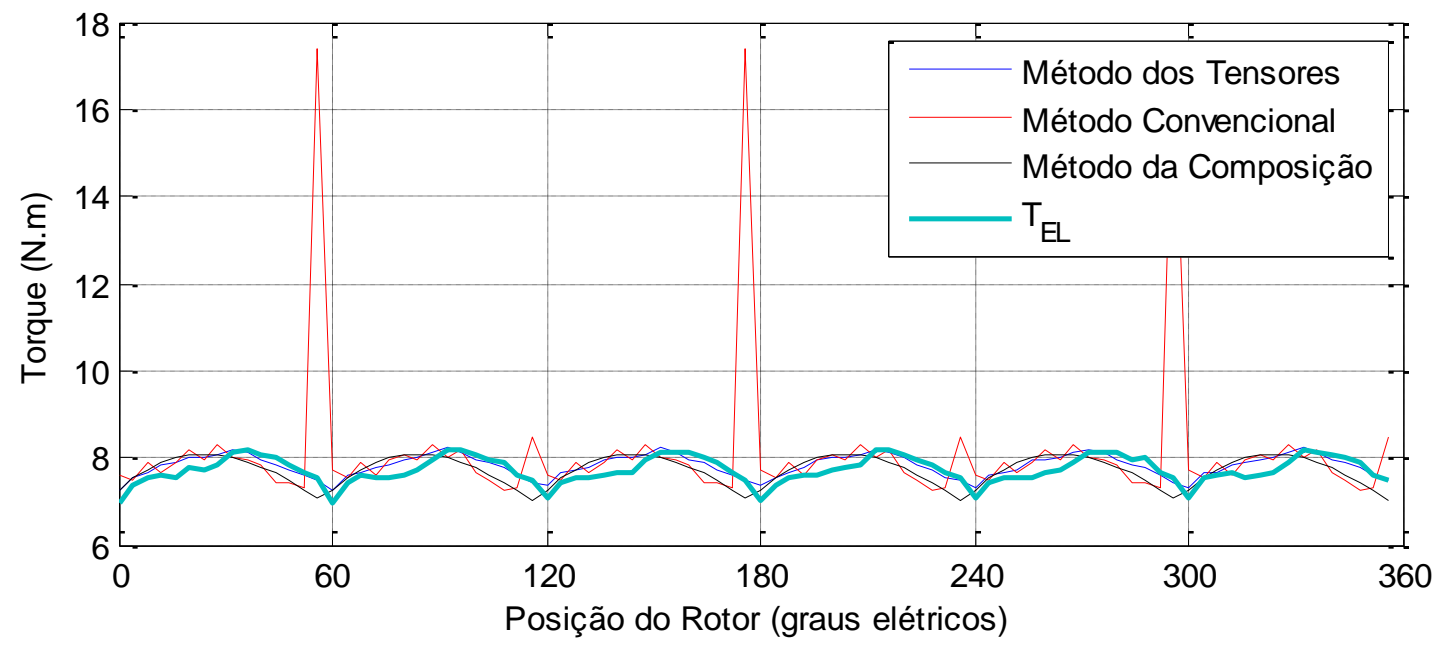


Tabela 4.3 - Torque de Borda

\begin{tabular}{ccccc}
\cline { 2 - 5 } & Vazio & 05A & 10A & 20A \\
\hline \hline Máximo $(\mathrm{mNm})$ & 13 & 14 & 12 & 6 \\
Mínimo $(\mathrm{mNm})$ & -13 & -14 & -21 & -39 \\
Médio $(\mathrm{mNm})$ & 0 & 0 & -4 & -15 \\
$\begin{array}{c}\text { Torque } / \text { Corrente } \\
\text { (mNm/A) }\end{array}$ & - & - & $-0,4$ & -8 \\
$\begin{array}{c}\text { Amplitude } \\
(\mathbf{m N m} / \mathbf{A})\end{array}$ & 13 & 14 & 16 & 27 \\
\hline \hline
\end{tabular}

Figura 4.20 - Torque de Borda (Carregamento de 5A)

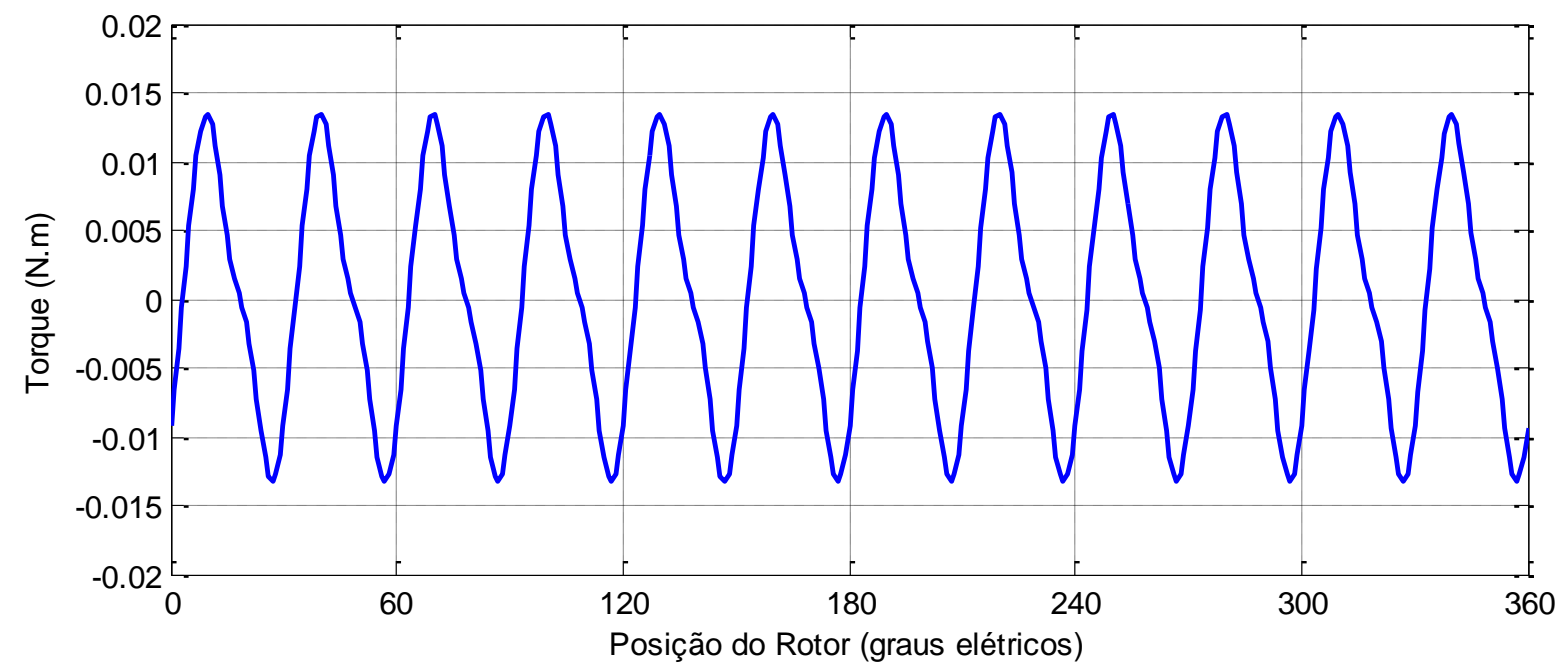

Figura 4.21 - Torque de Borda (Carregamento de 10A)

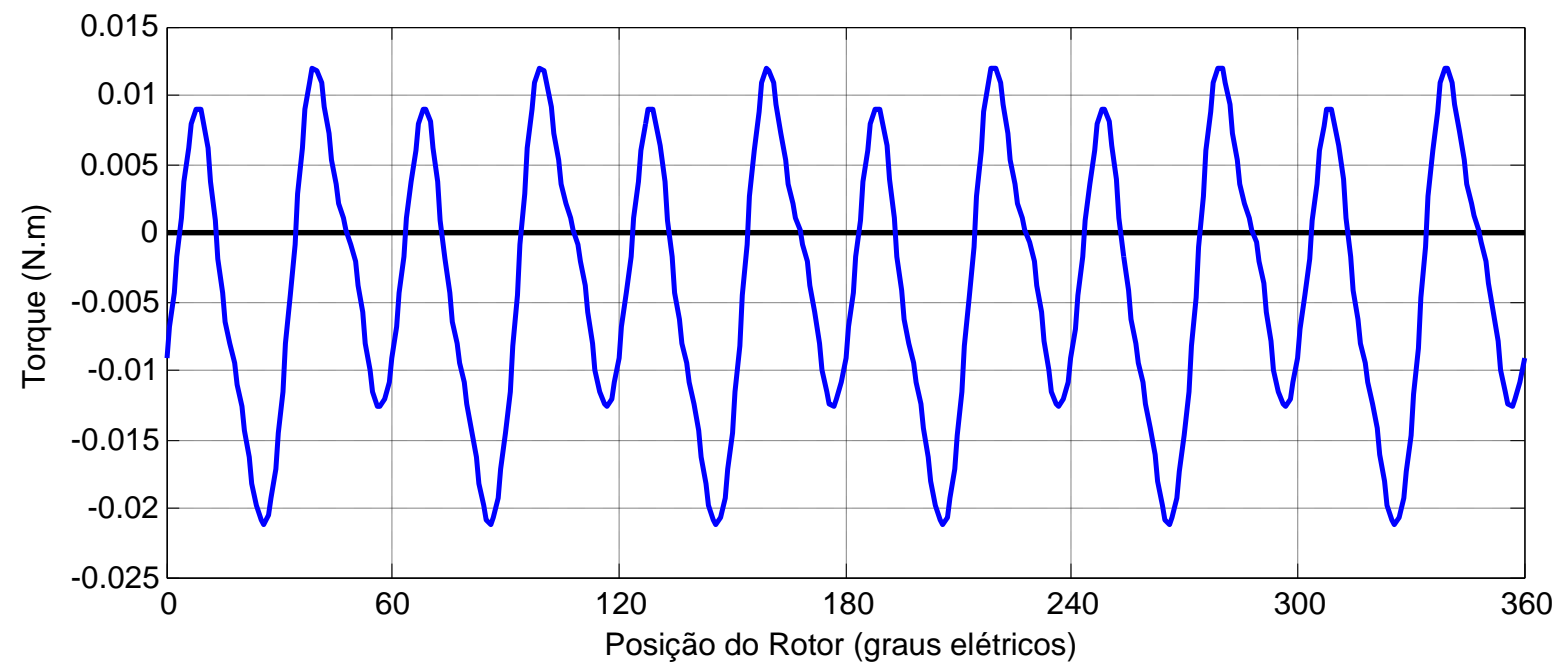


Figura 4.22 - Torque de Borda (Carregamento de 20A)

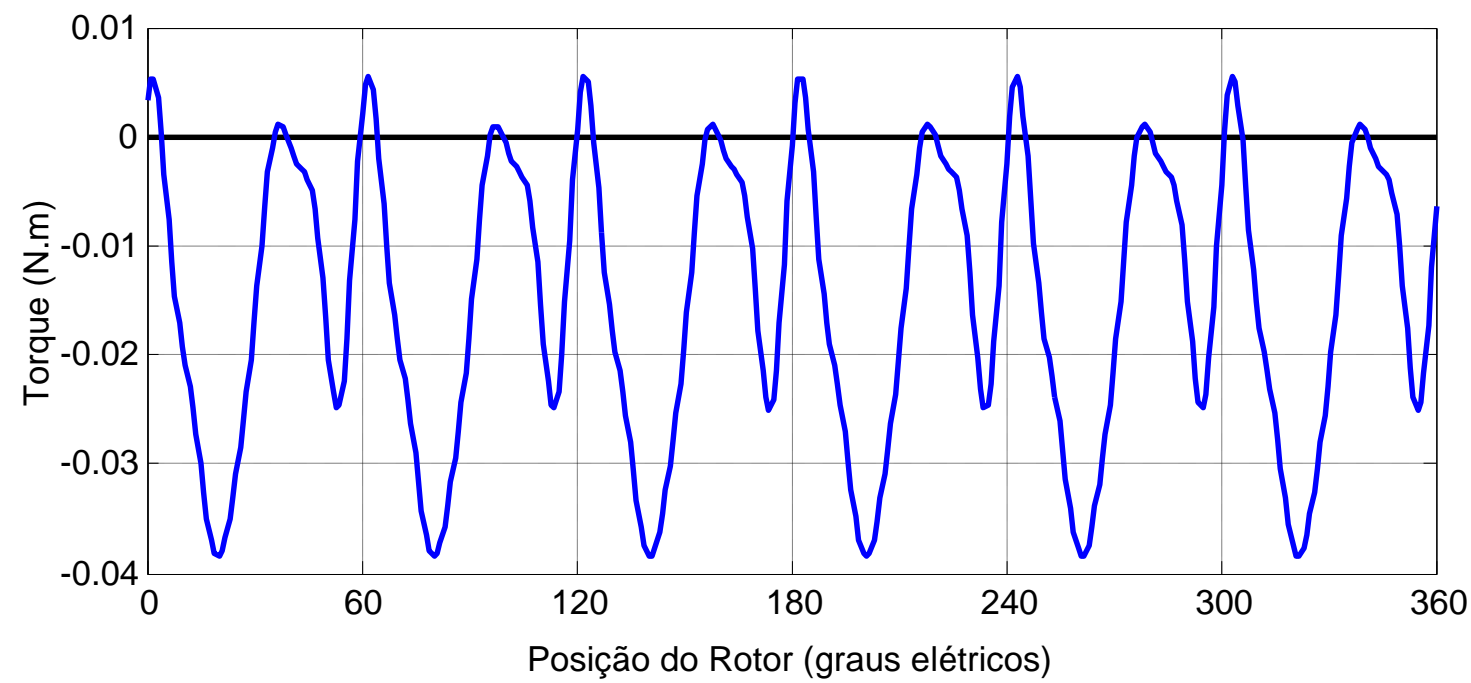

Do mesmo modo que os autores de [9]-[11], [13], [19], [25], [33], [34] encontraram valor médio diferente de zero para o torque de borda quando a máquina é carregada, o presente estudo apresenta o mesmo efeito, com valores médios de torque de borda diferentes de zero e que aumentam ao passo que o carregamento eletromagnético da máquina aumenta. A justificativa para o valor médio ser diferente de zero reside no fato de que a interação entre o campo magnético devido às correntes de armadura e o campo magnético provenientes dos ímãs produz um campo girante que afeta a malha de permeabilidade magnética dos dentes do estator. Como resposta, surgem alguns pontos de saturação nas sapatas dos dentes criando uma espécie de "saliência virtual síncrona" [13], [19], cuja interpretação física é semeIhante ao aumento da abertura de ranhura (daí o aumento na amplitude do torque de borda) e que neste caso está em atraso com o campo girante, gerando, portanto, um torque contrário ao sentido de rotação da máquina (vide que a média do torque de borda é negativa).

Portanto, nota-se claramente que o torque de borda não só contribui com oscilações indesejadas no torque eletromagnético como também contribui para a depreciação do valor médio do torque eletromagnético. Por não ser o objetivo da presente tese, as investigações relacionadas com o mecanismo de produção e redução das chamadas "saliências virtuais" citadas em [13], [19] e com a variação da frequência do torque de borda são deixadas como sugestões para trabalhos futuros.

Outro modo de se calcular/estimar esta componente do torque de relutância é por meio dos Tensores de Maxwell quando da simulação linear empregando-se apenas a corrente de armadura como fonte de fluxo magnético (quarta etapa de simulações proposta na Figura 2.2), como expressado em (4.1). 
Figura 4.23 - Amplitude e Frequência do Torque de Borda

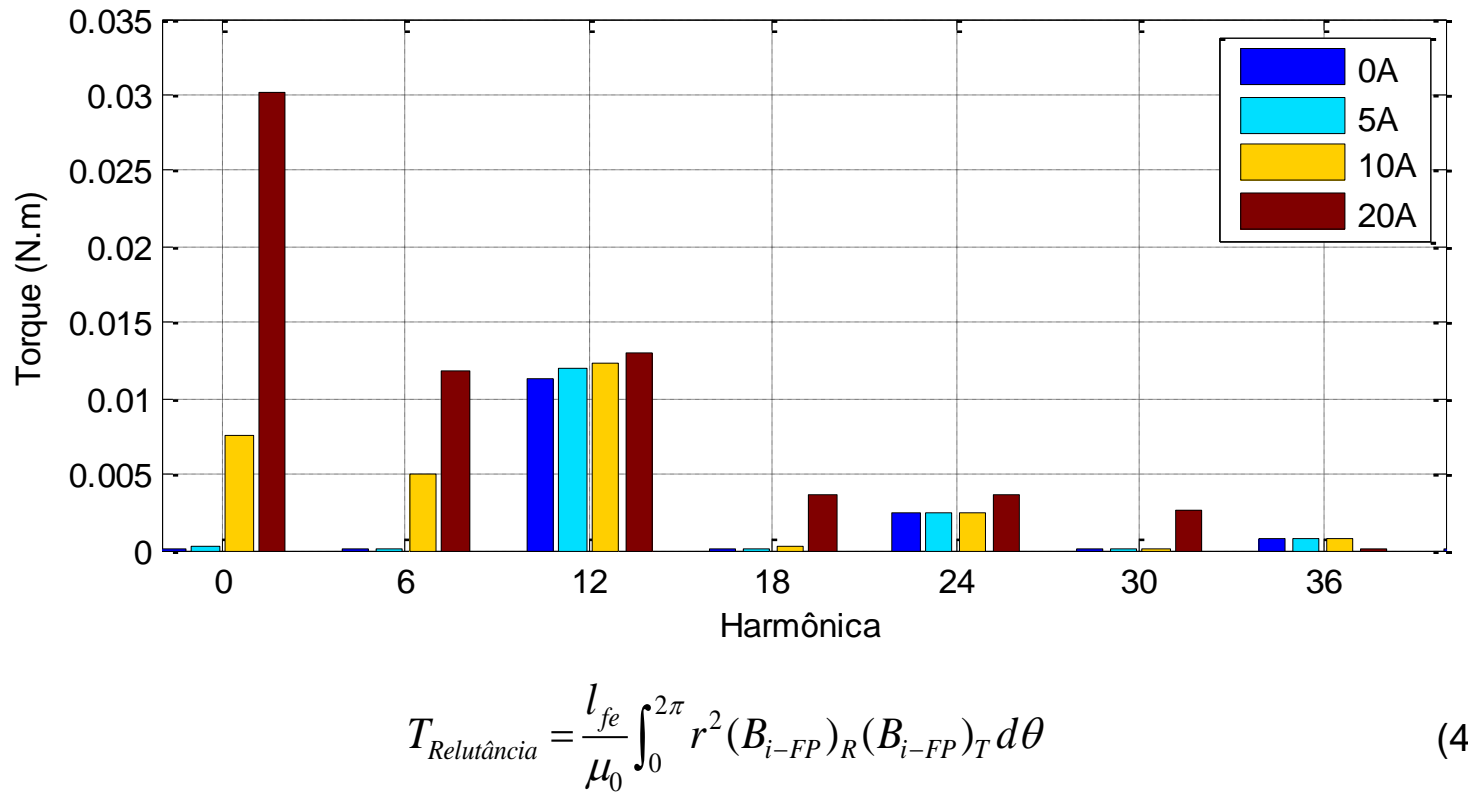

As formas de onda da indutância de linha para as condições de carregamento simuladas são apresentadas na Figura 4.24. Ao se observar essas formas de onda é possível presumir que o torque de relutância para a condição de carregamento de $5 \mathrm{~A}$ é praticamente nulo, já que a indutância para esta condição apresenta valor praticamente constante, com pequenas oscilações em torno de $59,1 \mathrm{mH}$. Para a condição de $10 \mathrm{~A}$, a indutância apresenta uma periodicidade de $60^{\circ}$ elétricos (seguindo a mesma periodicidade da alimentação e comutação das fases) e sua variação pico a pico é de aproximadamente $1 \mathrm{mH}$, contribuindo, portanto, para o surgimento de um torque de relutância. Dado que a variação da indutância na condição de carregamento de $10 \mathrm{~A}$ é negativa, o torque de relutância tem valor médio negativo, sendo contrário ao torque mútuo. Já a condição de $20 \mathrm{~A}$ apresenta uma variação maior no valor da indutância, indicando que o torque de relutância para esta condição será ainda maior.

Figura 4.24 - Indutância de Linha Vista pelo Inversor

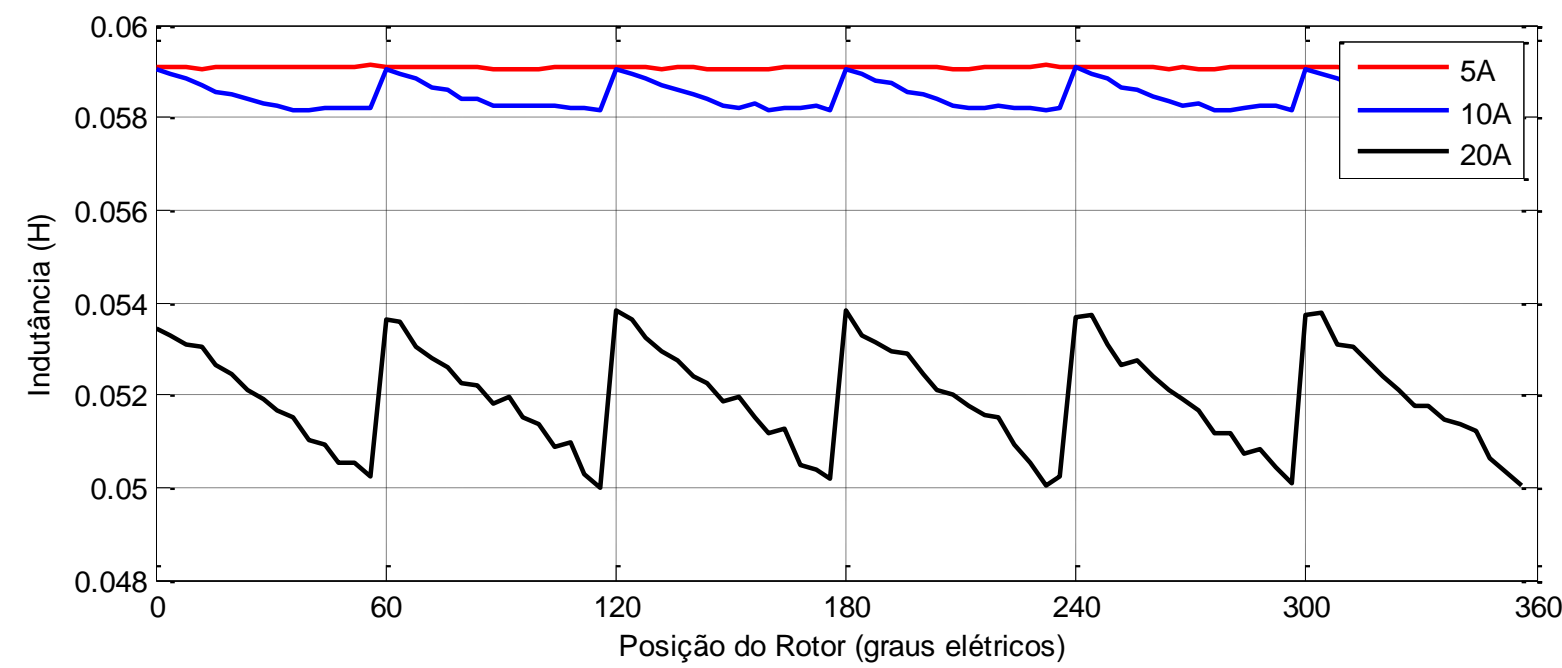


As Figuras 4.25 e 4.26 ilustra a forma de onda do torque de relutância para as condições de carregamento de 10 e 20A. A Tabela 4.4 apresenta os valores máximo, mínimo, médio de torque e a razão entre o valor absoluto do torque de relutância e a corrente de armadura. É mostrada também, a razão entre a amplitude do torque de relutância e a corrente de armadura.

\begin{tabular}{ccc} 
Tabela 4.4 - Torque de Relutância $\left(T_{\text {Relutancia }}\right)$ \\
\cline { 2 - 3 } & 10A & 20A \\
\hline \hline Máximo $(\mathbf{m N m})$ & 24 & 188 \\
\hline Mínimo $(\mathbf{m N m})$ & -78 & -345 \\
\hline Médio $(\mathbf{m N m})$ & -14 & -89 \\
\hline Amplitude $(\mathrm{mNm})$ & 102 & 266 \\
\hline $\begin{array}{c}\text { Torque } / \text { Corrente } \\
(\mathbf{m N m} / \mathbf{A})\end{array}$ & 1,4 & -45 \\
\hline $\begin{array}{c}\text { Amplitude/Corrente } \\
(\mathbf{m N m} / \mathbf{A})\end{array}$ & 10 & 133 \\
\hline \hline
\end{tabular}

Figura 4.25 - Torque de Relutância (Carregamento de 10A)

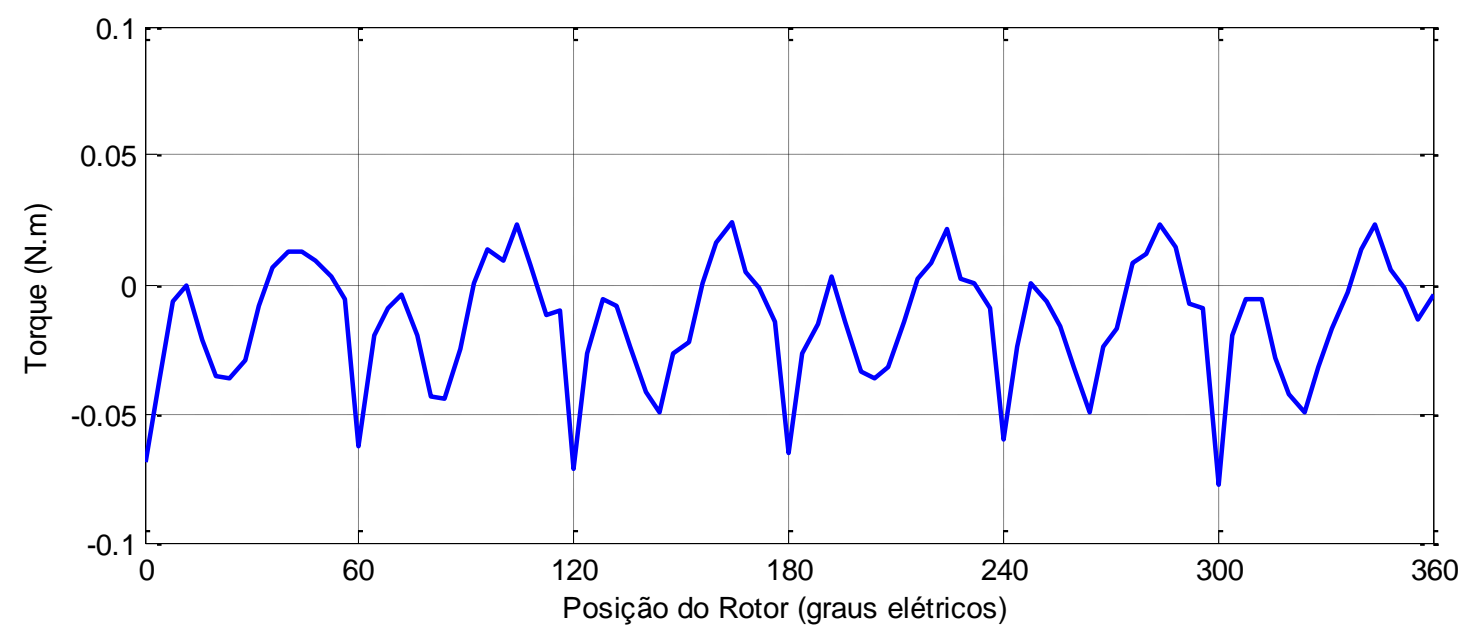

Figura 4.26 - Torque de Relutância (Carregamento de 20A)

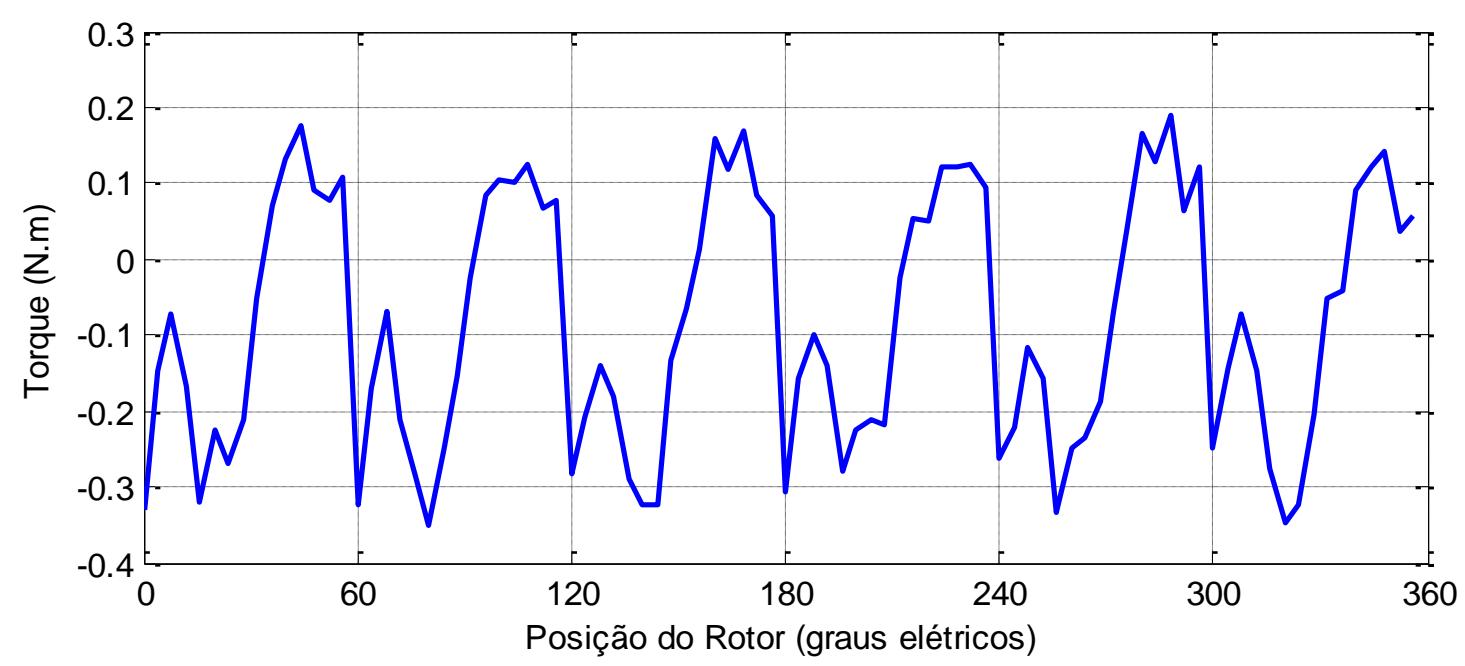


Como observado na Figura 4.24 e na Tabela 4.4, tanto a amplitude da variação da indutância quanto a participação do torque de relutância (o valor absoluto do mesmo) aumentam ao passo que a corrente de armadura aumenta. $O$ crescimento dessas razões é não linear, seguindo o comportamento da permeabilidade do material do estator. O valor médio negativo indica que o torque de relutância está em oposição ao sentido de rotação da máquina, reduzindo o torque final entregue pela mesma.

O torque eletromagnético para as simulações não lineares é chamado de $T_{E L}$, sendo descrito em (3.3), e leva em consideração os efeitos de saturação dos materiais ferromagnéticos do estator e do rotor. Tendo-se em vista que no Capítulo 3 são apresentadas três abordagens diferentes para a avaliação da força contra eletromotriz, uma pelo método convencional, outra por meio do método da composição das regiões [16] e uma outra por meio da associação entre os tensores de Maxwell e o Método da Permeabilidade Fixa, abre-se a possibilidade para três resultados diferentes no torque resultante da soma das componentes do torque eletromagnético. Portanto, a partir desta afirmação, é formulado o equacionamento para o torque resultante da soma das parcelas (4.2), onde o que os diferencia é como o torque mútuo é calculado.

$$
T_{\text {Soma }}=T_{\text {Mütuo }}+T_{\text {Borda }}+T_{\text {Relutancia }}
$$

As formas de onda do torque resultante da soma $\left(T_{\text {Soma }}\right)$ das parcelas do torque eletromagnético para as condições de carregamento de 5, 10 e 20A, calculadas pelos três métodos, são apresentadas da Figura 4.27 a Figura 4.29.

Notoriamente, a obtenção da força contra eletromotriz pelo método convencional (cálculo da força contra eletromotriz por meio da derivada do fluxo magnético concatenado) apresenta falhas ao ser utilizada para o cálculo do torque resultante uma vez que, resulta em um pico em torno do ponto de comutação das fases. Pico, este, que não está presente no torque não linear e nem no torque experimental. Reafirmando assim, a necessidade de um método que contorne este problema e apresente de forma precisa o cálculo da força contra eletromotriz. Além deste erro, o método convencional para obtenção da força contra eletromotriz tem como base os valores de fluxo concatenado calculados pelo próprio software de elementos finitos que apresenta ordem menor na precisão se comparado com o valor obtido para o vetor potencial magnético. 
Figura 4.27 - $T_{E L} v s T_{\text {Soma }}$ (Carregamento de 5A)

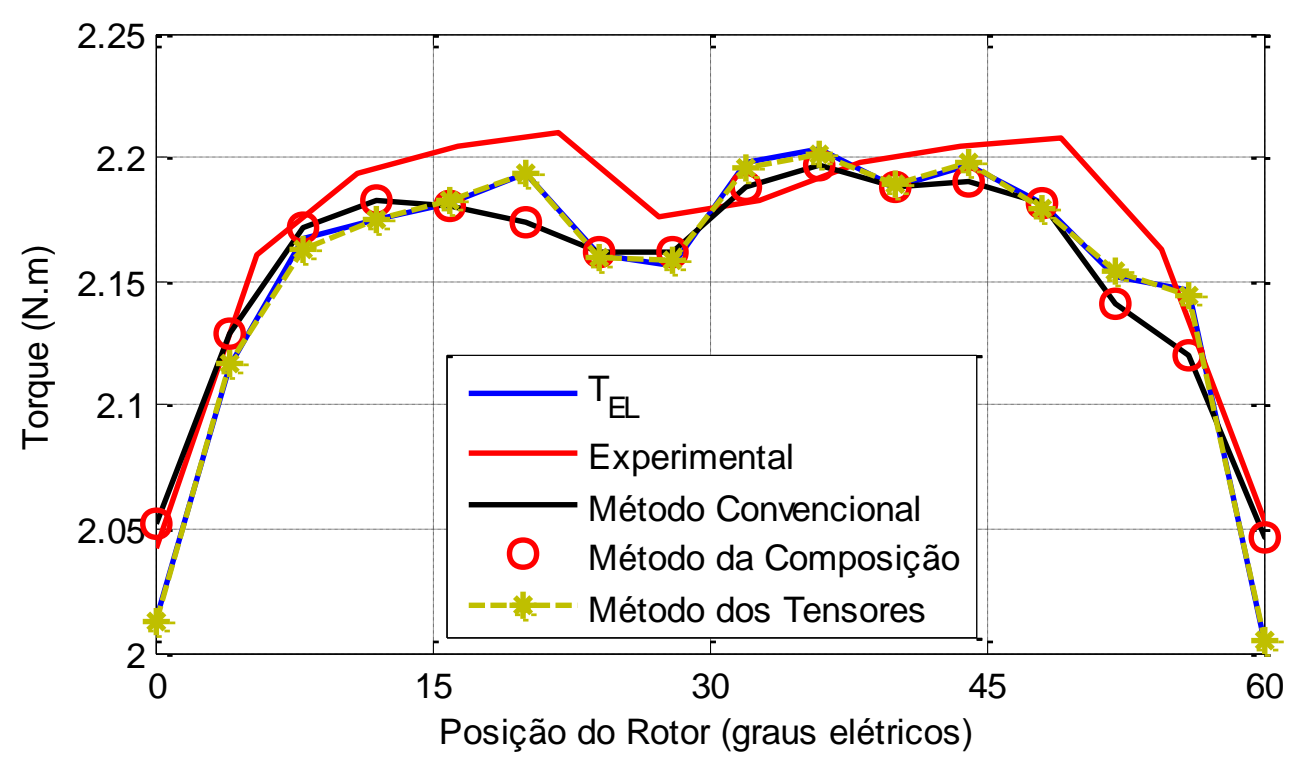

Figura 4.28 - $T_{E L} v s T_{\text {Soma }}$ (Carregamento de 10A)

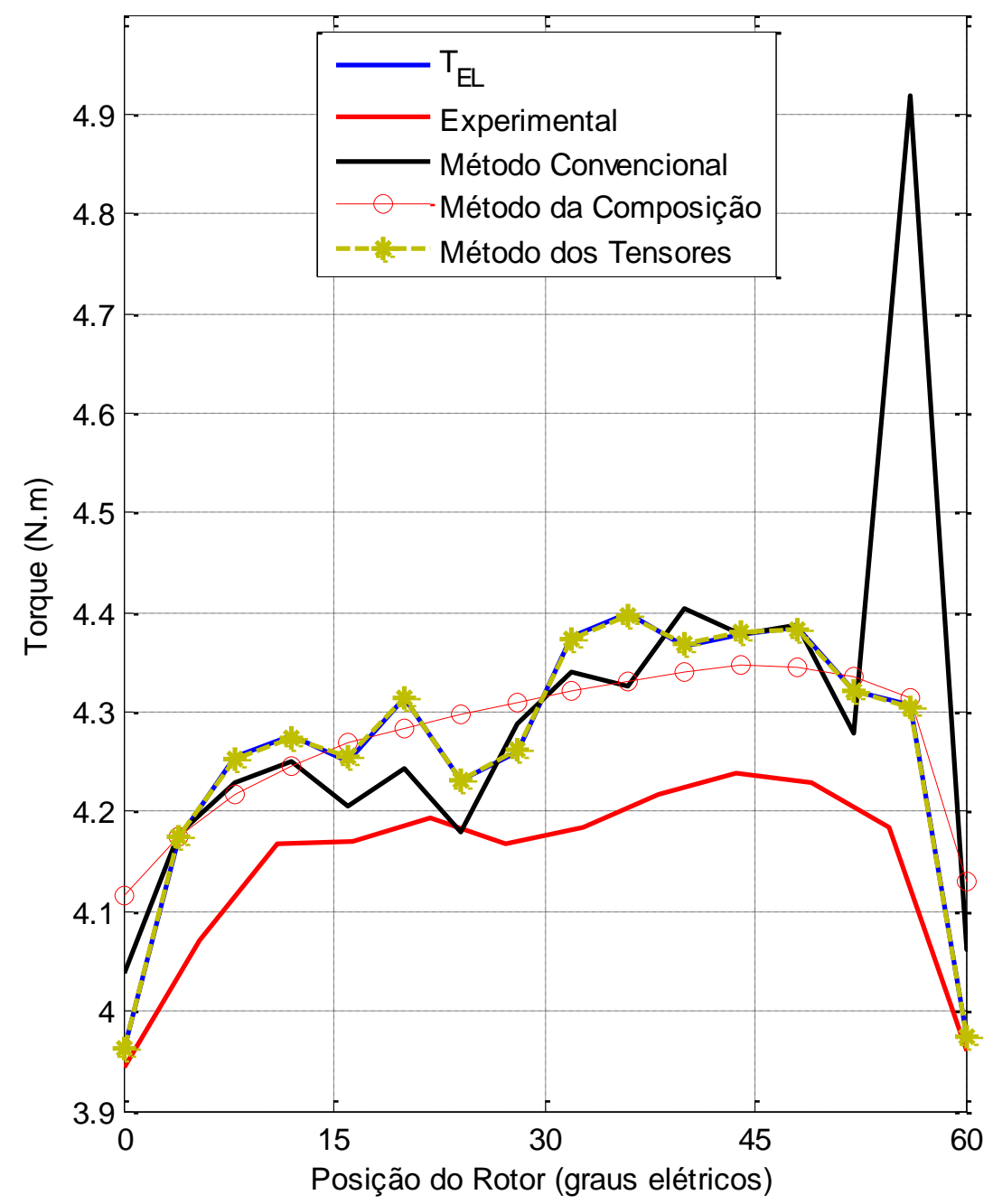


Figura 4.29 - $T_{E L} v s T_{\text {Soma }}$ (Carregamento de 20A)

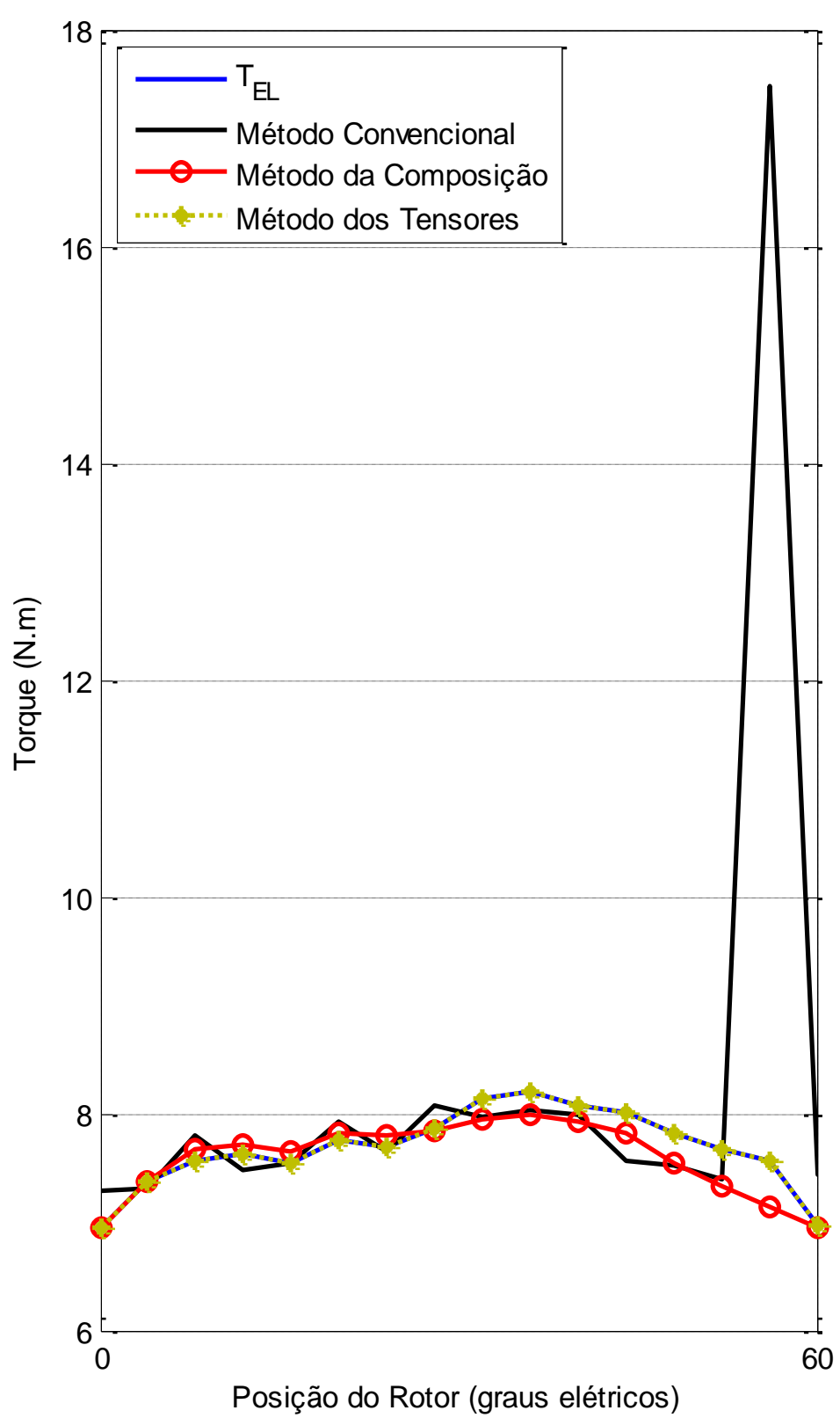

Por outro lado, as diferenças relativas entre o torque resultante calculado com base no método da composição das regiões para a força contra eletromotriz e o torque eletromanético $\left(T_{E L}\right)$ residem principalmente nos erros numéricos provenientes da aproximação de curvas no método da composição da força contra eletromotriz, como mencionado no Capítulo 3 e verificado nas Figuras 4.27 a 4.29. A diferença máxima entre seus valores é de $5 \%$ demonstrando que apesar de contornar o problema do método convencional para obtenção da força contra eletromotriz (que apresenta um pico no valor de torque próximo ao ponto de comutação), a obtenção da força contra eletromotriz pelo método da composição não apresenta precisão em seu cálculo. Ele ainda apresenta desvantagens computacionais claras em termos de implementação e tempo de resposta já que é necessário a implementação de um processo de 
aproximação de curvas como mencionado na Seção 3.4.1

Por outro lado, seus valores médios são próximos entre si e próximos ao valor do torque obtido por meio de simulação não linear $\left(T_{E L}\right)$. Entretanto, nota-se que as duas estimativas feitas para o comportamento do torque eletromagnético apresentam formas de onda diferentes entre si, sendo a aproximação feita utilizando o torque mútuo calculado com base na forma de onda da força contra eletromotriz pelo método dos tensores muito próxima ao torque eletromagnético da simulação não linear. Evidencia-se, dessa forma, a boa atuação do Método da Permeabilidade Fixa juntamente com os Tensores de Maxwell na obtenção da força contra eletromotriz em carga, e seu reflexo no cálculo do torque eletromagnético.

As diferenças relativas entre o torque resultante calculado com base no método dos tensores para a força contra eletromotriz e o torque eletromagnético $\left(T_{E L}\right)$ residem nos erros numéricos provenientes da linearização utilizando o Método da Permeabilidade Fixa por meio do programa computacional desenvolvido por [6], que trabalha com uma faixa de tolerância para geração do modelo para aplicação do método da permeabilidade fixa. A diferença relativa é mínima, apresentando como erro máximo $0,1 \%$. Portanto, a força contra eletromotriz obtida por meio do método dos tensores de Maxwell apresenta grande precisão quando implementado, contornando os problemas apresentados no método convencional (cálculo da força contra eletromotriz por meio da derivada do fluxo concatenado) e no método da composição.

\subsection{Caso 2}

Aqui são apresentados os resultados referentes ao emprego dos métodos para obtenção da força contra eletromotriz para o estudo de caso 2. Como mencionado, o segundo caso é uma modificação do primeiro caso, em que os ímãs são substituídos por ímãs de NeodímioFerro-Boro de maior densidade de energia, mantendo a espessura de 7,6mm e o entreferro de 1,35mm. Essa mudança eleva o valor de amplitude da força contra eletromotriz e também do torque de borda (cogging torque). Para este caso, são avaliados apenas dados simulados para as condições de 50\%, 100\% e $200 \%$ de carregamento.

\subsubsection{Condição em Vazio (OA)}

As formas de onda de fluxo concatenado com a fase A, força contra eletromotriz da fase $A$ e torque de borda para a operação em vazio são mostradas da Figura 4.30 a Figura 4.32 . 
Figura 4.30 - Fluxo Magnético Concatenado (Operação em vazio)

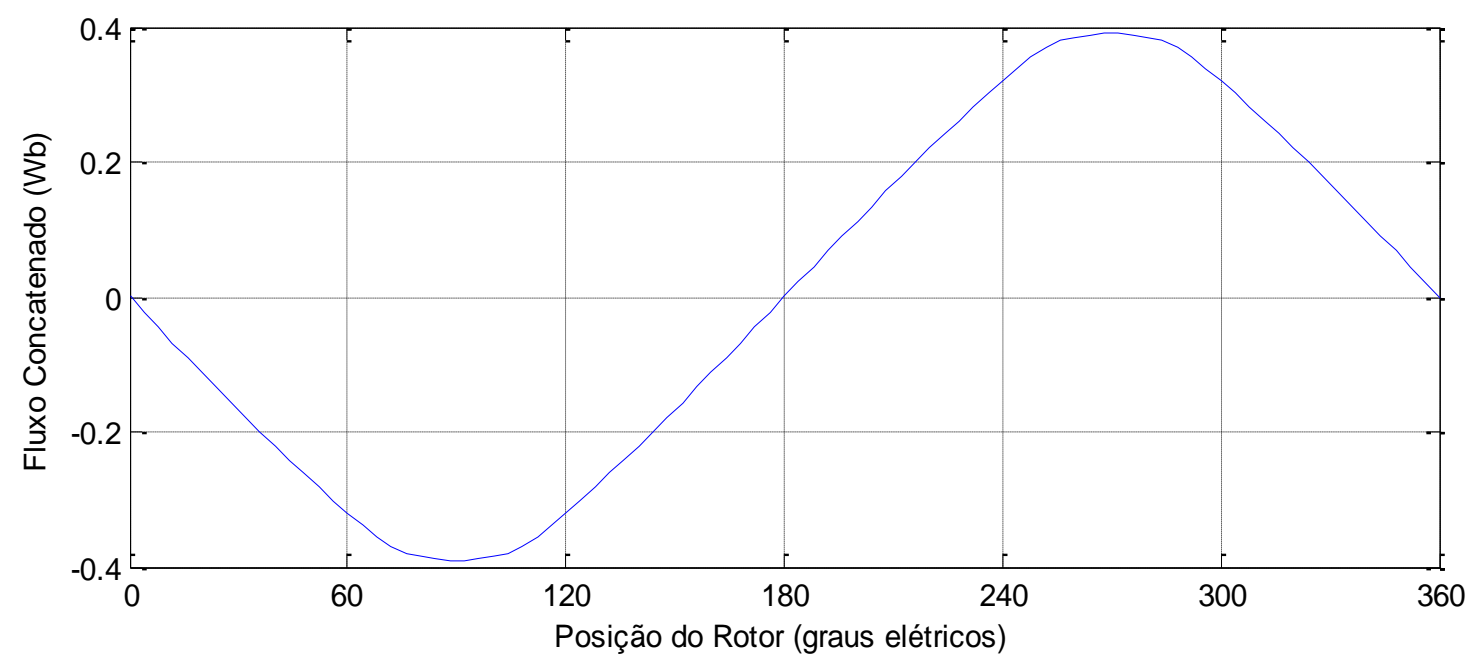

Figura 4.31 - Força Contra Eletromotriz (Operação em Vazio)

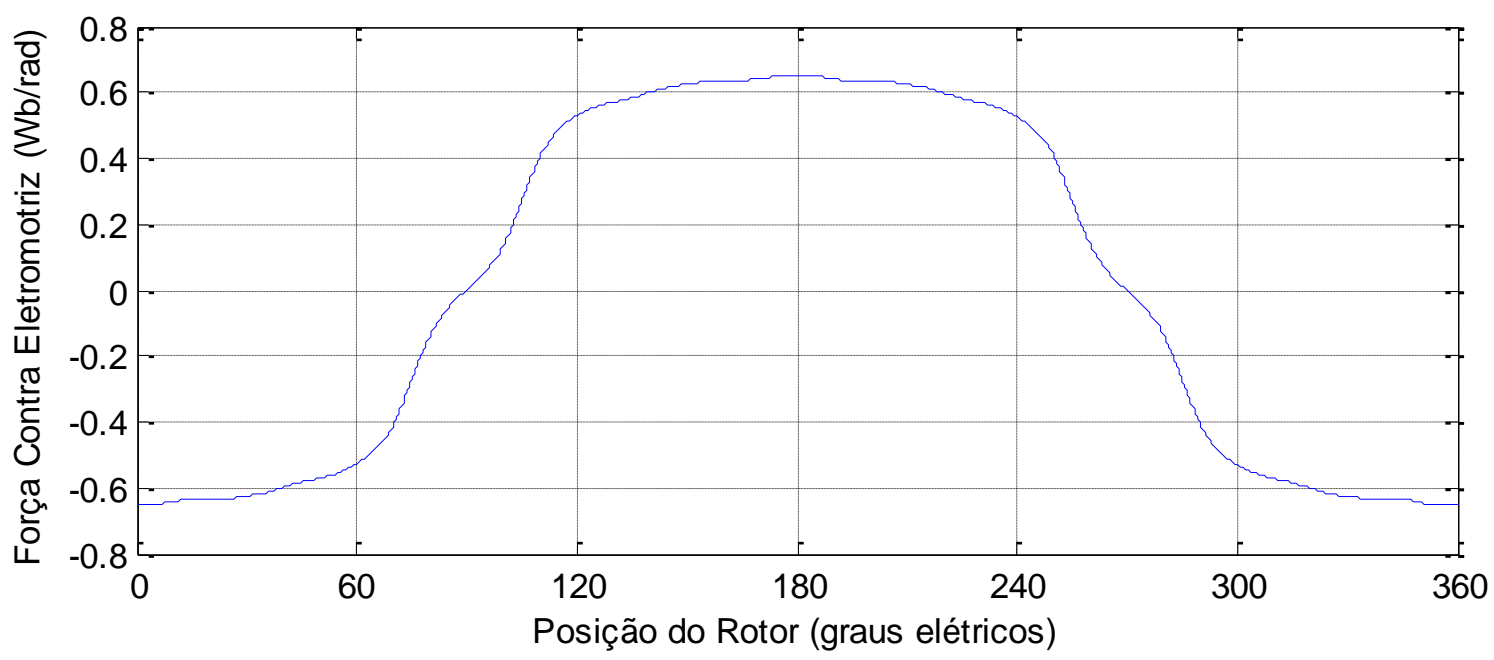

Figura 4.32 - Torque de Borda (Operação em vazio)

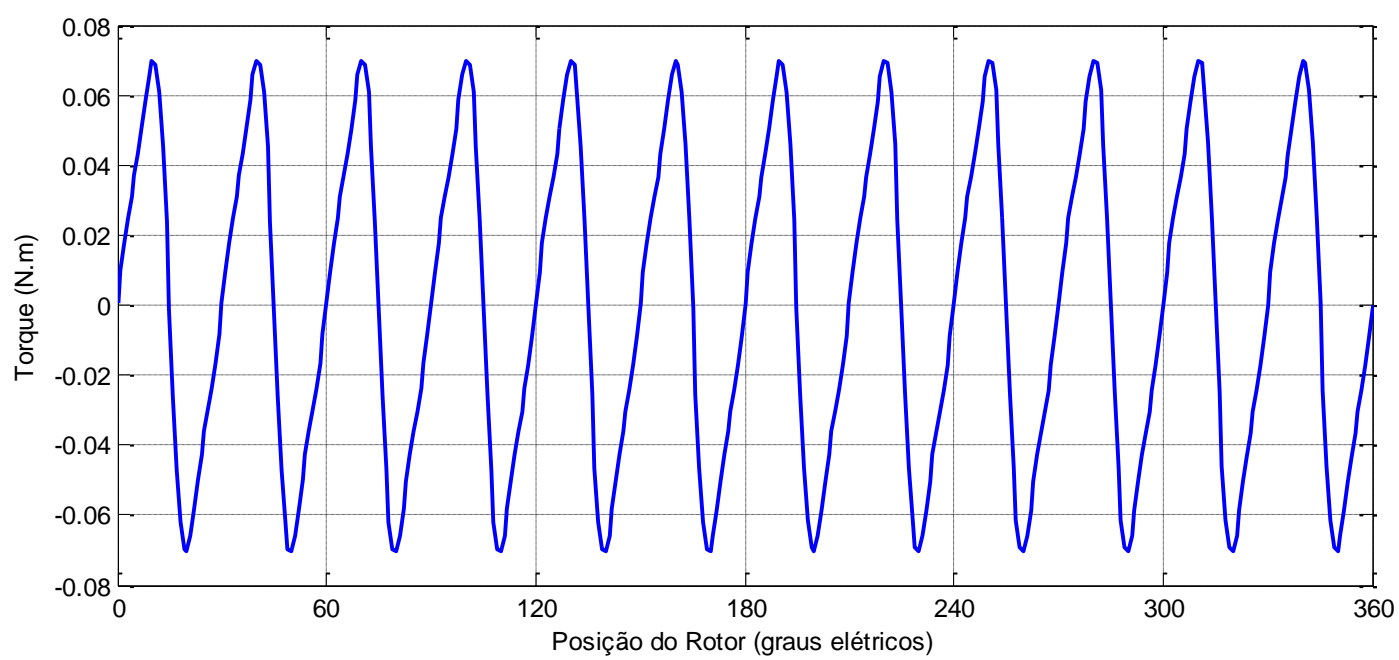




\subsubsection{Condição em Carregamento}

As formas de onda do fluxo magnético concatenado para a fase $A$ nas condições de carregamento de 5, 10 e 20A são ilustradas na Figura 4.33.

Valendo-se da aplicação da derivada sobre as formas de onda do fluxo magnético concatenado por fase (Método Convencional) apresentadas na Figura 4.33, são obtidas e apresentadas na Figura 4.34 as forças contra eletromotrizes. Nota-se, que a força contra eletromotriz é ocorrida de oscilações que se repetem a cada $60^{\circ}$ elétricos para todas as condições de carregamento, diferentemente do caso 1. Isso se dá graças ao ímã de Neodímio utilizado no caso 2, que apresenta maior densidade de energia que o ímã de ferrite, compensando o entreferro grande $(1,35 \mathrm{~mm})$.

Figura 4.33 - Fluxo Concatenado (Carregamentos de 5, 10 e 20A)

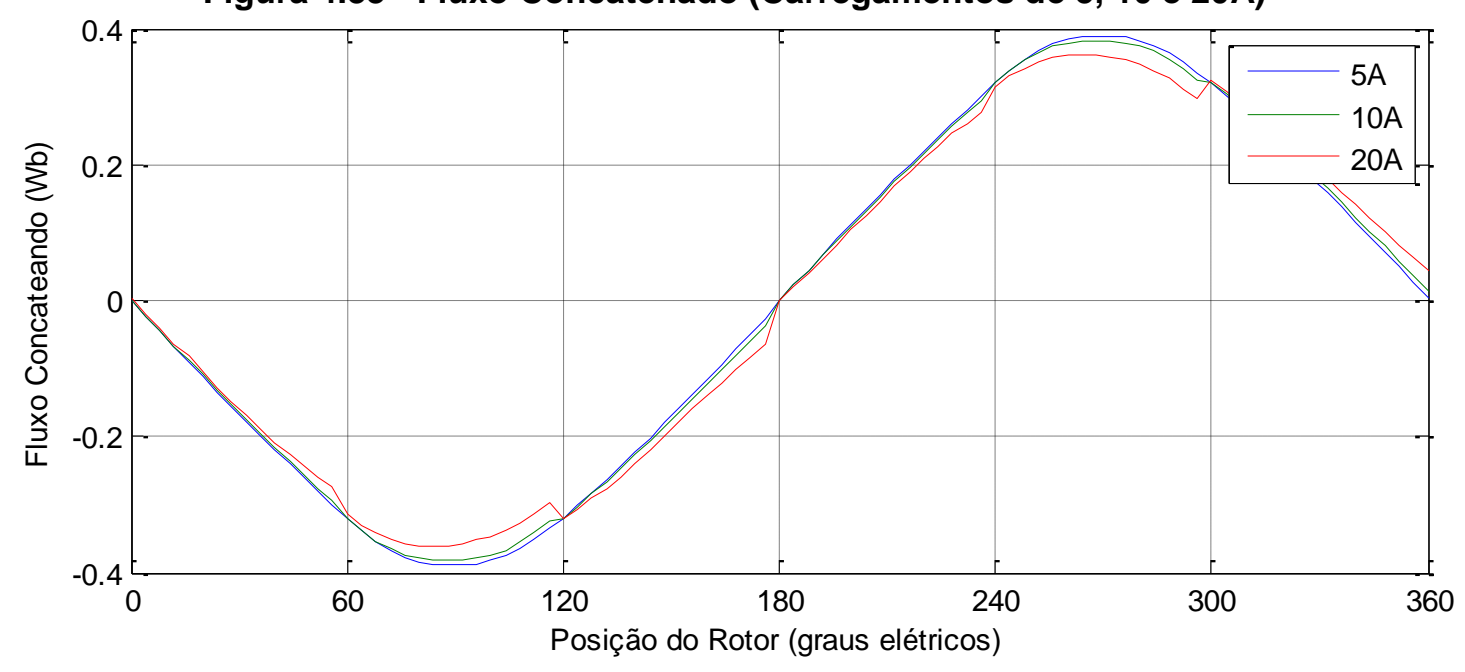

Figura 4.34 - Força Contra Eletromotriz - Método Convencional

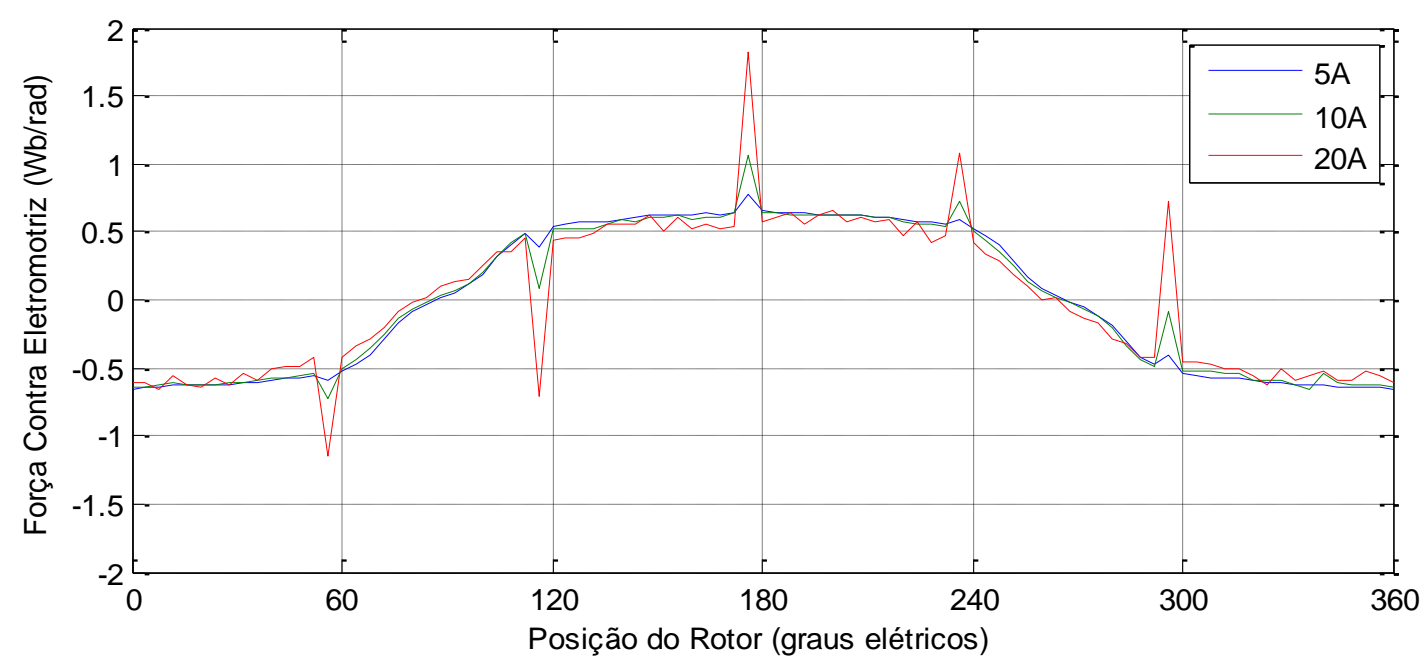


As três componentes resultantes da decomposição da forma de onda de fluxo magnético concatenado para a fase A são ilustradas nas Figuras 4.35 a 4.37, para as condições de carregamento eletromagnético de 5,10 e $20 \mathrm{~A}$.

Comparado ao caso 1, o presente caso apresenta para todas as condições de carregamento três regiões distintas que descrevem as componentes do fluxo. A partir dos resultados obtidos com a decomposição do fluxo magnético concatenado para a fase A, empregase a operação derivada nas regiões de fluxo magnético e são obtidas as formas de onda das forças contra eletromotrizes de cada região como ilustrado da Figura 4.38 a Figura 4.40. Em seguida, compõe-se as formas de onda de força contra eletromotriz para as condições de carregamento eletromagnético de 5, 10 e $20 \mathrm{~A}$.

As formas de onda da força contra eletromotriz composta para as condições de carregamento eletromagnético de 5, 10 e 20A são apresentadas na Figura 4.41.

Figura 4.35 - Componentes do Fluxo Magnético (Carregamento de 5A)

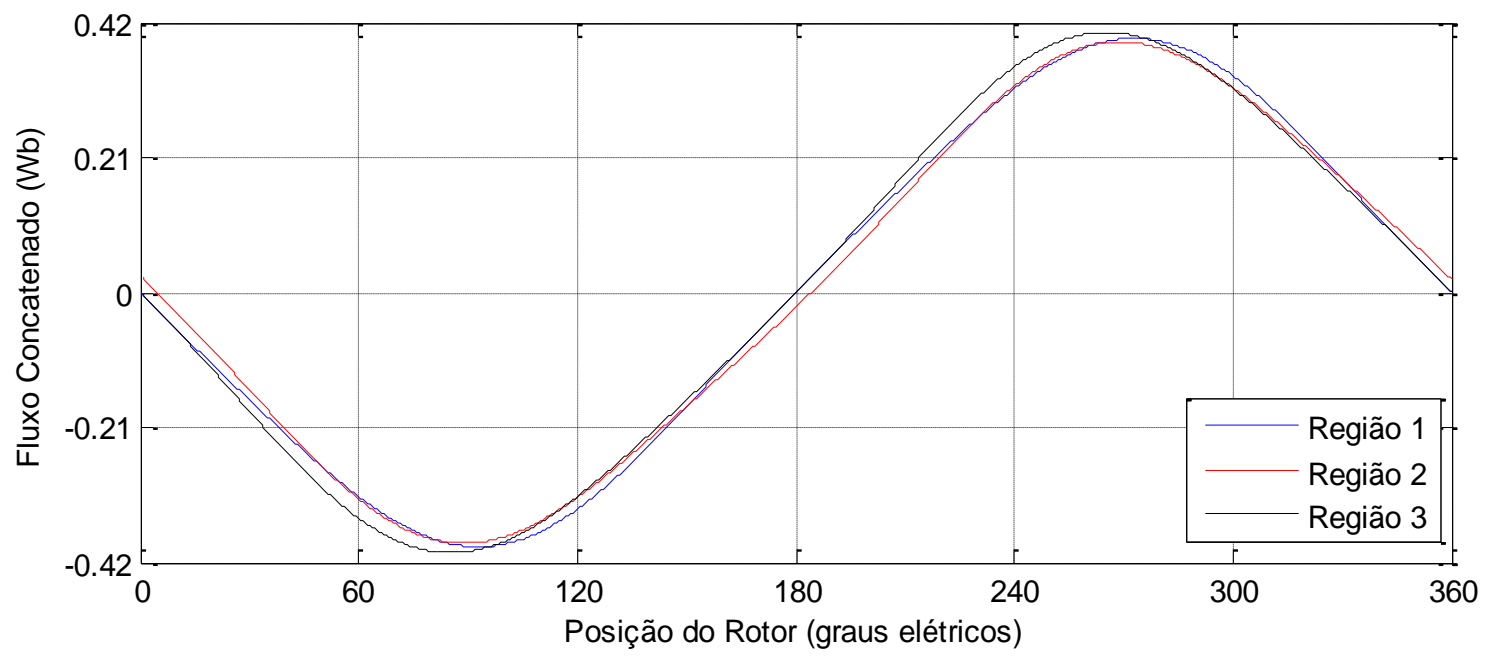

Figura 4.36 - Componentes do Fluxo Magnético (Carregamento de 10A)

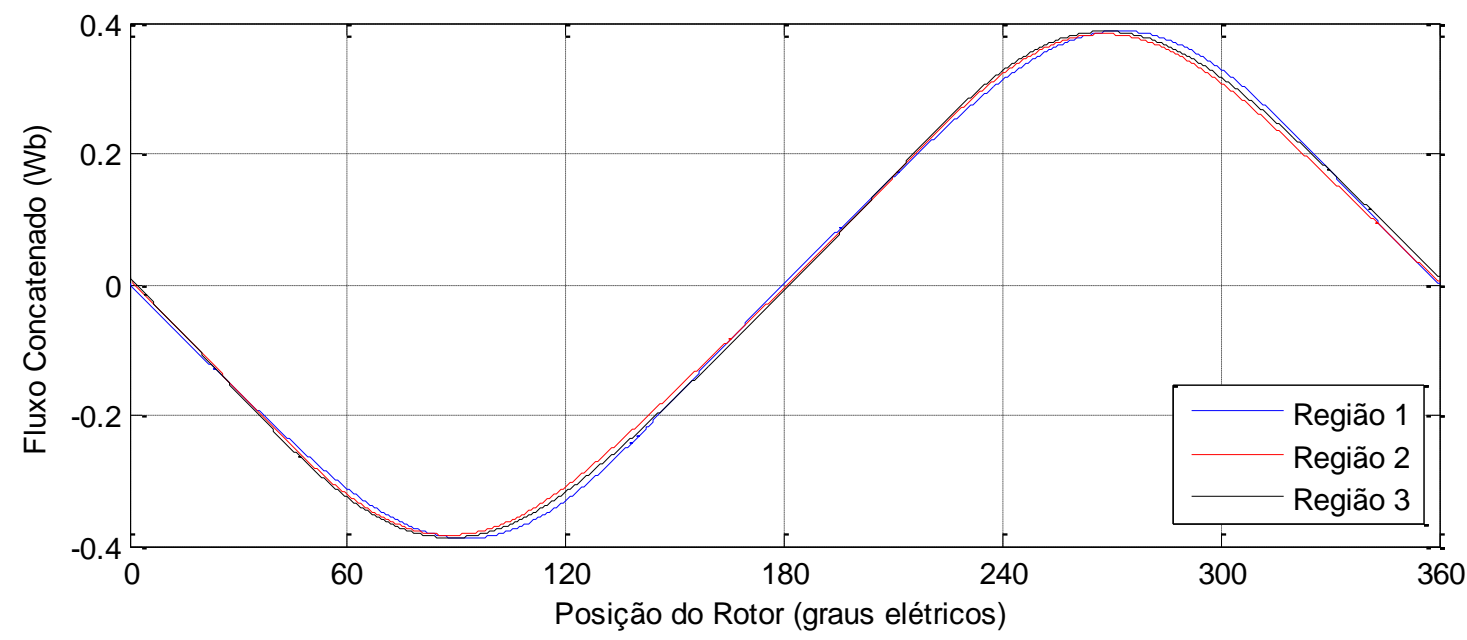


Figura 4.37 - Componentes do Fluxo Magnético (Carregamento de 20A)

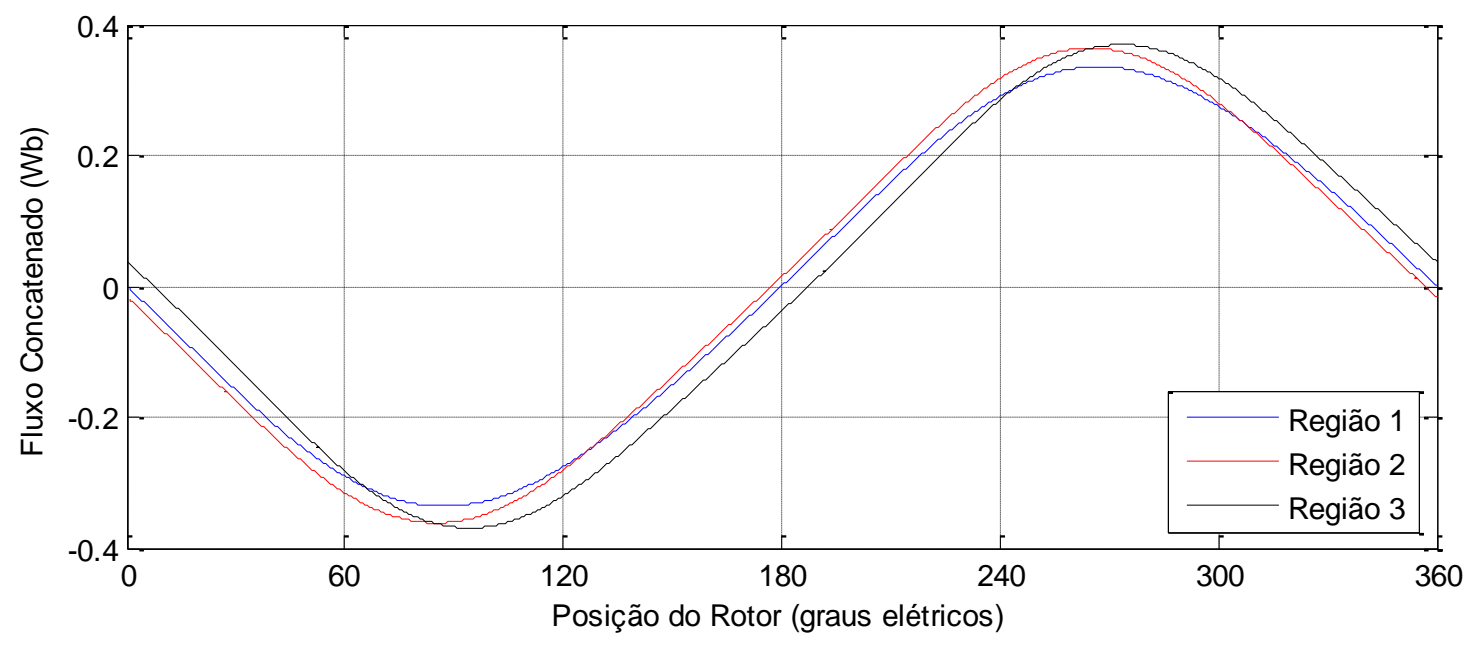

Figura 4.38 - Região 1: Componentes da Força Contra Eletromotriz

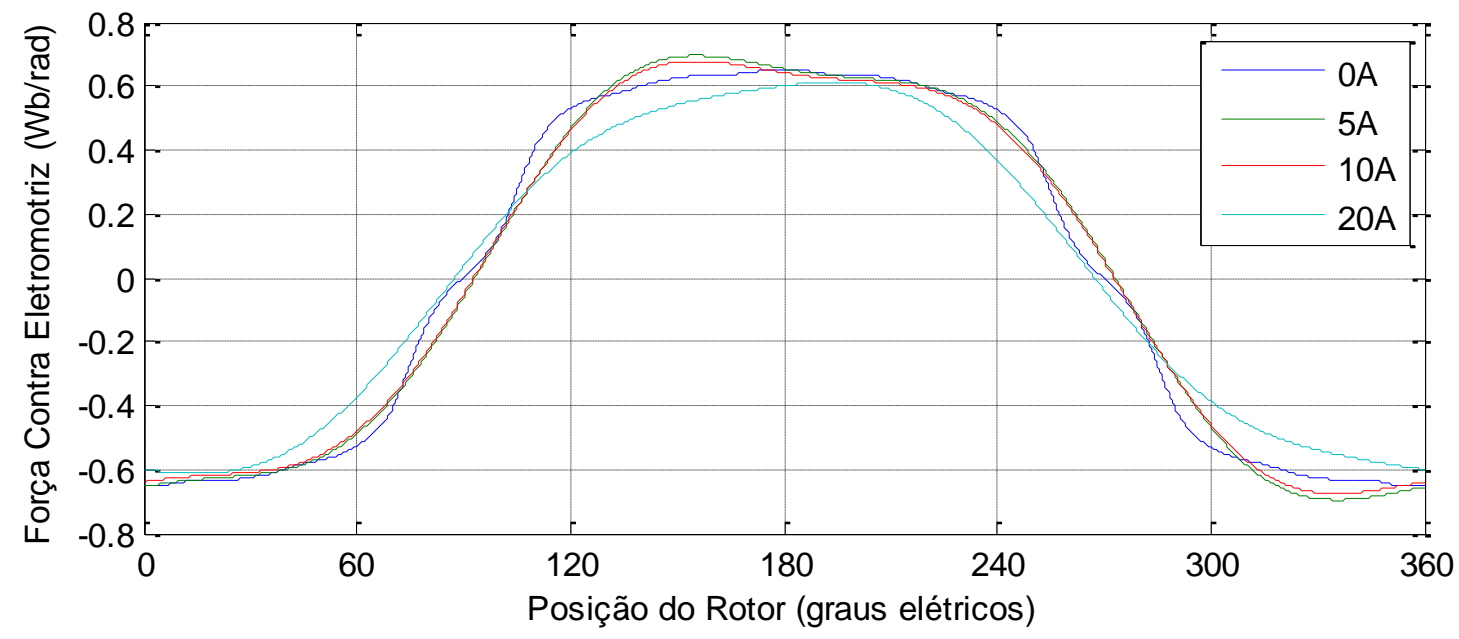

Figura 4.39 - Região 2: Componentes da Força Contra Eletromotriz

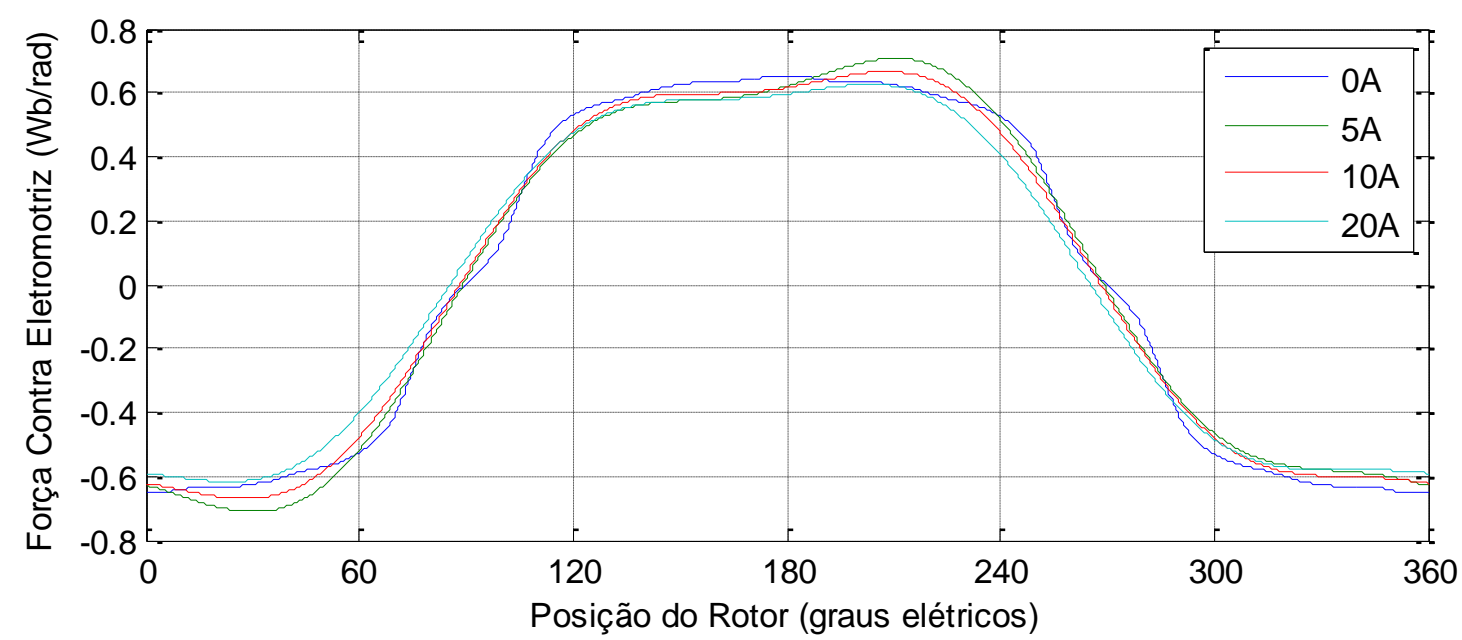


Figura 4.40 - Região 3: Componentes da Força Contra Eletromotriz

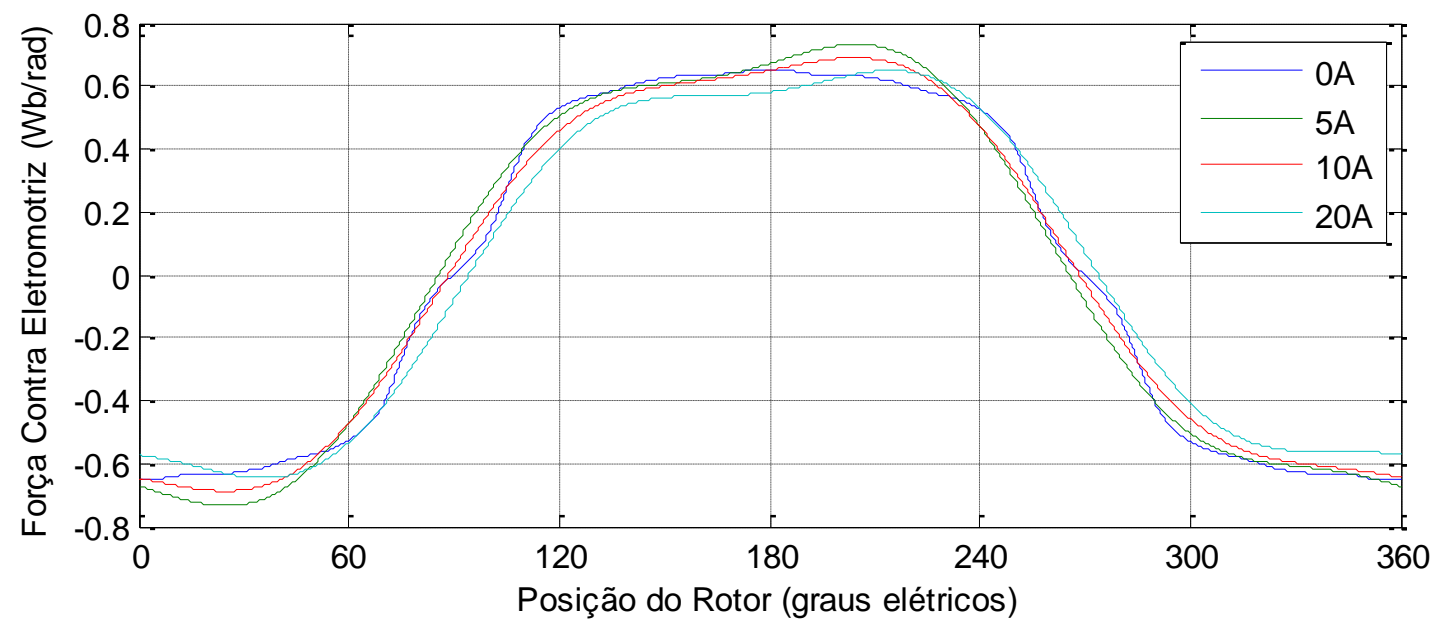

Figura 4.41 - Força Contra Eletromotriz - Método da Composição

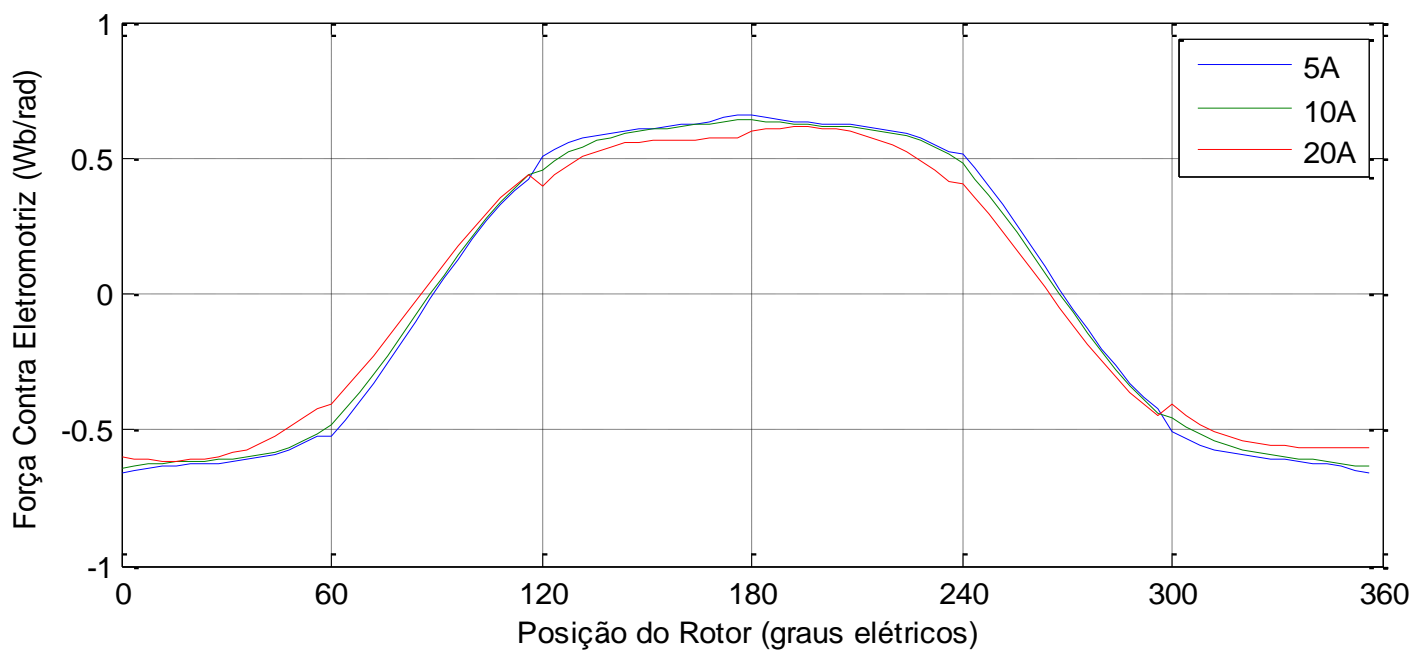

Da mesma forma que foi apresentado para o Caso 1, embora as formas de onda da força contra eletromotriz compostas ilustradas na Figura 4.41 não sejam suaves e contínuas em torno dos pontos de comutação ( $0^{\circ}, 60^{\circ}, 120^{\circ}, 180^{\circ}, 240^{\circ}, 300^{\circ}$ e $360^{\circ}$ elétricos), estas formas de onda são parcialmente suaves se observadas dentro dos intervalos de $60^{\circ}$ elétricos, contornando parcialmente o problema apresentado em [6], [12] e melhorando consideravelmente o cálculo do torque mútuo.

Aplicando-se o Método dos Tensores para a obtenção da força contra eletromotriz, obtém-se as formas de onda para as condições de carregamento de 5, 10 e 20A conforme ilustra a Figura 4.42.

Tomando-se por base as formas de onda da corrente de armadura apresentadas na Figura 4.3 e as formas de onda das forças contra eletromotrizes para as condições de carregamento simuladas, obtém-se as formas de onda do torque mútuo, sendo as mesmas com- 
paradas com as formas de onda do torque eletromagnético $\left(T_{E L}\right)$ para cada uma das condições, como ilustradas nas Figura 4.43 a Figura 4.45.

Figura 4.42 - Força Contra Eletromotriz - Método dos Tensores

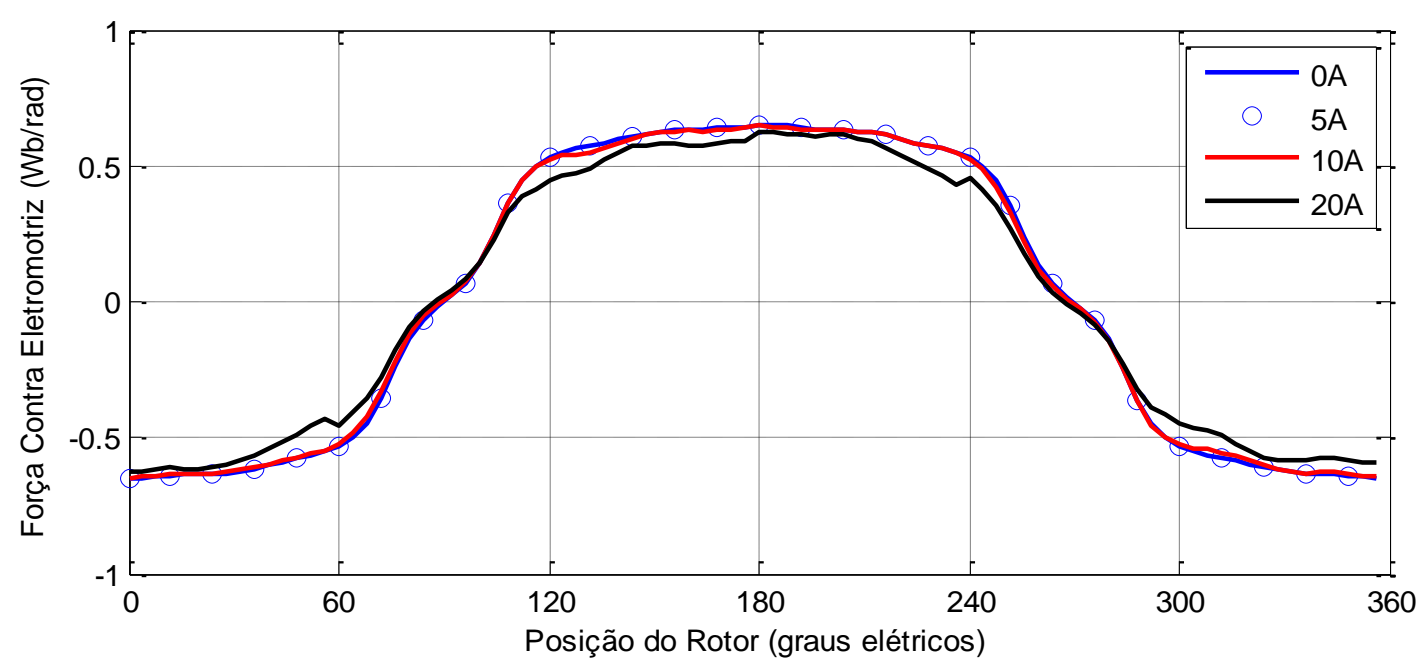

Figura 4.43 - Torque Mútuo v.s. $T_{E L}$ (Carregamento de 5A)

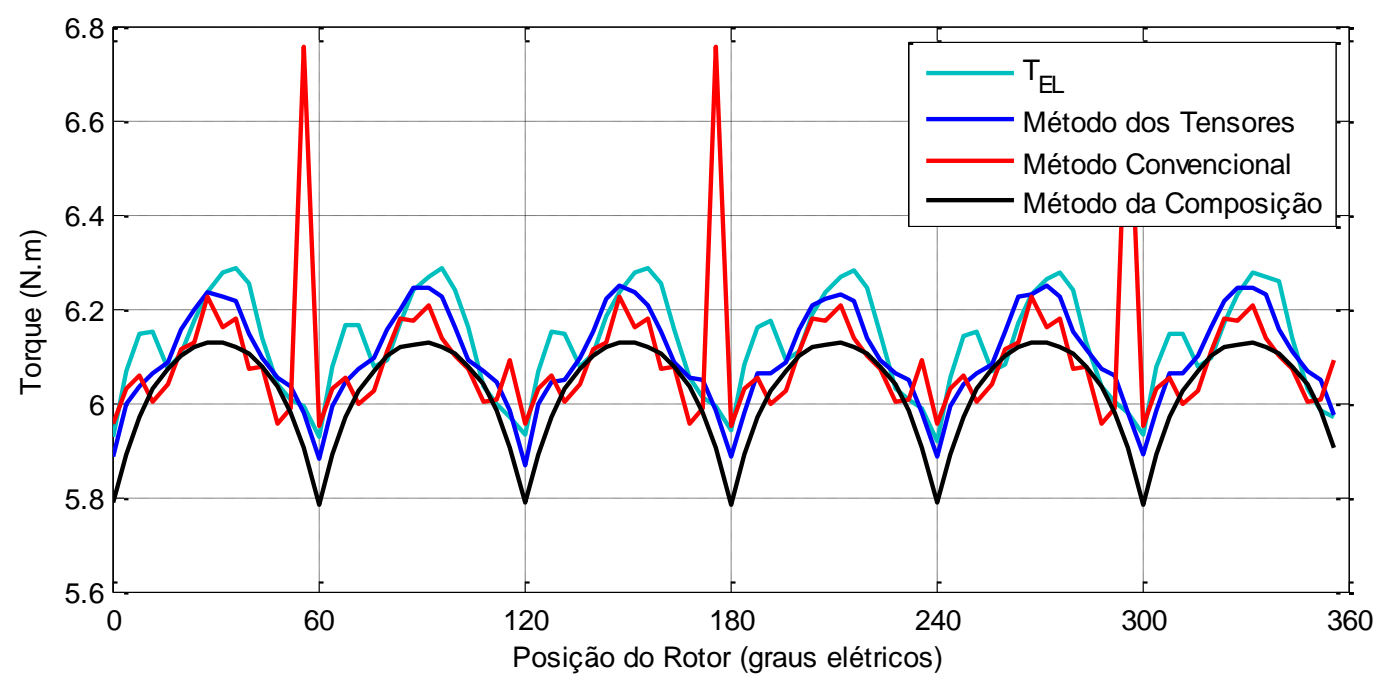

Figura 4.44 - Torque Mútuo v.s. $T_{E L}$ (Carregamento de 10A)

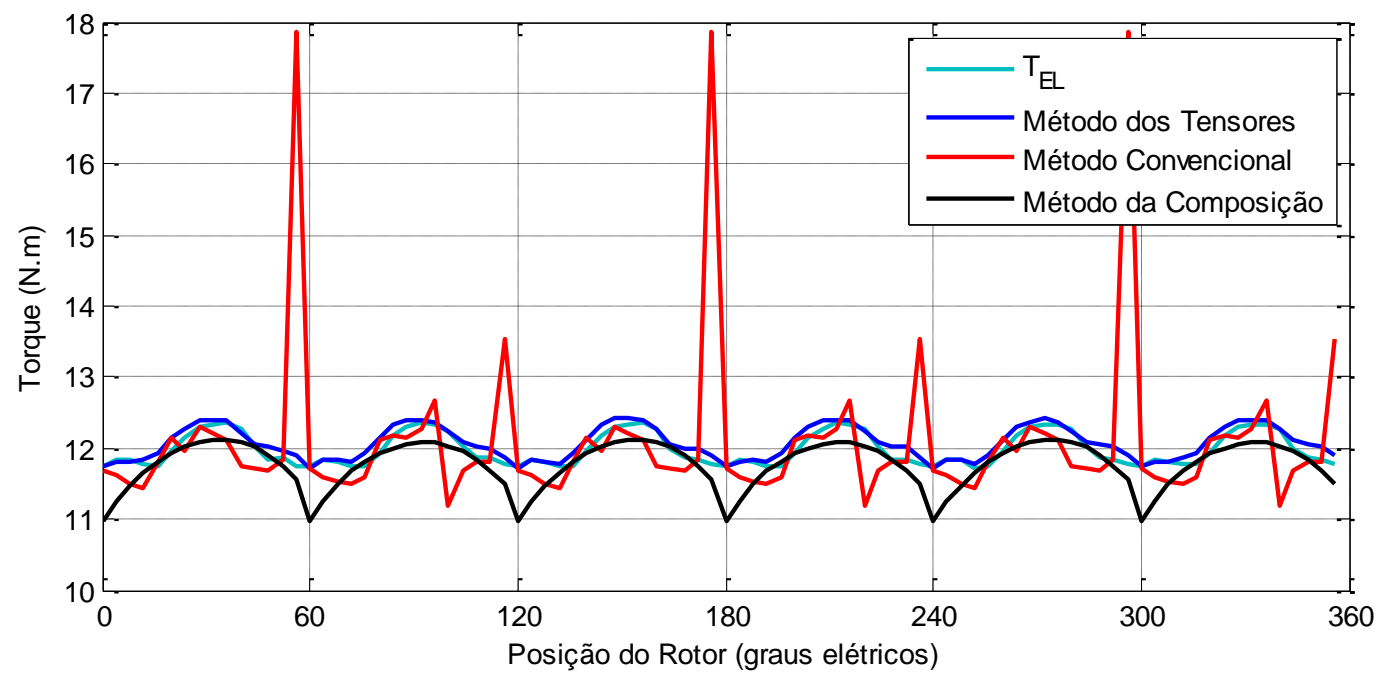


Figura 4.45 - Torque Mútuo v.s. $T_{E L}$ (Carregamento de 20A)

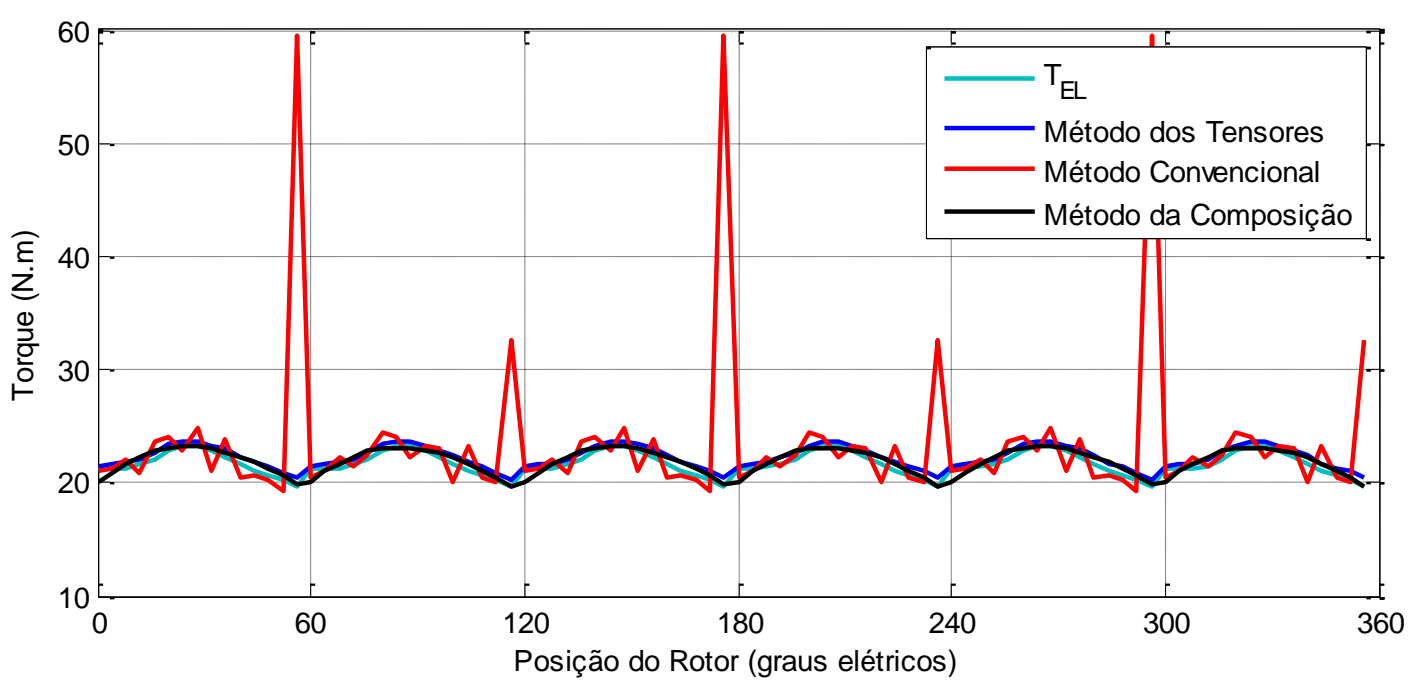

As formas de onda do torque de borda para as condições de carregamento de 5, $10 \mathrm{e}$ 20A são apresentadas nas Figuras 4.46 a 4.48. Os valores máximo, mínimo, médio e a razão entre o valor absoluto do torque de borda e a corrente de armadura são apresentados na Tabela 4.5, assim como o valor de amplitude deste torque. Como pode ser notado, os valores médios desta parcela do torque e suas amplitudes para as duas condições de carregamento aumentam à medida que o carregamento aumenta.

No caso sob investigação, a frequência fundamental de oscilação do torque de borda continuou em 12 vezes a frequência fundamental de uma revolução elétrica até o carregamento de 10A. Quando a máquina passa dessa condição de carregamento e atinge o carregamento de 20A, as frequências de oscilação do Torque de Borda mudam, tendo como frequência base 6 vezes a frequência fundamental de uma revolução elétrica, como ilustra a Figura 4.49 .

Assim como no Caso 1, os valores médios de torque de borda são diferentes de zero e aumentam ao passo que o carregamento eletromagnético da máquina aumenta.

Tabela 4.5 - Torque de Borda

\begin{tabular}{ccccc}
\cline { 2 - 5 } & Vazio & 05A & 10A & 20A \\
\hline \hline Máximo $(\mathrm{mNm})$ & 70 & 61 & 3 & -98 \\
Mínimo $(\mathrm{mNm})$ & -70 & -95 & -222 & -538 \\
\hline $\begin{array}{c}\text { Médio }(\mathrm{mNm}) \\
\text { |Torque|/Corrente } \\
(\mathbf{m N m} / \mathbf{A})\end{array}$ & 0 & -16 & -100 & -350 \\
$\begin{array}{c}\text { Amplitude } \\
(\mathbf{m N m} / \mathbf{A})\end{array}$ & 70 & 78 & 110 & 220 \\
\hline \hline
\end{tabular}


Figura 4.46 - Torque de Borda (Carregamento de 5A)

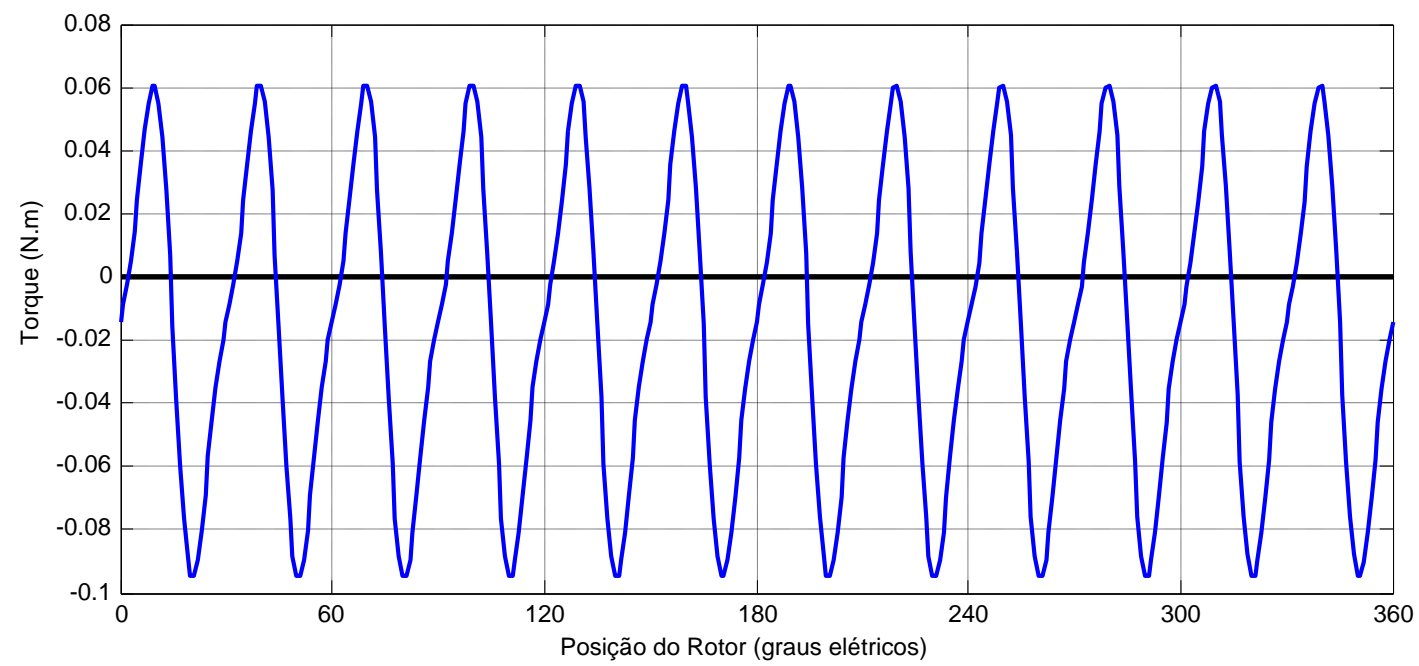

Figura 4.47 - Torque de Borda (Carregamento de 10A)

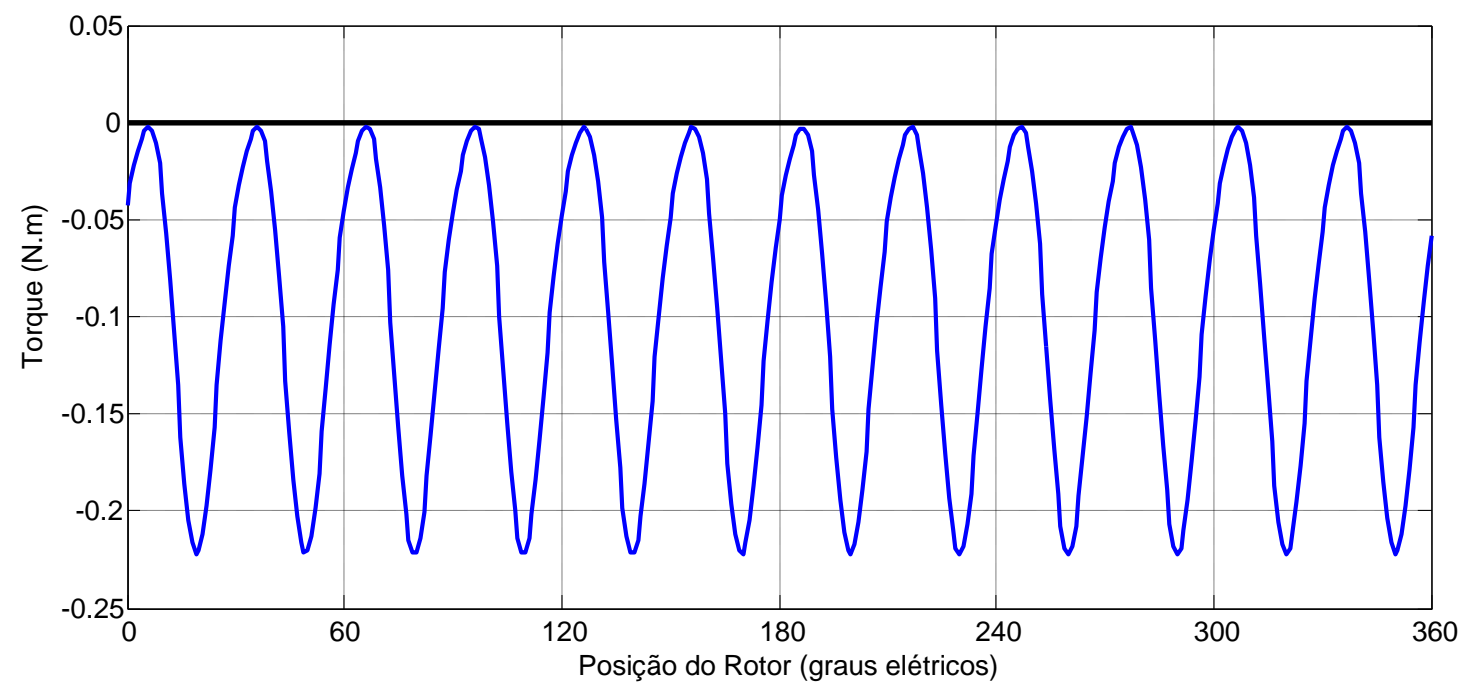

Figura 4.48 - Torque de Borda (Carregamento de 20A)

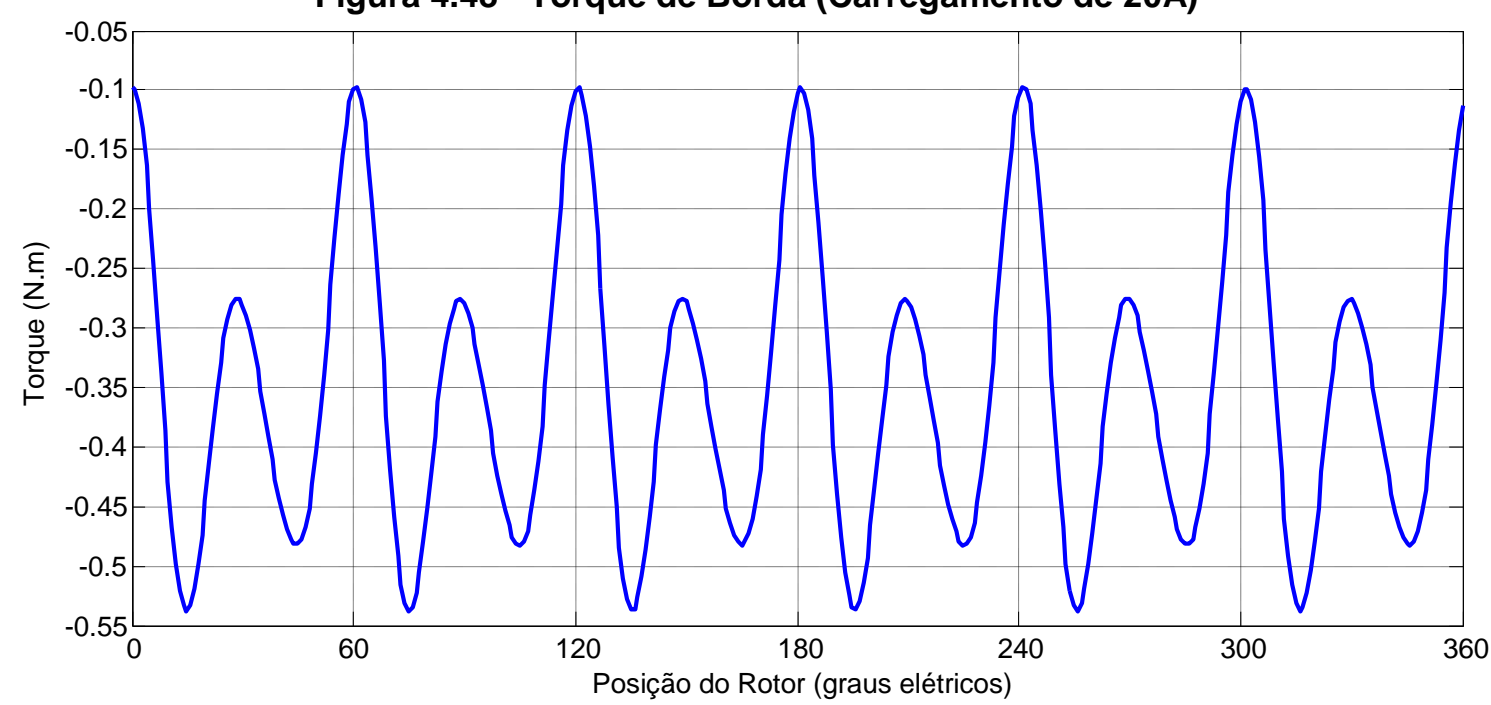


Figura 4.49 - Amplitude e Frequência do Torque de Borda

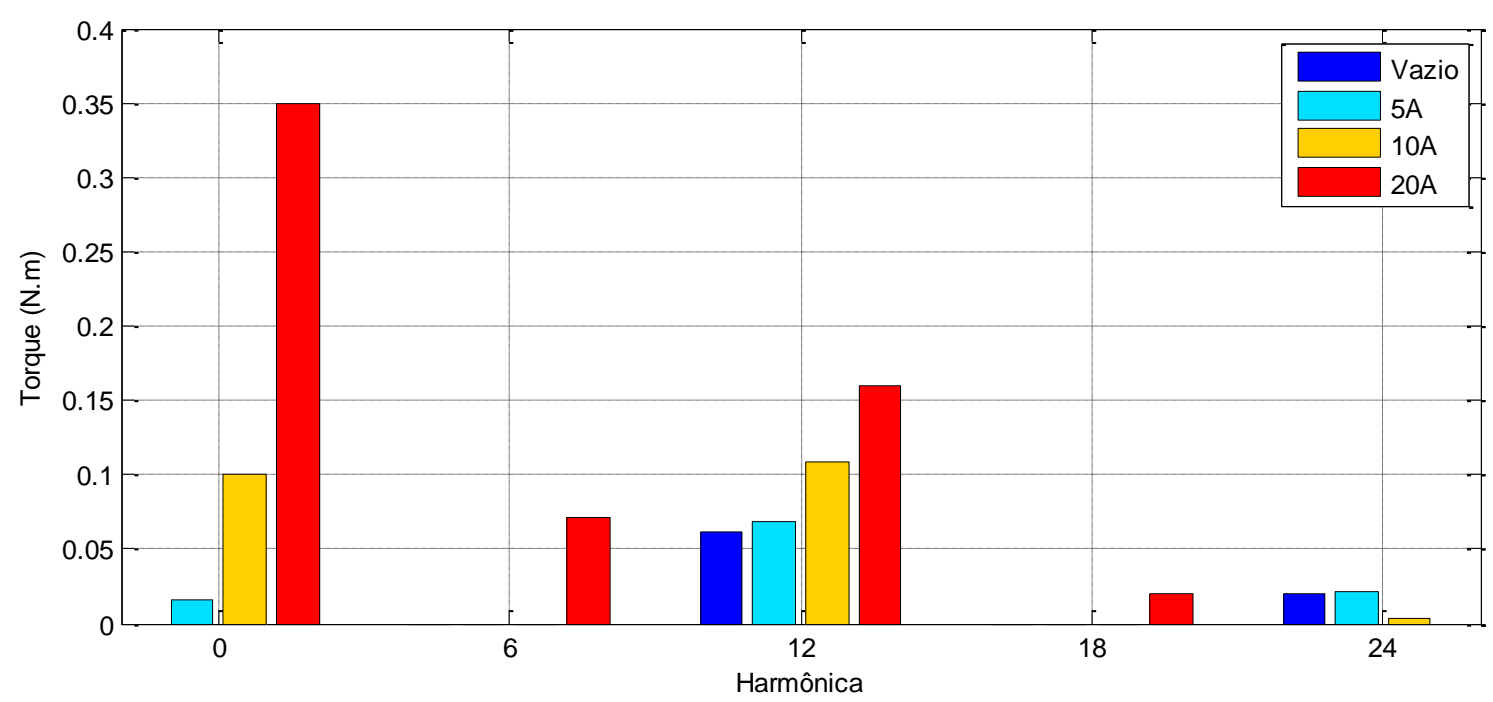

As formas de onda da indutância de linha para as condições de carregamento simuladas são apresentadas na Figura 4.50. Ao se observar essas formas de onda é possível presumir que o torque de relutância para a condição de carregamento de $5 \mathrm{~A}$ é baixa e próxima a $54 \mathrm{mH}$. Já para as condições de 10 e $20 \mathrm{~A}$, a indutância apresenta uma periodicidade de $60^{\circ}$ elétricos (seguindo a mesma periodicidade da alimentação e comutação das fases) e sua variação pico a pico é considerável, contribuindo, portanto, para o surgimento de um torque de relutância.

As Figuras 4.51 a 4.53 ilustram as formas de onda do torque de relutância para as condições de carregamento de 5, 10 e 20A. A Tabela 4.6 apresenta os valores máximo, mínimo, médio de torque e a razão entre o valor absoluto do torque de relutância e a corrente de armadura. É mostrada também, a razão entre a amplitude do torque de relutância e a corrente de armadura.

Figura 4.50 - Indutância de Linha Vista pelo Inversor

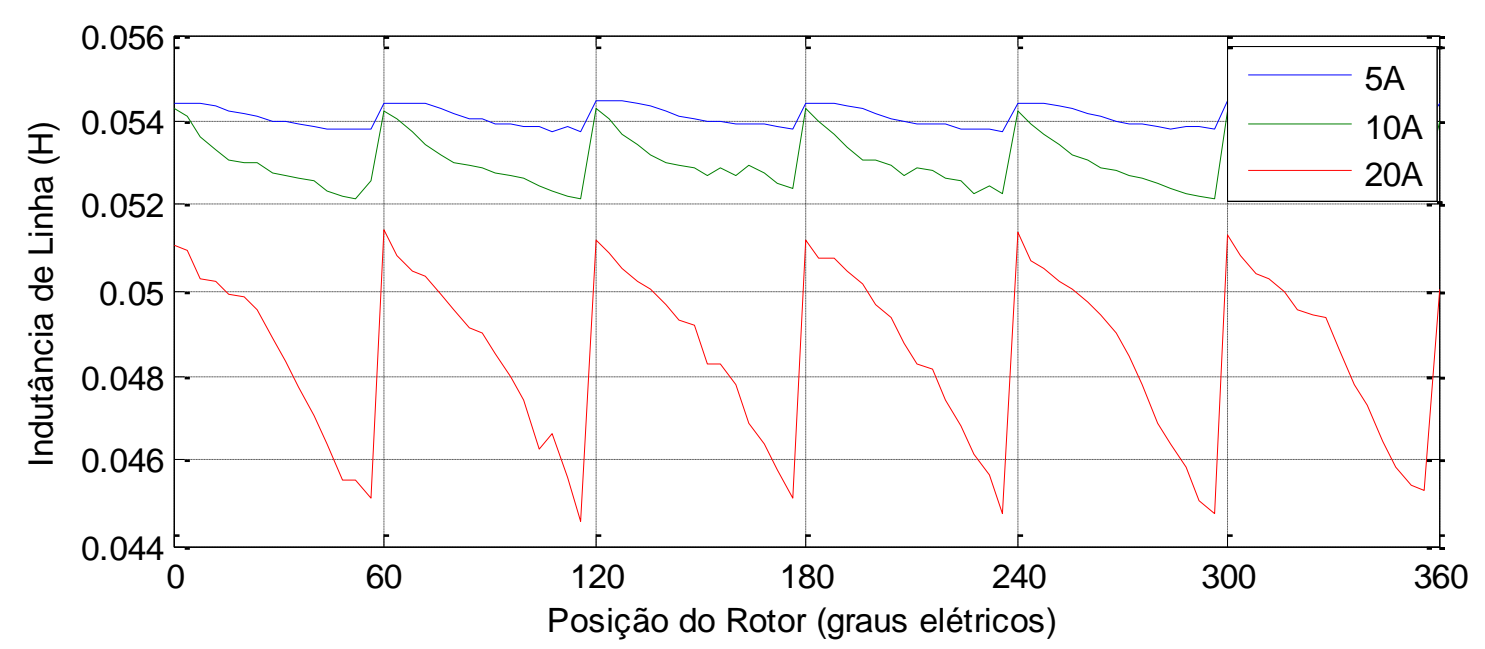


Figura 4.51 - Torque de Relutância (Carregamento de 5A)

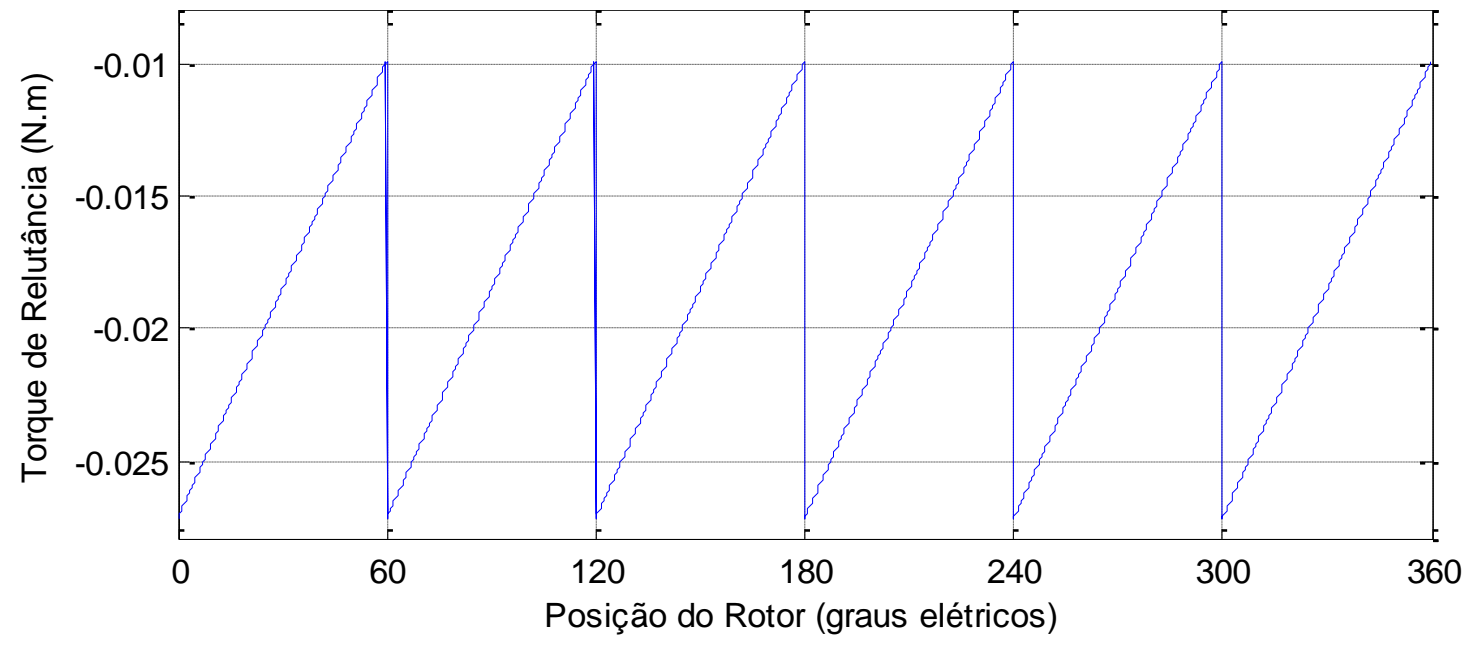

Figura 4.52 - Torque de Relutância (Carregamento de 10A)

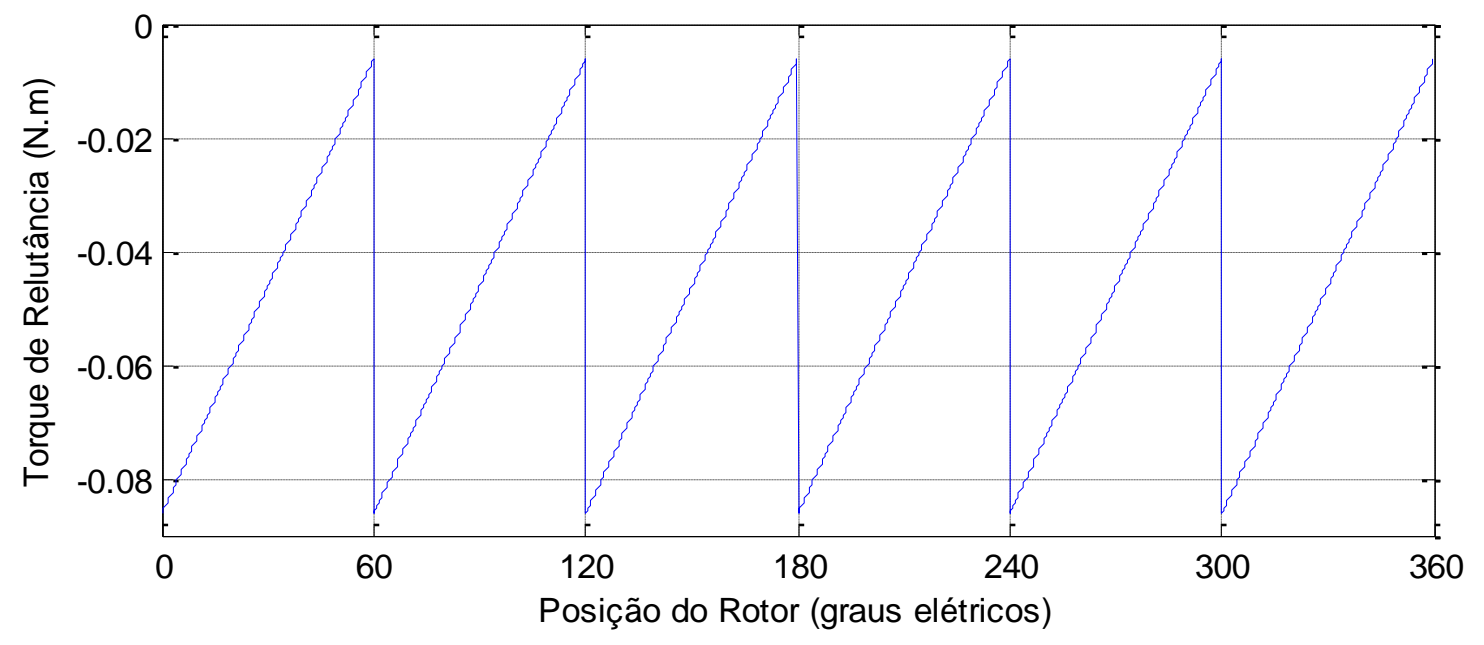

Figura 4.53 - Torque de Relutância (Carregamento de 20A)

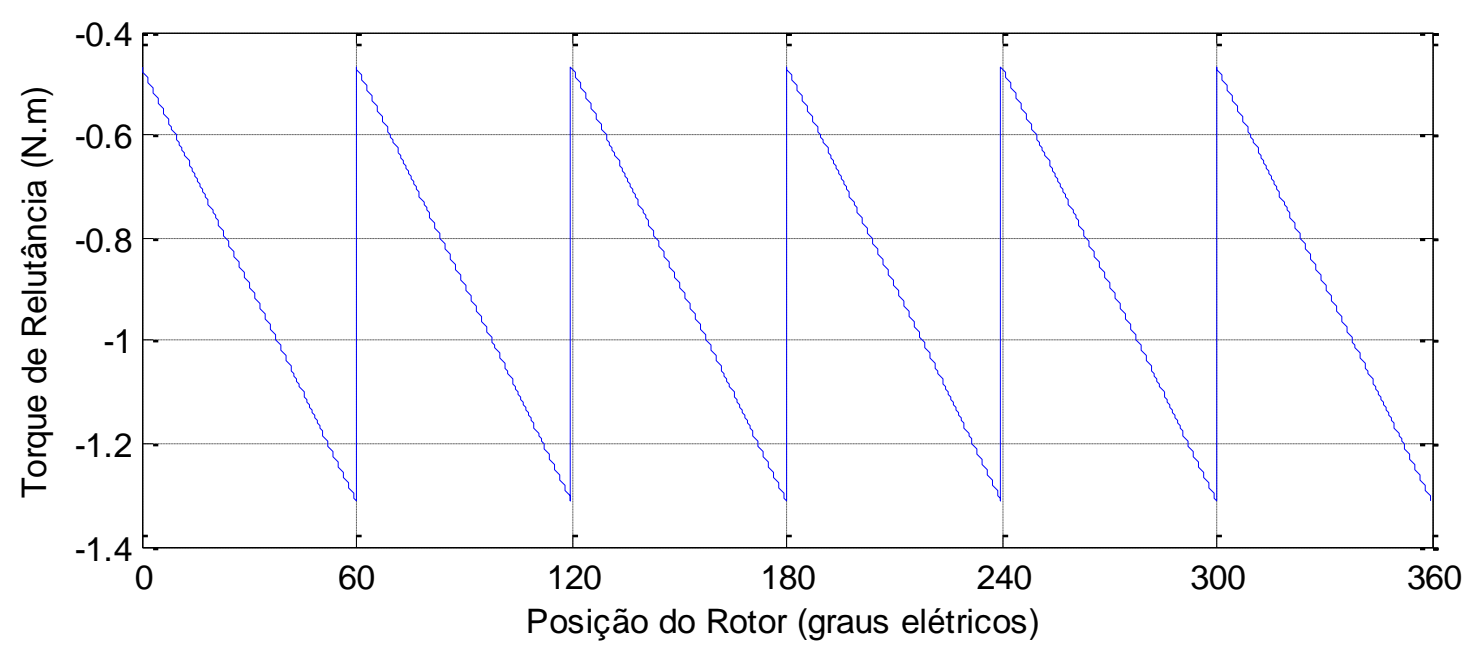


Tabela 4.6 - Torque de Relutância ( $\left.T_{\text {Relutancia }}\right)$

\begin{tabular}{cccc}
\cline { 2 - 4 } & 05A & 10A & 20A \\
\hline \hline Máximo $(\mathbf{m N m})$ & $-9,9$ & $-6,3$ & -468 \\
Mínimo $(\mathbf{m N m})$ & $-27,1$ & $-86,3$ & -1309 \\
Médio $(\mathbf{m N m})$ & $-18,5$ & $-46,3$ & -889 \\
\hline Amplitude $(\mathbf{m N m})$ & 17,3 & 80 & 841 \\
\hline $\begin{array}{c}\text { Torque } / / \text { Corrente } \\
(\mathbf{m N m} / \mathbf{A})\end{array}$ & 3,7 & 4,6 & 44,4 \\
$\begin{array}{c}\text { Amplitude/Corrente } \\
(\mathbf{m N m} / \mathbf{A})\end{array}$ & 3,5 & 8 & 42,1 \\
\hline \hline
\end{tabular}

Como observado, tanto a amplitude da variação da indutância quanto a participação do torque de relutância (o valor absoluto do mesmo) aumentam ao passo que a corrente de armadura aumenta.

A Figura 4.53 demonstra uma mudança no comportamento do torque de relutância para a condição de carregamento de $20 \mathrm{~A}$ quando comparado aos comportamentos do torque de relutância para as condições 5 e 10A de carregamento eletromagnético. Dada a relação direta entre as formas de onda do torque de relutância com as formas de onda da indutância de linha vista pelo inversor, é possível relacionar essa mudança no comportamento do torque de relutância com a mudança de comportamento da curva de indutância de linha vista pelo inversor para a condição de carregamento de 20A, como mostra a Figura 4.50. Na Figura 4.50 , a curva de indutância para a condição de $20 \mathrm{~A}$ apresenta concavidade voltada para baixo dentro de um intervalo de $60^{\circ}$ elétricos, ao contrário das curvas de indutância para as condições de 5 e 10A, que têm concavidade voltada para cima.

As formas de onda do torque resultante da soma $\left(T_{\text {Soma }}\right)$ das parcelas do torque eletromagnético para as condições de carregamento de 5, 10 e 20A, calculadas pelos três métodos, são apresentadas da Figura 4.54 a Figura 4.56.

Novamente, a obtenção da força contra eletromotriz pelo método convencional (cálculo da força contra eletromotriz por meio da derivada do fluxo concatenado) apresenta falhas ao ser utilizado para o cálculo do torque resultante uma vez que, resulta em um pico em torno do ponto de comutação das fases. Pico, este, que não está presente no torque não linear. Reafirmando novamente, a necessidade de um método que contorne este problema e apresente de forma precisa o cálculo da força contra eletromotriz. 
Figura $4.54-T_{E L} v s T_{\text {Soma }}$ (Carregamento de 5A)

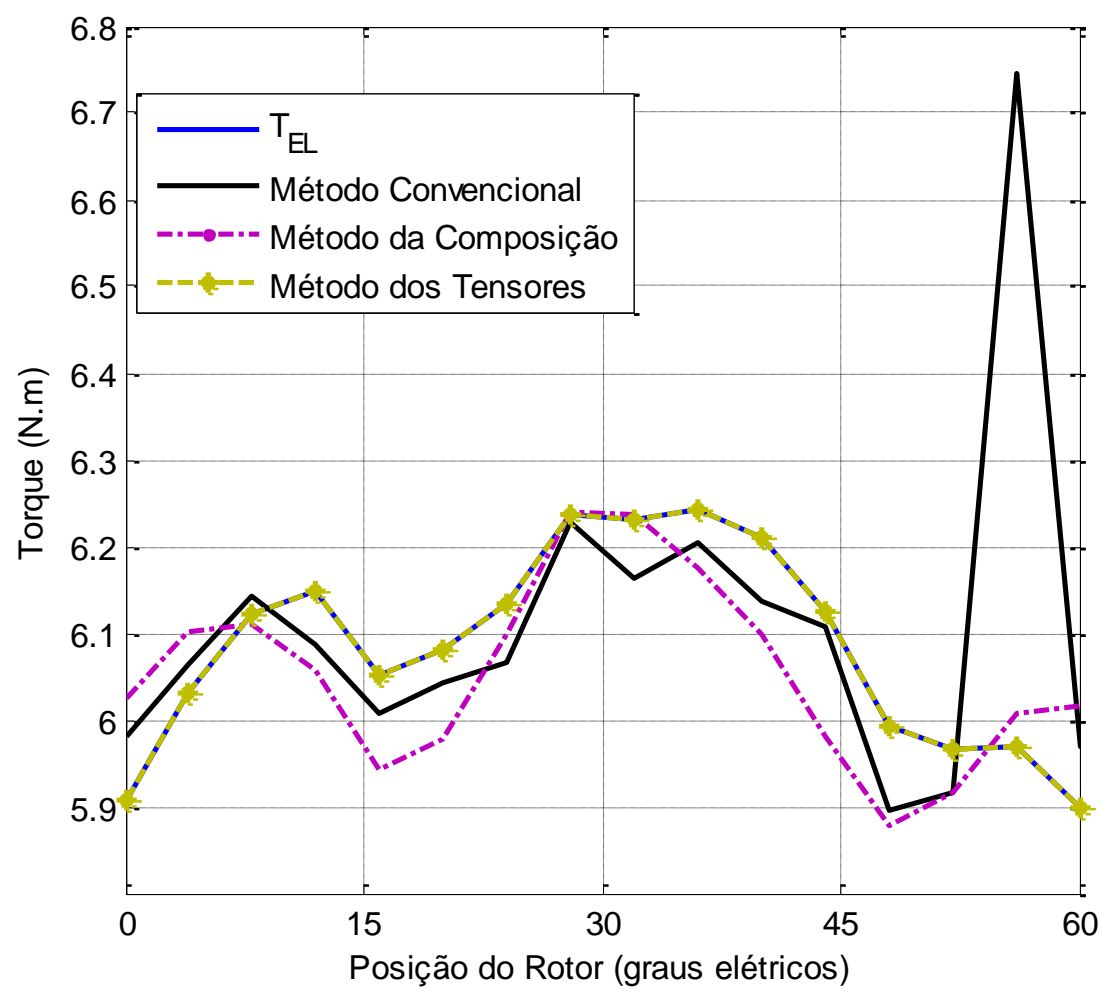

Figura 4.55 - $T_{E L} v s T_{\text {Soma }}$ (Carregamento de 10A)

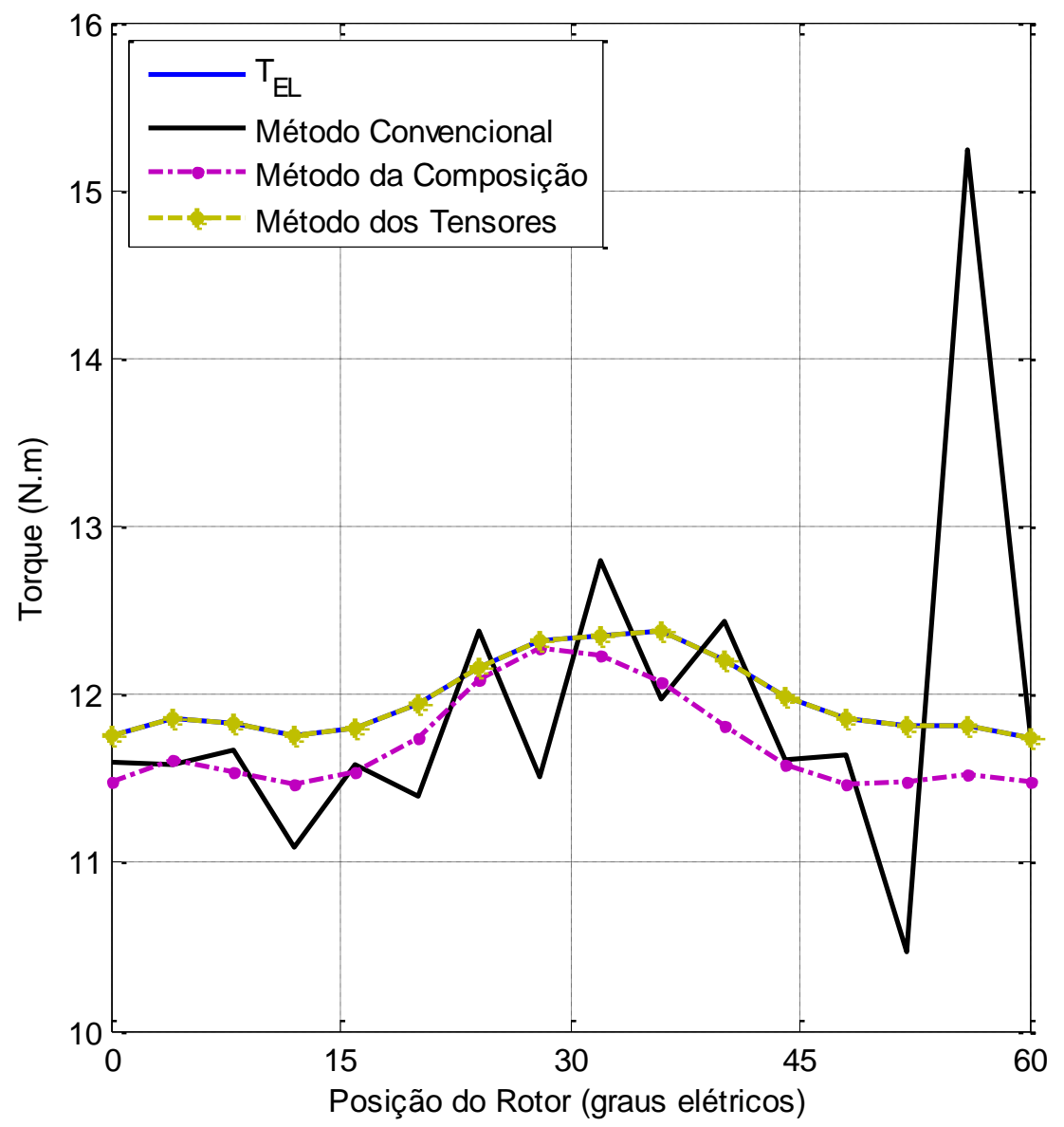


Figura $4.56-T_{E L} v S T_{\text {Soma }}$ (Carregamento de 20A)

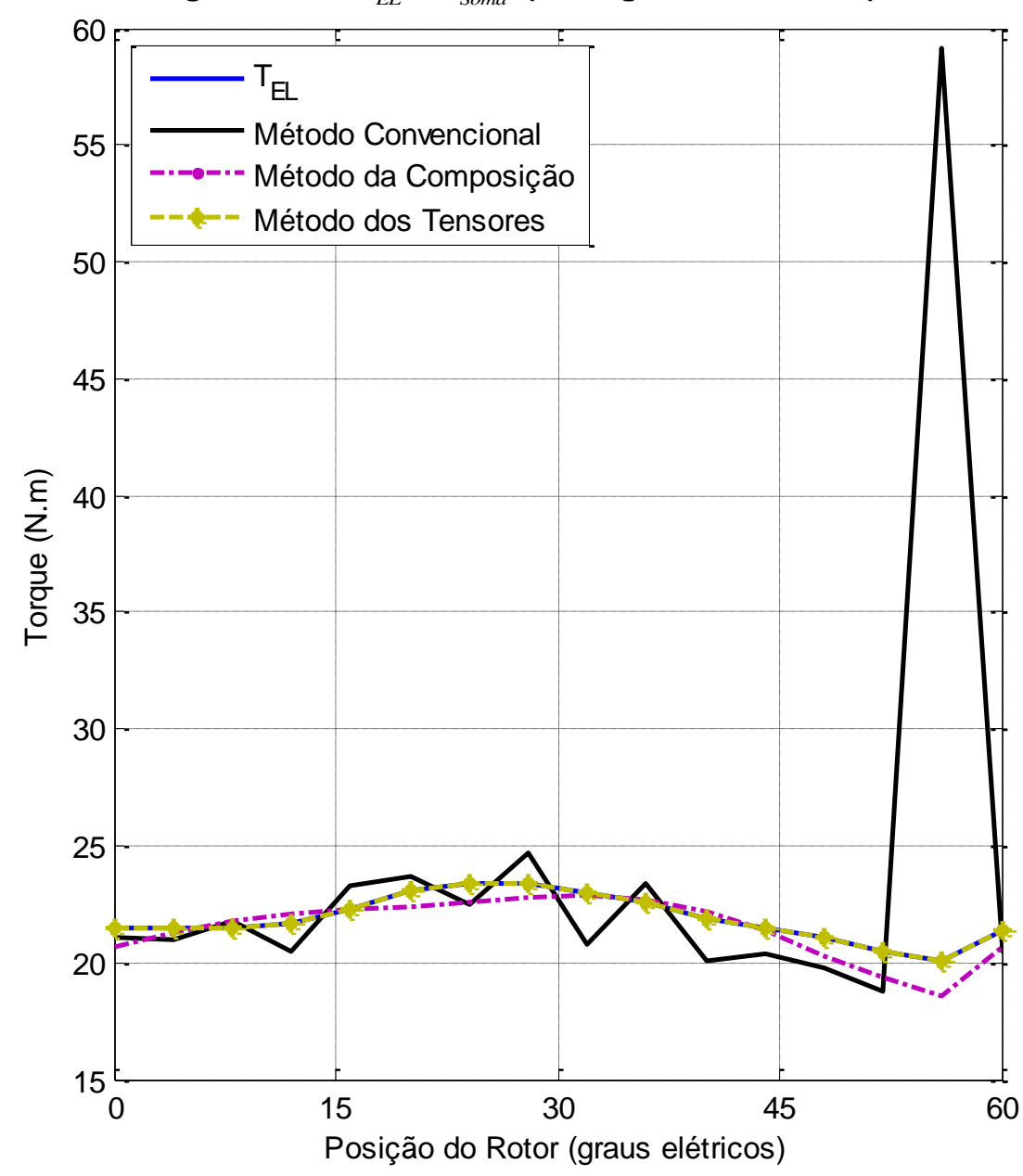

\subsection{Caso 3}

Aqui são apresentados os resultados referentes ao emprego dos métodos para obtenção da força contra eletromotriz para o estudo de caso 3. Como mencionado, este caso é uma modificação que mostra uma condição diferente para se avaliar o método de obtenção da força contra eletromotriz, já que nesta configuração de rotor têm-se torque de relutância considerável, além do torque de borda como característica intrínseca. Criando assim, um cenário mais 'ruidoso', como mencionado. Para este caso, são avaliados apenas dados simulados para as condições de $50 \%, 100 \%$ e $200 \%$ de carregamento.

\subsubsection{Condição em Vazio (OA)}

As formas de onda de fluxo magnético concatenado com a fase $A$, força contra eletromotriz da fase A e torque de borda para a operação em vazio são mostradas da Figura 4.57 
a Figura 4.59 .

Figura 4.57 - Fluxo Magnético Concatenado (Operação em vazio)

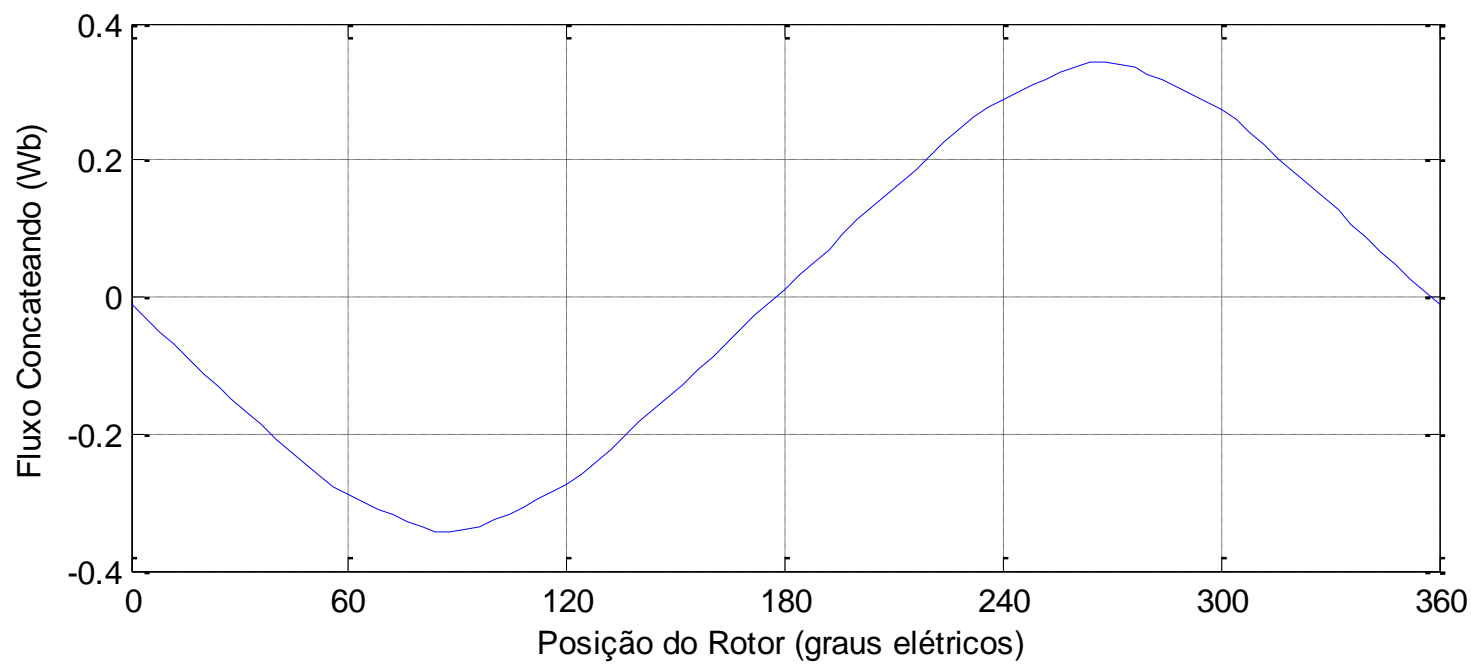

Figura 4.58 - Força Contra Eletromotriz (Operação em Vazio)

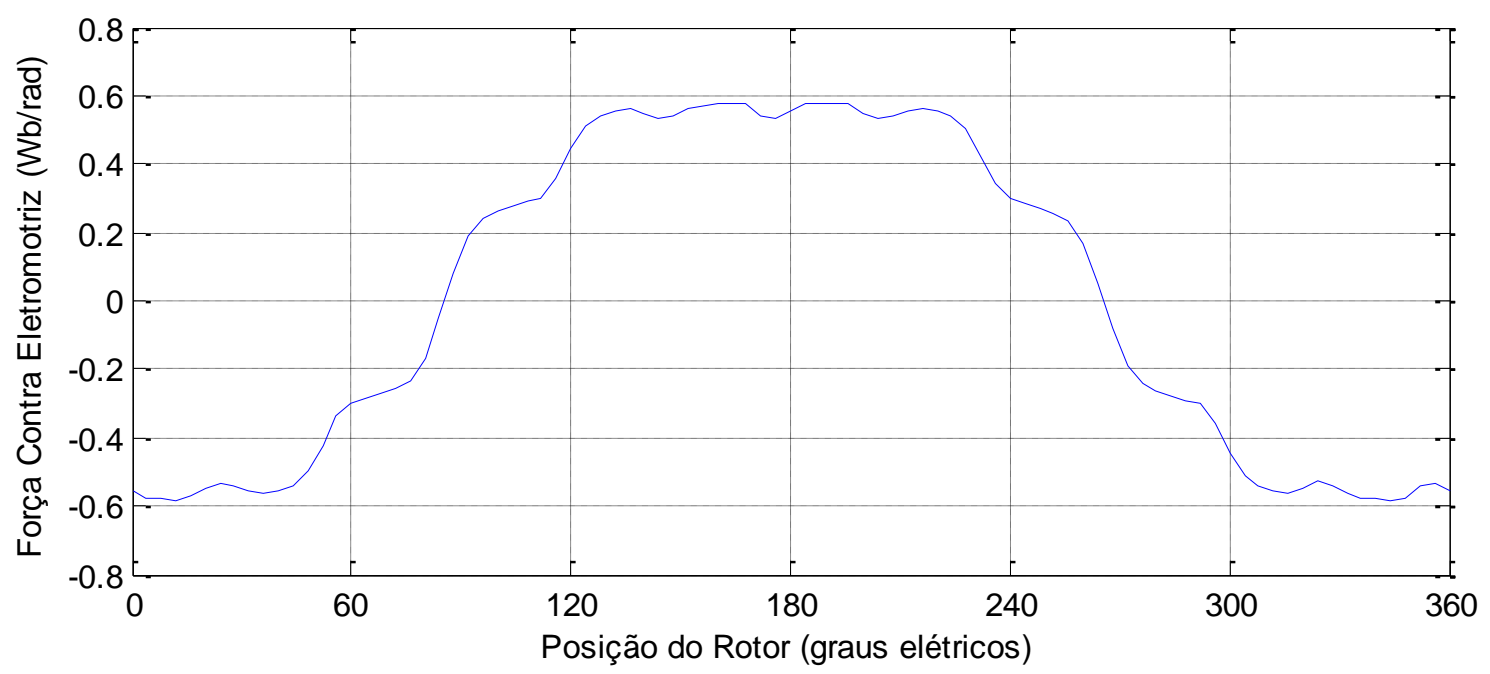

Figura 4.59 - Torque de Borda (Operação em vazio)

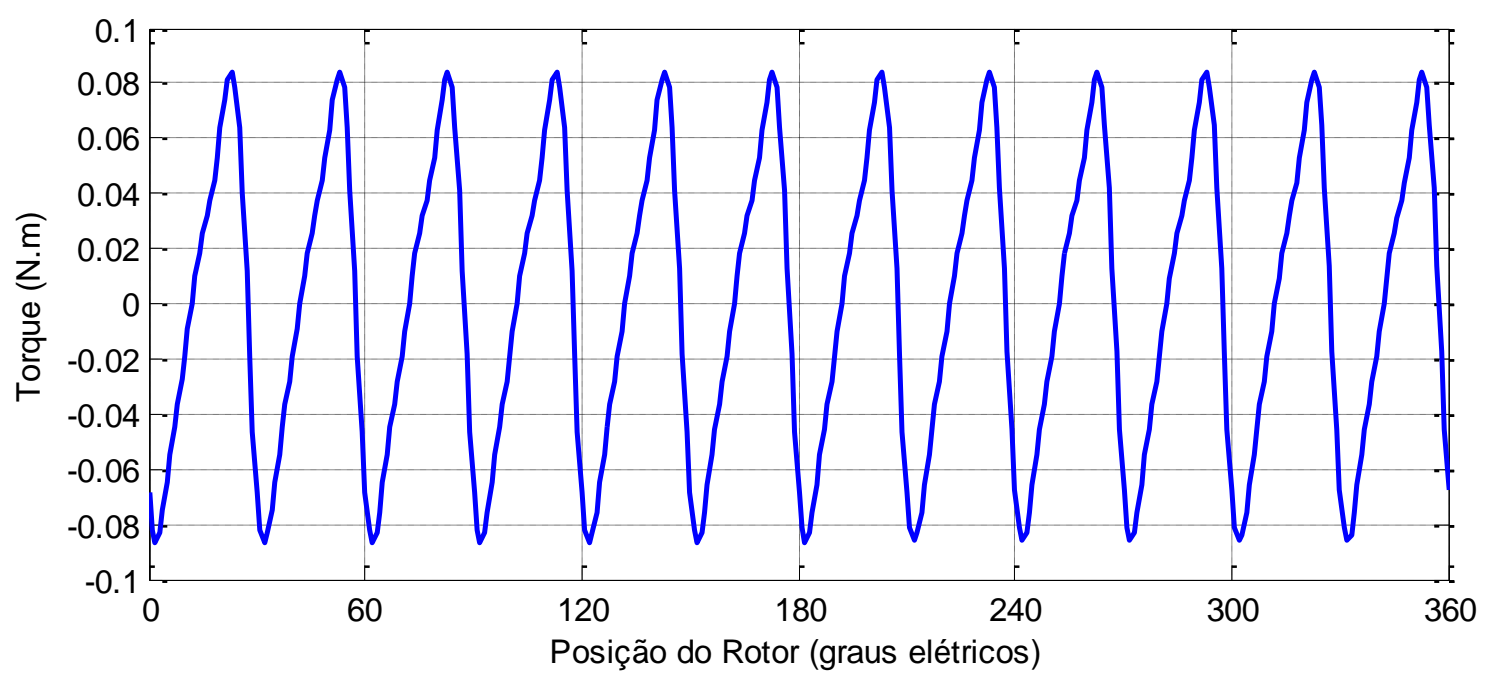




\subsubsection{Condição em Carregamento}

As formas de onda do fluxo magnético concatenado para a fase $A$ nas condições de carregamento de 5, 10 e 20A são ilustradas na Figura 4.60.

Figura 4.60 - Fluxo Magnético Concatenado (Carregamentos de 5, 10 e 20A)

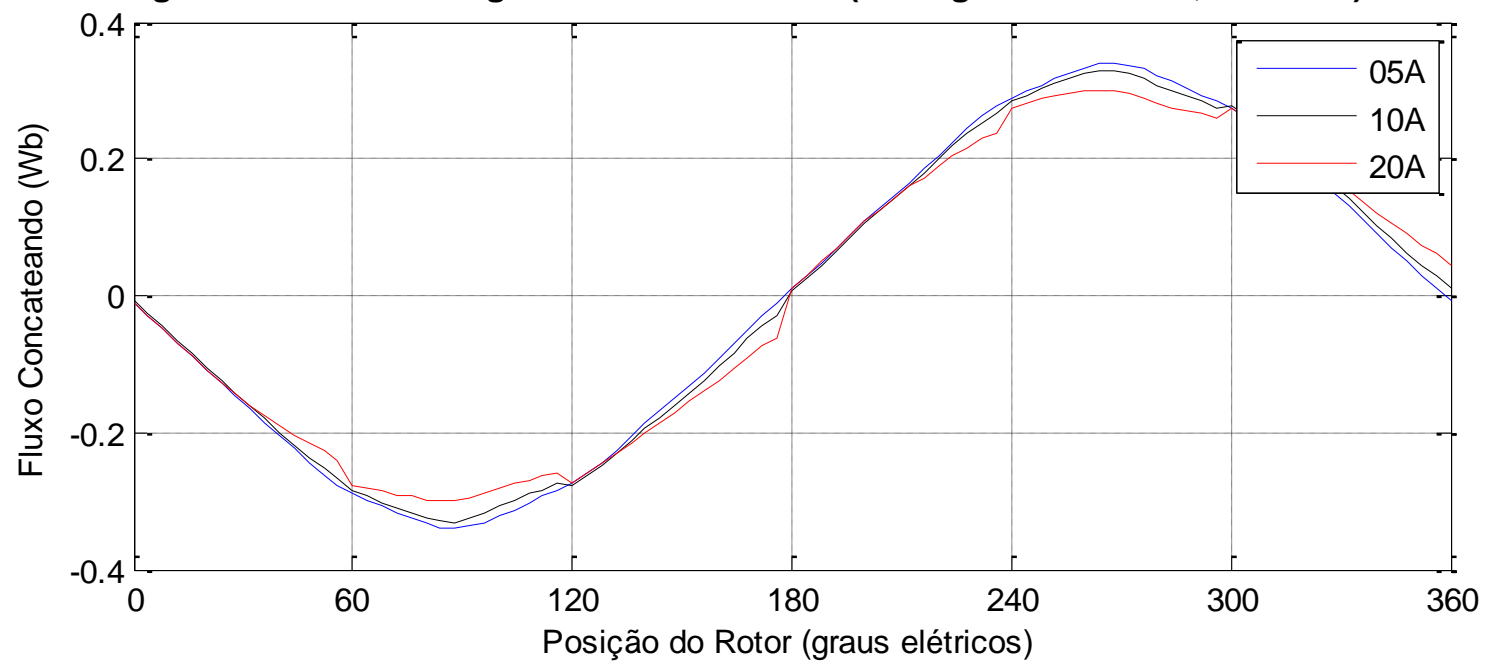

Valendo-se da aplicação da derivada sobre as formas de onda do fluxo magnético concatenado por fase (Método Convencional) apresentadas na Figura 4.57, são obtidas e apresentadas na Figura 4.61 as forças contra eletromotrizes.

As três componentes resultantes da decomposição da forma de onda de fluxo magnético concatenado para a fase A são ilustradas nas Figuras 4.62 a 4.64, para as condições de carregamento eletromagnético de 5, 10 e $20 \mathrm{~A}$.

Figura 4.61 - Força Contra Eletromotriz - Método Convencional

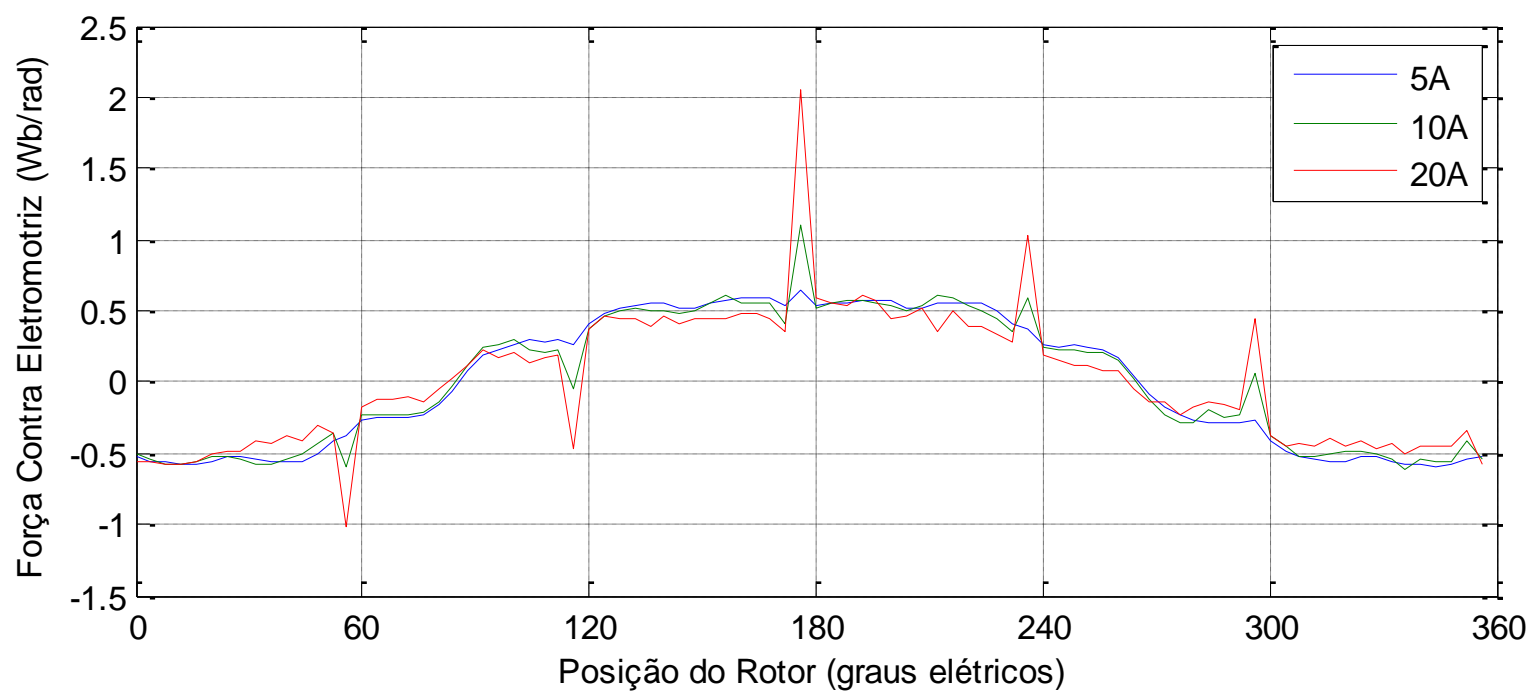


Figura 4.62 - Componentes do Fluxo Magnético (Carregamento de 5A)

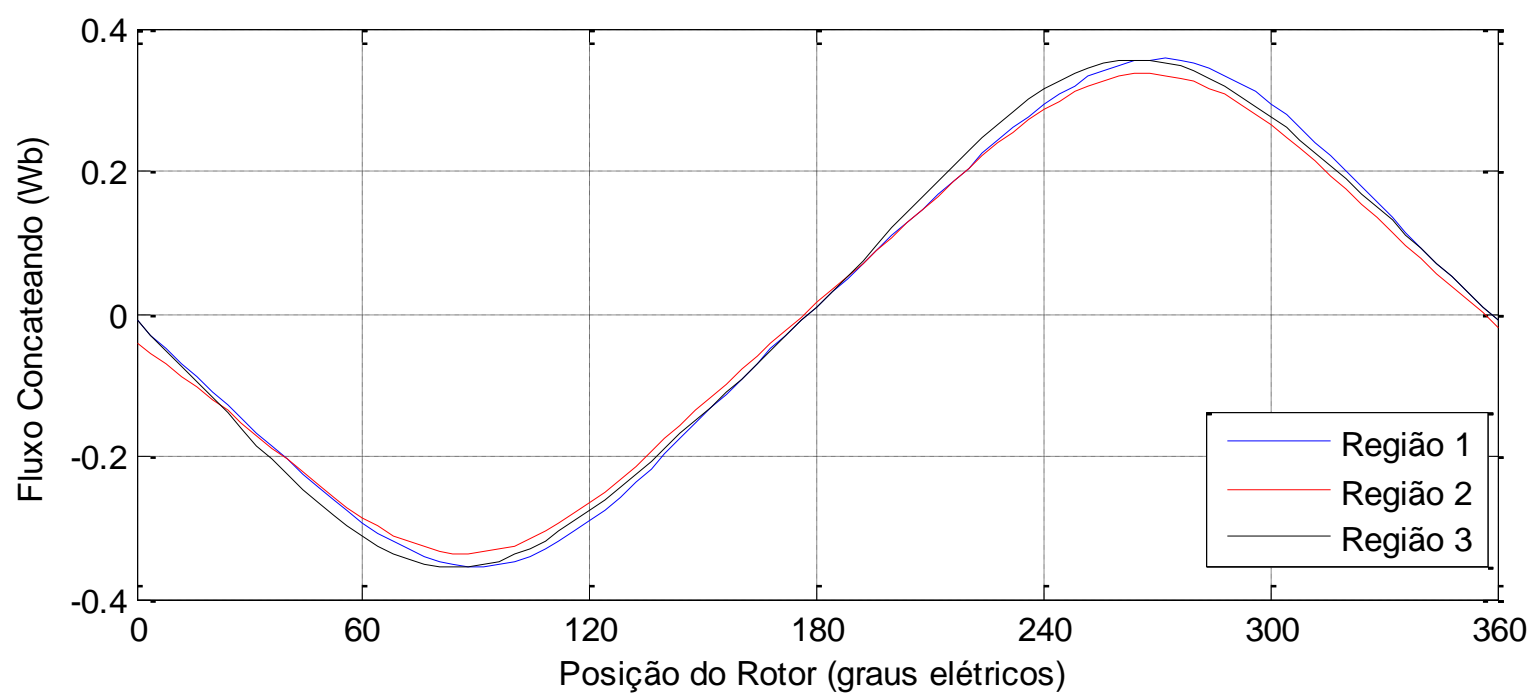

Figura 4.63 - Componentes do Fluxo Magnético (Carregamento de 10A)

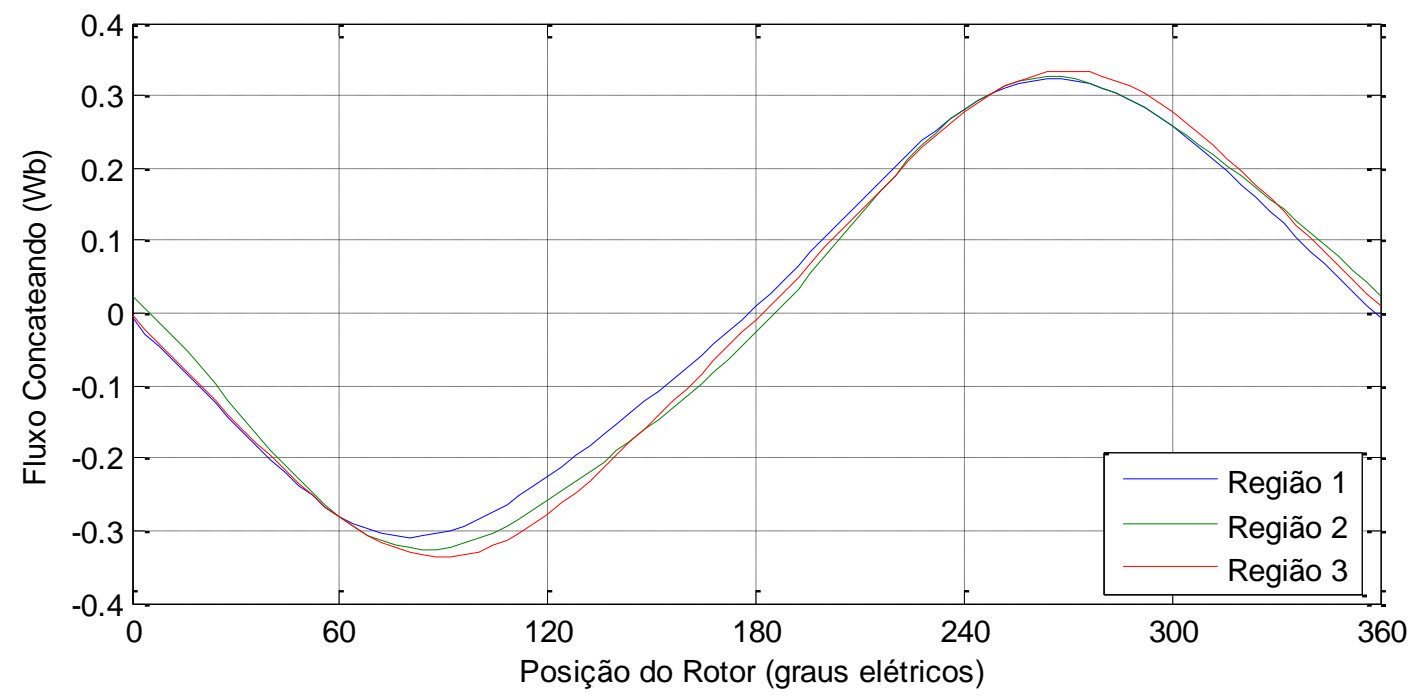

Figura 4.64 - Componentes do Fluxo Magnético (Carregamento de 20A)

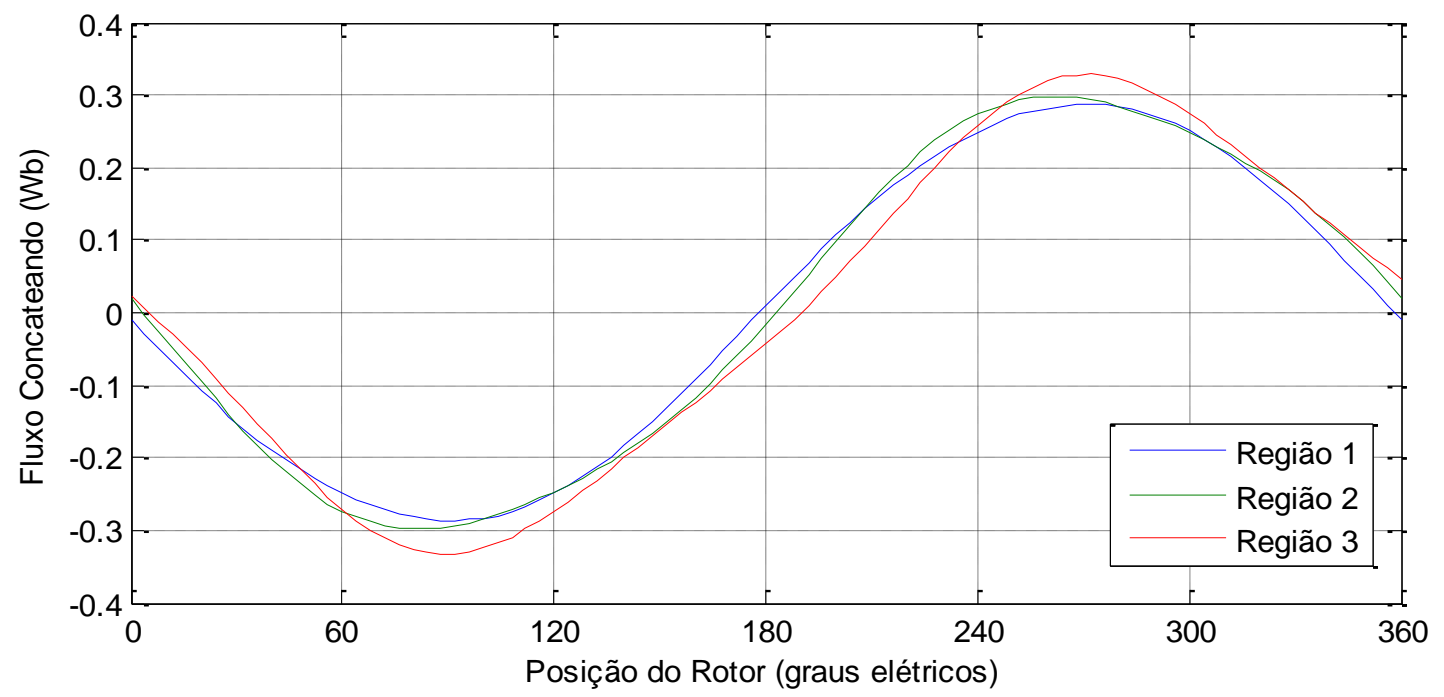


A partir dos resultados obtidos com a decomposição do fluxo magnético concatenado para a fase A, emprega-se a operação derivada nas regiões de fluxo magnético e são obtidas as formas de onda das forças contra eletromotrizes de cada região como ilustrado das Figuras 4.65 a 4.67. Em seguida, compõe-se as formas de onda de força contra eletromotriz para as condições de carregamento eletromagnético de 5, 10 e $20 \mathrm{~A}$.

As formas de onda da força contra eletromotriz composta para as condições de carregamento eletromagnético de 5, 10 e 20A são apresentadas na Figura 4.68.

Aplicando-se o Método dos Tensores para a obtenção da força contra eletromotriz, obtém-se as formas de onda para as condições de carregamento de 5, 10 e 20A conforme ilustra a Figura 4.69.

Figura 4.65 - Região 1: Componentes da Força Contra Eletromotriz

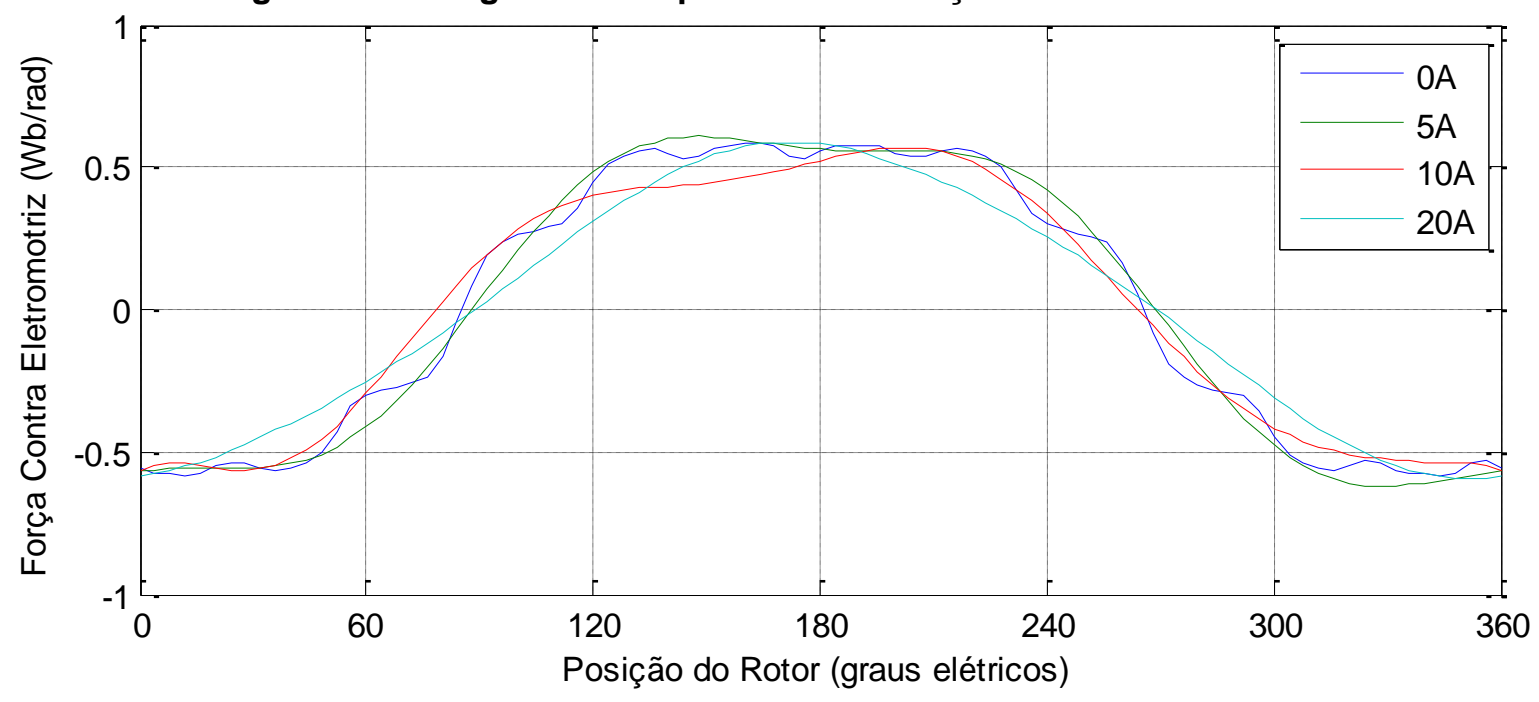

Figura 4.66 - Região 2: Componentes da Força Contra Eletromotriz

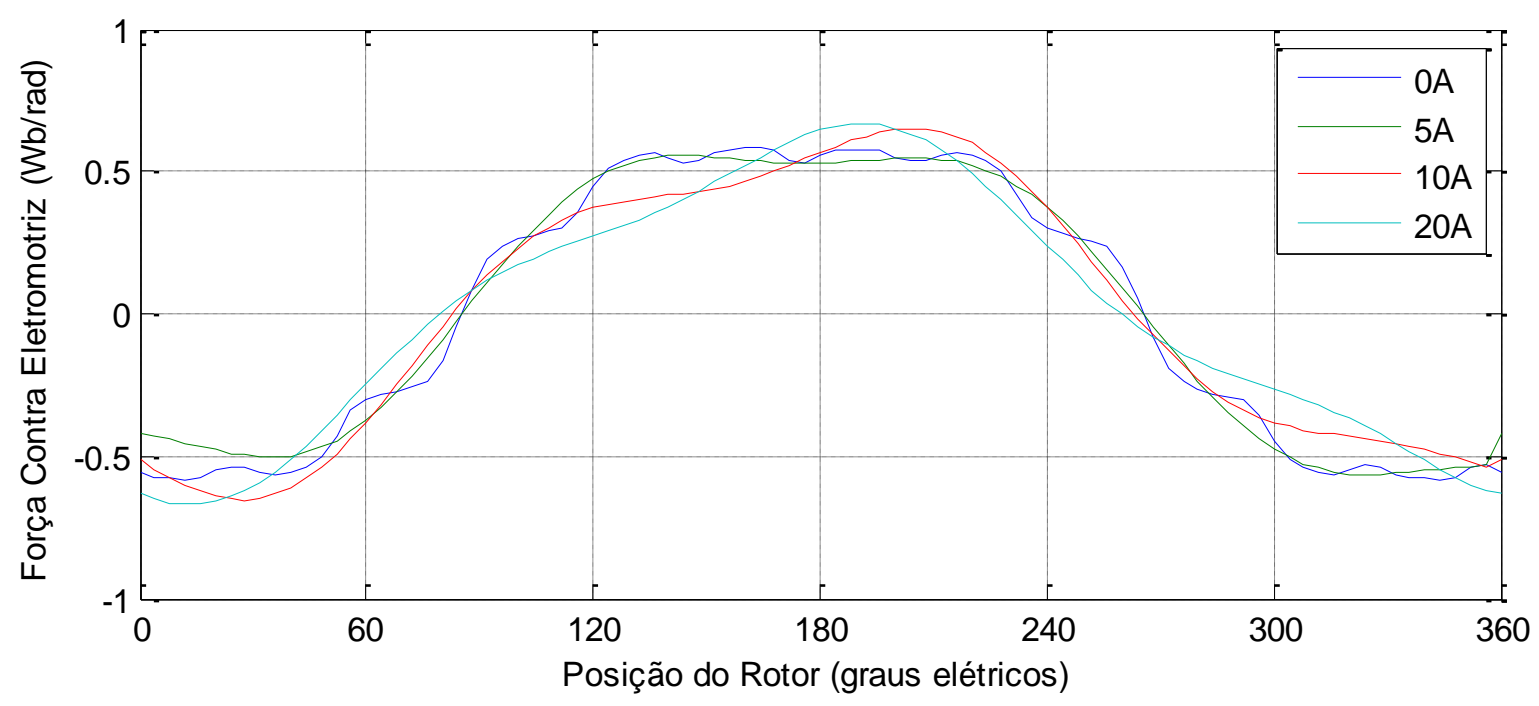


Figura 4.67 - Região 3: Componentes da Força Contra Eletromotriz

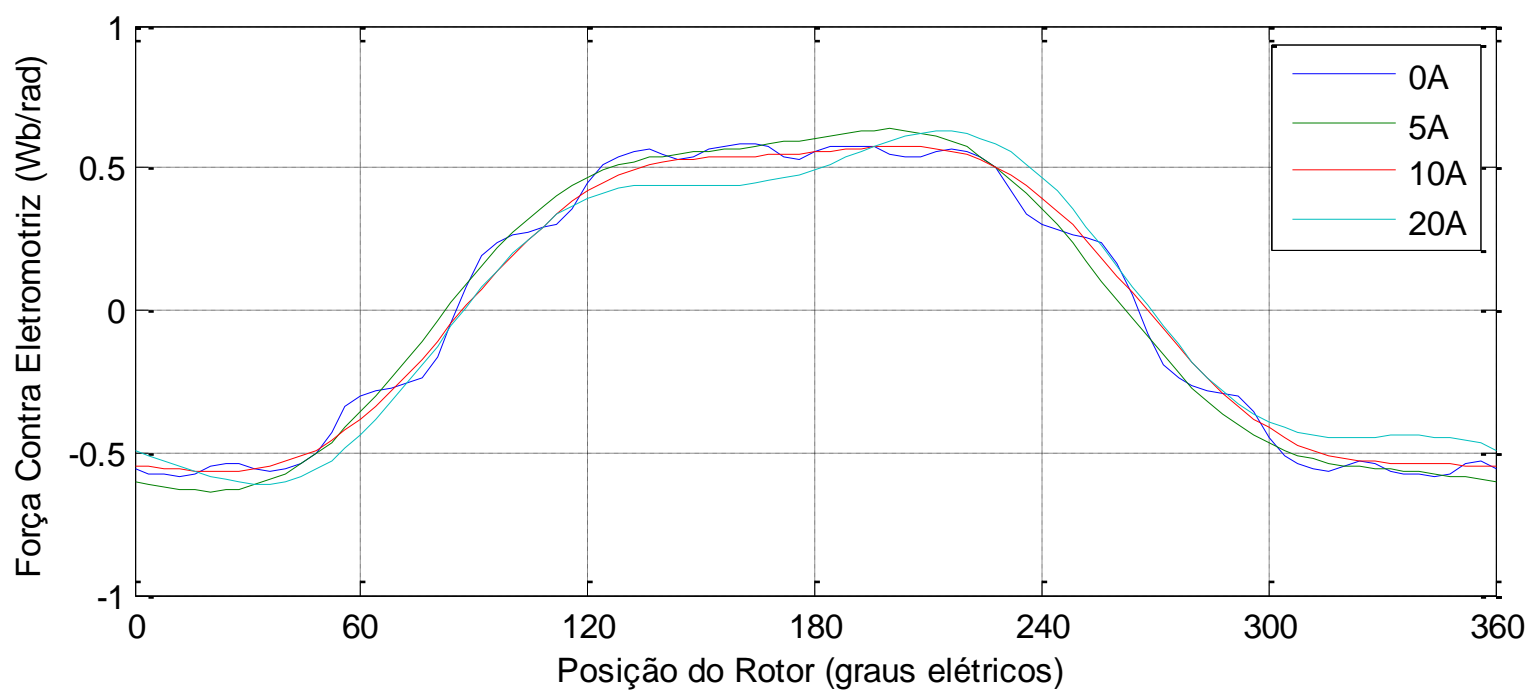

Figura 4.68 - Força Contra Eletromotriz - Método da Composição

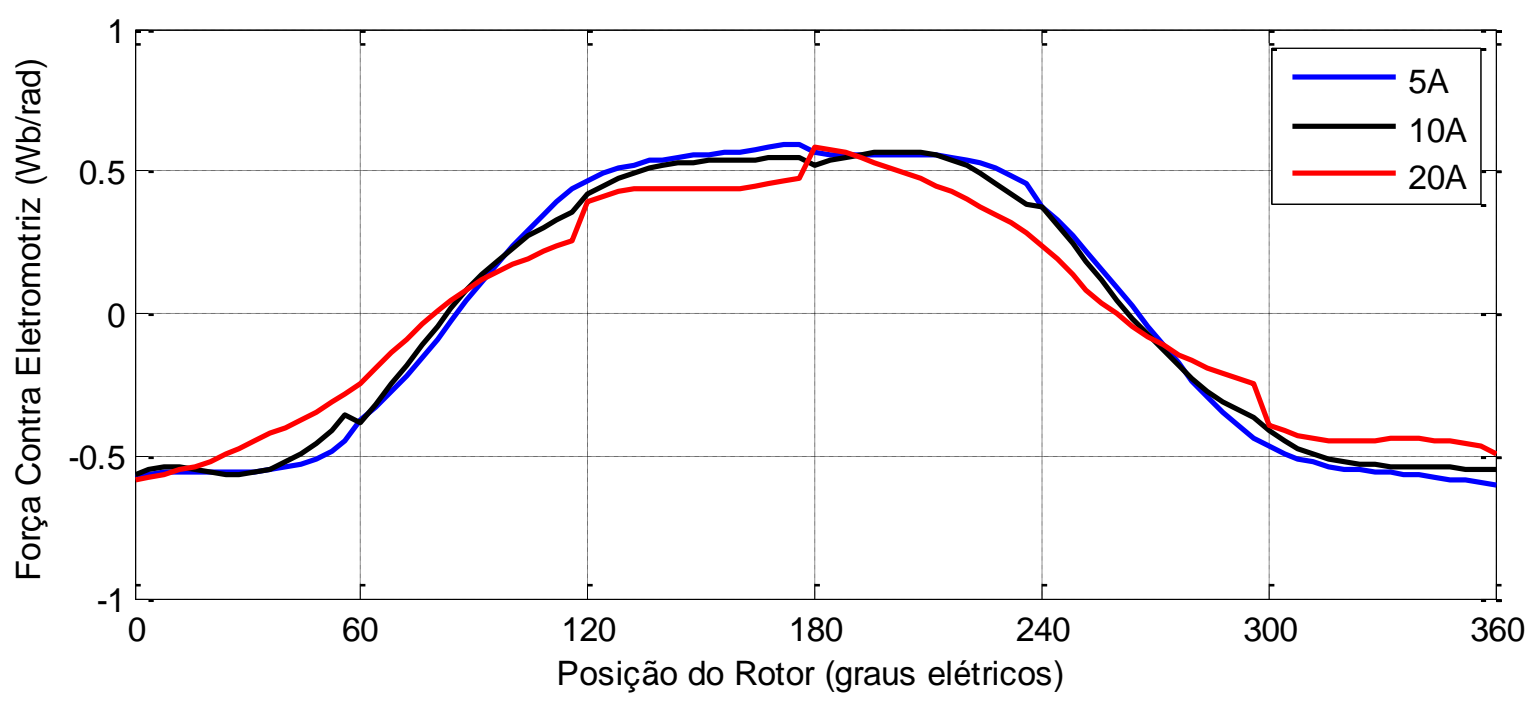

Figura 4.69 - Força Contra Eletromotriz - Método dos Tensores

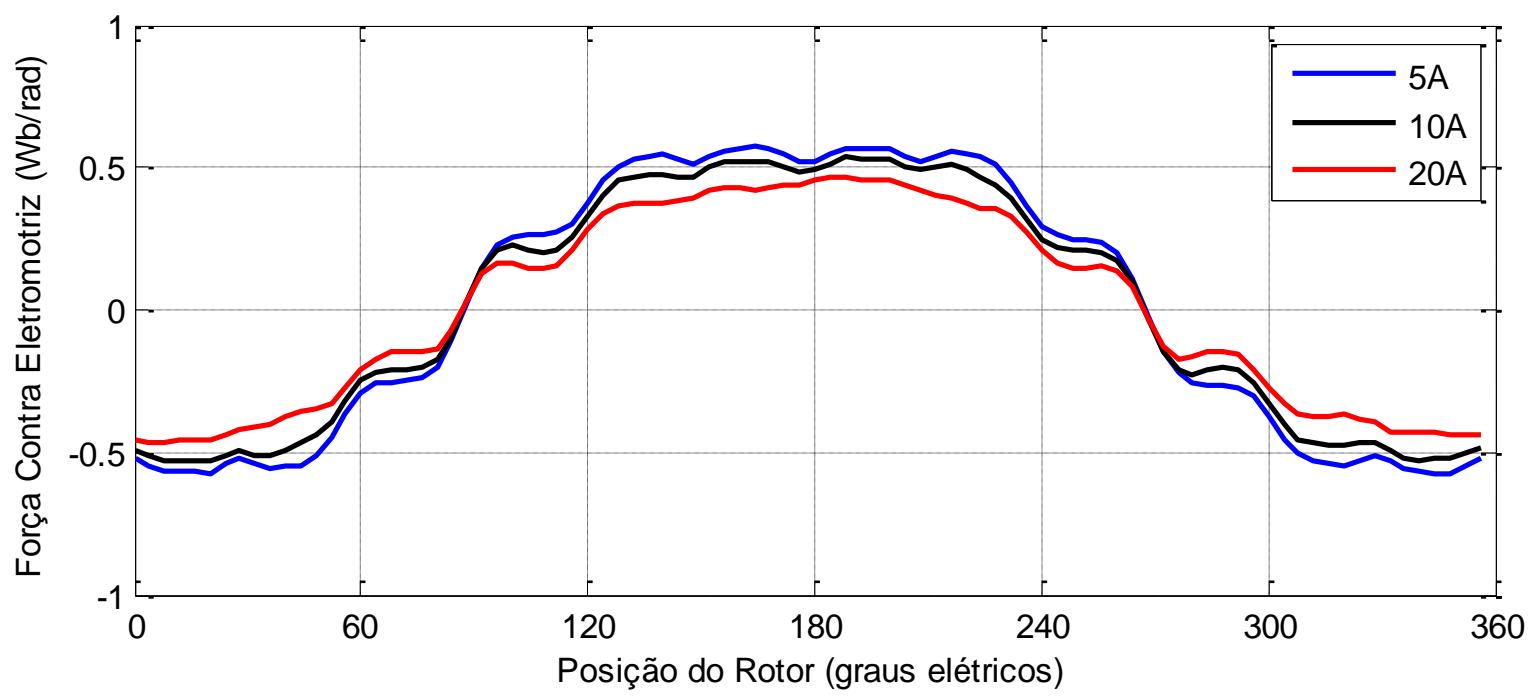


Tomando-se por base as formas de onda da corrente de armadura apresentadas na Figura 4.3 e as formas de onda das forças contra eletromotrizes para as condições de carregamento simuladas, obtém-se as formas de onda do torque mútuo, sendo as mesmas comparadas com as formas de onda do torque eletromagnético $\left(T_{E L}\right)$ para cada uma das condições, como ilustradas nas Figuras 4.70 a 4.72.

As formas de onda do torque de borda para as condições de carregamento de 5, 10 e $20 \mathrm{~A}$ são apresentadas nas Figuras 4.73 a 4.75. Os valores máximo, mínimo, médio e a razão entre o valor absoluto do torque de borda e a corrente de armadura são apresentados na Tabela 4.7, assim como o valor de amplitude deste torque. Como pode ser notado, os valores médios desta parcela do torque e suas amplitudes para as duas condições de carregamento aumentam à medida que o carregamento aumenta.

Figura 4.70 - Torque Mútuo v.s. $T_{E L}$ (Carregamento de 5A)

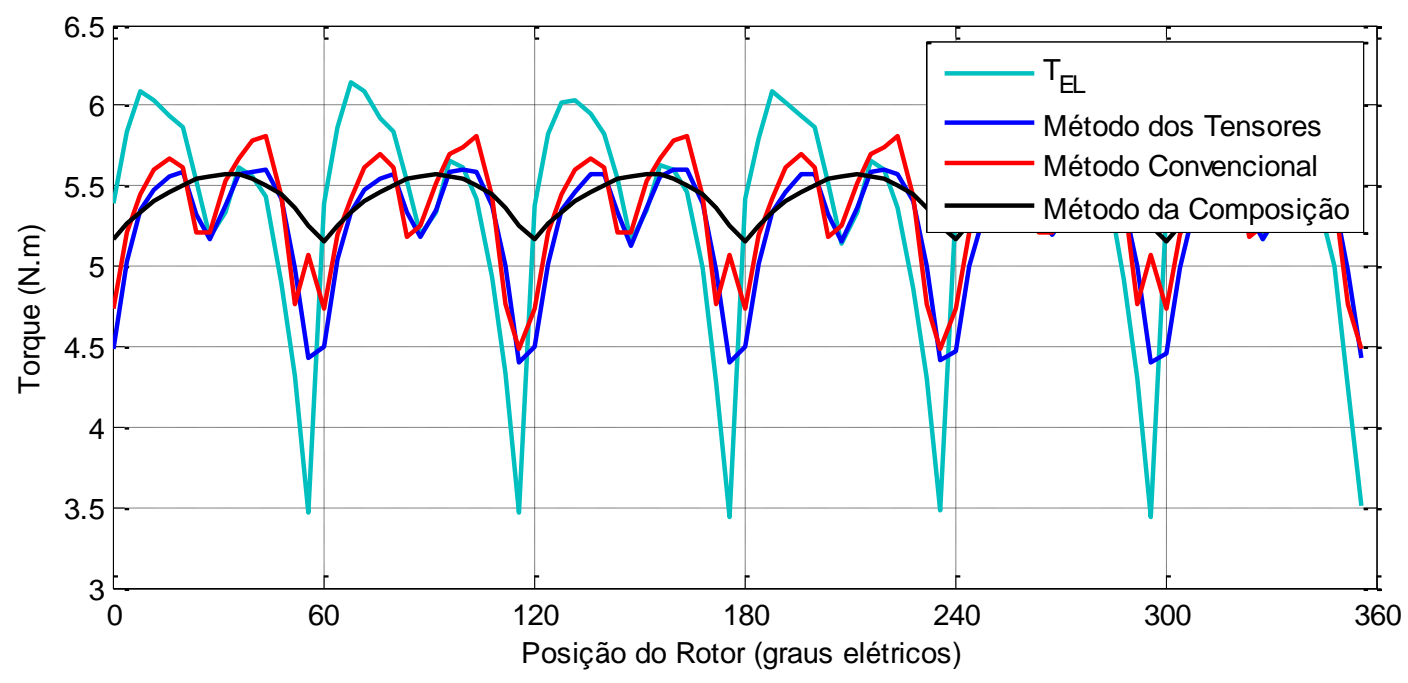

Figura 4.71 - Torque Mútuo v.s. $T_{E L}$ (Carregamento de 10A)

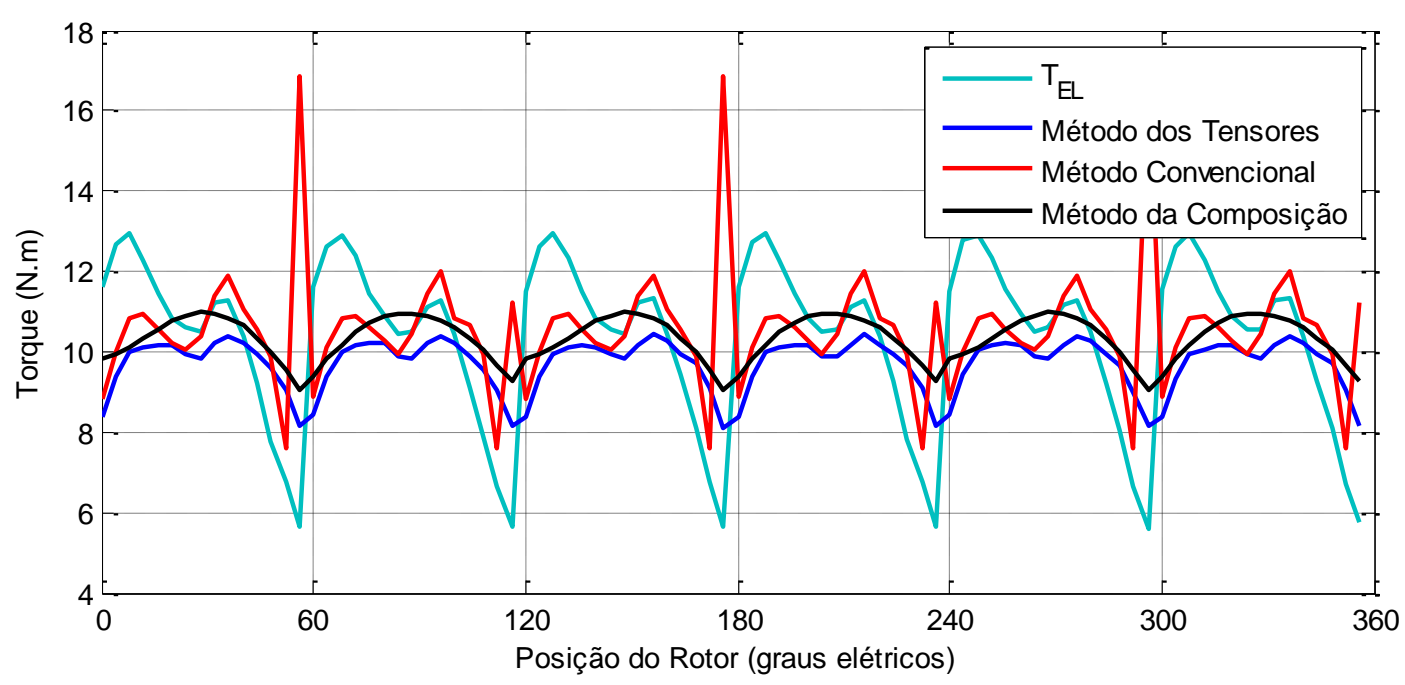


Figura 4.72 - Torque Mútuo v.s. $T_{E L}$ (Carregamento de 20A)

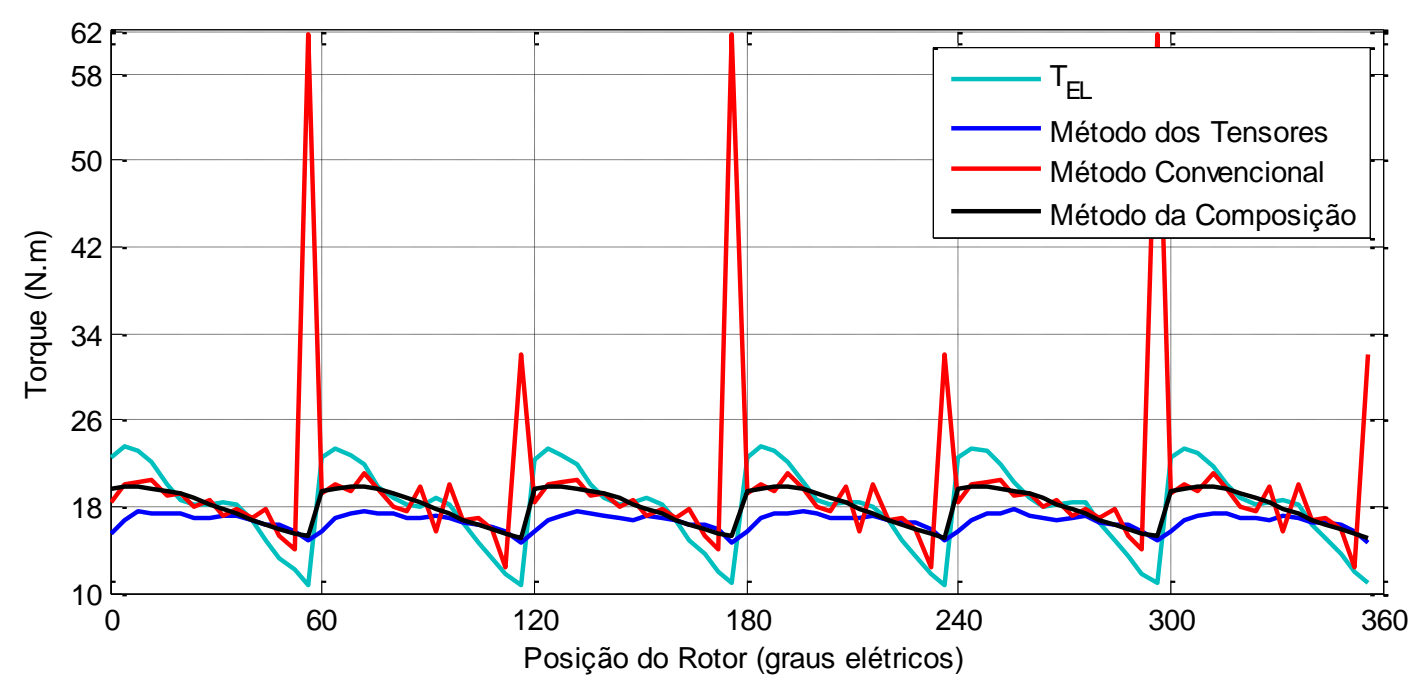

Dada a presença do torque de relutância devido à saliência no rotor, o torque de borda tem sua frequência afetada a partir do carregamento de $5 \mathrm{~A}$, tendo como frequência base 6 vezes a frequência fundamental de uma revolução elétrica, como ilustra a Figura 4.76. Seu valor médio, assim como nos Casos 1 e 2, é diferente de zero.

Tabela 4.7 - Torque de Borda

\begin{tabular}{ccccc}
\cline { 2 - 5 } & Vazio & 05A & 10A & 20A \\
\hline \hline Máximo $(\mathrm{mNm})$ & 84 & 27 & -116 & -20 \\
\hline Mínimo $(\mathrm{mNm})$ & -84 & -110 & -286 & -877 \\
\hline $\begin{array}{c}\text { Médio }(\mathrm{mNm}) \\
\text { |Torque|/Corrente }\end{array}$ & 0 & -52 & -196 & -343 \\
$\begin{array}{c}\text { (mNm/A) } \\
\text { Amplitude } \\
\text { (mNm/A) }\end{array}$ & - & -10 & -19 & -17 \\
\hline \hline
\end{tabular}

Figura 4.73 - Torque de Borda (Carregamento de 5A)

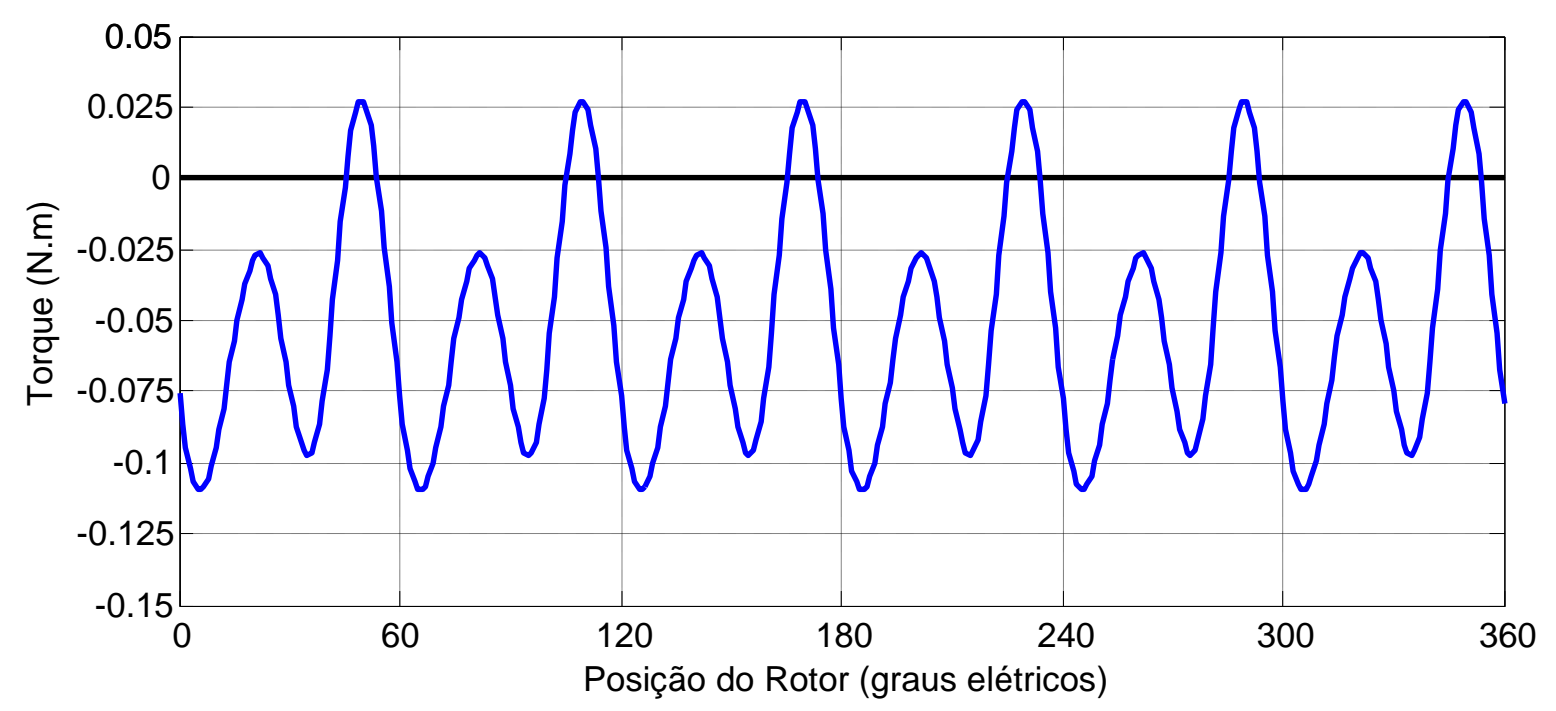


Figura 4.74 - Torque de Borda (Carregamento de 10A)

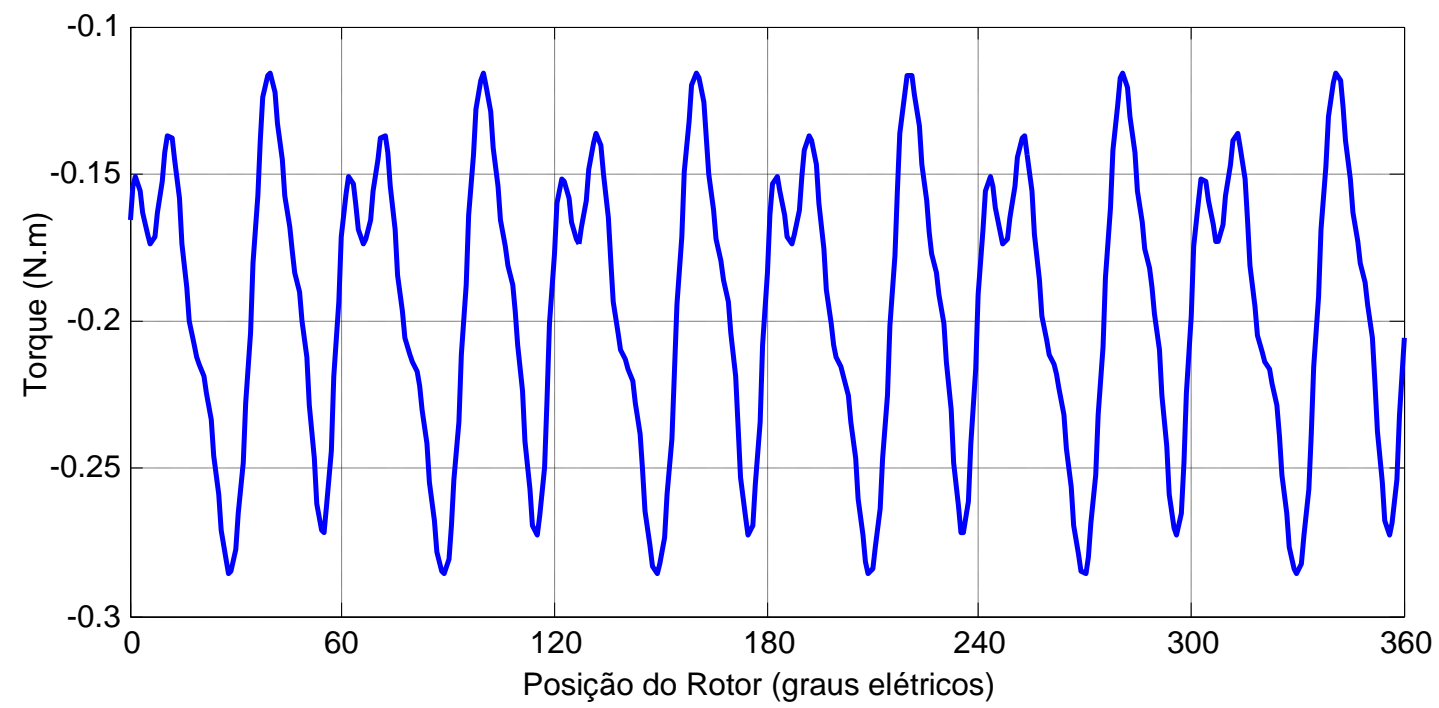

Figura 4.75 - Torque de Borda (Carregamento de 20A)

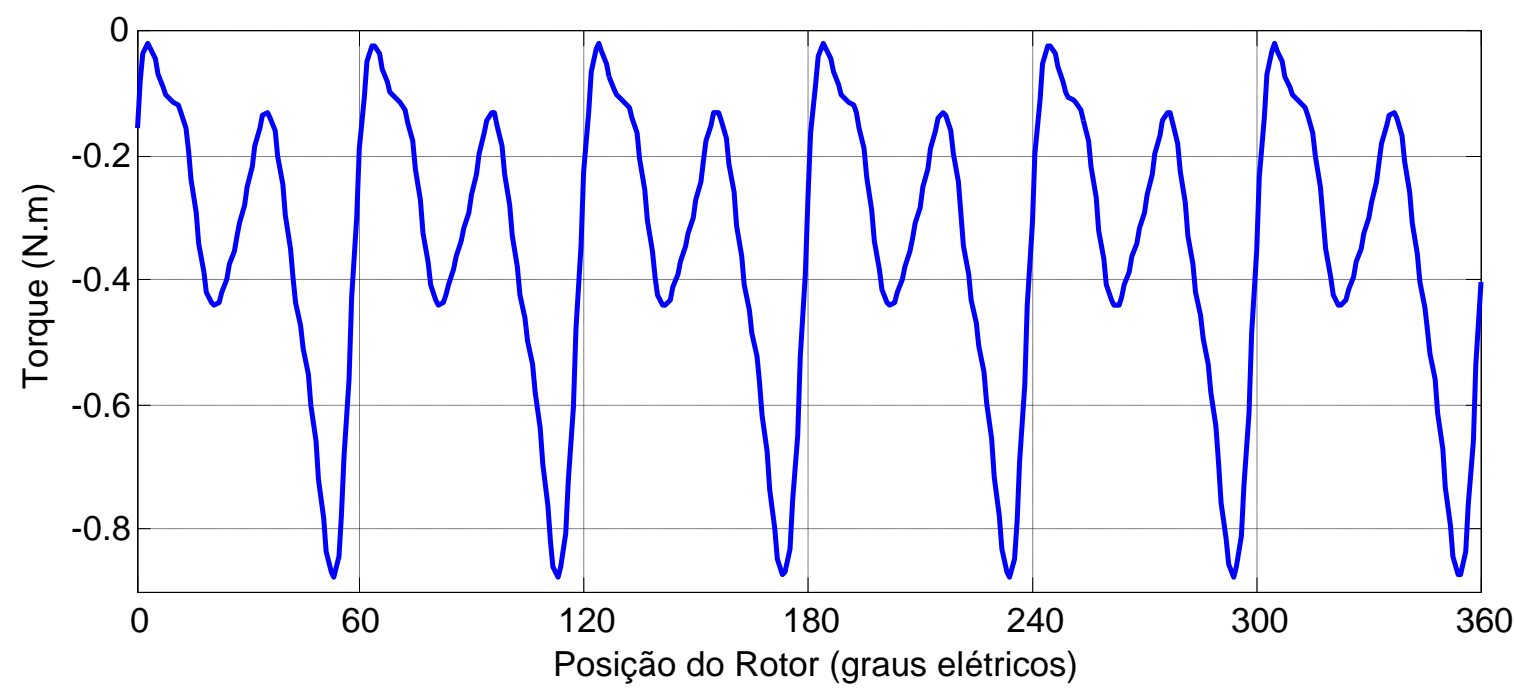

Figura 4.76 - Amplitude e Frequência do Torque de Borda

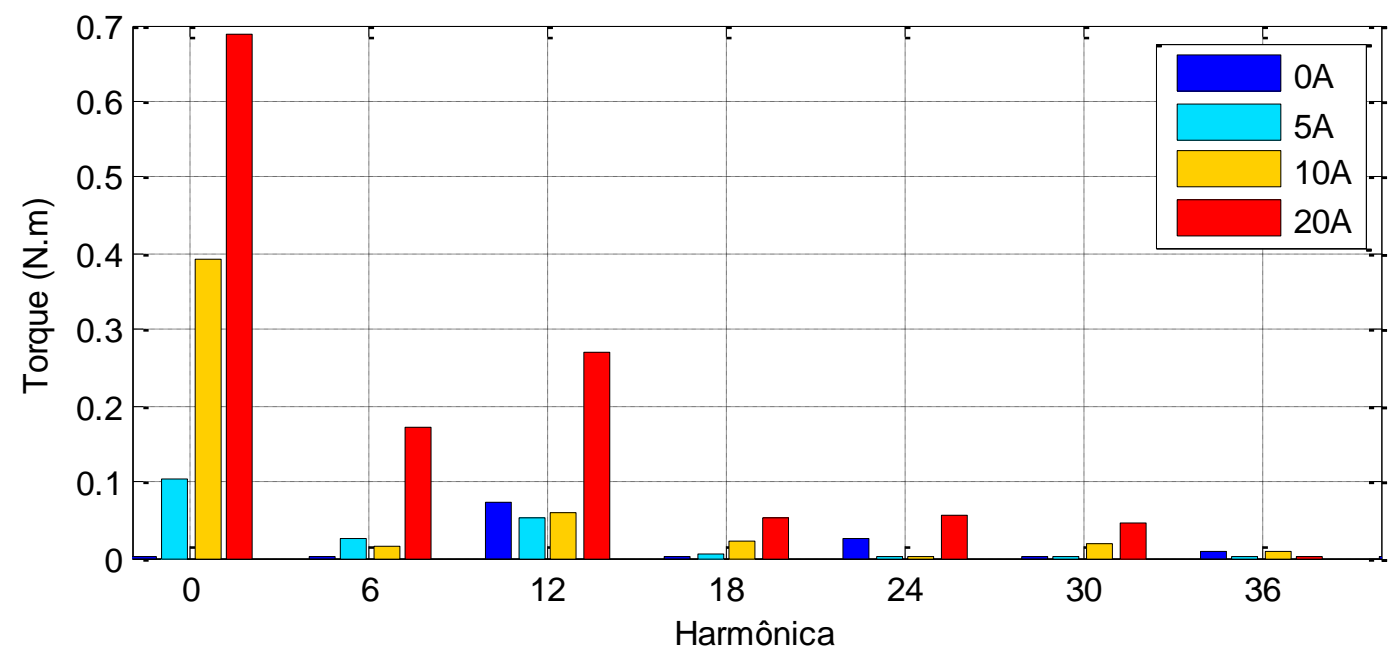


As formas de onda da indutância de linha para as condições de carregamento simuladas são apresentadas na Figura 4.77. Ao se observar essas formas de onda é possível presumir que o torque de relutância considerável, ora contribuindo com o torque eletromagnético ora degradando o valor final do torque eletromagnético.

As Figuras 4.78 a 4.80 ilustram as formas de onda do torque de relutância para a condição de carregamento de 5, 10 e 20A. A Tabela 4.8 apresenta os valores máximo, mínimo, médio de torque e a razão entre o valor absoluto do torque de relutância e a corrente de armadura. É mostrada também, a razão entre a amplitude do torque de relutância e a corrente de armadura. Já as formas de onda do torque resultante da soma $\left(T_{\text {Soma }}\right)$ das parcelas do torque eletromagnético para as condições de carregamento de 5, 10 e 20A, calculadas pelos três métodos, são apresentadas da Figura 4.81 a Figura 4.83.

Figura 4.77 - Indutância de Linha.

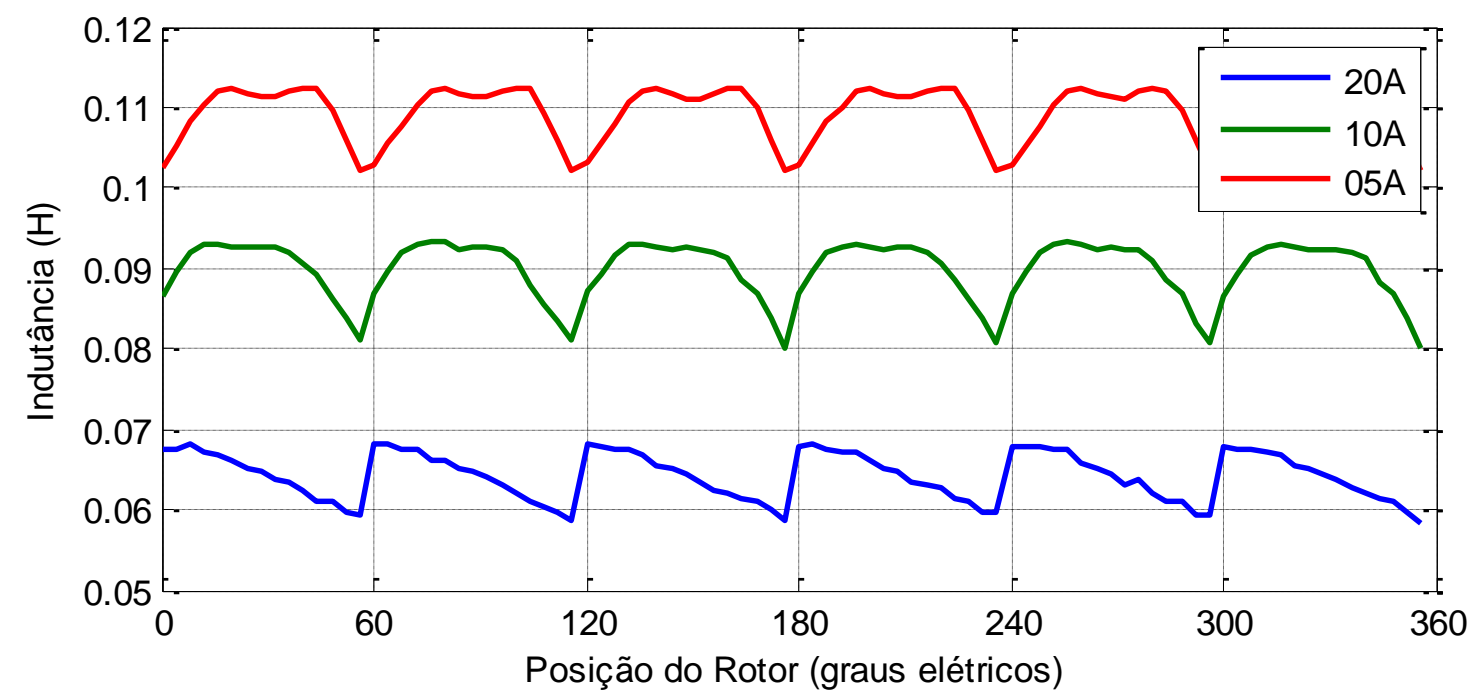

Figura 4.78 - Torque de Relutância (Carregamento de 5A)

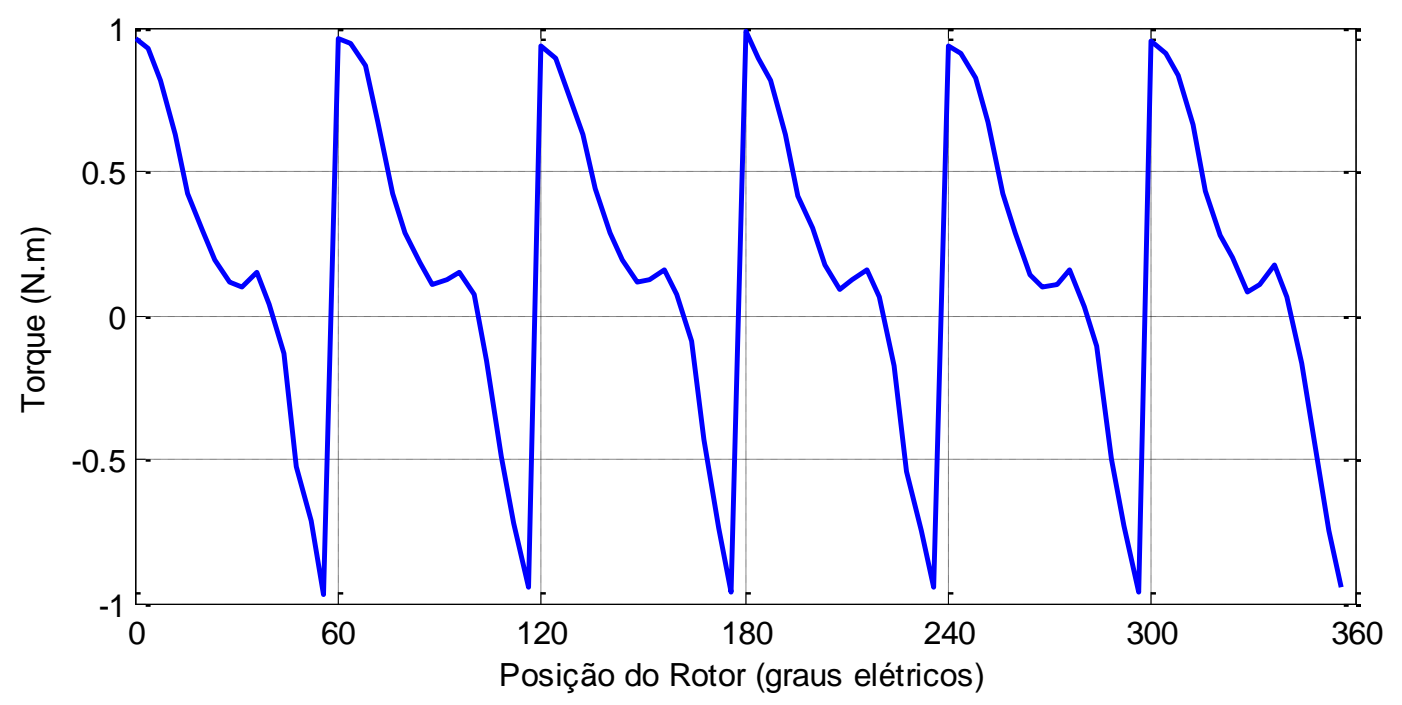


Figura 4.79 - Torque de Relutância (Carregamento de 10A)

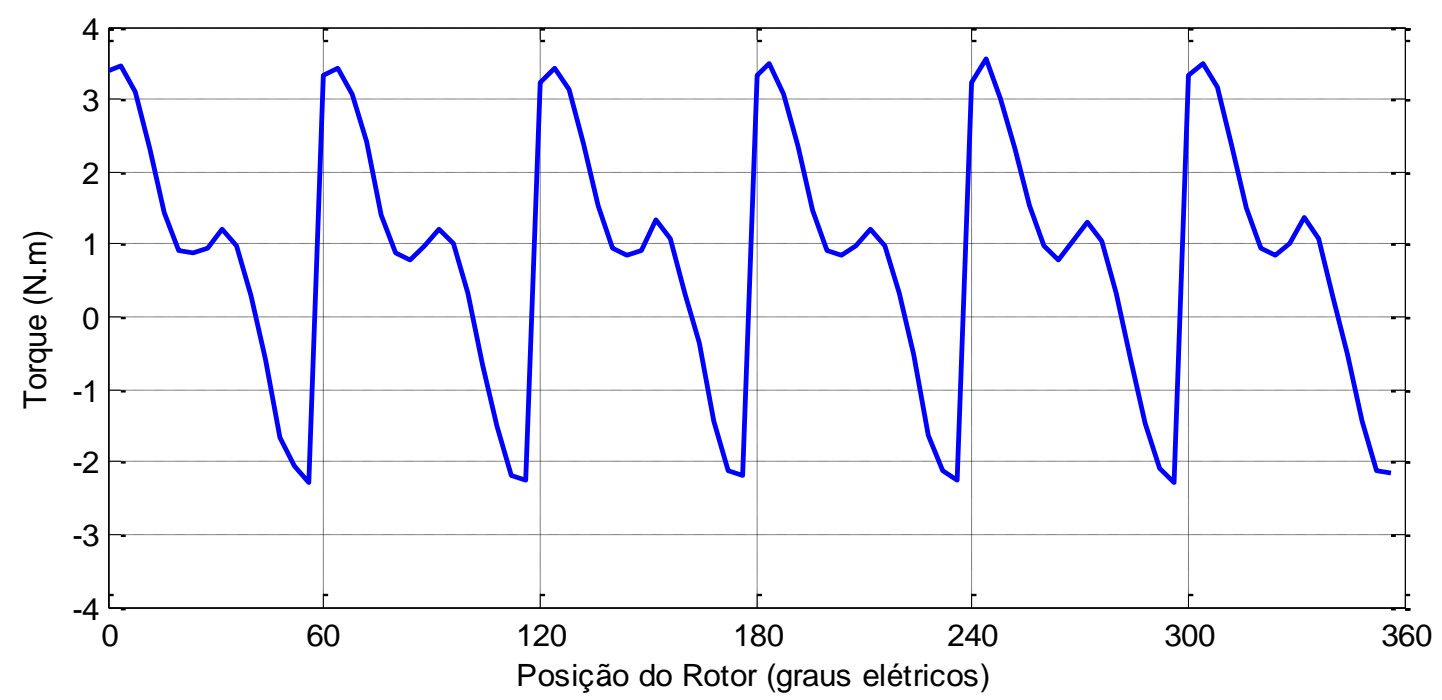

Figura 4.80 - Torque de Relutância (Carregamento de 20A)

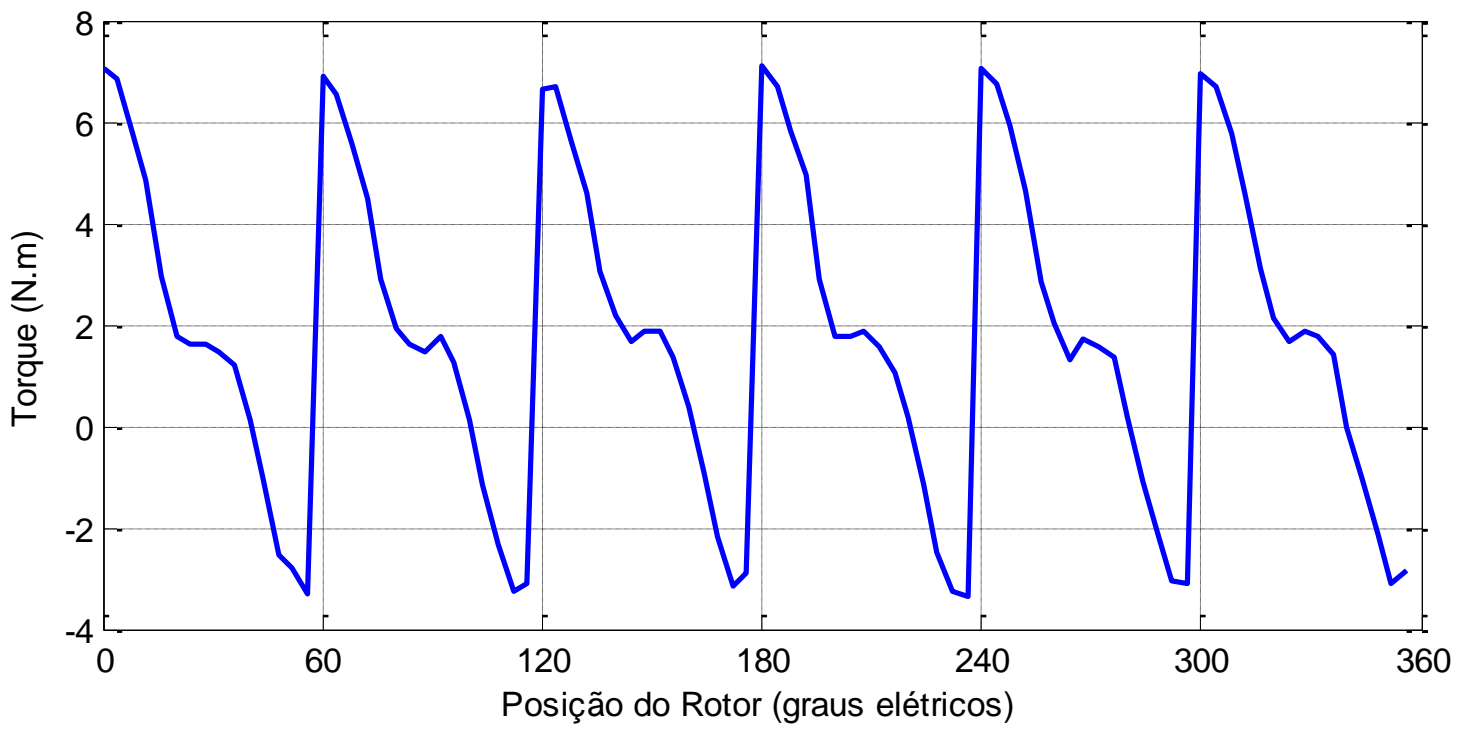

Tabela 4.8 - Torque de Relutância ( $T_{\text {Relutancia }}$ )

\begin{tabular}{cccc} 
& 05A & 10A & 20A \\
\hline \hline Máximo (Nm) & 0,985 & 3,565 & 7,086 \\
Mínimo (Nm) & $-0,966$ & $-2,298$ & $-3,352$ \\
Médio (Nm) & 0,157 & 0,844 & 1,72 \\
Amplitude (Nm) & 0,975 & 2,932 & 5,219 \\
$\begin{array}{c}\text { Torque } / \text { Corrente } \\
(\mathbf{N m} / \mathbf{A})\end{array}$ & 0,031 & 0,084 & 0,086 \\
$\begin{array}{c}\text { Amplitude/Corrente } \\
(\mathbf{N m} / \mathbf{A})\end{array}$ & 0,195 & 0,293 & 0,261 \\
\hline \hline
\end{tabular}


Figura $4.81-T_{E L} v s T_{\text {Soma }}$ (Carregamento de 5A)

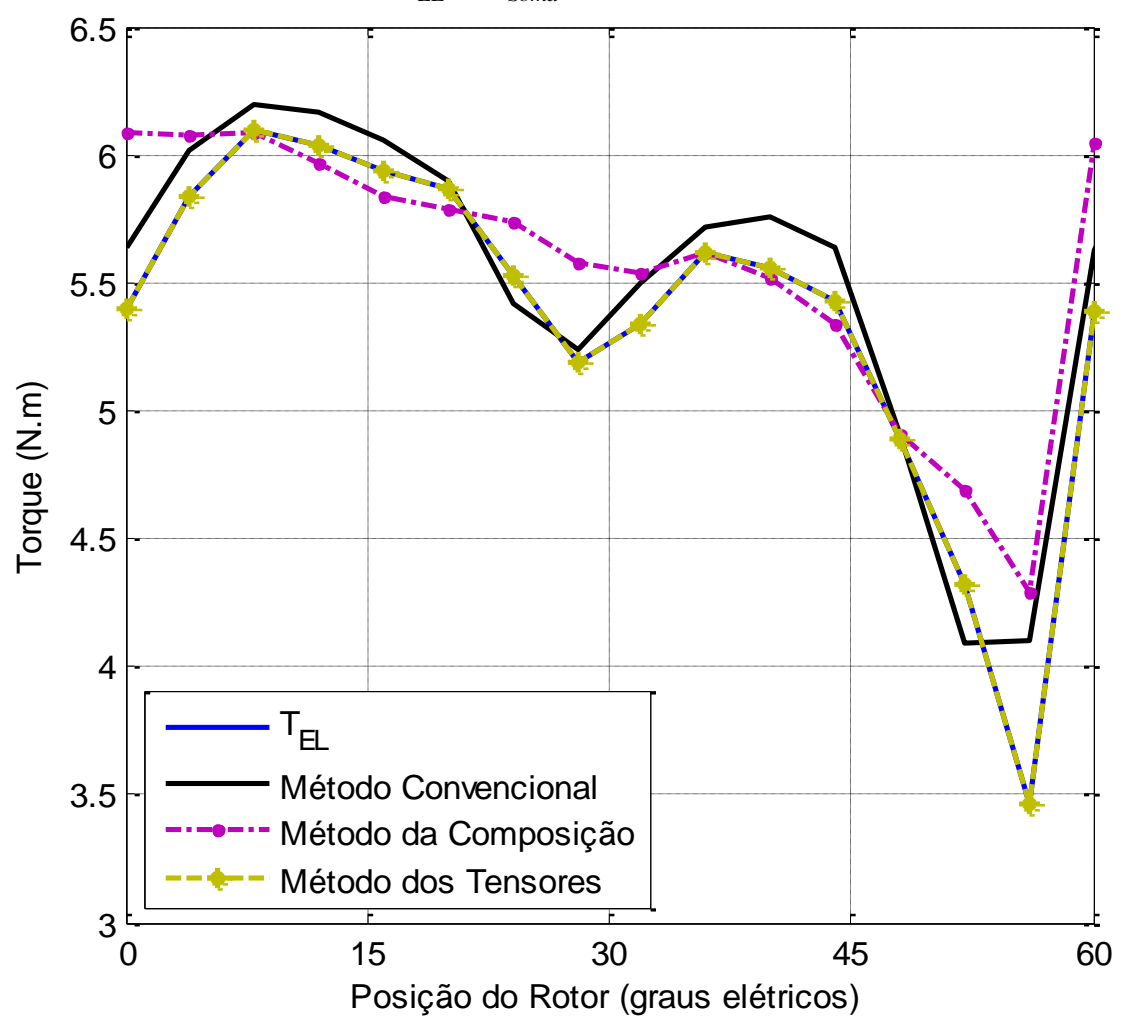

Figura $4.82-T_{E L} v s T_{\text {Soma }}$ (Carregamento de 10A)

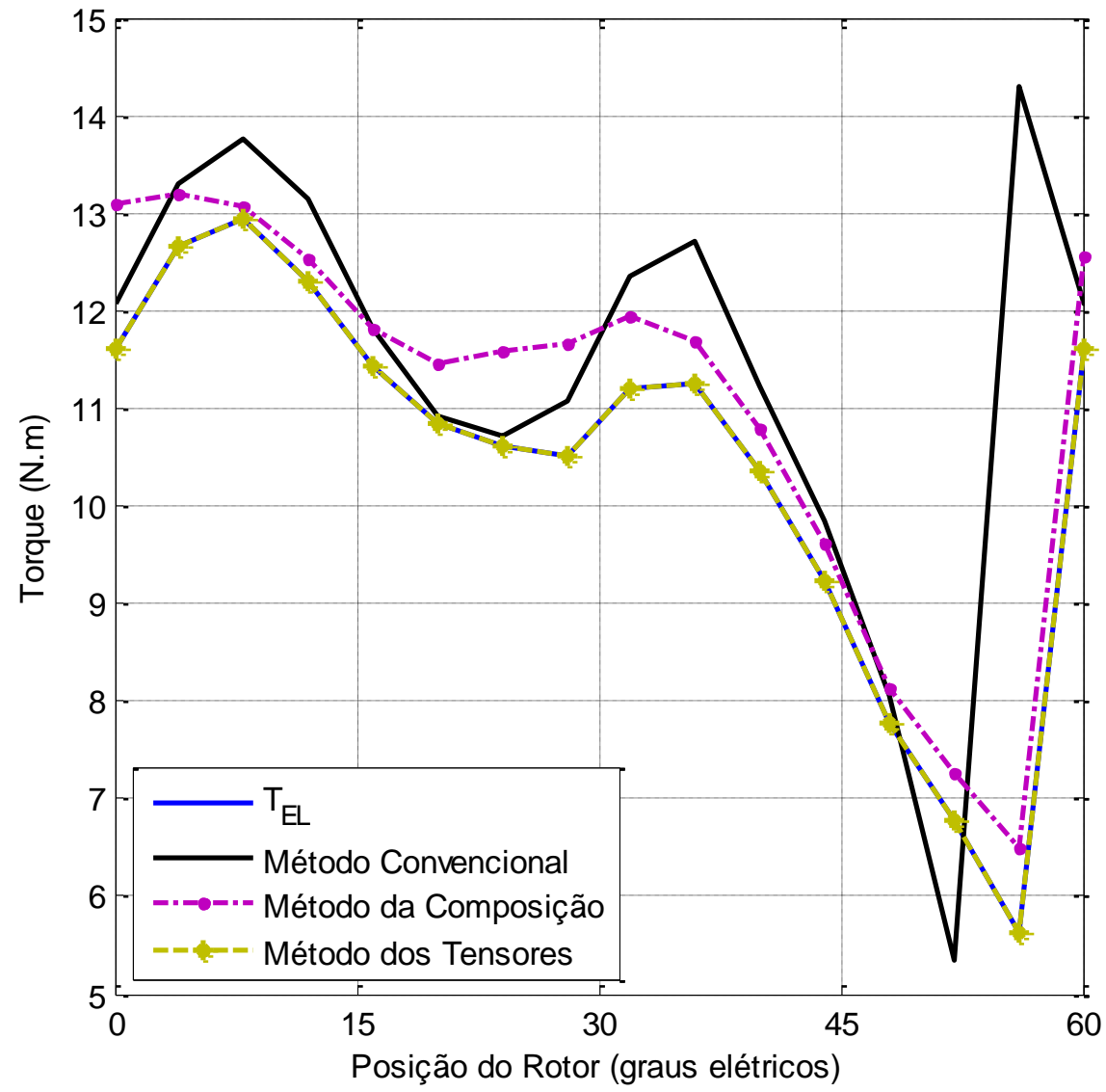


Figura $4.83-T_{E L} v S T_{\text {Soma }}$ (Carregamento de 20A)

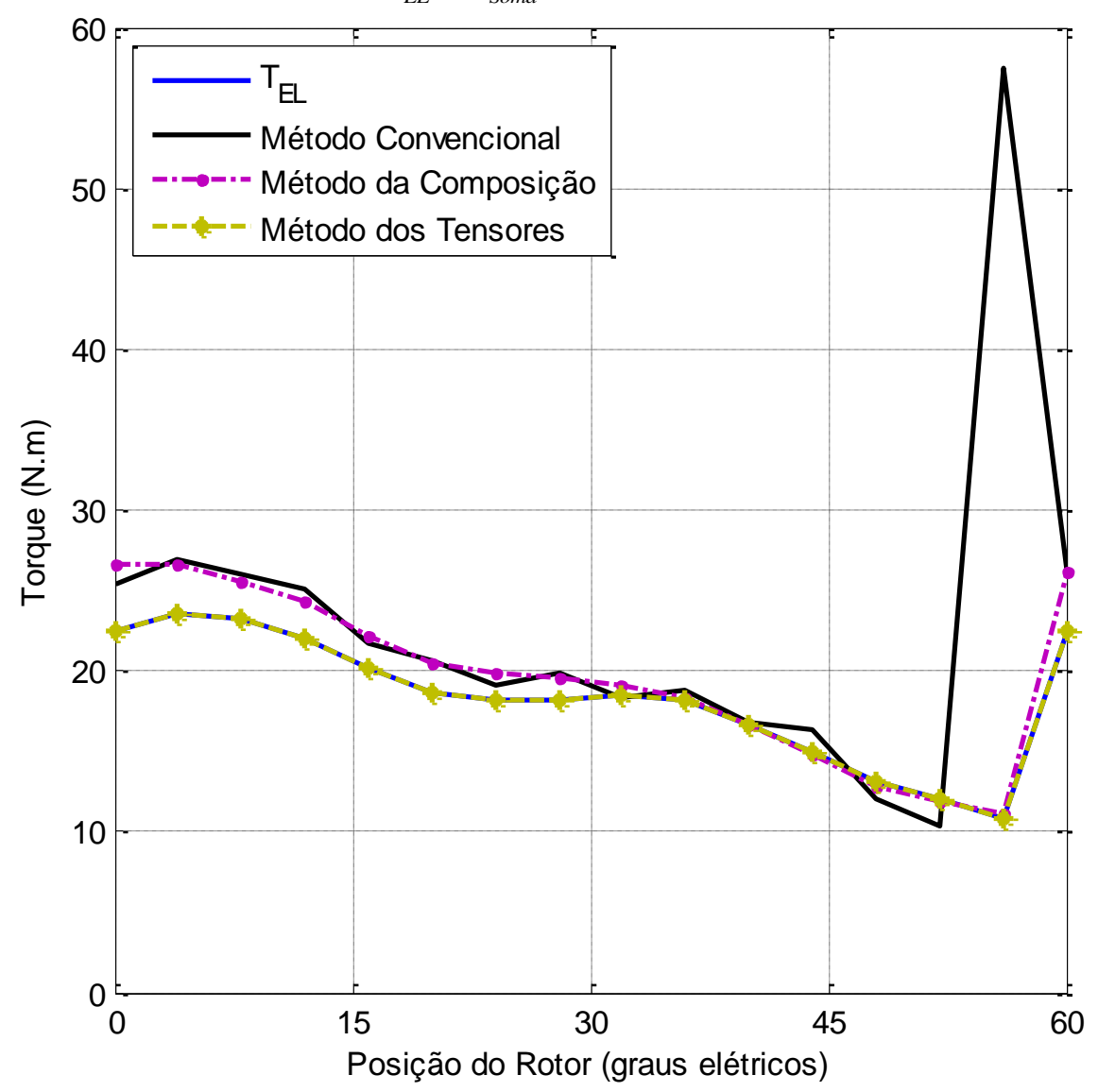

Nota-se que, mesmo em meio a um cenário 'ruidoso' em que as outras parcelas de torque também contribuem com as ondulações no torque eletromagnético $\left(T_{E L}\right)$, a obtenção da força contra eletromotriz por meio do método dos tensores se mostrou eficiente e preciso, sem apresentar distorções quando utilizado para o cálculo do torque resultante $\left(T_{\text {Soma }}\right)$ e carregando intrinsecamente todas as não linearidades presentes na força contra eletromotriz. Características, estas, que não estão presentes no método convencional e nem no método da composição das regiões.

Uma observação relevante diz respeito ao comportamento do método da composição das regiões na estimativa da força contra eletromotriz que de certa forma, pode ser visto como um filtro harmônico sobre a forma de onda do fluxo magnético concatenado. Esse fato é evidenciado por meio do processo de aproximação de curvas empregado no processo de decomposição das componentes do fluxo magnético. Onde é possível caracterizar alterações no fluxo e na força contra eletromotriz provenientes de um faixa considerável de harmônicos sem que estes harmônicos sofram influência direta da comutação das fases (que tem como frequência de ocorrência 6 vezes a fundamental). 
Se aplicado um filtro na forma de onda da força contra eletromotriz obtida após a aplicação do método convencional não se obtém um resultado semelhante ao método da composição das regiões visto que, as oscilações presentes no método convencional têm frequência próxima à fundamental ( 6 vezes a fundamental) e nesta frequência ( 6 vezes a fundamental) também se encontram contribuições relativas à saturação e ao carregamento. Um Exemplo da aplicação de um filtro após a aplicação do método convencional é mostrado em [12].

Com relação ao método dos tensores para a obtenção da força contra eletromotriz, pode-se afirmar que o mesmo apresenta grande precisão e exatidão na descrição da força contra eletromotriz, apresentando erros menores que $0,1 \%$ na estimação de $T_{\text {Soma }}$, como citado. Aliado a essa vantagem, tem-se ainda que o cálculo da força contra eletromotriz por meio do método dos tensores possibilita ao projetista relacionar de maneira mais direta o conteúdo harmônico da força contra eletromotriz com o conteúdo harmônico do vetor potencial magnético (e consequentemente o conteúdo harmônico da densidade de fluxo na superfície dos dentes) e também, relacionar a influência das dimensões do projeto na distorção da força contra eletromotriz à medida que o carregamento da máquina aumenta. Dessa forma, o método pode ser utilizado como uma ferramenta auxiliar durante o projeto da máquina a fim de se analisar a força contra eletromotriz e otimizar as dimensões estruturais buscando uma força contra eletromotriz menos sensível à saturação na faixa de operação desejada para a máquina.

Este método tem, entre outras vantagens, a avaliação da força contra eletromotriz utilizando-se de um processo integrativo, que ao contrário do método convencional (o qual utiliza-se de um processo derivativo), eleva a precisão da solução em um grau. A melhora na precisão se dá ainda pelo uso dos Tensores de Maxwell com Filtro Harmônico [22], [23]. Outra vantagem diz respeito à implementação desta nova etapa e das equações necessárias para o cálculo da força contra eletromotriz, que podem ser feitas por meio de script em qualquer software de análise em elementos finitos voltado para análise eletromagnética. 


\section{Capítulo 5}

\section{Conclusões}

A principal contribuição deste trabalho está na criação de dois novos métodos de cálculo da força contra eletromotriz em máquinas síncronas com ímã no rotor.

- Método da Composição das Regiões;

- Método dos Tensores.

A validação dos métodos para a obtenção da força contra eletromotriz foi realizada por meio da comparação do torque resultante com o torque não linear para três configurações distintas de motor síncrono com ímãs no rotor. Os resultados mostraram que o Método dos Tensores é superior aos demais métodos apresentados demonstrando erros menores que $0,1 \%$ comparados ao modelo não linear. Este método tem como base a proposta de uma nova etapa na simulação utilizando o método da permeabilidade fixa e o uso dos tensores de Maxwell com filtro harmônico. Alcançando-se assim, o objetivo principal desta tese.

Como conclusões e contribuições secundárias, destacam-se:

- Que comparados os resultados dos Torques Mútuos com o torque eletromagnético, é possível concluir que mesmo com o acréscimo do carregamento eletromagnético o torque mútuo continua sendo a parcela do torque a apresentar maior participação no valor total do torque;

- Semelhante à [10], a periodicidade do comportamento oscilatório do Torque de 
Borda (Cogging Torque) foi afetada com o carregamento eletromagnético da máquina, mostrando que esse fato não é um caso específico a uma forma de alimentação da máquina, e sim uma ocorrência geral, sejam as correntes senoidais ou não senoidais;

- A presença do Torque de Relutância mesmo em uma máquina que não apresente saliência no rotor, mostrando que esta característica não é exclusiva de uma forma de onda de alimentação, ocorrendo também em máquinas com correntes não senoidais;

No que diz respeito às sugestões propostas para continuidade da pesquisa, pode-se listar:

- O emprego do novo método dos tensores para obtenção da força contra eletromotriz em uma máquina síncrona de ímãs cuja forma de onda das correntes de alimentação seja senoidal. Validando assim, o método para os dois principais tipos de alimentação deste tipo de máquina.

- Investigação em detalhes das duas parcelas que constituem a força contra eletromotriz obtida pelo método dos tensores a fim de se identificar os efeitos da saturação e de parâmetros dimensionais (largura e formato da sapata do dente, espessura do dente, abertura de ranhura, etc.) em mais detalhes na constituição da força contra eletromotriz e, portanto, inferir sobre o projeto da máquina buscando uma forma de onda de força contra eletromotriz menos sensível à saturação.

- Investigações relacionadas com o mecanismo de produção das chamadas "saliências virtuais" citadas em [13], [19] e com a variação da frequência do torque de borda também são cabíveis de investigação futura. 


\section{Referências Bibliográficas}

[1] J. F. Gieras e M. Wing, Permanent magnet motor technology: design and applications, vol. 113. CRC Press, 2002.

[2] T. J. E. Miller e J. R. Hendersot Jr, Design of brushless permanent-magnet motors. Oxford University Press, 1995.

[3] K. T. Chau e C. C. Chan, "Overview of Permanent-Magnet Brushless Drives for Electric and Hybrid Electric Vehicles", IEEE Trans. Ind. Electron., vol. 55, n 6, p. 2246-2257, jun. 2008.

[4] D. C. Hanselman, Brushless Permanent-Magnet Motor Design. Mcgraw-Hill, 1994.

[5] N. Oliveira JR, "Acionamentos de avanço para máquinas-ferramenta e robôs. Comparação entre as técnicas CA/CC", Revista Siemens, 1990.

[6] G. T. Paula, "Influência da saturação no torque da máquina síncrona de ímã permanente no rotor", Universidade de São Paulo, Dissertação, 2013.

[7] M. Miyamasu e K. Akatsu, "Efficiency comparison between Brushless dc motor and Brushless AC motor considering driving method and machine design", IECON 2011 37th Annu. Conf. IEEE Ind. Electron. Soc., p. 1830-1835, nov. 2011.

[8] N. Bianchi, Electrical Machine Analysis Using Finite Elements, 1st ed. Boca Raton, FL: Taylor \& Francis, 2005.

[9] Z. Azar, Z. Q. Zhu, e G. Ombach, "Torque-speed performance analysis of fractional slot PM machines having concentrated windings using alternate methods", 6th IET Int. Conf. Power Electron. Mach. Drives (PEMD 2012), p. B73-B73, 2012.

[10] Z. Azar, Z. Q. Zhu, e G. Ombach, "Influence of Electric Loading and Magnetic Saturation on Cogging Torque, Back-EMF and Torque Ripple of PM Machines", IEEE Trans. 
Magn., vol. 48, n 10, p. 2650-2658, out. 2012.

[11] J. K. Tangudu, T. M. Jahns, A. M. EL-Refaie, e Z. Q. Zhu, "Lumped parameter magnetic circuit model for fractional-slot concentrated-winding interior permanent magnet machines", 2009 IEEE Energy Convers. Congr. Expo., p. 2423-2430, set. 2009.

[12] D. Wu e Z. Q. Zhu, "On-Load Voltage Distortion in Fractional Slot Surface-Mounted Permanent Magnet Machines Considering Local Magnetic Saturation", IEEE Trans. Magn., vol. 51, n 8, p. 1-10, ago. 2015.

[13] W. Q. Chu e Z. Q. Zhu, "Average Torque Separation in Permanent Magnet Synchronous Machines Using Frozen Permeability”, IEEE Trans. Magn., vol. 49, n³, p. 1202-1210, mar. 2013.

[14] G. T. Paula, J. R. B. A. Monteiro, T. E. P. Almeida, M. P. Santana, e W. C. A. Pereira, "Evaluation of Surface Mounted PM Machine's Parameters on Load Conditions Using Frozen Permeability Method. Part. I", in 23rd IEEE International Symposium on Industrial Electronics (ISIE 2014), 2014, p. 806-811.

[15] G. T. Paula, J. R. B. A. Monteiro, T. E. P. Almeida, M. P. Santana, e W. C. A. Pereira, “Evaluation of Surface Mounted PM Machine's Parameters on Load Conditions Using Frozen Permeability Method. Part. III", in 11th International Conference on Industry Applications (INDUSCON 2014), 2014.

[16] G. T. Paula, J. R. B. A. Monteiro, T. E. P. Almeida, M. P. Santana, e W. C. A. Pereira, “Evaluation of Surface Mounted PM Machine's Parameters on Load Conditions Using Frozen Permeability Method. Part. II", in 21st International Conference on Electrical Machines (ICEM 2014), 2014.

[17] E. Schmidt e M. Susic, "Parameter evaluation of permanent magnet synchronous machines with tooth coil windings using the frozen permeabilities method with the finite element analyses", 25th IEEE Can. Conf. Electr. Comput. Eng., p. 1-5, abr. 2012.

[18] J. Arellano-Padilla, C. Gerada, G. Asher, e M. Sumner, "Inductance characteristics of PMSMs and their impact on saliency-based sensorless control", Proc. 14th Int. Power Electron. Motion Control Conf. EPE-PEMC 2010, p. 1-9, set. 2010.

[19] W. Q. Chu e Z. Q. Zhu, "On-Load Cogging Torque Calculation in Permanent Magnet Machines”, IEEE Trans. Magn., vol. 49, nº 6, p. 2982-2989, jun. 2013.

[20] N. Bianchi e S. Bolognani, "Design techniques for reducing the cogging torque in surface-mounted PM motors", IEEE Trans. Ind. Appl., vol. 38, n 5, p. 1259-1265, set. 2002.

[21] M. S. Islam, S. Mir, T. Sebastian, e S. Underwood, "Design Considerations of 
Sinusoidally Excited Permanent-Magnet Machines for Low-Torque-Ripple Applications", IEEE Trans. Ind. Appl., vol. 41, n 4, p. 955-962, jul. 2005.

[22] M. Popescu, D. M. Ionel, T. J. E. J. E. Miller, S. J. Dellinger, e M. I. I. Mcgilp, "Improved finite element computations of torque in brushless permanent magnet motors.pdf", vol. 152, n², p. 271-276, 2005.

[23] D. M. Ionel, S. Member, M. Popescu, S. Member, M. I. Mcgilp, T. J. E. Miller, S. J. Dellinger, A. M. Stress, H. Filter, e H. F. T. Method, "Assessment of Torque Components in Brushless Permanent-Magnet Machines Through Numerical Analysis of the Electromagnetic Field", vol. 41, n 5, p. 1149-1158, 2005.

[24] N. Bianchi e S. Bolognani, "Magnetic models of saturated interior permanent magnet motors based on finite element analysis", Conf. Rec. 1998 IEEE Ind. Appl. Conf. ThirtyThird IAS Annu. Meet. (Cat. No.98CH36242), vol. 1, p. 27-34, 1998.

[25] J. K. Tangudu, T. M. Jahns, A. M. El-Refaie, e Z. Q. Zhu, "Segregation of torque components in fractional-slot concentrated-winding interior PM machines using frozen permeability", 2009 IEEE Energy Convers. Congr. Expo., p. 3814-3821, set. 2009.

[26] D. C. . Meeker, "Finite Element Method Magnetics." 2012.

[27] K. J. Binns, K. J. Binns, P. J. Lawrenson, e C. W. Trowbridge, The Analytical and Numerical Solution of Electric and Magnetic Fields. Wiley, 1995.

[28] A. A. Abdel-Razek, J. I. Coulomb, M. Feliachi, e J. Sabonnadiere, "The calculation of electromagnetic torque in saturated electric machines within combined numerical and analytical solutions of the field equations", IEEE Trans. Magn., vol. 17, n 6, p. 32503252, 1981.

[29] K. Hameyer, R. Mertens, U. Pahner, e R. Belmans, "New technique to enhance the accuracy of 2-D/3-D field quantities and forces obtained by standard finite-element solutions", in IEE Proceedings - Science, Measurement and Technology, 1988, p. 6775.

[30] T. S. Low, C. Bi, e Z. J. Liu, "A hybrid technique for electromagnetic torque and force analysis of electric machines", COMPEL - Int. J. Comput. Math. Electr. Electron. Eng., vol. 16, n 3, p. 191-205, 1997.

[31] S. J. Salon, Finite Element Analysis of Electrical Machines, 1st ed. Troy, NY: Kluwer Academic Publishers, 1995.

[32] M. Chabchoub, I. Ben Salah, G. Krebs, R. Neji, e C. Marchand, "PMSM cogging torque reduction: Comparison between different shapes of magnet", in 2012 1st International Conference on Renewable Energies and Vehicular Technology, REVET 2012, 2012, p. 
206-211.

[33] Z. P. Xia, Z. Q. Zhu, L. J. Wu, e G. W. Jewell, "Comparison of radial vibration forces in 10-pole/12-slot fractional slot surface-mounted and interior PM brushless AC machines", in The XIX International Conference on Electrical Machines - ICEM 2010, 2010, p. 1-6.

[34] Z. Q. Z. Zhu, S. Ruangsinchaiwanich, e D. Howe, "Synthesis of cogging-torque waveform from analysis of a single stator slot", IEEE Trans. Ind. Appl., vol. 42, n 3, p. 650-657, maio 2006.

[35] F. H. P. Teixeira, "Metodologia para projeto, construção e ensaios em máquina síncrona de ímã permanente - MSIP”, Universidade de São Paulo, Dissertação, 2006.

[36] D. Halliday, R. Resnick, e J. Walker, Fundamentos de Física, 9º ed. LTC, 2012.

[37] P. A. Tipler e G. Mosca, Física Para Cientistas e Engenheiros, 6ª ed. LTC, 2009.

[38] A. J. P. Durrer, "Análise do Campo Magnético de um Motor de Ímã Permanente no Rotor Utilizando o Método dos Elementos Finitos Análise do Campo Magnético de um Motor de Ímã Permanente no Rotor Utilizando o Método dos Elementos Finitos", Universidade de São Paulo, Dissertação, 2007. 


\section{Apêndice A: Bancada Experimental}

Como relatado ao longo do texto, os experimentos realizados neste trabalho estão relacionados às medidas da forma de onda da força contra eletromotriz em vazio e o torque eletromagnético para as condições de $5 \mathrm{~A}$ (50\% de carregamento) e $10 \mathrm{~A}$ (100\% de carregamento) para a máquina avaliada no Caso 1 e presente no Laboratório de Controle e Eletrônica de Potência do Departamento de Engenharia Elétrica da Escola de Engenharia de São Carlos (EESC-USP).

Nas seções a seguir são apresentados os arranjos e instrumentos utilizados na obtenção das formas de onda das variáveis de força contra eletromotriz e torque eletromagnético.

\section{A.1 Força Contra Eletromotriz (Operação em Vazio)}

O motor síncrono sem escovas e com ímãs de ferrite na superfície do rotor foi acionado por um motor de indução controlado por um inversor trifásico. Dado que a avaliação da força contra eletromotriz é realizada por fase no presente trabalho, esta é dada pela relação inversa entre a tensão terminal de fase (ligação fase A-Neutro) e a velocidade mecânica do motor quando o motor está em vazio.

As Figuras A.1 e A.2 ilustram o arranjo da bancada (motor síncrono acoplado ao motor de indução) e o esquema elétrico para a medição da força contra eletromotriz por meio de um osciloscópio. Com a entrada de alta impedância do osciloscópio e sua ponteira de medição ligada nos terminais da fase A (Va na Figura A.2) e do Neutro (Vn na Figura A.2), a medição da tensão Van é idêntica em valor e forma de onda à medição de $e_{a}$. Com a medição da 
velocidade do eixo mecânico dos motores por meio de um encoder é possível obter a força contra eletromotriz normalizada por meio de (A.1).

Figura A.1 - Arranjo para medição da força contra eletromotriz

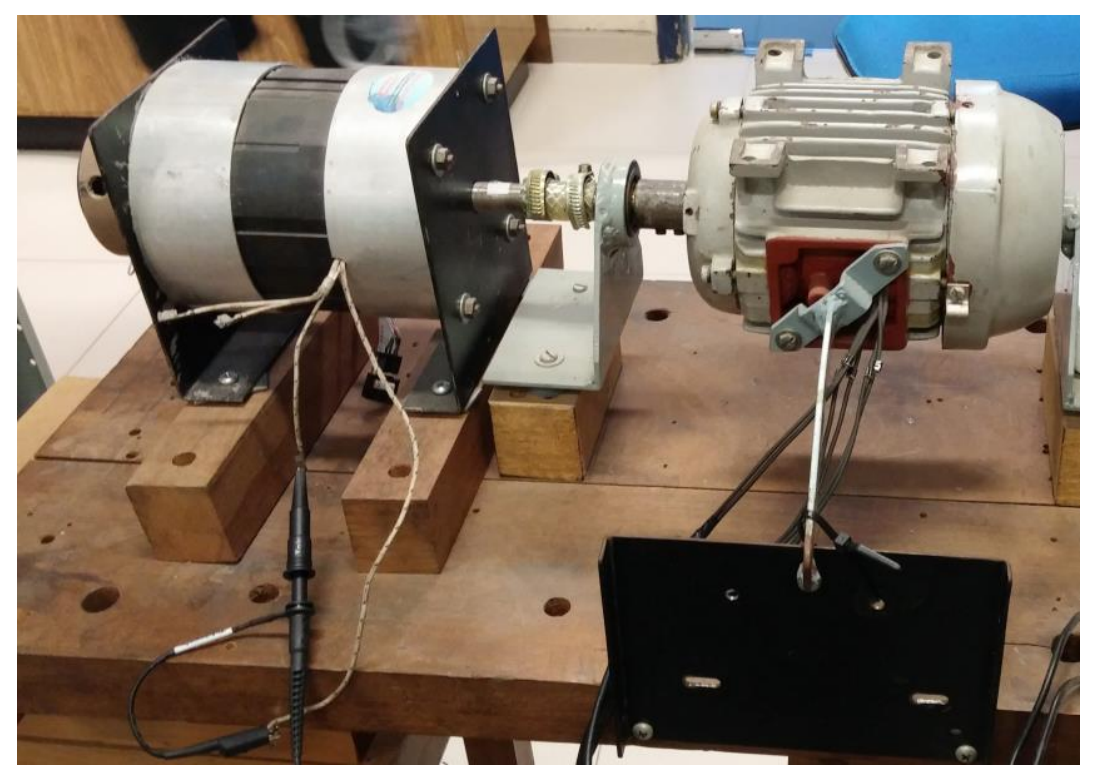

Figura A.2 - Esquema elétrico para medição da força contra eletromotriz

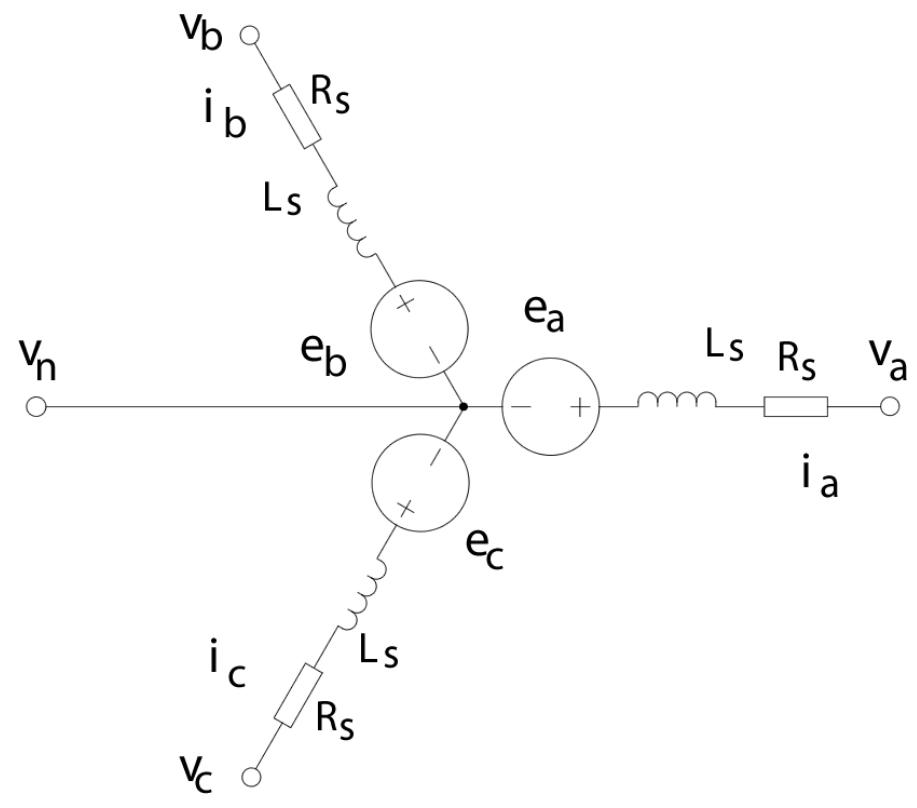

$$
\begin{gathered}
e_{a}=V_{a n} \\
\frac{e_{a}}{\omega_{M E C}}=\frac{V_{a n}}{\omega_{M E C}}
\end{gathered}
$$




\section{A.2 Torque Eletromagnético (Operação em Carga)}

A medição do torque eletromagnético foi realizada com o auxílio de um force gauge (Figura A.3) e discretizada em 10 passos de 3ํㅡㄹ mecânicos, tendo agora, o motor de indução desacoplado do motor síncrono. Para tanto, o eixo da máquina síncrona é posicionado em um ângulo $\theta$ sobre o force gauge, de maneira a apresentar força nula, sendo então as duas fases correspondentes à produção de torque para este ângulo e o seu valor medido pelo force gauge. Em seguida, desligam-se as duas fases, reposiciona-se o rotor com acréscimo de $3^{0}$ mecânicos e o procedimento anterior se repete até que sejam tomadas as medidas para todo o intervalo de $60^{\circ}$ elétricos (que para a máquina em estudo no corresponde à $30^{\circ}$ mecânicos).

Figura A.3 - Force Gauge

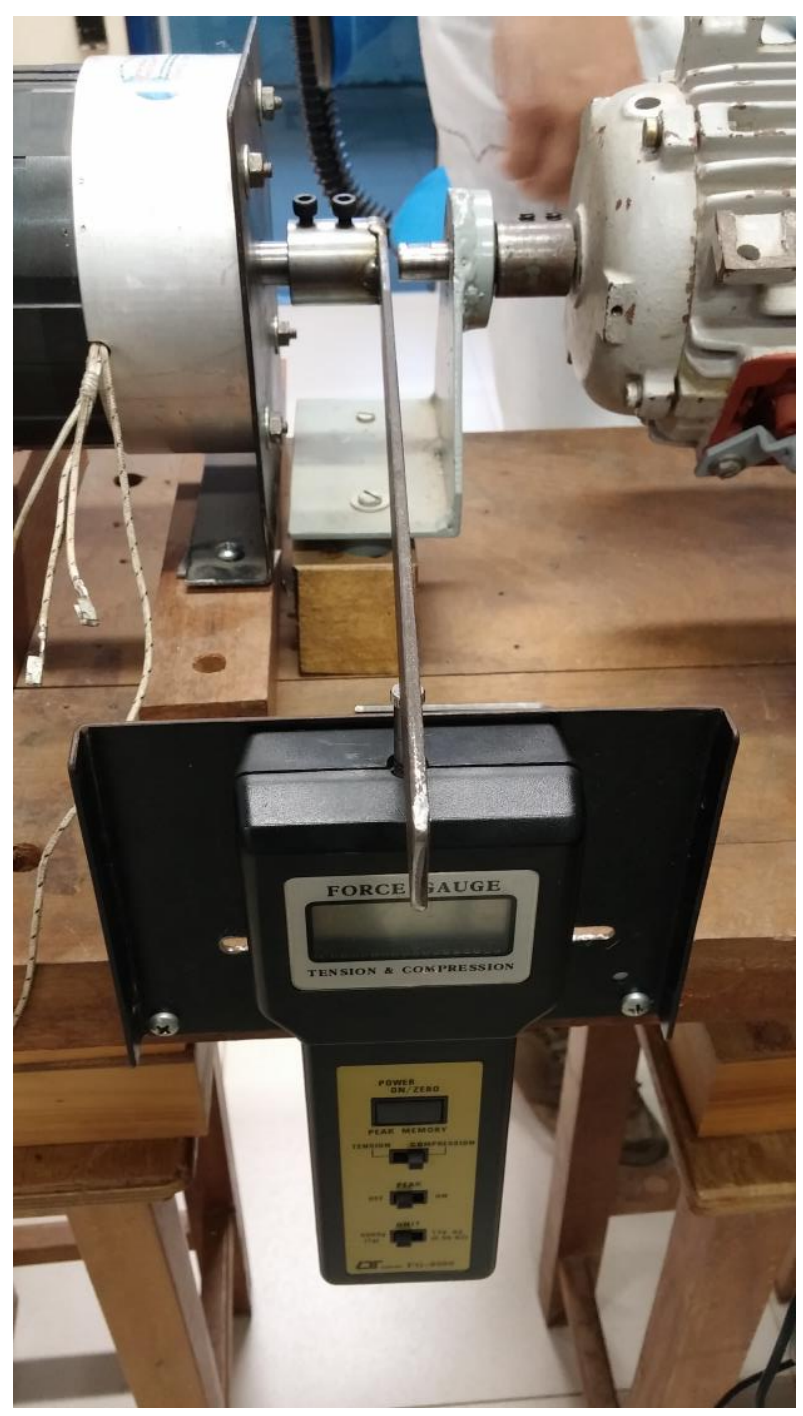

